\title{
Exploring the Effects of Reiki Self-Use on Health Literacy
}

\author{
Helen Elizabeth Gibson \\ Submitted in accordance with the requirements for the degree of \\ Doctor of Philosophy \\ The University of Leeds \\ School of Healthcare
}

September 2012 
The candidate confirms that the work submitted is her own and that appropriate credit has been given where reference has been made to the work of others.

This copy has been supplied on the understanding that it is copyright material and that no quotation from the thesis may be published without proper acknowledgement.

The right of Helen Elizabeth Gibson to be identified as author of this work has been asserted by her in accordance with the Copyright, Designs and Patents Act 1988.

(C) 2012 The University of Leeds and Helen Elizabeth Gibson 


\section{Acknowledgements}

Just for today be grateful......

There are a number of people to whom I would like to show gratitude for their love and support during the four years that I have been undertaking this work.

To my own Reiki Master (SD), without whom this research would not have been conceived. Thank you for introducing me to the wonderful energy that is Reiki and setting me on my path.

Thank you to Janet, Phillip, Paul, Joan, Ken and Jen......each and every one of you has helped me and supported me in ways you will never even realise. Lots of Love.

I would like to thank my supervisors, Andrew Long, Cath Jackson and Jill Edwards for their support and encouragement. Four years later I still feel like it was my lucky day when you were assigned as my supervisors.

This research would have not been possible without all the Reiki people who took part. I can't thank you enough for sharing your stories with me, for encouraging me and of course for the cups of tea!

Special Thanks also to Paul Dukes. 


\begin{abstract}
Health literacy represents the cognitive and social skills which determine the motivation and ability of individuals to gain access to, understand and use information in ways which promote and maintain good health (Nutbeam and World Health 1998:10). To date, there is a paucity of research looking at health literacy in terms of specific types of Complementary and Alternative Medicine (CAM) use. However, levels of current usage of CAM with their emphasis on raising awareness about health and healing suggest that they may be an acceptable and useful way to help people to manage their health and wellbeing. Reiki can be learned by anyone and, once a person has learned it, he or she is encouraged to regularly use Reiki on themselves as a means of self-care.
\end{abstract}

This research address the question; how does learning and self-use of Reiki enhance health literacy? The starting point of this multi-stage qualitative project was the formation of a theoretical model of Reiki health literacy based on a critical review of the Reiki and health literacy literature. The model was refined using unstructured interviews with a purposive sample of 10 Reiki Master Teachers and further explored in semi-structured interviews with 25 Reiki level one and two practitioners who regularly self use Reiki.

Analysis of the data indicated that participants perceived Reiki as an 'easy' skill to learn and valuable to use on a regular basis. Such self-use helped them make changes to their lifestyle, including diet and ways they coped at work. Reiki was used pro-actively to prevent illhealth and maintain good physical and emotional health. Participants spoke of using their Reiki knowledge and skills to self-treat minor physical ailments (headaches, muscular pains) and to manage mental and emotional problems such as worry, stress and anxiety.

This research develops, refines and applies a novel model of Reiki health literacy and in doing so provides supportive evidence of the potential of learning Reiki and its regular selfuse to enable a pro-active approach to health and well-being. Implications of this research include the use of Reiki as a supportive intervention for enhancing health literacy. Because 
anyone can learn and practise self-use of Reiki it may be a useful intervention for enhancing the health literacy skills of disadvantaged populations who are least likely to have highly developed health literacy skills. The research adds to the limited evidence base on self-use of Reiki and deepens understanding of the benefits of Reiki. 


\section{Contents}

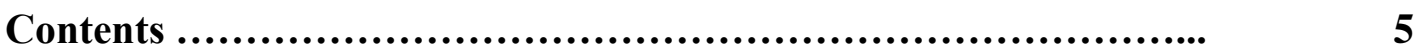

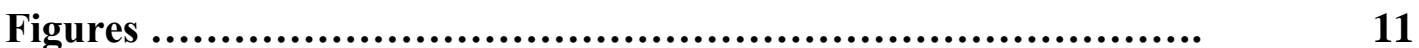

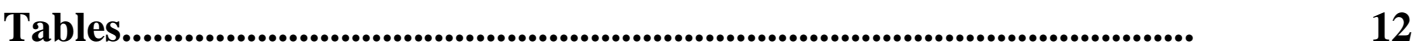

CHAPTER ONE: INTRODUCTION TO THE THESIS 13

Background and Relevance of the Research...................................... 13

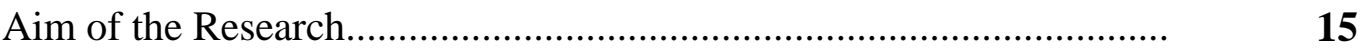

Objectives of the Research................................................................

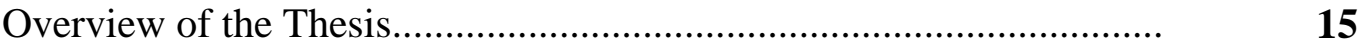

What might this PhD Add? ........................................................... 18

CHAPTER TWO: WHAT IS REIKI?

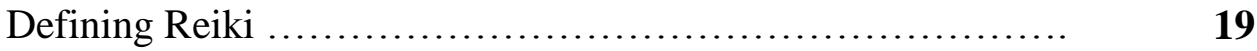

Issues in Researching the History of Reiki ...................

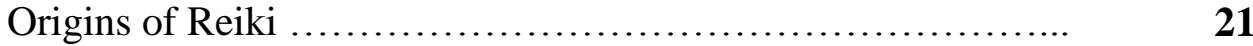

Differences between the Original Japanese System and 22

Western Reiki

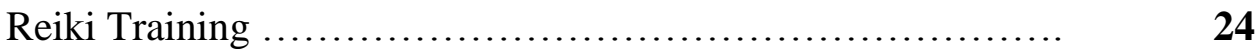

Treatment of Others............................................................

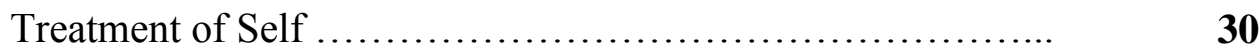

Potential effects of Reiki................................................... 31

Regulation of Reiki ...................................... 32

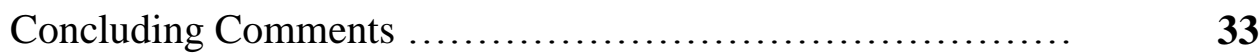

CHAPTER THREE: MAPPING THE REIKI LITERATURE AND 35

REVIEWING THE EVIDENCE BASE 
Mapping the Reiki Literature $\ldots \ldots \ldots \ldots \ldots \ldots \ldots \ldots \ldots \ldots \ldots . \ldots \ldots$

Results of the Mapping .................................. $\quad 36$

Question 1: Who uses Reiki (or who has it been used 38 with) and in what setting?

Question 2: What conditions/illnesses has Reiki been used to treat?

Question 3: What study designs have been used to Research Reiki?

Question 4: How is Reiki used on self and others?

Summary

Review of the Reiki Research Literature.................................... 43

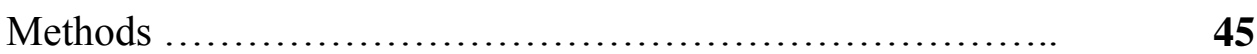

Review Questions .............................. $\quad 45$

Search Strategy $\ldots \ldots \ldots \ldots \ldots \ldots \ldots \ldots \ldots \ldots \ldots \ldots \ldots \ldots, \quad 45$

Study Appraisal .................................. $\quad \mathbf{4 6}$

Study Synthesis $\ldots \ldots \ldots \ldots \ldots \ldots \ldots \ldots \ldots \ldots \ldots \ldots \ldots, \quad 48$

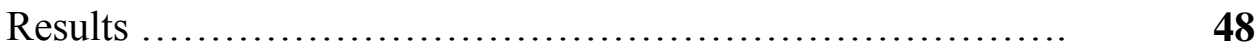

Review Articles on Reiki .......................... 49

Review of Individual Empirical Studies...................... $\quad \mathbf{5 7}$

Question 1: What are peoples experiences of Reiki (during or after a treatment)?

Question 2: What are the benefits of using Reiki? ...... $\quad 61$

Pain Management..................................... $\quad \mathbf{6 1}$

Anxiety Depression and Stress.................. $\quad \mathbf{7 6}$

Recovery after Illness............................ $\quad \mathbf{2 0}$ 
Other Benefits.

Benefits of Learning and Self-Use of Reiki

Summary

90

CHAPTER FOUR: CONCEPTUALISING HEALTH LITERACY

93

Introduction

93

Rationale and Methods of Identifying the Literature ...

93

Defining and Conceptualising Health Literacy

98

The Clinical Approach to Health Literacy

98

The Public Health Approach to Health Literacy ........

100

Nutbeam's Model of Health Literacy

103

Concluding Comments

CHAPTER FIVE: DEVELOPING A MODEL OF REIKI

HEALTH LITERACY

Introduction

Reiki and Health Literacy

105

Process of Developing the Model of Reiki Health Literacy........

105

Preliminary Reading

106

Development of the definition of each Level of Reiki Health Literacy

Development of the Potential Benefits of each Level of Reiki Health Literacy

The model of Reiki Health Literacy

Concluding Comments 


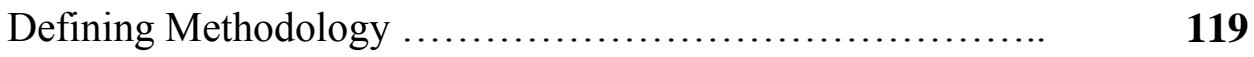

Characterising Qualitative Methodology ...................... $\quad \mathbf{1 2 0}$

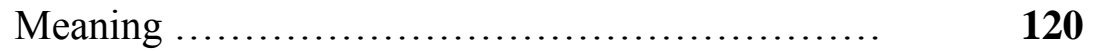

Natural Settings .................................. $\quad 121$

Textual Data .................................... $\quad \mathbf{1 2 1}$

Reflexivity ................................ $\quad \mathbf{1 2 2}$

Rationale for the use of Qualitative Methodology within this $\mathbf{1 2 2}$

Research

Influence of the Researcher's Biography..................................... $\quad \mathbf{1 2 3}$

Wellbeing of Participants During and After Interview.............. $\quad \mathbf{1 2 4}$

Concluding Comments........................................................... $\quad 125$

CHAPTER SEVEN: METHODS 126

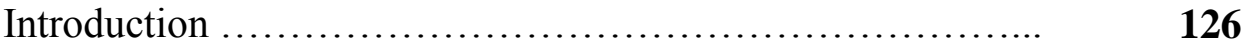

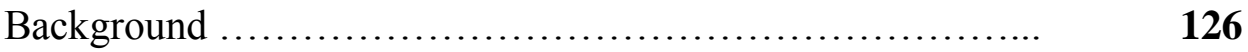

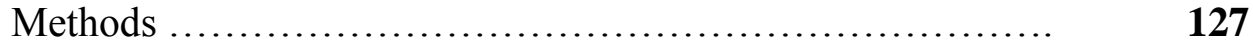

Phase One: Unstructured Interviews ............... $\quad \mathbf{1 2 8}$

Phase Two: Semi Structured Interviews ............. $\quad \mathbf{1 3 0}$

Phase Two: Vignettes .............................. $\quad 132$

Description of Vignettes ........................ $\quad 134$

Design and Development of Vignettes .............. $\quad \mathbf{1 3 8}$

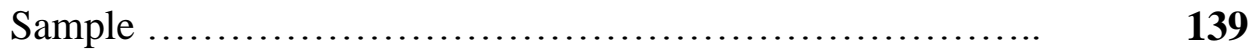

Phase One and Two: Method of Sampling ............ $\quad 141$

Phase One: Participants ......................... $\quad 141$

Phase Two: Participants .......................... $\quad \mathbf{1 4 2}$

Sample Size .................................. $\quad 143$ 
Phase One

Phase Two

Sample Diversity

Procedure for Recruitment

Phase One

Phase Two

Sampling Difficulties

Interview Process

Interview Schedule

Piloting and Refinement of the Interview Schedule.

Phase One

Phase Two

Data Analysis

Phase One and Phase Two

Process

Phase One

Phase Two

Trustworthiness of Researcher's interpretations

Concluding Comments

CHAPTER EIGHT: EXPLORATION OF THE REIKI HEALTH

LITERACY MODEL WITH REIKI MASTER TEACHERS

Introduction

Participants

Interpretation of Interview Data 
Functional Reiki Health Literacy: Initial Model ...... 169

Functional Reiki Health Literacy: Refined Model ..... 173

Summary of Functional Reiki Health Literacy ........ 182

Interactive Reiki Health Literacy ................. $\quad \mathbf{1 8 3}$

Interactive Reiki Health Literacy: Initial Model ....... $\quad \mathbf{1 8 6}$

Interactive Reiki Health Literacy: Refined Model ..... 196

Summary of Interactive Health Literacy ............ $\quad 206$

Critical Reiki Health Literacy ..................... $\quad \mathbf{2 0 7}$

Critical Reiki Health Literacy: Initial Model ......... $\quad 208$

Critical Reiki Health Literacy: Refined Model ........ $\quad 214$

Summary of Critical Reiki Health Literacy .......... $\quad \mathbf{2 1 9}$

CHAPTER NINE: EXPLORING THE APPLICABILITY OF THE 221

REIKI HEALTH LITERACY MODEL WITH LEVEL ONE AND

TWO SELF-USERS

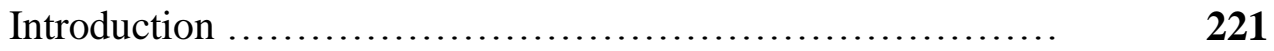

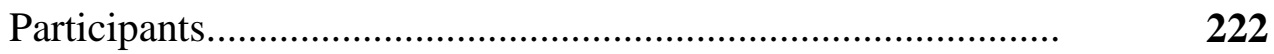

Interpretation of Interview Data................................ $\quad \mathbf{2 2 3}$

Functional Reiki Health Literacy $\ldots \ldots \ldots \ldots \ldots \ldots \ldots \ldots \ldots \ldots \ldots . \ldots \ldots$

Functional Reiki Health Literacy ................. $\quad \mathbf{2 2 3}$

Summary of Functional Reiki Health Literacy ........ $\quad 238$

Interactive Reiki Health Literacy $\ldots \ldots \ldots \ldots \ldots \ldots \ldots . . . \quad \quad 238$

Summary of Interactive Reiki Health Literacy ........ $\quad \mathbf{2 7 0}$

Critical Reiki Health Literacy $\ldots \ldots \ldots \ldots \ldots \ldots \ldots \ldots . . . \quad 270$

Summary of Critical Reiki Health Literacy .......... $\quad 290$

$\begin{array}{ll}\text { CHAPTER TEN: DISCUSSION } & 292\end{array}$

Introduction.................................................. 
Overview of the Thesis Argument.............................. 293

Part One: Theoretical and Conceptual Foundations.... 293

Part Two: Underlying Principles of the Research........ 294

Part Three: Refinement and Application of the Reiki 294

Health Literacy Model

Empirical and Theoretical Contributions.................... $\quad 294$

Objective One: Review the literature on Reiki........... 295

Objective Two: Identify key concepts associated with $\quad \mathbf{2 9 5}$

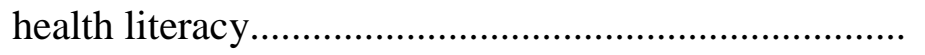

Objectives Three and Four: Develop a model of 296

Reiki health literacy and confirm and refine the Reiki health literacy model.

Objective Five: Uncover the specific effects of learning and self-use of Reiki on health literacy

Objective Six: Explore how Reiki health literacy is used in the context of health in daily life

Strengths and Limitations of the Research.

Concluding Comments and Recommendations for

Further Research

Bibliography 


\section{List of Figures}

2.1. Reiki Levels ................................................. $\quad \mathbf{2 6}$

2.2. Standard Hand Positions used during a Reiki Treatment ...... $\quad 60$

3.1. Documents identified in literature search $\quad 38$

3.2. Summary of Evaluation tool $\ldots \ldots \ldots \ldots \ldots \ldots \ldots \ldots \ldots \ldots \ldots \ldots \ldots \ldots \ldots$

4.1. Health Literacy Papers Included in the Conceptual Review ... 96

4.2. Nutbeam's Model of Health Literacy 104

5.1. Interpretations of Nutbeam's levels of Health Literacy ....... 108

5.2. A Model of Reiki Health Literacy ...................... $\quad \mathbf{1 1 6}$

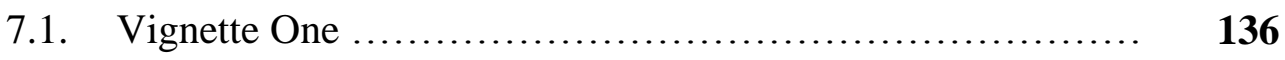

7.2. Vignette Two ....................................... 136

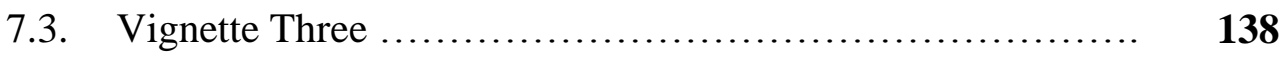

7.4. Summary of Interview Schedule for Phase one ............. 156

7.5. Summary of Interview Schedule for Phase two.............. 157

7.6. Amendment made to interview schedule post pilot (Phase One) $\mathbf{1 5 8}$

7.7. Amendment made to interview schedule post pilot (Phase Two) $\mathbf{1 6 0}$

7.8. Initial Codes for Phase One ........................... 163

7.9. Initial Codes for Phase Two (abridged) .................. 164

8.1. Summary of Components of Functional Reiki Health Literacy $\mathbf{1 7 0}$

8.2. Summary of Components of Interactive Reiki Health Literacy $\mathbf{1 8 6}$

8.3. Summary of Components of Critical Reiki Health Literacy 209

10.1 A Refined Model of Reiki Health Literacy 298 


\section{List of Tables}

3.1. Types of document included in mapping ..................... 39

3.2. People and settings where Reiki has been used ................ 40

3.3 Illnesses and Conditions for which Reiki used to Treat $\mathbf{4 2}$

3.4. Study Designs used to research Reiki ...................... 43

3.5 Mode of Use ............................................. 44

3.6. Summary of Reiki Review Articles ........................ $\quad 54$

3.7. Summary of evidence for people's experience of receiving 61

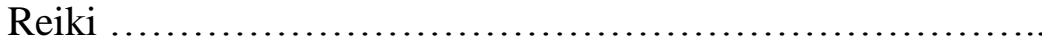

3.8. Summary of evidence for efficacy/effectiveness of Reiki for pain $\quad \mathbf{6 8}$ management

3.9. Summary of Evidence for Anxiety, Depression and Stress ...... $\mathbf{7 8}$

3.10. Summary of Evidence for the use of Reiki in Recovery after Illness $\mathbf{8 4}$

3.11 Summary of Evidence for the use of Reiki in other illnesses and $\quad \mathbf{8 8}$ conditions

3.12 Summary of Evidence for the benefits of learning and self-use of

Reiki

7.1. Recruitment Grid for Phase Two Sample

7.2. Method of Recruitment, Potential Participants Contacted and Total $\mathbf{1 5 2}$ Participated

8.1. Key Characteristics of the Sample ......................... 168

9.1. Key Characteristics of the Sample ........................... 223 


\section{Chapter One: Introduction to the Thesis}

\section{Background and Relevance of the Research}

Despite improvements in overall life expectancy, associated inter alia with 'improvements in public health, nutrition and medicine' (Royal Geographical Society 2012), life in modern society, pressures within the workplace, the ways individuals live their own lives and associated lifestyles and health inequalities all pose substantial challenges to the population's health. Consequences are evident in high levels of stress and psychological ill-health, sickness absenteeism and crises of obesity and the increasing prevalence of long-standing illness. Year upon year official statistics serve as a reminder that many people are not making healthy choices with regards their health and wellbeing. For example, the government's 'call to action' on obesity (2011) reported that 'A total of $23 \%$ of adults are obese (with a body mass index [...] of over 30); 61.3\% are either overweight or obese (with a BMI of over 25)' (Department of Health 2011:5). Similarly, $20 \%$ of adults reported smoking in 2010 (Health and Social Care Information Centre (HSCIC) 2012) and statistics relating to the mental health of the British population demonstrate that $9 \%$ of people meet the criteria for diagnosis of anxiety and depression (Mental Health Foundation 2012). In their recent survey (Mental Health Foundation 2012) $21 \%$ of respondents reported feeling stressed 'everyday'. Such statistics are commonplace despite a barrage of public health campaigns encouraging the nation's population to take better care of themselves. This begins to raise the question of 'why are these messages not getting through or being heeded by people?'

As a former research assistant within a University nursing department, such questions interested me, especially as after a bout of ill health in 2007 I discovered a way to take better care of my own health. Through learning Reiki, I quickly became aware of the sense of health and wellbeing that giving myself daily Reiki treatments provided. As a research assistant, with access to academic databases at my disposal, I was ever more eager to find out what research had been undertaken on Reiki, and in particular the self-use of Reiki. What gradually became evident was very little good quality research and even less into the self-use of Reiki. 
The opportunity to explore some of these issues more formally presented itself in 2008 when I applied for and was awarded a School of Healthcare PhD studentship at the University of Leeds to explore the potential contribution of complementary and alternative medicine (CAM) to population health. My PhD studentship was intended to build on existing research on CAM in the School for example, Ménière's syndrome, (Long and Bennett 2009), exploration of the effects of particular CAM modalities for example, shiatsu (Long 2009) and a stream of work on improving health literacy and informed decision-making for lifestyle behaviours for example diet and physical activity (Jackson C 2010); childhood immunisation (Jackson et al. 2011); diabetes self-management (Long AF and Gambling T 2012).

Within my first months, my supervisors encouraged me to familiarise myself with the literature on health literacy and I soon discovered that the concept of health literacy was one way that health promotion experts had framed the reasons behind such unhealthy lifestyle choices and behaviours. Broadly, health literacy represents the cognitive and social skills which determine the motivation and ability of individuals to gain access to, understand and use information in ways which promote and maintain good health (Nutbeam and World Health 1998:10). This led to my reframing my original interest and asking myself: 'could improving health literacy be a way to improve individuals' health, and thus the population's health more generally?' and 'was there potential for Reiki, as one complementary therapy that involved self-use, to play a role in this?'

Concurrent with increasing prevalence of long-standing conditions and societal and personal challenges to individuals' health and their lifestyles behaviour, the United Kingdom (and many Western countries) has witnessed a growing use of complementary and alternative medicine (CAM) (Thomas, Nicholl and Coleman 2001; Thomas and Coleman 2004; Frass et al. 2012). Reasons include dissatisfaction with medical care, side-effects of drug treatments as well as a search for alternative or complementary ways to treat and care for one's health(Vincent and Furnham 1996; Fulder 1998; Richardson 2004; Sointu 2006). Relatively little attention has however been given to the role of CAM in public health. Indeed, Bodeker (2002) has suggested that 'public health professionals need to define the public health dimensions of traditional and complementary medicine.' (1588). An early preliminary scan of 
the literature revealed a highly limited literature in the area of CAM and health literacy. Only research within one complementary modality (shiatsu) had explicitly raised the topic of health literacy, and within this only as a consequence of the findings and a search for a way to account for take-up of advice by the practitioner and its perceived impact on clients' health and well-being (Long 2009). Moreover, there was a distinct lack of literature defining the public health dimensions of CAM as urged by Bodeker (2002). And so the research presented in this thesis was conceived - a focus on Reiki, its self-user and it's potential to enhance individual's health literacy, and its subsequent refinement into a clear $\mathrm{PhD}$ research aim and associated objectives.

\section{Aim of the Research}

The aim of this $\mathrm{PhD}$ research was to explore how learning and self-use of Reiki enhances health literacy.

\section{Objectives of the Research}

1. Review the literature on Reiki

2. Identify key concepts associated with health literacy

3. Develop a model of Reiki health literacy

4. Confirm and refine the Reiki health literacy model

5. Uncover the specific effects of learning and self-use of Reiki on health literacy

6. Explore how Reiki health literacy is used in the context of health in daily life

\section{Overview of the Thesis}

There are nine further chapters in this thesis. Chapters Two through to Five of this thesis form the theoretical and conceptual foundation of the thesis. Chapter Two introduces the first foundation stone, by providing a brief overview of Reiki, a complementary therapy that involves the Reiki practitioner channelling energy through their hands into themselves and/or a recipient. Within this chapter the defining characteristics of this complementary therapy are elucidated. This chapter pays particular attention to a feature of Reiki that is intrinsic to this research, that is, the emphasis on self-use of Reiki at all levels of practice. 
Chapter Three provides an overview and critical review of the literature on Reiki. The chapter is divided into two parts. The first part presents a mapping of the Reiki literature indicating the breadth of material on the subject of Reiki. The reader's attention is drawn to the groups of people that use Reiki and the settings in which Reiki is used; the conditions and illnesses that Reiki can be used to treat; the study designs on which research into Reiki have been based; and how Reiki is used on self and others. The second part of this chapter comprises a systematic, critical literature review of the empirical research that has explored the effects of Reiki. Of particular importance to the focus of the $\mathrm{PhD}$, the chapter critically evaluates the research into self-use of Reiki.

Chapter Four introduces the core theoretical concept of the $\mathrm{PhD}$, health literacy. It does this by providing a critical overview of the conceptual literature on health literacy. One particular approach to conceptualising health literacy is explored in detail (Nutbeam 2000) as this approach underpins the subsequent development of a model of Reiki health literacy that forms the focus of the empirical element of the $\mathrm{PhD}$ study.

Chapter Five draws on the analysis and discussions of Chapters Two to Four and explores the potential of Reiki to enhance health literacy. It presents the initial model of Reiki health literacy. The model was constructed by drawing on the conceptual review of health literacy presented in Chapter Four, the theory and principles of Reiki (Chapter Two) and the critical review of the Reiki literature presented in Chapter Three. The three-step process involved in developing the content and definition of each level of the initial model of Reiki health literacy is also demonstrated.

Chapter Six marks the start of the empirical dimension of the $\mathrm{PhD}$ research. This chapter explores the methodological approach adopted in the empirical work, in particular, its drawing on a qualitative methodology. The chapter draws out key features of qualitative methodology and its emphasis on the concept of 'meaning' (acquiring an understanding of how people make meaning of the social world and how they experience the world around 
them), a preference for studying people in their natural settings, the collection of textual data and features surrounding approaches to rigour and reflexivity.

Chapter Seven presents and provides a rationale for the methods used during the course of the research. The empirical work of the $\mathrm{PhD}$ involves two phases of fieldwork, both of which explore participants' experiences of Reiki and thus face to face unstructured interviews (with Reiki Master Teachers) and semi-structured interviews (with Reiki self-users) were deemed appropriate methods of data collection for this research. Vignettes were also incorporated into the semi-structured interviews. This chapter includes summaries of the interview schedules and the vignettes. It explains how the interview schedules were piloted and refined and how the vignettes were designed. The chapter also presents the methods used to recruit participants to the research, the process of conducting the interviews and the approach adopted by the researcher to self disclosure and answering participant's questions. A key and final part of the methods provides insight into the data analysis process, in particular, use of a directed content analysis approach, supplemented in the phase two fieldwork by conventional content analysis. This includes details of the way these approaches were applied, how the interviews were coded and codes derived and how the trustworthiness of the researcher's interpretations was assured.

Chapters Eight and Nine present the analysis and interpretation of the data collected through the interviews with Reiki Master Teachers and Reiki self-users. Chapter Eight presents the findings from phase one (unstructured interviews with Reiki Master Teachers) in the context of its aim to confirm and refine the model of Reiki health literacy first presented in Chapter Five. This chapter commences by presenting the key characteristics of the sample. It then provides an analysis and interpretation of the interview data, structured around the three levels of the Reiki health literacy model, specifically the skills and knowledge that comprise each level, differentiating elements confirmed and those needing to be added to the model of Reiki health literacy. The chapter thus leads to a revised model of Reiki health literacy, the applicability of which was subsequently explored with Reiki level one and two self-users. 
Chapter Nine presents the analysis and interpretation of data collected with level one and two self-users of Reiki. The aim of this phase of the research was to explore the applicability of the Reiki health literacy model with Reiki level one and two self-users as a means of establishing if the Reiki health literacy model accurately captures people's experiences of using Reiki for self-care. The chapter begins by presenting the key characteristics of the participants and then examines each level of the Reiki health literacy model.

The final chapter of this thesis, Chapter Ten, draws together the work that was undertaken to meet the aim and address the objectives of the research. It discusses the findings of the research in relation to each of the research objectives and highlights the strengths and limitations of the study. In doing this it identifies how the findings of the research cohere with or challenges current knowledge and understanding of self-use of Reiki and particularly its relation to health literacy. The final part of the chapter reflects on the implications of this research and signposts to further research.

\section{What might this PhD add?}

This thesis aims to contribute to debate around the potential of CAM to enhance health literacy through examining one CAM modality, Reiki. An original model of Reiki health literacy is presented, developed through theoretical and conceptual work examining Reiki and the concept of health literacy and then further refined within a group of experts, Master Teachers of Reiki. The $\mathrm{PhD}$ also includes a critical review both of research evidence on Reiki, but also on Reiki self-use. Finally, the thesis illuminates and adds to understanding and insight into how self-use of one CAM modality may enhance individuals' health literacy. 


\section{Chapter Two: What is Reiki?}

The purpose of this chapter is to introduce the concept of Reiki and to provide an account of what is known about Reiki. The chapter begins by introducing the concept and various definitions of Reiki. A brief outline of some of the difficulties of tracing the history of Reiki is provided, before the origins of Reiki in Japan and the West ${ }^{1}$ and the differences between the two systems are discussed. The process of training in Reiki is described and two distinct features of the Reiki system that are taught to students, the Reiki principles and the Reiki symbols, are introduced. A description is also provided of how one treats others and the self with Reiki and a critical reflection on the effects one might anticipate from using Reiki based on its guiding theory and principles. This chapter concludes with consideration of the regulation of Reiki.

\section{Defining Reiki}

The word Reiki (pronounced 'ray-key') is of Japanese origin and literally translates as universal life force energy. In Japan and the West, the word Reiki has two slightly different meanings. In Japan, any form of healing that uses spiritual energy may be described as Reiki (Quest 2002). However, in the United Kingdom and other parts of the Western world, Reiki denotes a system of healing that originated in Japan and involves a practitioner channelling energy through their hands into the recipient. Commonly Reiki is considered a type of complementary therapy. Definitions of Reiki vary in their emphasis. Some highlight the fact that Reiki involves healing using the hands;

Reiki is a gentle, powerful, hands on healing technique. (Honervogt 2001:12)

Reiki - the great art of healing with the hands. (Yamaguchi 2007:9)

1 The term 'the West' is frequently used throughout the Reiki literature (Quest 2002; Rand, 2005; Vennells, 2005) but rarely defined. The meaning of the term can vary depending upon the context and period of time in which it is employed. Examples include economic, spiritual and political contexts. Herein, 'the West' is used in a geographical context to denote any country other than Japan and any non-Japanese practices. 
Other definitions draw attention to the use of energy within the Reiki system;

Reiki is an energy based healing and self-development system that originated in Japan. (Mellowship and Chrysostomou 2008:4)

Pertinent to this thesis, the fact that Reiki can be used on oneself is another feature often highlighted in definitions. The following definition provided by Quest (2002) includes the notion of self-use and combines elements of all of the above definitions;

Reiki is a safe, gentle, non-intrusive hands-on healing technique for use on yourself or with others, which uses spiritual energy to treat physical ailments without using pressure, manipulation or massage. (Quest 2002:3)

This definition is the one used in this thesis as it combines three core elements of Reiki, namely that, it is administered through the hands, it is an energy-based therapy and it can be used on self and others.

\section{Issues in Researching the History of Reiki}

Due to its Japanese roots, tracing the historical development of Reiki as a complementary therapy is problematic for two reasons. Firstly, there is a lack of primary documents relating to the founder of Reiki, Mikao Usui. Those that exist include Usui's memorial inscription and Reiki instruction manual which contains an interview with Usui. Both the memorial inscription and the instruction manual have been translated from Japanese to English. Information not derived from the above primary sources remains largely uncorroborated, taking the form of oral history. Language is the second problem associated with researching the history of Reiki. Historical documentation relating to Reiki is written in Japanese Kanji. Kanji are Chinese characters used in the written form of Japanese. This was the form of writing in usage at the time that Mikao Usui lived (1865 - 1926); therefore, any original documents relating to Reiki are written using Japanese Kanji from this period. In the 1940s this Kanji was simplified by the Japanese Government and, as a result, translating the old 
Kanji into modern Japanese can result in slightly different interpretations as the contemporary meanings of some of the older Kanji are different today.

What is known today and follows herein about the origins of the Reiki system is derived primarily from the work of Frank Arjava Petter (Petter 1997; Petter 1998; Usui and Petter 1998) who has translated the above mentioned primary sources into modern Japanese and then into English.

\section{Origins of Reiki}

Mikao Usui (1865 - 1926) is acknowledged as being the founder of the Reiki system. The primary source of information available about Usui's life comes from the inscription on his memorial stone, written by his students. Usui was a Buddhist monk who at the age of 57 took a 21day retreat that involved fasting and meditation. During this time, Usui is said to have had a 'satori'. 'Satori' is a term used in Buddhism which translates as 'understanding' and is used to refer to enlightenment. The satori experienced by Usui is said to have taken the form of Reiki energy entering the top of his head. After his retreat, Usui used Reiki on himself and his family before sharing his knowledge of Reiki with the public. In April 1922 he moved to Tokyo where he established the 'Usui Reiki Ryoho Gakkai' -- translated into English to mean the 'Usui Reiki healing society' -- and established a clinic where he treated patients and taught Reiki. His memorial inscription claims that he taught Reiki to over 2000 students (as translated by Petter 1997).

Hawayo Takata (1900 - 1980) is regarded as responsible for bringing Reiki to the West in the 1930s. Born and raised in Hawaii, Takata visited Tokyo in 1935 where she received Reiki treatment from Chujiro Hayashi for deteriorating health. Hayashi had been taught Reiki by Usui and when Takata's health was restored, she spent a year learning and practising Reiki in Hayashi's clinic. In 1937 Takata returned to Hawaii where she established her first Reiki clinic in Hilo. The clinic was a success and word spread. Until her death in 1980, Takata lived in Hawaii teaching and practising Reiki. She also taught classes in mainland USA. In the mid 1990s, when Western Reiki teachers began to research the origins of Reiki, it became apparent that Takata had made some changes to the system that differed from the original 
teachings of Usui. The style of Reiki taught by Takata is sometimes referred to as 'Western Reiki' to distinguish it from the style of Reiki originally taught by Usui. 'Western Reiki' is the form of Reiki most commonly taught and practised in the United Kingdom today.

\section{Differences between the Original Japanese System and Western Reiki}

After the death of Usui in 1926, it is alleged that his Reiki healing society, the 'Usui Reiki Ryoho Gakkai', split into several groups, most of which ceased after the Second World War (Stiene and Stiene 2005; Lübeck, Petter and Rand 2001). Yamaguchi (2007) notes that Reiki began to spread again in Japan in 1984. However the style of Reiki that re-emerged was one based on the teachings of Hawayo Takato that has become known as Western Reiki.

Some of the differences between the original system and the Western Reiki system are notable in the terminology used. For example, the use of the term 'Reiki Master' to describe a Reiki teacher is a Western term; in the original Japanese system there was no such title, because 'in spiritual practices 'master' denotes one who has become enlightened' (Rand 2001:15 cited in Lübeck, Petter and Rand 2001). Thus, in the original Japanese system someone who teaches Reiki is known simply as a teacher.

More differences are observed in the levels of teaching, in the hand placements and in the thinking underpinning the system. In the original Japanese system, there are six levels of training with the sixth level being the first level that a student learns and the first level being the final level. Level six is split into four parts; this was taught by Takata as level one Reiki. The second level is also divided into a further two parts. This contrasts with the three (one part) levels taught in the Western Reiki system. The placement of the hands in a series of twelve positions that is taught in the West was added by Western teachers and practitioners (Petter 2001) and was not part of the system taught by Usui. In the original Japanese system, Reiki practice relied more on the intuitive placement of the hands in any number of positions rather than a prescribed series of hand placements (Petter 2001; Quest 2002). This difference has been explained by Petter (1998) when he describes some of the cultural differences inherent in Eastern ways of thinking and feeling: 
'Japanese think in an abstract manner, [...] Logic is not a topic of interest in Japan.' (Petter 1998:41)

Petter concludes that for Reiki to be used by Western people, it needed to rely less on intuition and more on logic to reflect the (more logical and less intuitive) Western way of thinking. Similar culturally grounded differences between the 'Western' and 'Japanese' practice of Shiatsu have been noted by Adams (2002).

Vennells (2005) notes that in the Western system there is a focus more on the physical and mental healing aspects of Reiki, rather than its spiritual aspects, because this is what people feel most comfortable with (Vennells 2005). In the original Japanese system more emphasis is placed on Reiki as a spiritual practice. Lübeck (2001) notes some of the themes of the 'mystic path' of Reiki as being the life principles, 'meditation, the esoteric meaning of the Reiki symbols, and the Waka ${ }^{2}$ that Mikao Usui used to teach his students' (in Lübeck, Petter and Rand 2001:245).

Today, neither the original Japanese system nor the Western system of Reiki is considered the 'correct' approach within the Reiki community. Rather, it is acknowledged that there are subtle differences and as Yamaguchi (2007) appears to suggest that each system needs to be considered within its cultural context:

'It is possible that if the original form had been rigidly adhered to it would have fallen flat in other cultures and only a small number of people would have been blessed with Reiki. It is natural that in different cultures, Reiki should spread in different ways for the people with varying cultural backgrounds to accept it. I feel we shouldn't be focussing on the differences. Instead we need to focus on the universality of Reiki and its incredible healing capabilities' (Yamaguchi 2007:18)

\footnotetext{
${ }^{2}$ Waka is a form of Japanese poetry
} 
With the differences between the systems emerging there has in recent years been interest within the Reiki community of learning and practising the original Japanese system (Lübeck, Petter and Rand 2001; Stiene and Stiene 2005; Yamaguchi 2007). Today there are many variations of Reiki practised in both the West and Japan (Quest 2002). The remainder of this thesis will focus on Usui Reiki, the most commonly taught form of Western Reiki that is regarded as being brought to the West by Takata.

\section{Reiki Training}

There are no prerequisites for learning Reiki other than a desire to learn. Training is generally split into three levels: first, second and third (also known as Master level). An indication of the content of each level of Reiki teaching is provided in Figure 2.1 which is derived from Stiene and Stiene (2008) and is fairly typical of what is found in other Reiki instruction manuals, although it should be noted that content of courses may vary between teachers.

The levels of Reiki training are sequential, but, at the same time, complete within themselves. In other words, it is not necessary to undertake all three levels of training; as with the education system in the United Kingdom, taking A-levels does not necessitate that a person continues their education to degree level. 
Figure 2 1: Reiki Levels

\begin{tabular}{|l|l|}
\hline \multicolumn{2}{|l|}{ Reiki Levels } \\
\hline Level 1: Shoden in Japanese. & $\begin{array}{l}\text { It is the beginning of a student's journey in self- } \\
\text { healing using Reiki practices. It should teach a } \\
\text { foundation of the system and how to work with } \\
\text { Reiki on the self; how to strengthen one's inner } \\
\text { energy and begin a personal healing process. It } \\
\text { should also give one the confidence to work with } \\
\text { friends and family using Reiki techniques. }\end{array}$ \\
\hline Students should also receive four attunements at \\
this level.
\end{tabular}

(Stiene and Stiene 2008:25)

To be able to channel Reiki energy, a person must find a Reiki Master to teach them and 'attune' them to this energy. An attunement, which is sometimes also described as a spiritual empowerment, is a ceremony in which the Reiki Master passes the Reiki energy to their student and is one of the defining features of Reiki training. Without an attunement one is not able to access Reiki energy for self-use or use on others. The attunement is said to create a channel in the student through which the Reiki energy can flow. Students receive attunements with each level of Reiki practice that they learn. The attunement process is the 
means by which one acquires the ability to use Reiki, but as noted by Quest (2002) it is an uncommon way of acquiring knowledge and skills in the West:

This 'instant' acquisition of healing ability is one of the things that makes Reiki unique, but is probably also the most puzzling aspect of it to Western minds. We are not accustomed to anything so valuable or being achieved so effortlessly, yet in the East spiritual empowerments are a well known and accepted way of acquiring energy, knowledge, wisdom or insight.(Quest 2002:31)

Having received an attunement, one can channel Reiki for the remainder of one's life; however, should the person choose to discontinue with Reiki practice, this will be of no detriment to the self. Two other distinct features of Reiki training, the Reiki principles and the Reiki symbols, are also worthy of outline at this point as they will be referred to in forthcoming chapters.

\section{The Reiki Principles}

At level one Reiki, students are taught the Reiki principles, sometimes referred to as the Reiki 'precepts' or Reiki 'ideals'. The Reiki principles are described by Stiene and Stiene (2008) as 'a foundation to aid students in their journey toward spiritual development' (2008: 67). They comprise the following five phrases;

Just for today don't get angry

Just for today don't worry

Just for today be grateful

Just for today work hard

Just for today be kind to others

In the original Japanese system, the Reiki principles are known as the Gokai, and Yamaguchi (2007) states that they were regarded by traditional Reiki practitioners as 'their basic 
philosophy for life' (2007: 79). The Gokai were chanted at Reiki classes and meetings and also alone as part of a student's daily life (Yamaguchi 2007; Mellowship and Chrysostomou 2008). They were also used for meditation (Mellowship and Chrysostomou 2008). Today in the West, some Reiki teachers may encourage students to draw on the Reiki principles during meditation, or encourage them to chant the principles on a daily basis. However as a minimum 'students are encouraged to reflect on them and remember them as they go about their daily lives' (Rowland 2008:56).

\section{The Reiki Symbols}

At level two Reiki, the student is taught three 'symbols' and three corresponding 'mantras'. A mantra is ' $a$ word or sound that is repeated to aid concentration in meditation, particularly in Eastern spiritual traditions' (Quest 2002:154). At level three Reiki (Master level), the student is taught a further one symbol and corresponding mantra. As with the Reiki principles, the Reiki symbols can be incorporated into meditation practice; however, their use is primarily to change the way that the Reiki energy works. Using the Reiki symbols is said to 'add to the strength and versatility of the system of Reiki healing' (Rand 2005: II-5) and allows the practitioner 'to channel the correct frequency of energy for whatever condition you are treating, whether it is physical, emotional or spiritual' (Mellowship and Chrysostomou 2008:86). The symbols can be drawn physically on paper with the hand, or they can be drawn in the air with the hand or fingers, or they can be visualised (Quest 2002; Stiene and Stiene 2008). Once the symbol has been drawn the corresponding mantra is repeated three times either aloud or silently to activate the symbol. One of the three symbols, the distant symbol, taught at second degree, is worthy of particular explanation. The distant symbol allows the practitioner to send Reiki energy to another person over any distance, for example, in another town, country or another room. Quest (2002) also notes that this symbol may be used to 'send' Reiki to the past or the future.

The Reiki symbols are not reproduced within this thesis. This is because whilst pictures of the symbols can be viewed in some Reiki books and on the internet, they traditionally remain 'secret' until an individual learns second degree Reiki (Quest 2002) and students are requested not to share the symbols with people not attuned to Reiki. Rand (2005) explains the secrecy associated with the symbols: 
The reason for secrecy is twofold. First there is a personal issue. By keeping the symbols secret you demonstrate your respect for them [...] The second reason for keeping the symbols secret prior to the attunement is consideration for others. Since the power of the symbols comes from the attunement, showing them to those who have not received the attunement will not help them and could cause confusion. (Rand 2005: II-5)

\section{Treatment of Others}

When visiting a Reiki practitioner, the Reiki treatment will be explained to the client prior to commencing the treatment. In addition, a practitioner may seek information regarding their client's general state of health and whether they have any particular ailments that need specific attention. During the Reiki treatment the practitioner places his or her hands either directly on or slightly above the client in a series of 12 positions starting at the head, moving down the body and ending at the feet. During the session the practitioner is said to act as a channel for the Reiki energy which flows in through the top of the practitioner's head and out through the palms of his or her hands. The placement of the hands purposely corresponds with the seven major 'chakras'. Chakras are energy centres where Reiki can be most easily absorbed, transformed and distributed throughout the physical and energy bodies (Quest 2002:24). Each of the seven chakras corresponds to specific organs in the body.

The hand positions that are typically used during a Reiki treatment are presented in Figure 2.2. However it should be noted that depending upon the teacher (or the Reiki manual consulted) minor variations may be found in the hand placements and the order in which the hands are placed. Each hand position is held for between three and five minutes. 
Figure 2.2: Standard hand positions used during a Reiki treatment.

\begin{tabular}{|c|c|}
\hline $\begin{array}{l}\text { Practitioner Position (either standing or } \\
\text { seated) }\end{array}$ & $\begin{array}{l}\text { Hand position (palms facing down unless } \\
\text { otherwise stated) }\end{array}$ \\
\hline \multicolumn{2}{|c|}{ Client lays on back } \\
\hline \multirow{5}{*}{ Behind the head facing the client's feet } & Hands cupped over the eyes \\
\hline & Hands cupped over the ears \\
\hline & $\begin{array}{l}\text { Hands placed palms facing upwards on } \\
\text { the back of the head }\end{array}$ \\
\hline & $\begin{array}{l}\text { Hands rest on the collar bone, palms } \\
\text { facing the throat }\end{array}$ \\
\hline & Hands placed on the chest \\
\hline \multirow{3}{*}{ Either side of the client } & $\begin{array}{l}\text { Hands placed over the solar plexus } \\
\text { (between the breasts and the waist) }\end{array}$ \\
\hline & Hands placed over the stomach \\
\hline & $\begin{array}{l}\text { Hands placed in a 'V' over the pubic } \\
\text { bone or thighs }\end{array}$ \\
\hline \multicolumn{2}{|c|}{ Client turns over/ lays face down } \\
\hline \multirow{4}{*}{ Either side of the client } & Hands placed over the shoulders \\
\hline & Hands placed over the middle of the back \\
\hline & Hands placed over the waist \\
\hline & Hands placed over the soles of feet \\
\hline
\end{tabular}

Treatment can last between 30 minutes to one hour and, with the exception of shoes, the person receiving Reiki remains fully clothed. Jewellery is removed and typically the client will lie on either a massage table or the floor and is covered with a blanket. However, Reiki can be given whilst sitting or standing and the presence of shoes or jewellery will not inhibit the receipt of Reiki. After the Reiki session a practitioner will advise a client to drink plenty 
of water in the following days to help flush out any toxins that the Reiki treatment may have dislodged.

\section{Treatment of Self}

At Reiki level one, students are taught how to give themselves a Reiki treatment, sometimes referred to as how to self-heal. The procedure is the same as when treating another person and the hand positions presented in Figure 2 are applied to the self. Many Reiki Master Teachers consider self-treatment with Reiki to be of paramount importance. Quest (2003, below) stresses this, suggesting that it should be an individual's main focus regardless of what level of Reiki practice the person is at:

Whatever your motivation for becoming attuned to Reiki, self-healing needs to be your major focus, whether you've just begun your Reiki journey by taking a first degree course, or have been practising at second degree level for a few years or teaching as a Reiki master for a decade or more. You have the gift of Reiki primarily for your own benefit, whether you use it for other people or as well or not. (Quest 2003:33)

Reiki students are generally advised to carry out a Reiki treatment on themselves at least once per day (Mellowship and Chrysostomou 2008; Quest 2003). Self-healing is, in part, tradition, that is, it featured in the original system taught by Usui as 'a means to unite the body, mind and spirit to attain enlightenment' (Mellowship and Chrysostomou 2008:200). However, on a purely practical level, self-healing can have the same benefits as it can when given to another person (see Potential Effects of Reiki below). By self-treating with Reiki, an individual can actively take personal responsibility for her own health:

Learning to treat the self is actively taking one's health into one's own hands. This fearless act of self responsibility changes how a life situation is experienced. Reiki practitioners no longer need be victims of their circumstances but can choose to live optimally at every level. Life becomes easier as stress dissolves and perceptions alter. The immune system strengthens and illness takes a back seat in life. Most importantly, 
the connection to one's true spiritual nature is re-established. (Stiene and Stiene 2008:21)

Thus, self-healing is purported to be beneficial for physical, mental and spiritual health.

\section{The Potential Effects of Reiki}

As previously noted, some of the definitions of Reiki include the word 'healing'. Stiene and Stiene (2008) define healing as 'to make whole' (2008:17). They further argue that the notion of healing or making whole 'lies at the foundation of the system of Reiki' (2008:17). 'Healing' is not a word readily used within Western society where a biomedical discourse of health dominates. Rather, words such as 'treating' and 'curing' are more commonly used. However, with 'healing' at the core of the Reiki system it is unsurprising that many books and manuals on Reiki discuss the effects of Reiki within the context of the illnesses, injuries and conditions that Reiki can assist in the healing of. Some texts are entirely devoted to this subject, for example Reiki for Common Ailments (Hall 1999), whilst others discuss the benefits and effects of Reiki extensively, for example Quest (2002; 2003).

Reiki textbooks and manuals generally purport that any illness can be treated with Reiki (Stiene and Stiene 2008; Rand 2005; Hall 1999). Examples of specific complaints that Reiki may assist with listed within these texts include 'multiple sclerosis, heart disease, and cancer as well as skin problems, cuts, bruises, broken bones, headaches, colds, flu, sore throat, sunburn, fatigue, insomnia and impotence' (Rand I-12: 2005), and 'depression, insomnia and fear-based illnesses' (Stiene and Stiene 2008:18). However, some authors such as Quest (2002) describe the benefits of Reiki by categorising them as physical, mental, and emotional. The following exert from Quest (2002) is a typical example of the way in which many authors describe the effects of Reiki:

Physical Reiki supports and accelerates the body's own natural ability to heal itself, helping to alleviate pain and relieve other symptoms while cleansing the body of 
poisons and toxins. Reiki balances and harmonises the whole energy body, promoting a sense of wholeness, a state of positive wellness and an overall feeling of well-being.

Mental Reiki flows into all aspects of levels of a person's thinking process, allowing them to let go of negative thoughts, concepts and attitudes, and to replace them with positivity, peace and serenity. This leads to a state of deep relaxation, with the consequent release of stress and tension.

Emotional Reiki flows into all levels of a person's emotional energy [...] to encourage them to examine their emotional responses to people and situations, allowing them to let go of negative emotions such as anger or jealousy, and promoting the qualities of loving, caring, sharing and goodwill. (Quest 2002: 48-49)

Building on the above characterisation of the effects of Reiki, Mellowship and Chrysostomou (2008) describe how some of these effects might manifest in everyday life. The authors claim that a person who learns and self-treats with Reiki becomes 'more intuitive' and makes 'healthier decisions in life' (2008:28). They also claim that self use of Reiki improves a person's 'interactions and relationships with other people' (2008:28) and that individuals who practise self-use of Reiki 'can change the way you handle what life throws at you, in a way that is much more realistic and healthy for you' (2008:30). Thus, the effects of Reiki appear to extend beyond those associated with 'healing' health conditions to include effects on cognitive processes such as decision making, interactions and relationships and healthy coping mechanisms.

\section{Regulation of Reiki}

The issue of regulation in the field of Complementary and Alternative Medicine (CAM) has become pertinent since the House of Lords' report recommended 'improved regulatory structures' (House of Lords Select Committee on Science \& Technology 2000:3) for the complementary and alternative medicine professions. However, Reiki was one of a number of therapies not included in this report. Since the publication of the report many of the professional associations and bodies that represent complementary health practitioners have been working towards regulation. However there is a lack of coherence regarding regulation of CAM in general and Reiki specifically and a single regulatory body for CAM does not 
exist. Attempts to establish such a body have been problematic due to the differing interests of the therapies that may be considered as CAM. Instead, the field is characterised by a number of regulatory bodies that CAM practitioners may subscribe to or be registered with. These include the General Regulatory Council for Complementary Therapies (GRCCT, established 2008), the Complementary and Natural Healthcare Council (CHHC, established 2008) and the British Complementary Therapies Regulatory Council (BCTC, established 2008).

Currently in the United Kingdom only two complementary and alternative therapies are subject to statutory regulation: Chiropractic practice and Osteopathy. The regulation of Reiki (and many other complementary therapies) in the United Kingdom is voluntary as opposed to compulsory. There are a number of bodies and associations that a Reiki practitioner may subscribe to or be a member of, for example, The Reiki Association established 1991, The Reiki Alliance established 1983 (international), The UK Reiki Federation established 1999, and the International Association of Reiki Professionals established 1999. However, no single group is responsible for enforcing regulation. One of the largest professional Reiki organisations is the Reiki Federation which has played a pro-active role in developing a regulatory framework for the Reiki profession in the United Kingdom. The model of regulation that the Reiki Federation subscribes to is that of the General Regulatory Council for Complementary Therapies (GRCCT). Under the GRCCT each profession has its own voluntary Self-Regulation Group which feeds into the GRCCT. The Reiki Regulatory working group was established by members of the UK Reiki Federation in 2002 which became the Reiki Council in 2008. Today, the Reiki Council is the lead advisory body for professional Reiki practitioners in the UK.

\section{Concluding Comments}

In the United Kingdom and other parts of the Western world, Reiki is known as a system of healing that originated in Japan with Mikao Usui in the early 1900's and eventually migrated to the West in the 1930s owing to Hawayo Takata. The practice of Reiki involves a practitioner channelling energy through their hands into the recipient. Reiki can be used on self and others and training in Reiki is open to anyone with a desire to learn. Training is at three sequential levels and one of the unique features of each level of training is the 
'attunement': the means by which a person acquires the ability to channel the Reiki energy. Two other distinct features of Reiki training are the Reiki principles and the Reiki symbols. Self use of Reiki is considered by many Reiki teachers as paramount and as something that should be the main focus of each level of practice. Reiki can be used to treat or 'heal' a range of illnesses and medical conditions. The potential benefits of Reiki are wide ranging and include benefits to the physical, mental and emotional facets of an individual. Compulsory regulation of Reiki in the United Kingdom does not exist, rather, voluntary self-regulation characterises professional practitioners.

Having presented an account of what Reiki is, this thesis will now explore the breadth of material on Reiki within the academic literature and the evidence for of its efficacy as demonstrated by empirical research. This will take the form of a mapping exercise and a critical appraisal of selected research literature. 


\section{Chapter Three: Mapping the Reiki Literature and Reviewing the Evidence Base}

This chapter presents a mapping of the Reiki literature and a review of the empirical research that has explored the effects of Reiki. The purpose of this chapter is to provide an overview of the breadth of material on the subject of Reiki and to provide an account of the reported experiences of receiving Reiki and the reported benefits of Reiki treatment. The first part of the chapter comprises the mapping of the Reiki literature. Firstly, the questions that guided the mapping exercise are introduced. The results of the mapping are then presented, that is, the number of documents identified, excluded and included. Finally, this part of the chapter presents the documents included in the mapping in relation to the following themes; people and settings where Reiki is used; the study designs used to research Reiki; how Reiki is used on self and others (that is, hands on or distance); and the illnesses and conditions that Reiki is used to treat.

The second part of this chapter reviews the empirical research that has explored the effects of Reiki. Specifically it considers the reported experiences of receiving Reiki and the reported benefits of Reiki treatment. It begins with an account of the methods used when undertaking the review including the questions used to guide the review and the process of searching, retrieval and appraisal. An overview of the results of the critical appraisal of the literature is then provided and the results are discussed under headings that reflect the review questions: the use of Reiki for pain management; anxiety depression and stress; recovery after illness and the benefits of Reiki for 'other' conditions. In all except one of these studies the research focussed exclusively on Reiki practitioners providing Reiki to others. In contrast, the final section of this chapter critically reviews those studies that have explored the benefits of learning and practising self-use of Reiki.

\section{Mapping the Reiki Literature}

'Mapping' is defined by Hart as 'setting out, on paper, the geography of research and thinking that has been done on a topic' (Hart 1998:144). The purpose of mapping the 
literature for this thesis was to construct an overview of the literature on Reiki by addressing the following questions:

1. Who uses Reiki (or who it has been used with) and in what settings?

2. Which conditions / illnesses has Reiki been used to treat?

3. What study designs have been used to research Reiki?

4. How is Reiki used on self and others?

Eight databases and four preselected websites were searched in October 2011. The databases were: ASSIA, CINAHL, Cochrane Library, AMED (1985 - September 2011), EMBASE (1996 - 2011 week 39), MEDLINE (1996 - September 2011), PsycINFO (1806 - September 2011) and Web of Science. The websites were: International Centre for Reiki Training, OpenSigle, UK Reiki Federation and the World Health Organisation. These resources were chosen as they were deemed the most appropriate for identifying research that would address the above questions. Preselecting websites as opposed to using a search engine helped to limit the search to a manageable number of websites. In each resource, the keyword 'Reiki' was entered into the search facility.

Documents in English, focussing exclusively on the use of Reiki with humans were included. Books were excluded due to the fact that the author (HG), as a Reiki practitioner, had a preexisting knowledge of relevant texts. Book reviews and interviews with Reiki practitioners were also excluded from the mapping because it was not anticipated that they would address the mapping questions. Duplicate documents were also removed after searches had been undertaken as were documents that did not have an abstract.

\section{Results of the Mapping}

Figure 3.1 shows the number of documents identified as a result of searching the databases and websites. 
Figure 3.1 Documents identified in literature search

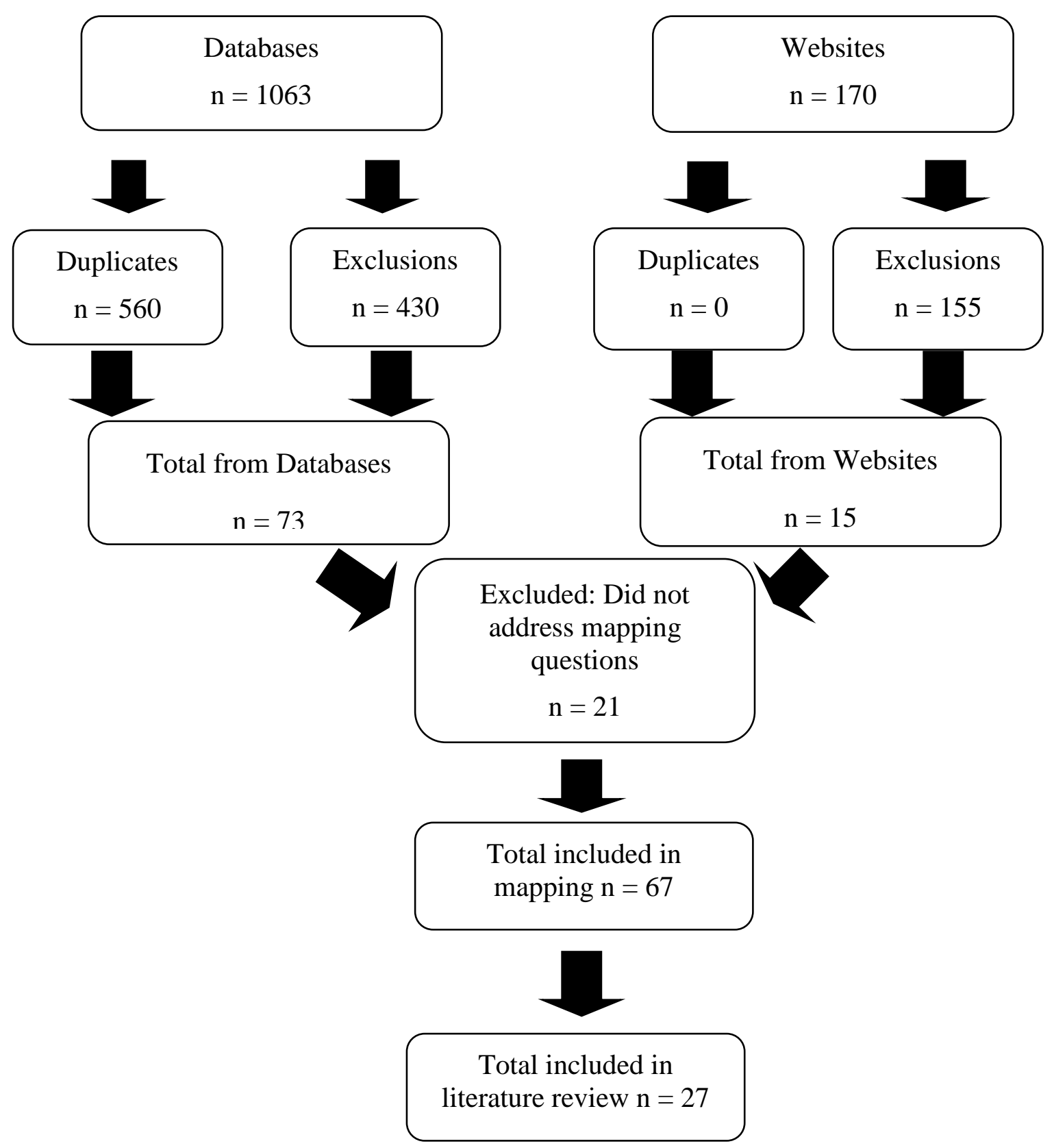

Across all resources searched, a total of 1233 documents were identified. A total of 560 documents were removed as they were duplicates and 585 were excluded as they were either in a language other than English, did not focus exclusively on Reiki, were a book, book review or interview with a Reiki practitioner, did not have an abstract, or they focussed on non-human subjects. A further 21 documents were removed as upon closer inspection of the 
abstract they did not address the mapping questions. The remaining 67 documents were included in the mapping. Table 3.1 summarises the types of document included.

Table 3.1: Types of Document Included in Mapping

\begin{tabular}{|l|c|}
\hline Document Type & N \\
\hline Report on Empirical Research & 27 \\
\hline Literature Review & 7 \\
\hline Other & 33 \\
\hline Total & $\mathbf{6 7}$ \\
\hline
\end{tabular}

Of the 67 documents included in the mapping, just under half were reports of empirical research with the remainder being 'other' types of document. These 33 'other' documents included descriptive accounts of the use of Reiki in specific settings, or with specific groups of people, case study reports, and commentaries on empirical research. The 27 empirical research studies and the seven literature reviews are fully described and appraised in the second part of the chapter.

\section{Question 1: Who uses Reiki (or who it has been used with) and in what settings?}

All 67 documents included in the mapping addressed this question. As explained in Chapter Two, there are no prerequisites for learning or receiving Reiki. It can be learned and selfused by anyone and likewise anyone can receive a Reiki treatment from a practitioner. The 67 documents appeared to reflect this and described the use of Reiki with a variety of people and in a variety of settings. Some documents included in the mapping discussed the use of Reiki with specific groups of people, for example, cancer patients or nurses; others discussed the use of Reiki in specific settings, for example, within hospices or general practice. Table 3.2 below summarises the groups of people with which Reiki has been used and the settings. Only those groups of people or settings that were described in more than one document are included in the table below $(n=41)$. The remainder are described following the table. 
Table 3.2: People and Settings where Reiki has been used

\begin{tabular}{|c|c|c|}
\hline & & Documents (N) \\
\hline \multirow[t]{9}{*}{ People } & Surgical Patients & 8 \\
\hline & Cancer Patients & 7 \\
\hline & Nurses (Healthy) & 5 \\
\hline & Healthy Volunteers & 4 \\
\hline & During Birth & 3 \\
\hline & Elderly People & 2 \\
\hline & HIV Patients & 2 \\
\hline & Mixture of people with ill health and good health & 2 \\
\hline & People with chronic illness (varied illnesses) & 2 \\
\hline \multirow[t]{2}{*}{ Settings } & Hospice Setting / Palliative Care & 4 \\
\hline & In hospitals (general - no specific groups of people) & 2 \\
\hline Total & & 41 \\
\hline
\end{tabular}

**** The terms used in this table reflect the author's descriptions of the research participants

Most frequently $(n=8)$, documents described the use of Reiki with people undergoing a variety of surgical procedures including: coronary, laparoscopic procedure, women undergoing breast biopsy, colonoscopy, hysterectomy and cancer surgery. One document did not specify the type of surgery or surgical patient and another document described the use of Reiki generically pre- and post-operatively. Seven documents described the use of Reiki with cancer patients and a further four documents described the use of Reiki in hospice / palliative care settings. This is perhaps unsurprising given that the use of complementary therapies is common amongst cancer patients (Corner et al. 2009). A number of documents were also identified $(n=9)$ that discussed the use of Reiki with 'healthy' people. Nurses were the participants in five of the nine documents and 'healthy volunteers' were described by the authors as the participants in a further four documents. 
In addition to the people and settings tabulated above, one document each was identified that described the use of Reiki with patients diagnosed with: Fibromyalgia; Alzheimer's disease; stroke; psychological depression and stress; acute coronary syndrome; cervical dysplasia; or Guillian Barre syndrome. People experiencing pain (for varied reasons) was also described in one document and the use of Reiki within the family in another. Amongst the other settings described in the documents, one each described the use of Reiki in: a prison; a centre for torture survivors; general practice; psychotherapy and counselling; and both general and oncology nursing practice.

In terms of setting, one document from the UK Reiki Federation listed examples of Reiki practice in what was referred to as 'innovative settings'. Of those settings listed within this document, eight were referred to in other documents, and are included in table 3.2 (above) or described in the above paragraph. However, this document listed some additional examples of settings where Reiki has been used including: brain injury rehabilitation centres; carers' associations; physiotherapy units; special needs - learning and behavioural difficulties; social services day care centres; drug and alcohol abuse / addiction programmes; rough sleepers projects; health, leisure and fitness centre; health and beauty spas; workplace occupational health units and air crew and passengers.

\section{Question 2: Which conditions / illnesses has Reiki been used to treat?}

Just under half $(\mathrm{n}=30)$ of the documents included in the mapping addressed this question by describing the use of Reiki with a specific condition or illness. This reflects the previous assertion that Reiki can theoretically be used to treat any condition or illness. The other 37 documents that did not describe the use of Reiki with specific illnesses or conditions were literature reviews or documents that described the use of Reiki in a particular setting (for example, hospitals) or with particular groups (for example, nurses). Table 3.3 lists the most frequently cited illnesses or conditions described in the documents and the number of documents that describes treating that condition with Reiki. 
Table 3.3 Illnesses and Conditions for which Reiki used to Treat

\begin{tabular}{|l|c|}
\hline \multicolumn{1}{|c|}{ Condition / Illness } & Documents (N) \\
\hline Cancer & 7 \\
\hline Anxiety & 6 \\
\hline Pain & 2 \\
\hline HIV/AIDS & 9 \\
\hline Other ( $=$ one) & $\mathbf{3 0}$ \\
\hline Total & \\
\hline
\end{tabular}

The illnesses or conditions most frequently in the documents were, cancer $(n=7)$, anxiety ( $n$ =6), pain ( $(n=6)$ and HIV / AIDS ( $n=2)$. One document each also discussed the use of Reiki for: cancer related fatigue; work related stress; stroke rehabilitation; depression; psychological depression and stress; chronic illness; acute coronary syndrome; decreasing memory and behaviour problems; and fibromyalgia.

\section{Question 3: What study designs have been used to research Reiki?}

Twenty-seven published empirical studies of Reiki were identified in the mapping and addressed this question. These 27 studies were included in the literature review presented in the final part of this chapter. Table 3.4 presents an overview of the types of study design researchers have employed when conducting empirical research into Reiki. 
Table 3.4: Study Designs used to Research Reiki

\begin{tabular}{|l|c|}
\hline Design* & N \\
\hline Randomised controlled trial & 13 \\
\hline Pre- / Post-test design & 4 \\
\hline Descriptive & 2 \\
\hline Phenomenological & 1 \\
\hline Other type of clinical trial (partially randomised) & 1 \\
\hline Case report series & 1 \\
\hline Single group repeated measure & 1 \\
\hline Counterbalanced crossover trial & 1 \\
\hline Unitary field pattern portrait study & 1 \\
\hline Unclear & $\mathbf{2 7}$ \\
\hline Total & \\
\hline
\end{tabular}

* Authors description of the study design

The majority of studies employed a trial design $(n=15)$ of which 13 were randomised controlled trials, one was a partially randomised trial and one was a counterbalanced crossover trial. Four studies employed a pre-test / post-test design. Descriptive study designs $(n=2)$ and phenomenological study designs $(n=2)$ were also apparent.

\section{Question 4: How is Reiki used on self and others?}

All the 27 empirical research studies addressed this question. As previously noted Reiki can be used on self and others primarily in two ways. It can be administered hands on (in person) or from a distance (practitioner absent) (see section on The Reiki Symbols, for details). Table 3.5 outlines the modes of use of Reiki discussed in the empirical studies. 
Table 3.5: Mode of use

\begin{tabular}{|l|l|c|}
\hline Recipient & Mode of Use & Documents (n) \\
\hline Others & $\begin{array}{l}\text { Hands on, administered by } \\
\text { Reiki Practitioner }\end{array}$ & 18 \\
\hline & $\begin{array}{l}\text { Distance Reiki administered } \\
\text { by Reiki Practitioner }\end{array}$ & 2 \\
\hline & $\begin{array}{l}\text { Combination Hands on and } \\
\text { Distance administered by } \\
\text { Reiki Practitioner }\end{array}$ & 3 \\
\hline Self & Unclear & 4 \\
\hline & Hands on & 0 \\
\hline Total & Distance & $\mathbf{2 7}$ \\
\hline
\end{tabular}

Most frequently the documents included in the mapping reported on the use of Reiki with others and administered to a recipient by a Reiki practitioner using the hand placements $(\mathrm{n}=$ 18). No documents were identified that focussed solely on the use of distance Reiki although four documents focussed on administering Reiki to another person using a combination of hands on and distance Reiki. Only four documents were identified that discussed self-use of Reiki and this was exclusively administered hands on as opposed to Reiki sent to the self from a distance.

\section{Summary of the Mapping}

In summary, 67 documents were identified for the mapping of the Reiki literature. These documents described the use of Reiki with a variety of people including surgical patients, cancer patients and nurses and in a variety of settings for example hospices, hospitals and prisons. Reiki can be used to treat any illness or condition and the mapping of the Reiki literature supported this with documents frequently describing the use of Reiki for cancer, anxiety, pain and HIV / AIDS, amongst others. Under half of the documents included in the mapping were empirical research studies and 13 of the 27 studies employed a randomised controlled trial design. Predominantly, the empirical research studies involved Reiki being 
administered to a recipient by a Reiki practitioner. There was a distinct lack of studies that included the use of distance Reiki and studies that explored self-use of Reiki were in the minority, with only four identified. The second part of this chapter comprises a literature review of the 27 empirical research studies on Reiki.

\section{Review of the Reiki Research Literature}

Two approaches to conducting literature reviews are prominent within the methodological literature on reviewing research evidence: the narrative review and the systematic review. Popay et al. (2006) note that the term 'narrative review' is often 'used to describe more traditional literature reviews' (2006:5) and Pope, Mays and Popay (2007) refer to narrative reviews as 'first generation literature reviews' (2007:4). Narrative reviews of research literature have historically been carried out by 'experts' in the field (Pope, Mays and Popay 2007). Characteristically they do not include a clearly defined or systematic search strategy or any inclusion and exclusion criteria. This type of literature review is not considered to produce reliable evidence for a number of reasons. Firstly, the lack of detail and transparency with regards to why material was selected for inclusion in the review and the search methods for identifying the material has led to criticisms that the authors of such reviews have been 'selective' in their choice of included material. Secondly, narrative reviews seldom appraise the quality of the included studies; as noted by Pope, Mays and Popay (2007) 'little consideration given to how study quality might affect the results'.

In contrast to narrative reviews, systematic reviews aim to address a predetermined research question by taking a 'systematic' approach to each of the main stages of the review process (identifying, appraising and synthesising the included studies). Procedures for each of the main stages are predetermined by a review protocol which is strictly adhered to throughout. Systematic reviews also include an appraisal of the quality of the included studies (Khan 2003; Aveyard 2007; Pope, Mays and Popay 2007). The systematic and transparent nature of this type of review has led to it being considered the most robust and least biased type of review (Petticrew and Roberts 2005) and, in the field of UK healthcare, has become synonymous with the 'Cochrane collaboration method of reviewing' (Aveyard 2007:13). 
The review of the literature that follows may be described as a literature review that was undertaken systematically due to the fact that it has some elements in common with a systematic review although not all. Unlike a systematic review, this literature review did not have a formal predetermined review protocol. However, this is not to suggest that the review was not conducted in a systematic manner. In common with a systematic review the decision was taken in advance that the review would address two predetermined research questions; the review had a clearly defined search strategy; an inclusion and exclusion criteria; and a strategy for appraising the studies using an evaluation tool.

\section{Methods}

The methods used to undertake the literature review are now described. Firstly, the review questions are specified; secondly, the search strategy is presented; thirdly, an account is provided on how the included studies were appraised; and, finally, the method of synthesising the studies is presented.

\section{Review Questions}

The literature review aimed to address the following two questions:

1. What are people's experiences of Reiki (during or after a treatment)?

2. What are the benefits of using Reiki?

\section{Search Strategy}

The review of the empirical literature on Reiki was undertaken simultaneously to the mapping of the literature; thus, the search strategy for the literature review involved the systematic search of the eight databases and four websites listed previously. The inclusion and exclusion criteria were also the same as that for the mapping of the Reiki literature and included documents in English, focussing exclusively on the use of Reiki with humans. Books, book reviews and interviews with Reiki practitioners were excluded. 


\section{Study Appraisal}

Following the identification and retrieval of the 27 empirical research studies and seven literature review documents, each document was appraised using an evaluation tool developed by the Health Care Practice Research and Development Unit (HCPRDU) at the University of Salford. This evaluation tool comprises a series of headings that prompt the reviewer to both describe and evaluate salient features of the study and has been 'tried, tested and modified within teaching and research' (Long 2002:62). The tool was modified to include prompts relevant to different study designs (qualitative, quantitative or literature/systematic review). A summary of the evaluation tool is presented below in figure 3.2. For the purpose of this literature review, the tool was tailored to include some prompts specific to Reiki, for example, the appropriateness of the practitioner giving Reiki. Example appraisals of a qualitative, a quantitative and a literature review using this evaluation tool can be viewed in appendix 1 . 
Figure 3.2: Summary of Evaluation Tool

\begin{tabular}{|c|c|}
\hline Descriptive prompts & Evaluative prompts \\
\hline $\begin{array}{l}\text { Aims of study } \\
\text { Aims of paper } \\
\text { Key findings }\end{array}$ & Summary evaluative comments \\
\hline $\begin{array}{l}\text { Study type } \\
\text { Intervention } \\
\text { Comparison intervention } \\
\text { Outcome criteria } \\
\text { Perspective of measures }\end{array}$ & $\begin{array}{l}\text { Sufficient detail } \\
\text { Sufficient breadth }\end{array}$ \\
\hline $\begin{array}{l}\text { Geographical and care setting } \\
\text { Setting rationale } \\
\text { Beginning and duration of study }\end{array}$ & Sufficient detail \\
\hline $\begin{array}{l}\text { Source population } \\
\text { Inclusion criteria } \\
\text { Exclusion criteria } \\
\text { Sample selection } \\
\text { Study size } \\
\text { Sample characteristics (age, gender, } \\
\text { ethnicity) }\end{array}$ & $\begin{array}{l}\text { Appropriate sampling frame } \\
\text { Appropriate sample (informants, setting, } \\
\text { events) }\end{array}$ \\
\hline $\begin{array}{l}\text { Practitioners giving Reiki } \\
\text { Treatment environment }\end{array}$ & $\begin{array}{l}\text { Appropriateness of practitioners giving Reiki } \\
\text { Conduciveness to treatment }\end{array}$ \\
\hline $\begin{array}{l}\text { Data collection methods } \\
\text { Researcher's role } \\
\text { Process of analysis }\end{array}$ & $\begin{array}{l}\text { Adequate description of fieldwork } \\
\text { Adequate description of analysis process } \\
\text { Adequate evidence to support analysis } \\
\text { Study findings set in broader context } \\
\text { Researcher's potential bias/position }\end{array}$ \\
\hline & $\begin{array}{l}\text { To what setting to generalise } \\
\text { To what population to generalise } \\
\text { Justified conclusions }\end{array}$ \\
\hline $\begin{array}{l}\text { Ethical committee approval } \\
\text { Informed consent } \\
\text { Other ethical issues }\end{array}$ & \\
\hline
\end{tabular}




\section{Study Synthesis}

The results of the literature review are presented in the form of narrative synthesis. A narrative synthesis is not the same as a narrative review. Rather, the term narrative synthesis indicates the approach to synthesising the studies included in the literature review, not the type of review itself. In contrast to a meta-analysis, 'the defining characteristic of lof a narrative synthesis] is that it adopts a textual approach to the process of synthesis to 'tell the story' of the findings from the included studies' (Popay et al. 2006:5). A narrative synthesis of the findings was appropriate given that there was no uniformity amongst the results of the systematic review, heterogeneity inter alia in the conditions addressed, or outcomes measures used to assess effects. The literature search identified both qualitative and quantitative research designs and studies with different focuses thus reducing the appropriateness of other forms of synthesis such as meta-analysis or meta-ethnography.

\section{Results}

The results of the literature review are based on 34 documents: 27 empirical research studies, three systematic reviews and four other types of literature review. Of the 34 documents, only four focussed on self-use of Reiki. The literature reviews of Reiki are outlined and discussed prior to the main body of this section. Two reasons lie behind the decision to separate the existing literature reviews from the results of this literature review. Firstly, as noted by Khan (2003), review articles usefully provide 'a quick overview of a wide range of evidence on a particular topic' (Khan et al 2003:1). In this respect, discussing the existing literature reviews foremost serves as an introduction to the empirical research that has been conducted on Reiki. Secondly, none of the previous literature reviews in their entirety addressed either of the questions set for this literature review. At the same time, due to the way that some of them had been synthesised, parts of individual reviews did address one or both of the questions. Given that one of the purposes of a review is to bring together all the evidence on one subject, it was considered preferable to report on the review articles together and as whole pieces as opposed to dividing them up.

The results of this literature review that is, the results from the critical appraisal of the empirical studies are presented thematically according to the review questions. Each 
document is described and appraised with the key strengths and key weaknesses noted for each study. For each theme a table summarising the evidence is also provided. The subsequent text begins by reviewing the 'reviews' of Reiki and is then followed by a review of the evidence of the individual empirical studies, separately for each of the four review questions.

\section{Review Articles on Reiki}

The search identified three systematic reviews and four 'other' types of literature review of Reiki. Of the four 'other' types of literature review, one was described as an 'integrative review' (Vitale 2007); one was described as a 'review of the literature' (Gallob 2003); another paper stated in the introduction that 'the research literature to date on Reiki will be reviewed and evaluated' (Miles and True 2003:62); and the fourth paper was described as 'an ongoing critical evaluation of Reiki in the scientific literature' (Baldwin et al. 2010:260).

The reviews differed in their focus and just over half $(n=4)$ focussed on the subject of Reiki broadly as opposed to specifying any one condition, population or setting. As Table 3.6 (below) shows, the four 'broad' reviews aimed to review and/or analyse or evaluate the Reiki literature (Baldwin et al. 2010; Gallob 2003; Miles and True 2003; Vitale 2007). One review specified the setting (healthcare) but not the population or condition (Herron-Marx et al. 2008a). The remaining two review articles were the most specific in their focus. One systematic review focussed specifically on the clinical effectiveness of Reiki for any medical condition as explored using randomised clinical trials (Lee, Pittler and Ernst 2008) and the other systematic review aimed to evaluate the quality of reporting of Reiki clinical trials in addition to the quality of evidence on the efficacy of Reiki in humans (Vandervaart et al. 2009).

The reviews ranged in scope with the smallest review including only four studies (Gallob 2003) and the largest including 26 studies (Baldwin et al. 2010). Common to all of the reviews was that each included some evaluation or commentary on the effectiveness of Reiki; this was regardless of whether or not the review specified this as one of its aims. Furthermore, the specificity as to what condition or population Reiki was effective for or with 
varied greatly. Some reviews cited evidence to suggest the effectiveness of Reiki. Baldwin et al. (2010) identified five studies that demonstrated the efficacy of Reiki as a 'healing modality'. Similarly, Herron-Marx et al. (2008b) identified six studies that demonstrated a significant effect of Reiki. Based on four studies, Gallob (2003) concluded that 'Reiki can assist with pain relief, enhance healing, foster relaxation, alleviate emotional distress and promote wellness in a holistic way' (Gallob 2003: 12) and Miles and True (2003) reported that there was 'evidence of the beneficial effects of Reiki' (Miles and True 2003: 69). Other reviews reported little or no evidence for the efficacy of Reiki, for example, the systematic review by Lee, Pittler and Ernst (2008) concluded that 'The evidence is insufficient to suggest that Reiki is an effective treatment for any condition' (Lee, Pittler and Ernst 2008:947). Baldwin et al. (2010) also cited two studies that did not provide evidence as to the efficacy of Reiki.

It is common practice for systematic reviews to evaluate the rigour of the studies included in the review due to the fact that the rigour with which a study has been conducted and reported can have an effect on the reliability and trustworthiness of the results. For example, in their systematic review of the therapeutic effects of Reiki, Vandervaart et al. (2009) found that the majority of studies $(n=9)$ included in their review reported a significant effect of Reiki. However, having evaluated the quality of the included studies, the authors claim that 11 of the 12 included studies were of poor quality. Similarly, the integrative review by Vitale (2007) identified studies demonstrating one significant and three non-significant findings in relation to the use of Reiki for stress / relaxation and depression. However, the author notes that 'these investigations reflect a wide range of internal and external validity research issues that affect the quality of the investigations (Vitale 2007: 170-171).

The quality of the literature reviews identified for this study was varied. Some reviews were of poor quality, for example the review of the literature by Gallob (2003) simply described the four studies that were included in the review without any reference to the search strategy, the inclusion and exclusion criteria, or how the studies were appraised. Similarly, the review by Miles and True (2003) summarised 13 studies. No account of the search strategy, the inclusion and exclusion criteria, or how the studies were appraised was presented and the review described studies that combined Reiki with other therapies. This presents challenges 
in using this review as support for the efficacy of Reiki given that it was not solely about Reiki. Other reviews such as those by Baldwin et al. (2010), Lee, Pittler and Ernst(2008) and Vandervaart et al. (2009) were of a high quality, characterised by their transparency in terms of their methods of undertaking the review. In between the poor quality reviews and the high quality reviews were reviews by Herron-Marx et al. (2008) and Vitale (2007). The systematic review by Herron-Marx et al. (2008) had in common with the high quality reviews the fact that it provided transparency regarding all the main elements of the review (search strategy, inclusion and exclusion criteria). However, one area of weakness is apparent in that appraisal of the studies only occurred at the selection phase of the study as a basis for determining inclusion rather as a means of evaluating each included study. Thus, the criteria used to determine the results of the study are unclear. Similarly, the integrative review by Vitale (2007) was also transparent in its account of the majority of the main elements of the review. In relation to the inclusion and exclusion criteria, this review was particularly clear on the definition of Reiki that the included studies had to be consistent with. However, the study was lacking an account of the criteria used to appraise the studies.

\section{Summary of Review Articles on Reiki}

The review of the literature identified three systematic reviews and four 'other' types of literature review of Reiki. The reviews were diverse in both their focus and their scope and there appeared to be a tendency to review the literature on Reiki broadly, as opposed to focussing on any one condition, population or setting. The purpose of review articles is to provide an overview of evidence on a topic and the review articles included in this review provided a mixture of evidence on the use of Reiki. Reviews by Baldwin (2010), HerronMarx (2008b), Gallob (2003) and Miles and True (2003) described significant effects of Reiki or made statements regarding the beneficial nature of Reiki. However, only one of these studies was evaluated as being of high quality. Conversely, the two reviews that reported little or no evidence for the efficacy of Reiki were both evaluated as being of high quality.

The review articles do not contribute to addressing the first question that my review aimed to address: What are people's experiences of Reiki (during or after a treatment)? They go some way to elucidating the benefits of Reiki, with one high quality review identifying five studies 
that demonstrated some efficacy of Reiki as a 'healing modality' (Baldwin et al. 2010) and one concluding that Reiki is not effective in the treatment of any condition (Lee, Pittler and Ernst: 2008). However taken as an entire body of work, the literature reviews on Reiki are clearly in their infancy and largely present conflicting conclusions. None of the review articles paid any significant attention to self-use of Reiki. 
Table 3.6: Summary of Reiki Review Articles

\begin{tabular}{|c|c|c|c|c|}
\hline Author & Aim or purpose of the review & Number of included studies & Main findings & $\begin{array}{l}\text { Summary Evaluative } \\
\text { Comments }\end{array}$ \\
\hline Baldwin et al. (2010) & $\begin{array}{l}\text { To systematically analyse } \\
\text { published peer reviewed studies of } \\
\text { Reiki }\end{array}$ & 26 & $\begin{array}{l}\text { Only } 12 \text { / } 26 \text { studies based on a } \\
\text { robust design and rated 'very } \\
\text { good' or 'excellent' by at least } \\
\text { one reviewer. Two provided no } \\
\text { support of the effectiveness of } \\
\text { Reiki, five provided some } \\
\text { support, and five demonstrated } \\
\text { strong evidence for use of Reiki } \\
\text { as a healing modality. }\end{array}$ & $\begin{array}{l}\text { Paper gives a full and } \\
\text { transparent account of the } \\
\text { 'touchstone process' - the } \\
\text { process used to evaluate } \\
\text { Reiki research. Review } \\
\text { undertaken by a small team } \\
\text { thus reducing the chance of } \\
\text { biased evaluations. Use of } \\
\text { own (piloted) evaluation } \\
\text { tool. Good use of tables to } \\
\text { illustrate results. }\end{array}$ \\
\hline Gallob (2003) & To review the Reiki literature & 4 & $\begin{array}{l}\text { No findings as such rather } \\
\text { descriptions provided of each of } \\
\text { the four included studies. } \\
\text { Author concludes } \\
\text { 'Published anecdotes and } \\
\text { preliminary studies suggest that } \\
\text { Reiki can assist with pain relief, } \\
\text { enhance healing, foster } \\
\text { relaxation, alleviate emotional } \\
\text { distress and promote wellness in } \\
\text { a holistic way. Reiki also offers } \\
\text { benefits to the practitioner in } \\
\text { the form of a powerful method } \\
\text { for self-care that can be } \\
\text { integrated into daily } \\
\text { routines'(12). }\end{array}$ & $\begin{array}{l}\text { This review of the literature } \\
\text { cites only four pieces of } \\
\text { research. It is little more } \\
\text { than a summary of the } \\
\text { literature. There is no } \\
\text { transparency regarding } \\
\text { inclusion/exclusion criteria, } \\
\text { search strategy, or } \\
\text { appraisal. However, it does } \\
\text { acknowledge the fact that } \\
\text { Reiki can be used as a self- } \\
\text { care practice, something } \\
\text { that is often overlooked in } \\
\text { favour of discussion } \\
\text { regarding it being used on } \\
\text { clients / patients. }\end{array}$ \\
\hline
\end{tabular}




\begin{tabular}{|c|c|c|c|c|}
\hline Herron-Marx et al. (2008) & $\begin{array}{l}\text { To determine what the national } \\
\text { and international evidence reveals } \\
\text { about the use of Reiki in health } \\
\text { care }\end{array}$ & 10 & $\begin{array}{l}\text { Research on Reiki has been } \\
\text { undertaken in the areas of; } \\
\text { surgery, chronic illness, } \\
\text { neurology, stroke rehabilitation, } \\
\text { cancer care, cancer pain and } \\
\text { mental health. Professional } \\
\text { groups conducting research } \\
\text { included organisations for } \\
\text { nurses; psychologists; mental } \\
\text { health professionals; medics; } \\
\text { rehabilitation professionals; and } \\
\text { cancer care professionals. } \\
\text { Study designs included: } \\
\text { experimental, quasi } \\
\text { experimental quasi } \\
\text { experimental, cohort-study and } \\
\text { case series. Data gathering } \\
\text { methods included } \\
\text { questionnaires or visual or } \\
\text { analogue scales. Three studies } \\
\text { used placebo Reiki. Six studies } \\
\text { showed significant effects of } \\
\text { Reiki, one study showed no } \\
\text { effect. }\end{array}$ & $\begin{array}{l}\text { This systematic review } \\
\text { provides excellent detail of } \\
\text { the search strategy, the } \\
\text { inclusion and exclusion } \\
\text { criteria. However, quality } \\
\text { assessment only occurred at } \\
\text { the selection phase of the } \\
\text { study as basis for } \\
\text { determining inclusion } \\
\text { rather than as a means of } \\
\text { evaluating each included } \\
\text { study. Thus when the } \\
\text { author concludes that 'the } \\
\text { review revealed a corpus of } \\
\text { methodologically sound } \\
\text { research into Reiki' (40) it } \\
\text { is unclear as to the criteria } \\
\text { used to determine this. }\end{array}$ \\
\hline
\end{tabular}




\begin{tabular}{|c|c|c|c|c|}
\hline Lee et al. (2008) & $\begin{array}{l}\text { To summarise and critically } \\
\text { evaluate the data from randomised } \\
\text { clinical trials of the clinical } \\
\text { effectiveness of Reiki in the } \\
\text { treatment of any medical } \\
\text { condition. }\end{array}$ & 9 & $\begin{array}{l}\text { In total, the trial data for any } \\
\text { one condition are scarce and } \\
\text { independent replications are not } \\
\text { available for each condition. } \\
\text { Most trials suffered from } \\
\text { methodological flaws such as } \\
\text { small sample size, inadequate } \\
\text { study design and poor reporting. } \\
\text { The evidence is insufficient to } \\
\text { suggest that Reiki is an effective } \\
\text { treatment for any condition. }\end{array}$ & $\begin{array}{l}\text { This is a rigorous } \\
\text { systematic review. There is } \\
\text { good level of detail } \\
\text { regarding the search } \\
\text { strategy, study inclusion } \\
\text { and exclusion criteria and } \\
\text { quality assessment. Quality } \\
\text { was assessed using a } \\
\text { modified version of the } \\
\text { Jadad scoring system. } \\
\text { However, this is a narrow } \\
\text { review of nine RCTs with } \\
\text { copious exclusion criteria. } \\
\text { The authors provide a } \\
\text { rationale for this. } \\
\text { However, given the } \\
\text { apparent small number of } \\
\text { RCTs in the area it would } \\
\text { arguably be worth taking } \\
\text { into consideration other } \\
\text { types of study as } \\
\text { exploratory studies are } \\
\text { often a precursor to larger } \\
\text { scale RCTs. }\end{array}$ \\
\hline
\end{tabular}




\begin{tabular}{|c|c|c|c|c|}
\hline Miles and True (2003) & $\begin{array}{l}\text { To review and evaluate the } \\
\text { research literature to date on } \\
\text { Reiki. }\end{array}$ & 13 & $\begin{array}{l}\text { No findings as such. Rather, } \\
\text { summarises the } 13 \text { studies and } \\
\text { concludes that although there } \\
\text { are design limitations evidence } \\
\text { of the beneficial effects of Reiki } \\
\text { make a compelling case for the } \\
\text { need for further research. }\end{array}$ & $\begin{array}{l}\text { This review of the literature } \\
\text { does not include } \\
\text { information of how studies } \\
\text { were identified, the criteria } \\
\text { by which they were } \\
\text { included or how they were } \\
\text { evaluated. A useful } \\
\text { summary table is provided } \\
\text { but only includes } \\
\text { summaries of the RCTs. A } \\
\text { table summarising the other } \\
\text { studies would also have } \\
\text { been useful. This review } \\
\text { also includes studies that } \\
\text { combined Reiki with other } \\
\text { therapies. Thus any } \\
\text { findings may not solely be } \\
\text { a result of Reiki. }\end{array}$ \\
\hline Vandervaart et al.(2009) & $\begin{array}{l}\text { To evaluate the quality of } \\
\text { reporting of clinical trials using } \\
\text { Reiki as the treatment modality } \\
\text { and to evaluate the quality of } \\
\text { existing evidence on the efficacy } \\
\text { of Reiki in humans. }\end{array}$ & 12 & $\begin{array}{l}\text { All } 12 \text { trials were lacking in } \\
\text { either one of three key areas } \\
\text { (randomisation, blinding and } \\
\text { accountability of all patients). } \\
\text { Nine of } 12 \text { trials detected a } \\
\text { significant therapeutic effect; } \\
\text { however } 11 \text { of the } 12 \text { studies } \\
\text { were ranked as 'poor'. }\end{array}$ & $\begin{array}{l}\text { This systematic review } \\
\text { includes a thorough } \\
\text { description of the databases } \\
\text { searched, the inclusion and } \\
\text { exclusion criteria and the } \\
\text { process of quality } \\
\text { assessment. However this } \\
\text { review only included } \\
\text { clinical trials. }\end{array}$ \\
\hline
\end{tabular}




\begin{tabular}{|c|c|c|c|c|}
\hline Vitale (2007) & $\begin{array}{l}\text { To begin the systematic process of } \\
\text { evaluating the findings of } \\
\text { published Reiki research. }\end{array}$ & 16 & $\begin{array}{l}\text { In relation to stress/relaxation- } \\
\text { depression one study showed } \\
\text { significant findings and three } \\
\text { showed non-significant } \\
\text { findings. However due to } \\
\text { methodological flaws the author } \\
\text { concludes that there is a weak } \\
\text { state of knowledge about the } \\
\text { use of Reiki for stress/relaxation } \\
\text { management or depression. } \\
\text { In studies investigating the } \\
\text { effect of Reiki on pain the } \\
\text { author concludes that } \\
\text { methodological flaws 'limit the } \\
\text { generalisability of the findings } \\
\text { for Reiki as an adjunctive pain } \\
\text { strategy' (172). } \\
\text { Three studies were included that } \\
\text { investigated biological } \\
\text { correlates and the use of Reiki. } \\
\text { One study showed that Reiki } \\
\text { had an effect on haematological } \\
\text { indicators and one study showed } \\
\text { Reiki to have an effect on two } \\
\text { indicators of autonomic nervous } \\
\text { system function. } \\
\text { One study investigated the } \\
\text { effect of Reiki on wound } \\
\text { healing reporting non- } \\
\text { significant findings. } \\
\text { One study on chronic illness } \\
\text { and Reiki use demonstrated a } \\
\text { difference after Reiki treatment. }\end{array}$ & $\begin{array}{l}\text { This integrative review } \\
\text { provides a clear account of } \\
\text { the search strategy and the } \\
\text { inclusion and exclusion } \\
\text { criteria. It provides a } \\
\text { particularly useful } \\
\text { definition of Reiki that the } \\
\text { included studies had to be } \\
\text { consistent with. However, } \\
\text { the study does not provide } \\
\text { an account of the criteria } \\
\text { used to appraise the studies } \\
\text { and one study included in } \\
\text { the review studied Reiki in } \\
\text { combination with other } \\
\text { complementary modalities. }\end{array}$ \\
\hline
\end{tabular}




\section{Review of Individual Empirical Studies on Reiki}

The empirical studies included in the review are now presented. They are divided so as to reflect the review questions that they address. The review questions are used as headings and, where appropriate, the studies are further divided thematically reflecting the complexity of addressing the questions. Each document is described and appraised with the key strengths and key weaknesses noted for each study. For each question a table summarising the evidence is also provided. In the case of the second question, multiple tables of evidence are provided to account for the different benefits of using Reiki.

\section{Question 1: What are People's Experiences of Reiki (During or After a Treatment)?}

Research exploring people's subjective experiences either during a Reiki treatment or immediately after receiving Reiki was found to be extremely limited with only two qualitative studies identified that address this issue. These studies are summarised in table 3.7 (overleaf).

Engebretson and Wardell (2002) used observation and interviews to explore the experiences of 23 healthy volunteers during and after a Reiki treatment. The researchers observed slowed speech in participants after receiving Reiki. Participants stated that it was difficult to describe their experience of Reiki or to 'put it into words'; some of the experiences reported included changed orientation to time, place and environment, perceptions of floating or sinking, general unawareness of parts of the body and a change in state of awareness. Physical sensations reported included numbness, involuntary muscle twitching, feelings of heat and heightened sensations of sound. The authors use the term 'paradox' (experience that is inexplicable, contradictory or not common sense) to describe what participants experienced. This research provides valuable insight into the subjective experiences of receiving Reiki. Strengths of the study include the thorough manner in which it is reported; there is an excellent description of the process of analysis and ample quotes to support the emerging themes. There are no obvious weaknesses to the study.

Ring (2009) explored the experiences, perceptions and expressions of people who received Reiki. The study is described as a 'unitary field pattern portrait' which Ring states is 'a new 
and emerging interpretive approach to inquiry in the hermeneutic-phenomenological tradition with the purpose of creating a unitary understanding of the dynamic kaleidoscopic and symphonic pattern manifestations that emerged from the pandimensional human/environmental field mutual process of a phenomenon associated with human betterment and wellbeing' (Ring 2009:251). The study involved 11 participants, two of whom were reported to have health conditions. Each participant received one 1-hour Reiki session with the author interviewing the participants after their Reiki session. The author reported the emerging themes of experiencing Reiki as follows:

(a) Bearing the burden of hardship, distress, suffering, and sorrow;

(b) Simultaneous perceptions of Reiki as warm and cool, neutral and intense, dark ice, tingling, and warm thick liquid;

(c) Perceptions of speeding up and slowing down;

(d) Transitioning awareness;

(e) Stillness of mind;

(f) Past and future melting into the timeless now;

(g) Heightened awareness; and

(h) All embracing embodiment of integrated awareness, harmony, and health.

(Ring 2009: 256)

The above findings provide some useful insights into how Reiki might potentially be experienced and some of the author's findings are consistent with those of Engebretson and Wardell (2002), described above, for example, feeling heat / warmth and a change in state of awareness. Some elements of the research are well described and presented; and there is good description of the process of analysis and ample supporting data. However, a key weakness of the study is that the 'unitary field pattern portrait' approach is not well explained, thus making interpretation and evaluation of the results difficult for anyone unfamiliar with Rogerian theory. Table 3.7 (below) summarises the research into people's experience of receiving Reiki. 


\section{Summary of People's Experiences of Reiki}

The review of the literature on people's experiences of Reiki highlights the fact that this is an area that has not been extensively explored within empirical research. The studies that have explored this issue draw attention to cognitive experiences of receiving Reiki (for example a changed state of awareness, perceptions of floating or a stillness of mind) and also to physical experiences of receiving Reiki (for example feelings of heat or tingling sensations). 
Table 3.7: Summary of Evidence for People's Experience of Receiving Reiki

\begin{tabular}{|c|c|c|c|c|c|}
\hline $\begin{array}{l}\text { Author and } \\
\text { Country }\end{array}$ & $\begin{array}{l}\text { Aim or } \\
\text { Purpose of } \\
\text { the Research }\end{array}$ & $\begin{array}{l}\text { Study } \\
\text { Design }\end{array}$ & $\begin{array}{l}\text { Participants } \\
\text { Sample size } \\
\text { Gender } \\
\text { Composition of } \\
\text { Sample } \\
\end{array}$ & Main Findings & Summary Evaluative Comments \\
\hline $\begin{array}{l}\text { Engebretson } \\
\text { and Wardell } \\
\text { (2002) } \\
\text { USA }\end{array}$ & $\begin{array}{l}\text { To explore the } \\
\text { experience of } \\
\text { receiving } \\
\text { Reiki }\end{array}$ & $\begin{array}{l}\text { Descriptive; } \\
\text { interviews } \\
\text { and } \\
\text { observation }\end{array}$ & $\begin{array}{l}\text { Healthy volunteers } \\
\mathrm{N}=23 \\
17 \text { female, } \\
5 \text { male* }\end{array}$ & $\begin{array}{l}\text { Researchers observed slowed speech in participants after } \\
\text { receiving Reiki. Participants stated it was difficult to describe } \\
\text { their experience of Reiki or 'put it into words'. Participants } \\
\text { reported a change in state of awareness. Changed orientation } \\
\text { to time, place and environment, perceptions of floating or } \\
\text { sinking, general unawareness of parts of the body. Physical } \\
\text { sensations reported included numbness, involuntary muscle } \\
\text { twitching, feelings of heat, heightened sensations of sound. } \\
\text { Symbolic experiences included feeling relaxed, calm, peaceful, } \\
\text { detachment and clarity. }\end{array}$ & $\begin{array}{l}\text { The study is well reported and the } \\
\text { authors add strength to their claims } \\
\text { by including thorough description } \\
\text { of the process of analysis. }\end{array}$ \\
\hline $\begin{array}{l}\text { Ring (2009) } \\
\text { USA }\end{array}$ & $\begin{array}{l}\text { To describe } \\
\text { the changes in } \\
\text { pattern } \\
\text { manifestations } \\
\text { that } \\
\text { individuals } \\
\text { experienced } \\
\text { associated } \\
\text { with receiving } \\
\text { Reiki, and to } \\
\text { present the } \\
\text { theoretical } \\
\text { understanding } \\
\text { of these } \\
\text { changes. }\end{array}$ & $\begin{array}{l}\text { Unitary } \\
\text { field pattern } \\
\text { portrait }\end{array}$ & $\begin{array}{l}\text { Mixture of healthy } \\
\text { participants and } \\
\text { participants with a } \\
\text { health condition } \\
\mathrm{N}=11 \\
9 \text { female, } \\
2 \text { male }\end{array}$ & $\begin{array}{l}\text { (a) Bearing the burden of hardship, distress, suffering, and } \\
\text { sorrow; } \\
\text { (b) Simultaneous perceptions of Reiki as warm and cool, } \\
\text { neutral and intense, dark ice, tingling, and warm thick liquid; } \\
\text { (c) Perceptions of speeding up and slowing down; } \\
\text { (d) Transitioning awareness; } \\
\text { (e) Stillness of mind; } \\
\text { (f) Past and future melting into the timeless now; } \\
\text { (g) Heightened awareness; and } \\
\text { (h) All embracing embodiment of integrated awareness, } \\
\text { harmony, and health. }\end{array}$ & $\begin{array}{l}\text { Good description of the process of } \\
\text { analysis and ample supporting data. } \\
\text { However, 'unitary field pattern } \\
\text { portrait' approach is not well } \\
\text { explained thus making } \\
\text { interpretation and evaluation of the } \\
\text { results difficult. }\end{array}$ \\
\hline
\end{tabular}

*error in document - does not add up to 23

NB: Unless stated Reiki was administered hands on by a Reiki practitioner in all studies. 


\section{Question 2: What are the Benefits of Using Reiki?}

This section discusses the potential benefits that may be derived from receiving Reiki from a practitioner or from self-use of Reiki. Empirical research studies have evaluated the efficacy of using Reiki for a variety of illness and conditions including pain management, anxiety, depression, stress and recovery after illness. Other illnesses and conditions for which the efficacy of Reiki has been evaluated include Alzheimer's disease, chronic illness and with chemotherapy patients. A small number of studies also considered the benefits of learning and self-use of Reiki.

For those studies that focused on the use of Reiki to manage pain and those that focused on the use of Reiki for managing anxiety, depression and stress, the outcome measures used in the studies are described before the synthesis. The reason for this is that a study's results and conclusions hinge on the outcomes of the research activity. Thus the method used to measure an outcome must be valid and reliable for the claims of the research to be assessed. The reason for describing the outcome measures for pain management and for anxiety, depression and stress but not for recovery after illness or for the benefits associated with learning and self-use of Reiki is that across the former studies there was some consistency in the outcomes being measured and the tools used to measure the outcomes. This was not the case with those studies that evaluated the role of Reiki in recovery after illness; there was no consistency amongst the illnesses that participants were recovering from. Similarly, within the studies that focussed on the benefits of learning and self-use of Reiki, a variety of different outcomes were identified and measured. Thus in the case of these types of study no useful insights would be gained from describing individual outcomes and outcome measures.

\section{i. Pain Management}

Nine studies were identified that explored the benefits of Reiki in relation to pain management. Table 3.8 summarises the evidence in relation to the efficacy of Reiki for pain management.

\section{Measures}

In five of the nine empirical studies a Visual Analogue Scale (VAS) was used to measure pain (Assefi et al. 2008; Olson, Hanson and Michaud 2003; Olson and Hanson 1997; Vitale 
and O'Connor 2006; Miles 2003). Only Olson and Hanson (1997) and Vitale and O'Connor (2006) commented on the validity of their chosen measurement scales. Olsen and Hanson (1997) note that it is difficult to establish reliability when measuring pain using a VAS. However, the authors also state that replicating the VAS in the form of a Likert scale improved reliability. Vitale and O'Connor (2006) comment that visual analogue scales 'have had extensive evaluation for reliability and validity' (Vitale and O'Connor 2006: 268).

Dressen L. J Singg (1997) used the McGill pain questionnaire and asserted that this measure is reliable, valid and consistent. Meland (2009) used the Wong-Baker FACES pain rating scale to measure pain in the elderly. The Wong-Baker scale was originally designed for use with children and has been well validated with this group (Tomlinson et al. 2010; Garra et al. 2010). Although the authors of the rating scale note that the scale has been used successfully with adults including the elderly, there does not appear to be any literature validating its use with this group. Richeson et al. (2010) used the Faces Pain Scale to measure pain. As with the Wong-Baker FACES scale, this instrument was also originally developed for use with children. However, the authors note that it has been validated with adults and demonstrates 'construct validity and strong reproducibility over time' (Richeson et al 2010:192). Finally, Hulse, Stuart-Shor and Russo (2010) state using 'a self-report instrument developed by the nurse PI' (ibid: 22) to measure pain (and anxiety). The only other information provided about the scale is that it was a 0-10 'Likert-type' rating scale. The authors do not account for the reliability or validity of their scale.

\section{The Efficacy of Reiki for Pain Management}

The majority of studies that have considered the efficacy of Reiki for use with different types of pain suggest that Reiki has a beneficial effect ( $n=8$ of 9). Olson, Hanson and Michaud (2003) concluded that Reiki when used in conjunction with standard opioid pain management strategies relieved pain and improved quality of life in patients with advanced cancer. In this randomised controlled trial, Reiki recipients reported significant improvements in pain and experienced a drop in blood pressure and pulse when compared to those receiving opioid treatment plus rest. Participants receiving Reiki also reported a statistically significant improvement in the psychological component of quality of life. Strengths of the study 
include the use of randomisation and a control group and weaknesses include a small sample (see table 3.8 for further details).

An earlier study by the same research team investigating the effect of Reiki treatment on pain reported similar findings (Olson and Hanson 1997). After a single Reiki treatment, participants experiencing moderate pain (for a variety of reasons) reported a statistically significant reduction in pain $(p=0.001)$. One of the key strengths of this study was that the Reiki treatment was provided in a Reiki therapist's office, thus reflecting the conditions in which one would expect to receive Reiki, that is, dimmed lights, candlelight, and soft music playing in the background. However, this was a single arm trial without a control group. The authors suggest that the experience of pain is influenced by cultural and social factors and the study would have benefitted from collecting additional qualitative data to explore this.

Vitale and O'Connor (2006) found that in women undergoing abdominal hysterectomy reports of pain were significantly lower 24 hours after surgery $(p=0.04)$ in women receiving Reiki and traditional nursing care, compared to women undergoing the same procedure and receiving only traditional care. A secondary finding of the study was that the group of women receiving Reiki experienced shorter surgery time $(\mathrm{p}=0.004)$. This study indicates that Reiki may be beneficial in reducing pain in this group of patients. This conclusion is strengthened by the study's rigour. The research team demonstrated excellent control for extraneous variables using randomisation. Each patient had the same pain protocol (that is, how much pain relief they received and when), the same Reiki practitioner, the same Reiki treatment, the same anaesthesia and the same medications post-operatively. There were no apparent weaknesses in the study.

Dressen and Singg (1997) explored the effects of Reiki on pain and selected affective and personality variables of chronically ill patients. Their sample included participants who were experiencing pain from a number of sources including headache, cancer and arthritis. When compared to progressive muscle relaxation and placebo Reiki, Reiki was effective in reducing pain. This study is reported in a clear and concise manner and provides persuasive evidence to suggest that Reiki is effective in reducing pain. The trial was well designed and 
included a large sample $(\mathrm{n}=120)$, a control group and the use of randomisation. However the logic of comparing Reiki to progressive muscle relaxation is not well explained. Whilst one of the effects of Reiki may well be relaxation, Reiki and progressive muscle relaxation are different types of therapy.

Richeson et al. (2010) explored the effects of Reiki on older adults who experienced pain, depression and / or anxiety. Twenty adults aged 57 - 76 participated and were randomly assigned to receive either Reiki one day per week for eight weeks or to a waiting list control. Pain was measured using the Faces Pain Scale at baseline and again after the intervention. The results of the study show that Reiki decreased symptoms of pain, depression and anxiety $(\mathrm{p}=<0.001)$ when compared to the waiting list control group. This is a well reported study. However the authors suggest caution when interpreting the findings as the use of music during the Reiki treatment may have confounded the findings. Participants were also provided with what the authors described as individualised treatment based on the participant's needs' (Richeson et al. 2010:190). Conducting the Reiki treatments in this manner is an ethical way of undertaking research and reflects the use of Reiki in 'the real world'. However, the fact that not all participants necessarily received the same, standardised, intervention is usually considered a weakness in trials not assessing complementary modalities.

A pilot study by Hulse, Stuart-Shor and Russo (2010) examined the use of Reiki prior to colonoscopy with 21 participants. Patients were assigned to one of two groups; preprocedure Reiki or usual colonoscopy care. Pain and anxiety were measured at three points (at baseline, after the Reiki intervention, and after the colonoscopy procedure). Participants receiving Reiki prior to the colonoscopy procedure reported less pain than at baseline after the Reiki treatment; however, this was not statistically significant. After the colonoscopy procedure no differences were observed in levels of self-reported pain between the group who received Reiki and the group who received normal care. This study had a number of limitations that are acknowledged by the authors. The study was non-blinded and only partially randomised due to the fact that some patients requested to be in the group receiving Reiki. The authors also note that due to a small sample size, confounding variables could not 
be controlled. However, the study was a pilot and the authors suggest ways that these limitations could be overcome in future studies.

Miles (2003) evaluated a programme that was implemented to teach Reiki first degree to people with HIV and AIDS. Thirty participants completed a Visual Analogue Scale before and after a Reiki self-treatment or a Reiki treatment administered by another student. Participants in both groups reported an average drop in pain rating from 2.73 to 1.83 on the VAS after receiving Reiki. No statistically significant differences were observed between the self-treating group and the group that received Reiki from another student. One of the key strengths of this report is that it offers evidence in support of Reiki self-use to manage pain in this group of patients. However it is a 'preliminary report' and, as such, lacks detail on the sample composition, the use of power calculations and the use of randomisation.

Meland (2009) has also suggested that Reiki is beneficial for pain management; however there are significant weaknesses apparent in this study and ultimately it contributes little to the evidence base for the use of Reiki for pain. It describes a series of case reports on the use of Reiki with six elderly participants, three of whom were experiencing pain. Participants received a 20-minute Reiki treatment, twice a week over a 4-week period. After the eight Reiki sessions, two of the participants reported a reduction in pain. However the results of the study are based on only three participants and the study lacks commentary on whether the pain measurement scale (Wong-Baker Smiley Face Scale) is a valid measurement tool with this population. In addition, the participants in this report all had a diagnosis of dementia which potentially may confound the results.

Finally, Assefi et al. (2008) did not find any evidence that Reiki was beneficial as an adjunctive treatment for fibromyalgia; neither distance nor hands-on Reiki treatment improved the pain, fatigue, well-being or physical and mental functioning of patients with fibromyalgia. This trial was well designed and rigorously conducted using a randomised, double blind, placebo controlled design. Arguably, it presents reliable evidence for Reiki having no effect on this type of pain. However, it is notable that participants in this trial had a mean pain score of $6.4 \mathrm{~cm}$ (as measured by a 10-point VAS). This mean score represents 
'average' pain as opposed to extreme cases of people with high and minimal pain. The authors note that the study was also not powered to detect subtle changes. There is no accounting for how participants felt during or after receiving Reiki. Therefore whilst the authors conclude that Reiki did not prove beneficial for the symptoms of fibromyalgia, it is unknown if receiving Reiki was beneficial in other areas of participants' lives such as their perspective on their illness or their ability to 'cope' with their pain. 
Table 3.8: Summary of Evidence for the Efficacy of Reiki for Pain Management

\begin{tabular}{|c|c|c|c|c|c|}
\hline $\begin{array}{l}\text { Author and } \\
\text { country }\end{array}$ & $\begin{array}{l}\text { Aim / Purpose } \\
\text { of the } \\
\text { Research } \\
\end{array}$ & Study Design & $\begin{array}{l}\text { Participants, Sample } \\
\text { size, Gender of sample }\end{array}$ & Main Findings & Summary Evaluative comments \\
\hline $\begin{array}{l}\text { Olson et al (2003) } \\
\text { Canada }\end{array}$ & $\begin{array}{l}\text { To compare } \\
\text { pain, quality of } \\
\text { life and } \\
\text { analgesic use } \\
\text { in a sample of } \\
\text { patients with } \\
\text { cancer pain } \\
\text { who received } \\
\text { either standard } \\
\text { opioid } \\
\text { management } \\
\text { plus rest or } \\
\text { standard opioid } \\
\text { management } \\
\text { plus Reiki }\end{array}$ & $\begin{array}{l}\text { Randomised } \\
\text { controlled } \\
\text { trial }\end{array}$ & $\begin{array}{l}\text { Patients with cancer } \\
\text { pain } \\
\mathrm{N}=24 \\
15 \text { female } \\
9 \text { male }\end{array}$ & $\begin{array}{l}\text { Reiki when used in conjunction } \\
\text { with standard opioid pain } \\
\text { management strategies relieved } \\
\text { pain and improved quality of life }\end{array}$ & $\begin{array}{l}\text { Strengths of the study include the use of } \\
\text { randomisation and a control. } \\
\text { Study limited by a small sample size. Authors note } \\
\text { that } 100 \text { participants would be needed to detect a } \\
20 \% \text { reduction in pain score. }\end{array}$ \\
\hline $\begin{array}{l}\text { Olson and Hanson } \\
\text { (1997) } \\
\text { Canada }\end{array}$ & $\begin{array}{l}\text { To explore the } \\
\text { usefulness of } \\
\text { Reiki as an } \\
\text { adjuvant to } \\
\text { opioid therapy } \\
\text { in the } \\
\text { management of } \\
\text { pain }\end{array}$ & $\begin{array}{l}\text { Clinical trial } \\
\text { (single arm) }\end{array}$ & $\begin{array}{l}\text { People experiencing } \\
\text { pain for varied reasons } \\
\mathrm{N}=20 \\
18 \text { female } \\
2 \text { male }\end{array}$ & $\begin{array}{l}\text { Participants who received Reiki } \\
\text { reported a statistically significant } \\
\text { reduction in pain }(\mathrm{p}=0.001 \text {. })\end{array}$ & $\begin{array}{l}\text { Main strength of the study is that the conditions in } \\
\text { which the Reiki treatment was given are reflective } \\
\text { of the conditions under which one would expect to } \\
\text { receive Reiki. Weaknesses include lack of a } \\
\text { control group and qualitative data to explore the } \\
\text { cultural and social factors mediating the experience } \\
\text { of pain. }\end{array}$ \\
\hline $\begin{array}{l}\text { Vitale and } \\
\text { O’Connor (2006) } \\
\text { USA }\end{array}$ & $\begin{array}{l}\text { To compare } \\
\text { reports of pain } \\
\text { and levels of } \\
\text { state anxiety in } \\
2 \text { groups of } \\
\text { women after } \\
\text { abdominal } \\
\text { hysterectomy }\end{array}$ & $\begin{array}{l}\text { Randomised } \\
\text { controlled } \\
\text { trial }\end{array}$ & $\begin{array}{l}\text { Women undergoing } \\
\text { abdominal hysterectomy } \\
\mathrm{N}=22 \\
22 \text { female }\end{array}$ & $\begin{array}{l}\text { Reports of pain significantly } \\
\text { lower } 24 \text { hours after surgery } \\
\text { ( } \mathrm{p}=0.04 \text { ) in women receiving } \\
\text { Reiki and traditional nursing care } \\
\text { compared to control. Women } \\
\text { receiving Reiki experienced } \\
\text { shorter surgery time }\end{array}$ & $\begin{array}{l}\text { Excellent control for extraneous variables using } \\
\text { randomisation. Excellent consistency - each patient } \\
\text { had the same pain protocol, the same Reiki } \\
\text { practitioner, the same Reiki treatment, the same } \\
\text { anaesthesia and the same medications post- } \\
\text { operatively. There were no apparent weaknesses to } \\
\text { the study }\end{array}$ \\
\hline
\end{tabular}




\begin{tabular}{|c|c|c|c|c|c|}
\hline $\begin{array}{l}\text { Dressen and Singg } \\
\text { (1997) } \\
\text { USA }\end{array}$ & $\begin{array}{l}\text { To compare } \\
\text { Reiki, } \\
\text { progressive } \\
\text { muscle } \\
\text { relaxation, no } \\
\text { therapy } \\
\text { (control), and } \\
\text { false Reiki } \\
\text { (placebo) with } \\
\text { regard to pain } \\
\text { reduction, } \\
\text { emotional } \\
\text { improvement, } \\
\text { personality } \\
\text { enhancement, } \\
\text { and spiritual } \\
\text { growth in } \\
\text { chronically ill } \\
\text { patients }\end{array}$ & $\begin{array}{l}\text { Randomised } \\
\text { controlled } \\
\text { trial }\end{array}$ & $\begin{array}{l}\text { People experiencing } \\
\text { pain due to varied } \\
\text { chronic illness } \\
\mathrm{N}=120 \\
72 \text { female } \\
48 \text { male }\end{array}$ & $\begin{array}{l}\text { Reiki effective in reducing pain } \\
\text { when compared to progressive } \\
\text { muscle relaxation and placebo } \\
\text { Reiki }\end{array}$ & $\begin{array}{l}\text { Clear and concise study. Strengths include the use } \\
\text { of randomisation, a control group and a placebo } \\
\text { group and a large sample size. The authors provide } \\
\text { good insight into potential confounders such as } \\
\text { seriousness of illness, multiple experimenters, } \\
\text { multiple sites, religiosity and social support } \\
\text { available to the patient. Logic of comparing Reiki } \\
\text { to progressive muscle relaxation is not well } \\
\text { explained. }\end{array}$ \\
\hline $\begin{array}{l}\text { Richeson } \text { et } \\
\text { al.(2010) USA }\end{array}$ & $\begin{array}{l}\text { To evaluate the } \\
\text { effect of Reiki } \\
\text { as an } \\
\text { alternative and } \\
\text { complementary } \\
\text { approach to } \\
\text { treating } \\
\text { community- } \\
\text { dwelling older } \\
\text { adults who } \\
\text { experience } \\
\text { pain, } \\
\text { depression and } \\
\text { /or anxiety }\end{array}$ & $\begin{array}{l}\text { Randomised } \\
\text { controlled } \\
\text { trial }\end{array}$ & $\begin{array}{l}\text { Older adults } \\
\text { experiencing pain, } \\
\text { depression and / or } \\
\text { anxiety } \\
\mathrm{N}=20 \\
12 \text { female } \\
8 \text { male }\end{array}$ & $\begin{array}{l}\text { Reiki decreased symptoms of } \\
\text { pain, depression and anxiety } \\
\text { ( } p=0.000 \text { ) when compared to the } \\
\text { waiting list control group }\end{array}$ & $\begin{array}{l}\text { Well reported study. However the use of music } \\
\text { during the Reiki treatment may have confounded } \\
\text { the findings. } \\
\text { Use of individualised treatment is ethical and } \\
\text { reflects the provision of Reiki treatment outside of } \\
\text { a trial situation. }\end{array}$ \\
\hline
\end{tabular}




\begin{tabular}{|c|c|c|c|c|c|}
\hline $\begin{array}{l}\text { Hulse et al (2010) } \\
\text { USA }\end{array}$ & $\begin{array}{l}\text { To investigate } \\
\text { the feasibility } \\
\text { of using a } \\
\text { modified Reiki } \\
\text { intervention } \\
\text { prior to } \\
\text { colonoscopy to } \\
\text { reduce anxiety } \\
\text { and improve } \\
\text { the experience } \\
\text { of patients } \\
\text { undergoing } \\
\text { this procedure }\end{array}$ & $\begin{array}{l}\text { Clinical Trial } \\
\text { (partially } \\
\text { randomised) }\end{array}$ & $\begin{array}{l}\text { Patients undergoing } \\
\text { colonoscopy } \\
\mathrm{N}=21 \\
11 \text { Female } \\
9 \text { Male }\end{array}$ & $\begin{array}{l}\text { Reiki group reported less pain } \\
\text { than at baseline after the Reiki } \\
\text { treatment; however not } \\
\text { statistically significant. No } \\
\text { differences observed post } \\
\text { procedure in levels of pain } \\
\text { between the Reiki group and the } \\
\text { group who received normal care }\end{array}$ & $\begin{array}{l}\text { Weaknesses include non-blinding and only partial } \\
\text { randomisation. Authors note that due to a small } \\
\text { sample size confounding variables could not be } \\
\text { controlled. However, the study was a pilot and the } \\
\text { authors suggest ways that these limitations could be } \\
\text { overcome in future studies. }\end{array}$ \\
\hline $\begin{array}{l}\text { Miles (2003) } \\
\text { USA }\end{array}$ & $\begin{array}{l}\text { To evaluate an } \\
\text { educational } \\
\text { programme } \\
\text { teaching } \\
\text { patients with } \\
\text { HIV first } \\
\text { degree Reiki }\end{array}$ & $\begin{array}{l}\text { Pre and post- } \\
\text { test design }\end{array}$ & $\begin{array}{l}\text { Patients with HIV / } \\
\text { AIDS experiencing pain } \\
\text { and anxiety } \\
\mathrm{N}=30 \\
\text { Gender composition of } \\
\text { sample not stated }\end{array}$ & $\begin{array}{l}\text { Participants experienced an } \\
\text { average drop in pain rating from } \\
2.73 \text { to } 1.83 \text { on the visual } \\
\text { analogue scale after receiving } \\
\text { Reiki }\end{array}$ & $\begin{array}{l}\text { One of the key strengths of this report is that it } \\
\text { offers evidence in support of Reiki self-use to } \\
\text { manage pain in this group of patients. However it } \\
\text { is a 'preliminary report' and as such lacks detail on } \\
\text { many aspects of the study. }\end{array}$ \\
\hline $\begin{array}{l}\text { Meland (2009) } \\
\text { USA }\end{array}$ & $\begin{array}{l}\text { N/A - Case } \\
\text { report series }\end{array}$ & Case series & $\begin{array}{l}\text { Elderly participants with } \\
\text { dementia, anxiety and } \\
\text { pain } \\
\mathrm{N}=6 \\
4 \text { female } \\
2 \text { male }\end{array}$ & $\begin{array}{l}\text { Two participants reported a } \\
\text { reduction in pain }\end{array}$ & $\begin{array}{l}\text { Significant weaknesses include sample size (three } \\
\text { participants) and questions over validity of outcome } \\
\text { measure. }\end{array}$ \\
\hline $\begin{array}{l}\text { Assefi et al (2008) } \\
\text { USA }\end{array}$ & $\begin{array}{l}\text { To determine } \\
\text { whether Reiki } \\
\text { is beneficial as } \\
\text { an adjunctive } \\
\text { fibromyalgia } \\
\text { treatment }\end{array}$ & $\begin{array}{l}\text { Randomised } \\
\text { controlled } \\
\text { trial }\end{array}$ & $\begin{array}{l}\text { People with } \\
\text { Fibromyalgia } \\
\mathrm{N}=100 \\
92 \text { female } \\
8 \text { male }\end{array}$ & $\begin{array}{l}\text { No evidence that hands-on or } \\
\text { distance Reiki beneficial as an } \\
\text { adjunctive treatment for } \\
\text { Fibromyalgia }\end{array}$ & $\begin{array}{l}\text { Well designed and rigorously conducted trial using } \\
\text { a randomised, double blind, placebo controlled } \\
\text { design. } \\
\text { Participants experiencing 'average' pain as opposed } \\
\text { to high or minimal pain. } \\
\text { Would have benefited from consideration of how } \\
\text { patients coped with their pain after receiving Reiki. }\end{array}$ \\
\hline
\end{tabular}

NB. In all studies Reiki was administered hands-on by a Reiki practitioner. The exception to this is the study by Meland (2009) (highlighted) where the mode of use of Reiki was unclear 


\section{ii. Anxiety, Depression and Stress}

Ten studies were identified that explored the psychological benefits of Reiki, in particular the benefits relating to anxiety, depression and stress. Table 3.9 summarises the evidence in relation to the efficacy of Reiki for this type of condition.

\section{Measures}

Of the eight studies that measured anxiety, four used the State Trait Anxiety Inventory (STAI) (Wardell and Engebretson 2001; Miles 2003; Vitale and O'Connor 2006; Potter 2007). The STAI is a frequently used measure of anxiety (Miles 2003; Groth-Marnat 2009) and is considered to be reliable and valid. Richeson et al. (2010) used the Hamilton Anxiety scale (HAM-A), the reliability and validity of which is accounted for by the authors. Hulse, Stuart-Shor and Russo (2010) state using 'a self-report instrument developed by the nurse PI' (ibid: 22) to measure pain and anxiety. The only other information provided about the scale is that it was a 0-10 'Likert - type' rating scale. The authors do not account for the reliability or validity of their scale. Two studies, (Meland 2009; Thomas 2005) did not state what instrument was used to measure anxiety in their study.

Studies by Shore (2004), Thomas (2005), Potter (2007) and Richeson et al. (2010) have included measures of depression. Instruments used to measure depression include the Beck Depression Inventory (BDI) and the Beck Hopelessness Scale (BHS), which measures negative attitudes about the future, the Centre for Epidemiological Studies Depression Scale (CES-D) the Hospital Anxiety and Depression Scale (HADS) and the Geriatric Depression Scale - short form (GDS-15), an instrument specifically designed for use in those over the age of 55. Shore (2004) who used the BDI and the BHS commented that all instruments had been 'assessed for reliability; internal validity and test re-test validity' (Shore 2004:44). The CES-D as used by Potter (2007) has been validated in a cancer population. The HADS is used to measure anxiety and depression amongst those 'experiencing physical symptoms associated with illness' (Potter 2007:242) however the author does not account for its reliability or validity. Richeson et al. (2010) comment that the validity and reliability of the GDS-15 scale is well established. Thomas (2005) did not state what instrument was used to measure depression in their study. 
Stress was measured within one study (Shore 2004) using the Perceived Stress Scale (PSS). As with the other instruments used in the study the author accounts for the reliability and validity of the scale. Two further studies (MaCkay, Hansen and McFarlane 2004; Wardell and Engebretson 2001) also evaluated the effect of Reiki on stress although in these two studies physiological measures were used. MaCkay, Hansen and McFarlane (2004) recorded seven measures that correlate with the autonomic nervous system (heart rate; systolic, diastolic, and mean blood pressures; cardiac vagal tone; cardiac sensitivity to baroeflex and respiration rate). Similarly Wardell and Engebretson (2001) recorded blood pressure, skin conductance, muscle tension and skin temperature; all measures associated with stress reduction and relaxation. In addition, Wardell and Engebretson (2001) also took swabs of cortisol and Immunoglobulin A (IgA), measures of stress response. One other study included in this section did not report adequately on their measurement tools (Thomas 2005).

\section{The Efficacy of Reiki for Anxiety, Depression and Stress}

\section{Anxiety}

Seven out of the eight studies that explored the use of Reiki in reducing anxiety produced positive results suggesting the efficacy of Reiki for this condition.

The previously mentioned study by Vitale and O'Connor (2006) that explored the use of Reiki with women undergoing abdominal hysterectomy also reported on levels of state anxiety in participants. Women in the study who received Reiki had lower levels of anxiety upon discharge of hospital. However, the logic of measuring anxiety after surgery and upon discharge is not explained. Arguably it would have been interesting and more beneficial to assess anxiety prior to going into hospital and upon admission to hospital when levels of anxiety are likely to be at their highest.

The previously mentioned study by Miles (2003) evaluating a programme teaching Reiki first degree to people with HIV and AIDS measured participants levels of anxiety in addition to their levels of pain. Thirty participants completed a State Trait Anxiety Inventory scale before and after a Reiki self-treatment or a Reiki treatment administered by another student. Participants in both the self Reiki and Reiki from another person groups reported a mean drop 
in anxiety from 32.6 to 22.8 . No significant differences were observed between the selftreating group and the group that received Reiki from another student.

In a series of case reports, Meland (2009) described the use of Reiki with six elderly participants diagnosed with dementia as well as pain and anxiety. The results of the study in relation to pain are described above. Participants received a 20-minute Reiki treatment, twice a week over a 4-week period. The author reports that 'anxiety levels, as reported to the nurse by participants, dropped for 5 out of the 6 participants' (Meland 2009: 56). Unfortunately it is unclear as to what measure of anxiety was employed and as with the results on pain it is notable that the diagnosis of dementia in all the participants may have confounded the findings.

The pilot study by Hulse, Stuart-Shor and Russo (2010) described above, that examined the use of Reiki prior to colonoscopy, also included measurements of anxiety at three points (baseline, after the Reiki intervention and after colonoscopy procedure). Whilst the authors report that participants experienced statistically significant reductions in self-reported anxiety after the Reiki intervention the same problem as with the findings on pain is apparent: the type of scale used to measure anxiety is unclear and its reliability or validity are unaccounted for.

Thomas (2005) reported the results of a 1-year study of a Reiki programme that was introduced in a nursing home. Over a period of 1 year, Reiki was offered to residents twice weekly. Participants were divided into three groups according to their symptoms. Group A consisted of patients experiencing stress, anxiety, loneliness and depression. The author reported that 'participating residents in group A reflected less irritability, stress and anxiety overall, while experiencing greater levels of peace, calm, and relaxation on a more consistent basis' (Thomas 2005: 45). Unfortunately the method of measuring these changes is not specified and no data are presented (qualitative or quantitative) to support the findings. Furthermore it is unclear how many participants were included in the study; in one instance the author states that 60 patients were studied, divided into three groups (Thomas 2005:44). 
However she later states that 'a minimum of 10 patients was studied in each group' (Thomas: 2005:45).

Wardell and Engebretson (2001) used biological measures to explore whether Reiki had an effect on relaxation or stress reduction. Twenty-three participants received a 30-minute Reiki treatment and physiological measures associated with stress reduction and relaxation (blood pressure, skin conductance, muscle tension and skin temperature) were recorded throughout the treatment. In addition, anxiety was measured before and after the Reiki treatment using the STAI and cortisol and Immunoglobulin A (IgA) (measure of stress response) levels were measured before and after the Reiki treatment. The results indicated that Reiki significantly reduced state anxiety $(\mathrm{p}=0.02)$ and systolic blood pressure $(\mathrm{p}=0.003)$. Muscle tension was significantly reduced before and during Reiki treatment but not after $(\mathrm{p}=0.049)$. Level of cortisol before and after Reiki treatment was not statistically significant but levels of IgA rose significantly $(\mathrm{p}=0.003)$ after Reiki treatment. This, the authors note, indicates a possible increase in immune function. There are some weaknesses inherent in this study including the lack of a control group. Furthermore, the use of machinery to measure biological correlates created an artificial situation and only two Reiki hand positions were used thus casting doubt on how representative this study is of a 'real' Reiki session.

Richeson et al.'s (2010) study described in the above section on pain, explored the effects of Reiki on older adults who experienced pain, depression and / or anxiety. Twenty adults aged $57-76$ participated and were randomly assigned to receive either Reiki 1 day per week for 8 weeks or a waiting list control. Anxiety was measured at baseline and after the intervention. The results of the study show that Reiki decreased symptoms of anxiety $(p=0.000)$ when compared to the waiting list control group. This is a well reported study however; the authors note that anxiety levels may have been particularly high in this sample as participants frequently reported during pre-testing their concerns regarding employment and retirement.

MaCkay, Hansen and McFarlane (2004) observed that 'one of the most commonly reported effects of Reiki is that of relaxation or a reduction in stress' (2004:1077). Based on this observation, the authors suggest that if Reiki was to reduce stress there would be a 
measurable effect on the autonomic nervous system - the part of the nervous system responsible for emotion. In this randomised controlled trial, 45 healthy participants were assigned to one of three groups. The first group received rest plus a 30-minute Reiki treatment, the second group received rest plus a 30-minute placebo Reiki treatment and the third group received rest only. Seven measures that correlate with the autonomic nervous system (heart rate; systolic, diastolic, and mean blood pressures; cardiac vagal tone; cardiac sensitivity to baroeflex and respiration rate) were recorded continuously for all three groups. In the group who received Reiki, statistically significant changes were seen in all but one of the seven measures. However, when these measurements were compared to the group receiving placebo Reiki, only two measures, heart rate (0.005) and diastolic blood pressure (0.04) showed a statistically significant decrease, leading the authors to conclude that Reiki has an effect on the autonomic nervous system. The conditions under which Reiki was administered for this study were extremely artificial due to the participants being wired to machinery throughout to measure autonomic nervous system function. This does not reflect Reiki treatment outside of a clinical setting and therefore raises questions about the generalisability of the findings of this study. Nonetheless, the study was well designed with the use of a placebo and a control group. It is also well reported with ample detail on the instrumentation, study protocol and data analysis.

The one study to find no evidence for the efficacy of Reiki in reducing levels of anxiety was that of Potter (2007). This study found no significant differences in mean distress scores between a group receiving Reiki before and after breast biopsy compared with a group receiving conventional care. Whilst it is notable that this study employed a randomised control design, the validity of the findings is questionable due to the sample size and composition. As noted by the authors the sample size $(n=35)$ was insufficient to determine efficacy (Potter 2007: 241). Furthermore, the sample reported low levels of anxiety at baseline and comprised women who lived and worked within a university environment, many of whom were healthcare professionals. Thus it is difficult to make any generalisations from this study regarding the benefits Reiki might have in relation to distress. 


\section{Depression}

Shore (2004) found both distance and hands-on Reiki to be effective in reducing symptoms of depression. Her study is the only one identified amongst the literature to comment on the length of time post treatment for which Reiki is effective. This study demonstrated that the effects of Reiki on symptoms of psychological depression lasted at least one year following six hours of treatment.

The above described study by Thomas (2005) explored the effects of Reiki on depression as well as anxiety. The author reported that 'Forty percent of group A's participants were diagnosed with depression' (Thomas 2005: 45). The author does not specify exactly what the effect of Reiki was on this forty percent of participants and as described above there are significant flaws in the reporting of this study.

The above described study by Potter (2007) found no significant differences in the mean score of depression between a group of patients receiving Reiki before and after breast biopsy compared with a group receiving conventional care. As noted above, this study was well designed however; the weaknesses inherent in the study also apply to the findings on depression.

Richeson et al. (2010) study, described above under the heading of pain and, again, under the heading of anxiety also found Reiki to have a positive effect on depression. Depression was measured at baseline and after the intervention. The results of the study showed that those in the group who received Reiki experienced a statistically significant decrease in the measure of depression $(\mathrm{p}=0.000)$ when compared to the waiting list control group. As previously noted, this is a well reported study but the authors do suggest caution when interpreting the findings due to the potential of the use of music in the Reiki sessions to confound the findings. 


\section{Stress}

Four studies (Wardell and Engebretson 2001; MaCkay, Hansen and McFarlane 2004; Shore 2004; Thomas 2005) all of which have been described above, explored the effects of Reiki on stress. Studies by Wardell and Engebretson (2001) and MaCkay, Hansen and McFarlane (2004) both used physiological markers to measure stress levels throughout the duration of a Reiki treatment. The results of Wardell and Engebretson's (2001) study indicated a significant reduction in some of the physiological markers associated with stress such as state anxiety $(\mathrm{p}=0.02)$, systolic blood pressure $(\mathrm{p}=0.003)$ and muscle tension (before and during Reiki treatment) $(\mathrm{p}=0.049)$. MaCkay, Hansen and McFarlane (2004) reported similar findings with statistically significant changes observed in all but one of the seven measures. However, when these measurements were compared to the group receiving placebo Reiki, only two measures, heart rate $(\mathrm{p}=0.005)$ and diastolic blood pressure $(\mathrm{p}=0.04)$ showed a statistically significant decrease. Both studies are well reported with good detail relating to all aspects of the research protocol. However, the conditions under which the Reiki treatment was performed does not reflect how Reiki is usually administered: receiving Reiki does not involve the client being wired to machinery, nonetheless the fact that positive results were reported given these artificial conditions is encouraging and makes a valuable contribution to the literature.

Shore's study found a significant decrease in levels of stress $(p=<.01)$ between the group receiving Reiki and the placebo group. Furthermore, measures of stress continued to decrease when participants who had received Reiki were followed up, one year later. The study was thoroughly reported with good detail of the methods used and the results. There are no apparent weaknesses to the study.

Thomas's (2005) study, described previously, also included participants that were experiencing stress. The author found that these participants 'reflected less irritability, stress and anxiety overall, while experiencing greater levels of peace, calm, and relaxation on a more consistent basis' (Thomas 2005: 45) after receiving Reiki. This study has many weaknesses, particularly, the absence of an account of methods used within the research or the instrument used to measure stress. No data are presented to support any of the findings. 
Table 3.9: Summary of Evidence for Anxiety, Depression and Stress

\begin{tabular}{|c|c|c|c|c|c|}
\hline $\begin{array}{l}\text { Author and } \\
\text { country }\end{array}$ & Aim / Purpose of the research & Study Design & $\begin{array}{l}\text { Who or where } \\
\text { and Sample size }\end{array}$ & Main findings & Summary Evaluative comments \\
\hline $\begin{array}{l}\text { Vitale and } \\
\text { O'Connor } \\
\text { (2006) } \\
\text { USA }\end{array}$ & $\begin{array}{l}\text { To compare reports of pain and } \\
\text { levels of state anxiety in two } \\
\text { groups of women after abdominal } \\
\text { hysterectomy }\end{array}$ & $\begin{array}{l}\text { Randomised } \\
\text { controlled } \\
\text { trial }\end{array}$ & $\begin{array}{l}\text { Women } \\
\text { undergoing } \\
\text { abdominal } \\
\text { hysterectomy } \\
\mathrm{N}=22\end{array}$ & $\begin{array}{l}\text { Women in the study who received Reiki } \\
\text { had lower levels of anxiety upon } \\
\text { discharge of hospital. }\end{array}$ & $\begin{array}{l}\text { Excellent control for extraneous } \\
\text { variables using randomisation. } \\
\text { However, the logic of measuring } \\
\text { anxiety after surgery and upon } \\
\text { discharge is not explained. }\end{array}$ \\
\hline $\begin{array}{l}\text { Miles (2003) } \\
\text { USA }\end{array}$ & $\begin{array}{l}\text { To evaluate an educational } \\
\text { programme teaching patients with } \\
\text { HIV first degree Reiki }\end{array}$ & $\begin{array}{l}\text { Pre and post- } \\
\text { test design }\end{array}$ & $\begin{array}{l}\text { Patients with HIV } \\
\text { / AIDS } \\
\text { experiencing pain } \\
\text { and anxiety } \\
\mathrm{N}=30 \\
\text { Gender } \\
\text { composition of } \\
\text { sample not stated }\end{array}$ & $\begin{array}{l}\text { Participants reported a mean drop in } \\
\text { anxiety from } 32.6 \text { to } 22.8 \text {. as measured } \\
\text { by the STAI }\end{array}$ & $\begin{array}{l}\text { One of the key strengths of this } \\
\text { study is that it offers evidence in } \\
\text { support of Reiki self-use to manage } \\
\text { pain in this group of patients. } \\
\text { However it is a 'preliminary report' } \\
\text { and as such lacks detail on many } \\
\text { aspects of the study. }\end{array}$ \\
\hline $\begin{array}{l}\text { Meland } \\
(2009) \\
\text { USA }\end{array}$ & N/A - Case report series & $\begin{array}{l}\text { Case Report } \\
\text { series }\end{array}$ & $\begin{array}{l}\text { Elderly } \\
\text { participants with } \\
\text { dementia, anxiety } \\
\text { and pain } \\
\mathrm{N}=6 \\
4 \text { female } \\
2 \text { male }\end{array}$ & $\begin{array}{l}\text { Participants experienced reduced } \\
\text { anxiety after a twenty minute Reiki } \\
\text { treatment, twice per week over a four } \\
\text { week period. }\end{array}$ & $\begin{array}{l}\text { Significant weaknesses include six } \\
\text { participants. The instrument used to } \\
\text { measure Reiki is unclear. } \\
\text { Dementia diagnosis may potentially } \\
\text { confound results. }\end{array}$ \\
\hline $\begin{array}{l}\text { Hulse } \text { et } \\
\text { al .(2010) } \\
\text { USA }\end{array}$ & $\begin{array}{l}\text { To investigate the feasibility of } \\
\text { using a modified Reiki } \\
\text { intervention prior to colonoscopy } \\
\text { to reduce anxiety and improve the } \\
\text { experience of patients undergoing } \\
\text { this procedure }\end{array}$ & $\begin{array}{l}\text { Clinical Trial } \\
\text { (partially } \\
\text { randomised) }\end{array}$ & $\begin{array}{l}\text { Patients } \\
\text { undergoing } \\
\text { colonoscopy } \\
\mathrm{N}=21 \\
11 \text { female } \\
9 \text { male }\end{array}$ & $\begin{array}{l}\text { Participants experienced statistically } \\
\text { significant reductions in self reported } \\
\text { anxiety after the Reiki intervention. }\end{array}$ & $\begin{array}{l}\text { Weaknesses include non-blinding } \\
\text { and only partial randomisation. } \\
\text { The study lacks some key details, } \\
\text { notably the type of scale used to } \\
\text { measure anxiety is unclear and its } \\
\text { reliability or validity is unaccounted } \\
\text { for. } \\
\text { Authors note that due to a small } \\
\text { sample size confounding variables } \\
\text { could not be controlled. However, }\end{array}$ \\
\hline
\end{tabular}




\begin{tabular}{|c|c|c|c|c|c|}
\hline & & & & & $\begin{array}{l}\text { the study was a pilot and the authors } \\
\text { suggest ways that these limitations } \\
\text { could be overcome in future studies. }\end{array}$ \\
\hline $\begin{array}{l}\text { Thomas } \\
(2005) \\
\text { USA }\end{array}$ & $\begin{array}{l}\text { To evaluate the effectiveness of } \\
\text { Reiki healing as a means to } \\
\text { improving the overall quality of } \\
\text { live in a nursing home }\end{array}$ & Unclear & $\begin{array}{l}\text { Nursing home } \\
\text { patients } \\
\text { experiencing } \\
\text { stress, anxiety, } \\
\text { loneliness and } \\
\text { depression } \\
\mathrm{N}=\text { unclear }\end{array}$ & $\begin{array}{l}\text { Participants reported less stress and } \\
\text { anxiety in nursing homes patients who } \\
\text { received Reiki. }\end{array}$ & $\begin{array}{l}\text { This study has many weaknesses, } \\
\text { particularly, the absence of an } \\
\text { account of methods used within the } \\
\text { research or the instrument used to } \\
\text { measure stress or anxiety. It is } \\
\text { unclear how many participants were } \\
\text { included in the study and no data is } \\
\text { presented to support any of the } \\
\text { findings. }\end{array}$ \\
\hline $\begin{array}{l}\text { Wardell and } \\
\text { Engebretson } \\
\text { (2001) } \\
\text { USA }\end{array}$ & $\begin{array}{l}\text { To test a framework of relaxation } \\
\text { or stress reduction as a mechanism } \\
\text { of touch therapy }\end{array}$ & $\begin{array}{l}\text { Single group } \\
\text { repeated } \\
\text { measure } \\
\text { design }\end{array}$ & $\begin{array}{l}\text { Healthy } \\
\text { participants } \\
\mathrm{N}=23 \\
18 \text { female } \\
5 \text { male }\end{array}$ & $\begin{array}{l}\text { Reiki significantly reduced state anxiety } \\
(\mathrm{p}=0.02) \text { and systolic blood pressure } \\
(\mathrm{p}=0.003) \text {. Muscle tension was } \\
\text { significantly reduced before and during } \\
\text { Reiki treatment but not after ( } \mathrm{p}= \\
0.049) \text {. Level of cortisol before and } \\
\text { after Reiki treatment was not } \\
\text { statistically significant but levels of IgA } \\
\text { rose significantly ( } \mathrm{p}=0.003 \text { ) after Reiki } \\
\text { treatment. }\end{array}$ & $\begin{array}{l}\text { This study is well reported and } \\
\text { provides a useful insight into the } \\
\text { biological correlates of Reiki } \\
\text { healing. Power calculations were } \\
\text { undertaken prior to the study and } \\
\text { indicated that } 14 \text { participants were } \\
\text { needed so final sample exceeded } \\
\text { minimum number. } \\
\text { Weaknesses include the lack of a } \\
\text { control group. The use of machinery } \\
\text { to measure biological correlates } \\
\text { created an artificial situation and } \\
\text { only tow Reiki hand positions were } \\
\text { used thus casting doubt on how } \\
\text { representative this study is of a 'real' } \\
\text { Reiki session. }\end{array}$ \\
\hline $\begin{array}{l}\text { Richeson et } \\
\text { al. }(2010) \\
\text { USA }\end{array}$ & $\begin{array}{l}\text { To evaluate the effect of Reiki as } \\
\text { an alternative and complementary } \\
\text { approach to treating community- } \\
\text { dwelling older adults who } \\
\text { experience pain, depression and } \\
\text { /or anxiety }\end{array}$ & $\begin{array}{l}\text { Randomised } \\
\text { Controlled } \\
\text { Trial }\end{array}$ & $\begin{array}{l}\text { Older adults } \\
\text { experiencing pain, } \\
\text { depression and / } \\
\text { or anxiety } \\
\mathrm{N}=20 \\
12 \text { female } \\
8 \text { male }\end{array}$ & $\begin{array}{l}\text { Reiki decreased symptoms of anxiety } \\
(\mathrm{p}=0.000) \text { and depression }(\mathrm{p}=0.000) \\
\text { when compared to the waiting list } \\
\text { control group }\end{array}$ & $\begin{array}{l}\text { This is a well reported study } \\
\text { however the use of music during the } \\
\text { Reiki treatment may have } \\
\text { confounded the findings. Use of } \\
\text { individualised treatment ethical but } \\
\text { implies that not all participants } \\
\text { necessarily received the same, }\end{array}$ \\
\hline
\end{tabular}




\begin{tabular}{|c|c|c|c|c|c|}
\hline & & & & & standardised, intervention. \\
\hline $\begin{array}{l}\text { MaCkay, } \\
\text { Hansen and } \\
\text { McFarlane } \\
(2004) \\
\text { UK }\end{array}$ & $\begin{array}{l}\text { To investigate if Reiki has any } \\
\text { effect on indices of autonomic } \\
\text { nervous system function }\end{array}$ & $\begin{array}{l}\text { Randomised } \\
\text { Controlled } \\
\text { Trial }\end{array}$ & $\begin{array}{l}\text { Healthy } \\
\text { participants } \\
\mathrm{N}=45 \\
24 \text { female } \\
21 \text { male }\end{array}$ & $\begin{array}{l}\text { Statistically significant changes seen in } \\
\text { six of seven measures in group } \\
\text { receiving Reiki. However, only heart } \\
\text { rate }(0.005) \text { and diastolic blood pressure } \\
(0.04) \text { decreased significantly when } \\
\text { compared to group receiving placebo } \\
\text { Reiki }\end{array}$ & $\begin{array}{l}\text { This study was well designed with } \\
\text { the use of a placebo and control } \\
\text { group. All aspects of the study are } \\
\text { well reported. One weakness to this } \\
\text { randomised controlled trial, as noted } \\
\text { by the authors is a small sample size }\end{array}$ \\
\hline $\begin{array}{l}\text { Potter (2007) } \\
\text { USA }\end{array}$ & $\begin{array}{l}\text { To determine feasibility of testing } \\
\text { Reiki for women undergoing } \\
\text { breast biopsy }\end{array}$ & $\begin{array}{l}\text { Randomised } \\
\text { controlled } \\
\text { trial }\end{array}$ & $\begin{array}{l}\text { Women } \\
\text { undergoing breast } \\
\text { biopsy } \\
\mathrm{N}=32\end{array}$ & $\begin{array}{l}\text { Study found no evidence for the } \\
\text { efficacy of Reiki in reducing levels of } \\
\text { anxiety or depression. }\end{array}$ & $\begin{array}{l}\text { Study's strengths include the use of } \\
\text { a randomised control design. } \\
\text { However, the sample size was } \\
\text { insufficient to determine efficacy } \\
\text { and the demographics of the } \\
\text { participants make it difficult to } \\
\text { generalise from the findings }\end{array}$ \\
\hline $\begin{array}{l}\text { Shore (2004) } \\
\text { USA }\end{array}$ & $\begin{array}{l}\text { To test the hypothesis that the } \\
\text { Reiki energy is the rather than } \\
\text { touch is the causal factor related to } \\
\text { significant findings in energetic } \\
\text { healing research and to investigate } \\
\text { the long term effects of energetic } \\
\text { healing on symptoms of } \\
\text { psychological distress }\end{array}$ & $\begin{array}{l}\text { Randomised } \\
\text { controlled } \\
\text { trial }\end{array}$ & $\begin{array}{l}\text { Participants } \\
\text { experiencing } \\
\text { symptoms of } \\
\text { depression and } \\
\text { stress } \\
\mathrm{N}=45 \\
\text { Gender } \\
\text { composition of } \\
\text { sample not stated }\end{array}$ & $\begin{array}{l}\text { Both distance and hands on Reiki } \\
\text { effective in reducing symptoms of } \\
\text { depression and stress. }\end{array}$ & $\begin{array}{l}\text { The study's strengths are its use of } \\
\text { randomisation and a placebo group. } \\
\text { The study is well reported with gooc } \\
\text { detail of the methods used and the } \\
\text { results. } \\
\text { This study is the only one identified } \\
\text { amongst the literature to comment } \\
\text { on the length of time post treatment } \\
\text { for which Reiki is effective. }\end{array}$ \\
\hline
\end{tabular}

NB: In all studies Reiki was administered hands on by a Reiki practitioner except the two studies highlighted. In the study by Meland (2009) the mode of use of Reiki was unclear and in the study by Shore (2004) a combination of hands on Reiki administered by a practitioner and distance Reiki was used. 


\section{iii. Recovery after Illness}

Four studies were identified that explored the benefits of Reiki in relation to recovery after illness. Table 3.10 summarises the evidence in relation to the use of Reiki in recovery after illness.

Friedman et al. (2010) studied the effects of Reiki on 37 patients within the first 72 hours of recovery after acute coronary syndrome. Patients were randomised into three groups to receive either Reiki, a classical music intervention or rest. During the 72 hours readings were taken of the participant's high frequency heart rate variability (HF HRV) using a Holter monitor (a standard instrument for measuring heart activity) and emotional state as measured using a 10 point Likert scale. In the group of patients who received Reiki a significant increase was observed in their mean HF HRV $(\mathrm{p}=0.02)$ when compared to baseline. This change was significantly greater than with those who received the classical music intervention $(\mathrm{p}=0.007)$ or rest $(\mathrm{p}=0.025)$. In the Reiki group, Likert score for all positive emotional states increased and negative states decreased. Given that increased HRV predicts outcome after acute coronary syndrome, the authors suggest that Reiki has a potential clinical role in the post acute coronary syndrome inpatient setting. This study is well reported. It provides sufficient detail on the majority of aspects of the study protocol for a replicate study to be undertaken. In particular good detail is provided on how the consistency of treatment was ensured and also on the statistical tests used to control for known confounding variables. The study is weakened only slightly by lack of detail on the type of Likert scale used to measure participants' emotional state and its reliability was not commented on. Furthermore the study would have benefitted from details on the procedure use to randomise participants.

Tsang, Carlson and Olson (2007) examined the effects of Reiki on fatigue, pain, anxiety and quality of life in cancer patients who had recently completed chemotherapy and concluded that Reiki was moderately effective 'at reducing cancer related fatigue and may have more broad ranging effects on overall quality of life' (Tsang, Carlson and Olson 2007:31). In this counterbalanced crossover pilot trial, 16 participants were randomly assigned to two groups: Reiki or resting control. In the Reiki group, participants received seven Reiki sessions over a five day period. The resting control group were requested to rest for 45 minutes each day 
over a 5-day period. All participants received both treatment conditions. The Functional Assessment of Cancer Therapy Fatigue subscale (FACT-F) was used to measure fatigue and was administered to participants before and after the Reiki or rest period. The FACT-F is described by the authors as having 'demonstrated strong internal consistency as well as acceptable test-retest reliability' (Tsang, Carlson and Olson 2007:28). The Functional Assessment of Cancer Therapy, general version (FACT-G) was used to measure quality of life and was administered to both treatment groups before and after Reiki or rest. The authors note that this assessment scale is 'validated' and has 'acceptable test - retest reliability' (ibid: 28). The Edmonton Symptom Assessment System Questionnaire (ESAS) was also administered to participants before and after each Reiki session and before and after each rest session. The ESAS is specifically designed for use with patients receiving palliative care and amongst other symptoms, measures pain and anxiety. The authors account for internal consistency and validity of this instrument.

The authors report that the change in mean fatigue score in the Reiki condition was close to significant $(\mathrm{p}=.051)$. The Reiki condition also produced a statistically significant reduction in pain $(\mathrm{p}=<.05)$ and anxiety $(\mathrm{p}<.005)$ and improved quality of life $(\mathrm{p}<.01)$. No statistically significant changes in fatigue, pain, anxiety or quality of life were observed in the resting condition. When the two conditions were compared (Reiki versus rest) there was no statistically significant difference in the mean fatigue scores between the Reiki and rest control $(\mathrm{p}=.236)$, or between the pain and anxiety scores. However, a statistically significant difference in scores of the quality of life was observed when the Reiki condition was compared to the rest condition $(\mathrm{p}<.05)$. This pilot trial is extremely well reported with good detail of the measures used, the treatment protocol and the procedure for data analysis. All results are tabulated and $\mathrm{p}$ values provided. Despite a small sample size, this was a pilot trial and the authors account for how such limitations will be overcome in future clinical trials.

Sharma et al. (2000) examined whether Reiki had any effect on the haemodynamics, inflammatory markers or psychological outcome of 50 patients undergoing coronary artery bypass graft surgery. Hands-on Reiki was administered to patients on 3 successive days prior to surgery and then from a distance for 18 days after surgery. A further 50 patients undergoing the same procedure acted as a control and received placebo Reiki. The authors 
report that there were no statistically significant differences between the two groups on any of the haemodynamic, inflammatory or psychological measures and also no difference between the groups in terms of length of stay in intensive care or hospital stay. Ample data is provided in the paper to support these findings. This study presents compelling evidence to suggest that Reiki has no benefit for this group of patients. The measures used in the study were standard biomedical measures and both the General Health Questionnaire and the World Health Organisation Quality of Life (WHOQOL) questionnaire are considered robust indicators of psychological health.

Shiflett et al. (2002) concluded that Reiki had no significant effect on functional recovery in post stroke rehabilitation or depressed mood. Measurement instruments included the Functional Independence Measure (FIM) and the CES-D of depressed mood. This study employed a randomised, placebo controlled, double blind design. However, in many instances there is a distinct lack of detail for this study such as which hand positions were used and where in the hospital the Reiki treatments were given. Furthermore the two groups were not comparable at baseline. 
Table 3.10: Summary of Evidence for the use of Reiki in Recovery after Illness

\begin{tabular}{|c|c|c|c|c|c|}
\hline $\begin{array}{l}\text { Author } \\
\text { and } \\
\text { country }\end{array}$ & Aim / Purpose of the research & Study Design & $\begin{array}{l}\text { Participants, } \\
\text { sample size, } \\
\text { gender of } \\
\text { sample }\end{array}$ & Main findings & $\begin{array}{l}\text { Summary Evaluative } \\
\text { comments }\end{array}$ \\
\hline $\begin{array}{l}\text { Friedman } \\
\text { et al } \\
(2010) \\
\text { USA }\end{array}$ & $\begin{array}{l}\text { To determine whether Reiki treatment } \\
\text { would improve HRV (heart rate } \\
\text { variability) in patients recovering from } \\
\text { acute coronary syndrome }\end{array}$ & $\begin{array}{l}\text { Randomised } \\
\text { controlled trial }\end{array}$ & $\begin{array}{l}\text { Patients } \\
\text { recovering from } \\
\text { acute coronary } \\
\text { syndrome } \\
\mathrm{N}=37 \\
10 \text { female } \\
27 \text { male }\end{array}$ & $\begin{array}{l}\text { Significant increase in mean HF HRV } \\
(\mathrm{p}=0.02) \text { in Reiki group compared to } \\
\text { baseline. Reiki group demonstrated } \\
\text { increase in positive emotional states } \\
\text { and decrease in negative states. }\end{array}$ & $\begin{array}{l}\text { Study is well reported and } \\
\text { provides sufficient detail on the } \\
\text { study protocol for a replicate } \\
\text { study to be undertaken. Good } \\
\text { detail provided on how the } \\
\text { consistency of treatment was } \\
\text { ensured and also on the } \\
\text { statistical tests used to control } \\
\text { for known confounding } \\
\text { variables. } \\
\text { Study is weakened only slightly } \\
\text { by lack of detail on the type of } \\
\text { Likert scale used. Study would } \\
\text { have benefitted from details on } \\
\text { the procedure used to randomis } \\
\text { participants. }\end{array}$ \\
\hline $\begin{array}{l}\text { Tsang et } \\
\text { al (2007) } \\
\text { Canada }\end{array}$ & $\begin{array}{l}\text { Examine the effects of Reiki on fatigue, } \\
\text { pain, anxiety and o overall quality of life }\end{array}$ & $\begin{array}{l}\text { Counterbalanced } \\
\text { crossover pilot } \\
\text { trial }\end{array}$ & $\begin{array}{l}\text { Cancer patients } \\
\text { who had recently } \\
\text { completed } \\
\text { chemotherapy } \\
\mathrm{N}=16 \\
13 \text { female } \\
3 \text { male }\end{array}$ & $\begin{array}{l}\text { Change in mean fatigue score in the } \\
\text { Reiki condition was close to significant } \\
(\mathrm{p}=.051) \text {. Statistically significant } \\
\text { reduction in pain }(\mathrm{p}=<.05) \text { and anxiety } \\
(\mathrm{p}<.005) \text { and improved quality of life } \\
(\mathrm{p}<.01) \text { in Reiki condition. Statistically } \\
\text { significant difference in quality of life } \\
\text { when the Reiki condition was } \\
\text { compared to the rest condition }(\mathrm{p}<.05)\end{array}$ & $\begin{array}{l}\text { An extremely well reported } \\
\text { study; good detail of the } \\
\text { measures used in the study, the } \\
\text { treatment protocol and the } \\
\text { procedure for data analysis. All } \\
\text { results tabulated and p values } \\
\text { provided. } \\
\text { However, the study had a small } \\
\text { sample size fitting for a pilot. } \\
\text { The authors account for how } \\
\text { such limitations will be } \\
\text { overcome in future clinical } \\
\text { trials. }\end{array}$ \\
\hline
\end{tabular}




\begin{tabular}{|c|c|c|c|c|c|}
\hline $\begin{array}{l}\text { Sharma et } \\
\text { al }(2000) \\
\text { Country } \\
\text { unclear }\end{array}$ & $\begin{array}{l}\text { To prospectively assess the role of Reiki } \\
\text { in patients undergoing elective coronary } \\
\text { artery bypass grafting as an aspect of } \\
\text { modulating the blood loss, inflammatory } \\
\text { response, haemodynamic and } \\
\text { psychological variables }\end{array}$ & $\begin{array}{l}\text { Randomised } \\
\text { controlled trial }\end{array}$ & $\begin{array}{l}\text { Patients } \\
\text { undergoing } \\
\text { coronary artery } \\
\text { bypass graft } \\
\text { surgery } \\
\mathrm{N}=100 \\
\text { Gender } \\
\text { composition } \\
\text { unreported }\end{array}$ & $\begin{array}{l}\text { No statistically significant differences } \\
\text { between the Reiki and control group on } \\
\text { any of the haemodynamic, } \\
\text { inflammatory or psychological } \\
\text { measures. No difference between the } \\
\text { groups in terms of length of stay in } \\
\text { intensive care or hospital }\end{array}$ & $\begin{array}{l}\text { Ample data provided in support } \\
\text { of findings. } \\
\text { Measures were standard } \\
\text { biomedical measures and both } \\
\text { the General Health } \\
\text { Questionnaire and the World } \\
\text { Health Organisation Quality of } \\
\text { Life (WHOQOL) questionnaire } \\
\text { are considered robust indicators } \\
\text { of psychological health. }\end{array}$ \\
\hline $\begin{array}{l}\text { Shiflett et } \\
\text { al (2002) } \\
\text { USA }\end{array}$ & $\begin{array}{l}\text { (1) To evaluate the effectiveness of } \\
\text { Reiki as an adjunctive treatment for } \\
\text { patients with sub acute stroke who were } \\
\text { receiving standard rehabilitation as } \\
\text { inpatients. (2) To evaluate a double } \\
\text { blinded procedure for training Reiki } \\
\text { practitioners. (3) To determine whether } \\
\text { or not double-blinded Reiki and sham } \\
\text { practitioners could determine which } \\
\text { category they were in }\end{array}$ & $\begin{array}{l}\text { Randomised } \\
\text { controlled trial }\end{array}$ & $\begin{array}{l}\text { Patients } \\
\text { recovering from } \\
\text { stroke } \\
\mathrm{N}=50 \\
19 \text { female } \\
31 \text { male }\end{array}$ & $\begin{array}{l}\text { No significant effect on functional } \\
\text { recovery in post stroke rehabilitation or } \\
\text { depressed mood }\end{array}$ & $\begin{array}{l}\text { Strengths include a randomised, } \\
\text { placebo controlled, double blind } \\
\text { design. } \\
\text { However, there was a lack of } \\
\text { detail such as which hand } \\
\text { positions were used and where } \\
\text { in the hospital the Reiki } \\
\text { treatments were given. } \\
\text { Two groups were not } \\
\text { comparable at baseline. }\end{array}$ \\
\hline
\end{tabular}

NB: In all studies Reiki was administered hands on by a Reiki practitioner except the two studies highlighted. In the study by Tsang et al.

(2007) the mode of use of Reiki was unclear and in the study by Sharma (2000) a combination of hands on Reiki administered by a practitioner and distance Reiki was used 


\section{iv. Other Benefits}

This section presents the evidence from three studies that explored 'other' possible effects of Reiki. Those studies that did not cohere with the above themes -- that is, the efficacy of Reiki for pain management, anxiety, depression, stress or recovery after illness -- are included in this section. Table 3.11 summarises the evidence in relation to the use of Reiki for these 'other' conditions and illnesses.

Crawford, Leaver and Mahoney (2006) explored the efficacy of using Reiki treatment to improve memory and behaviour deficiencies in patients with mild cognitive impairment or mild Alzheimer's disease. Within this study the Annotated Mini-Mental State Examination (AMMSE) was used to measures cognitive impairment and the Revised Memory and Behaviour Problems Checklist (RMBPC) was used to measures behaviour change. Both instruments are reliable and valid (Crawford, Leaver and Mahoney 2006). Over a 4-week period increases were observed in mental functioning and memory behaviour problems in participants $(n=24)$ receiving 30 minutes of Reiki on a weekly basis. Despite the relatively small sample, the authors concluded that Reiki 'shows promise' for use with patients with mild cognitive impairment or mild Alzheimer's. Furthermore, this study is one of only a few that suggests benefit of using Reiki beyond the individual. The authors note that primary caregivers can become attuned to Reiki at no (or little) cost and provide it to their clients with potential beneficial results in the amount of nursing care they need.

Brewitt, Vittetoe and Hartwell (1997) evaluated the therapeutic effects of Reiki on a small sample of five participants with varying chronic illnesses. Participants were given 11, 1-hour Reiki sessions over a period of 9 weeks. The researchers measured changes in electrical skin resistance at 40 points on the hands and feet at three points during the study using a 'LISTEN' device. Three of the 40 skin points showed significant differences after the Reiki treatment and increased to the 'normal' range. The authors note that these three skin points correspond with the neuroendocrine-immune system and when the reading taken from these points is below normal this can be an indication of chronic illness and depletion of chi (commonly interpreted as energy). This study is problematic in that the device used to take measurements is not a standard medical instrument and the authors present very little information on it. There was no consistency in terms of the Reiki treatment provided; the 
study employed four different Reiki practitioners at level two and one Master level practitioner. Given that the sample comprised only five participants with varying chronic illnesses any therapeutic effects are not generalizable to any one particular chronic illness.

A recent study by Catlin and Taylor-Ford (2011) examined whether Reiki had an effect on the comfort and wellbeing of cancer patients receiving outpatient chemotherapy. Described by the authors as 'an experimental, double-blind, randomly assigned study' (Catlin and Taylor-Ford 2011: E124), 189 patients were assigned to one of three groups. The first group received a 20 minute Reiki intervention, the second group received placebo Reiki and the third group received usual care. Patients in the group who received Reiki and patients in the group who received placebo Reiki demonstrated increased comfort and wellbeing ( $\mathrm{p}=$ $<0.05)$. When the measures were divided into physical comfort and wellbeing and mental comfort and wellbeing, both the placebo Reiki group and the actual Reiki group showed an increase in mental comfort and wellbeing but not physical comfort or wellbeing. The group who received usual care did not demonstrate an improvement in either comfort or wellbeing. The authors state that 'the intervention that improved patient comfort and well-being may have been the attentive presence of a designated nurse at the bedside' (ibid; E218). This study was extremely well reported. The concepts of comfort and wellbeing are highly subjective, yet the authors are transparent in providing definitions that informed the study. There are also detailed descriptions of the treatment received by each group. The reliability and validity of the Reiki intervention was assured by a focus group of Reiki practitioners conducted prior to the study. The two instruments used to measure comfort and wellbeing (HTCQ and a Well-being Analogue Scale) are well described and their validity and reliability is accounted for by the authors. 


\section{Table 3.11: Summary of Evidence for the use of Reiki in other Illnesses and Conditions}

\begin{tabular}{|c|c|c|c|c|c|}
\hline $\begin{array}{l}\text { Author and } \\
\text { Country }\end{array}$ & $\begin{array}{l}\text { Aim / Purpose of the } \\
\text { Research }\end{array}$ & Study Design & $\begin{array}{l}\text { Participants, } \\
\text { Sample size, } \\
\text { Gender of Sample }\end{array}$ & Main Findings & Summary Evaluative Comments \\
\hline $\begin{array}{l}\text { Crawford et } \\
\text { al (2006) } \\
\text { USA }\end{array}$ & $\begin{array}{l}\text { To explore the efficacy of } \\
\text { using Reiki treatment to } \\
\text { improve memory and } \\
\text { behaviour deficiencies in } \\
\text { patients with mild cognitive } \\
\text { impairment or mild } \\
\text { Alzheimer's disease }\end{array}$ & $\begin{array}{l}\text { Randomised } \\
\text { controlled } \\
\text { trial }\end{array}$ & $\begin{array}{l}\text { Patients with mild } \\
\text { cognitive } \\
\text { impairment or mild } \\
\text { Alzheimer's } \\
\text { disease. } \\
\mathrm{N}=24 \\
16 \text { female } \\
8 \text { male }\end{array}$ & $\begin{array}{l}\text { Increased mental functioning and } \\
\text { memory behaviour problems in } \\
\text { participants receiving } 30 \text { minutes of } \\
\text { Reiki on a weekly basis. }\end{array}$ & $\begin{array}{l}\text { One of the strengths of this study is that it } \\
\text { provides an insight into potential } \\
\text { confounders that may affect the results of } \\
\text { Reiki research, namely that the } \\
\text { participants were familiar with Reiki. } \\
\text { The study had a small, but adequate } \\
\text { sample size and demonstrates an } \\
\text { occasional lack of detail. }\end{array}$ \\
\hline $\begin{array}{l}\text { Brewitt et al } \\
\text { (1997) } \\
\text { Country } \\
\text { unclear }\end{array}$ & $\begin{array}{l}\text { Explore if hands-on Reiki } \\
\text { improves health status of } \\
\text { patients with chronic illness as } \\
\text { evaluated by electro-dermal } \\
\text { screening }\end{array}$ & $\begin{array}{l}\text { Pre and Post- } \\
\text { test design }\end{array}$ & $\begin{array}{l}\text { Participants with } \\
\text { varying chronic } \\
\text { illnesses } \\
\mathrm{N}=5 \\
\text { Gender } \\
\text { composition of the } \\
\text { sample not } \\
\text { specified }\end{array}$ & $\begin{array}{l}\text { Three of } 40 \text { skin points showed } \\
\text { significant differences in measure after } \\
\text { the Reiki treatment and increased to the } \\
\text { 'normal' range. }\end{array}$ & $\begin{array}{l}\text { This study suffered from a small sample } \\
\text { (5) making it difficult to generalise the } \\
\text { results. Furthermore there was no } \\
\text { consistency in terms of the treatment } \\
\text { provider; the study used five different } \\
\text { Reiki Practitioners. } \\
\text { The measurement instrument is not a } \\
\text { standard medical instrument and the } \\
\text { authors present very little information on } \\
\text { it. }\end{array}$ \\
\hline $\begin{array}{l}\text { Catlin and } \\
\text { Taylor Ford } \\
\text { (2011) USA }\end{array}$ & $\begin{array}{l}\text { To determine whether } \\
\text { provision of Reiki therapy } \\
\text { during outpatient } \\
\text { chemotherapy is associated } \\
\text { with increased comfort and } \\
\text { well-being }\end{array}$ & $\begin{array}{l}\text { Randomised } \\
\text { controlled } \\
\text { trial }\end{array}$ & $\begin{array}{l}\text { Patients receiving } \\
\text { chemotherapy } \\
\mathrm{N}=189 \\
\text { Gender } \\
\text { composition of the } \\
\text { sample not } \\
\text { specified }\end{array}$ & $\begin{array}{l}\text { Patients receiving Reiki and patients } \\
\text { receiving placebo Reiki demonstrated } \\
\text { increased comfort and wellbeing ( } \mathrm{p}= \\
<0.05) \text {. Both the placebo Reiki group } \\
\text { and the actual Reiki group showed an } \\
\text { increase in mental comfort and } \\
\text { wellbeing but not physical comfort or } \\
\text { wellbeing. }\end{array}$ & $\begin{array}{l}\text { There are no apparent weaknesses to this } \\
\text { study. }\end{array}$ \\
\hline
\end{tabular}

NB: All Reiki was provided hands-on by a practitioner with the exception of Crawford et al (highlighted) where the mode of use was unclear 


\section{v. Benefits of Learning and Self-Use of Reiki}

This final section of the chapter reviews the empirical studies that have explored self-use of Reiki. This section is of particular importance to this thesis given that this is the focus of the research.

The benefits of learning Reiki and self-use of Reiki has been the focus of four studies. Two of the four studies included some quantitative measure of benefit (Brathovde 2006; Cuneo et al. 2011). Brathovde's study used the Caring Efficacy Scale to measure if nurses who learned Reiki level one would perceive changes in their ability to self care or care for others. The Caring Efficacy scale is described by the author as 'a reliable instrument of selfassurance in the ability of a caregiver to express and demonstrate a caring relationship, and have confidence in providing care without depleting the self' (Brathovde 2006:97). Cuneo et al. (2011) used the Perceived Stress Scale (PSS) to measure stress before and after undertaking Reiki level one training and cite the instrument as being reliable and valid (ibid 2011:35). In both these studies the quantitative data was supported with qualitative data. In contrast to these two studies, Vitale (2009) solely used interviews to explore the benefits Reiki practitioners gained through their self-use of Reiki as did Whelan and Wishnia (2003). This study is somewhat anomalous as it evaluates the benefits that nurses who practise Reiki on patients gain for themselves during a Reiki session rather than post-treatment. That is, the study participants were not themselves receiving Reiki from another person nor where they practising self use of Reiki.

Brathovde's (2006) pilot study sought to determine if the caring perceptions of healthcare providers would change as a result of being taught Reiki level one as a self-care practice. Despite a small sample $(n=10)$, the benefits were apparent. A statistically significant increase $(\mathrm{p}=0.028)$ was noted in participants response to a Caring Efficacy Scale after learning Reiki. Participants reported a sense of spirituality, increased self-care, feeling a healing presence and increased personal awareness after learning Reiki. A noteworthy feature of this study is that not all of the participants practised Reiki on themselves but since receiving their attunement many had noticed that they were taking better care of themselves in other ways. This is particularly interesting as it suggests evidence for it being the attunement rather than the act of giving Reiki to oneself that results in changes to self-care. 
The author also notes that for some participants lifestyle changes had occurred since learning Reiki and although they were hesitant about attributing the changes directly to learning Reiki they did not want to dismiss the changes as entirely coincidental.

Similarly, Vitale (2009) explored the lived experience of nurses who practise Reiki for selfcare. Some of the benefits of using Reiki for self-care as reported by the nurses in this study included stress management, the ability to achieve clarity of thought and to restore oneself to a tranquil and 'centred' state. Feelings of having a sense of connection with the self, others, and the universe and a sense of spirituality were also reported. This study was thoroughly conducted and the author demonstrated excellent reflexivity. The only apparent weakness to this study is that it did not draw upon a representative sample thus making generalisation problematic.

A recent study that focussed on Reiki self-use by Cuneo et al. (2011) found that self-use of Reiki helped to reduce perceived stress in nurses. The study aimed to 'assess the impact of Reiki education, training and practice on work related stress of the RN (Registered Nurse)' (Cuneo et al. 2011:35). The study reported on 26 nurses who attended an 8-hour Reiki level one training session. Within the training participants were taught how to self-treat and were provided with supplementary handouts. After the Reiki training, participants were asked to undertake 10 to 15 minutes of self Reiki daily for a period of 21 days. Measures of perceived stress were taken at baseline and after the 21-day intervention period using Cohen's Perceived Stress Scale (PSS). Participants were also requested to note down their experiences of Reiki self-treatment in a diary provided by the research team. Seventeen of the 26 participants provided follow-up data and a mean 5.9 point decrease in the PSS score was observed in the nurses. Comments from participants' diaries support this finding with participants frequently noting that they slept better / well / fell asleep; felt relaxed, calm and peaceful; felt warm / hot. This study was only based on a small sample and the authors note that the findings may not be generalisable to other nurses. However, the study is well reported and sufficient details are provided for the study to be replicated. The authors support their findings with quantitative data and qualitative data and the instrument used to measure stress is cited as being reliable and valid (ibid 2011:35). 
Whelan and Wishnia (2003) evaluated the benefits received by nurse / Reiki practitioners during a Reiki / client therapy session. Practitioner benefits included calmness, being more grounded, spiritual addition to their lives and gratitude in sharing. Their perception of potential benefits for clients related to help in the healing process, bringing relaxation and calmness and help in reducing pain. This was a small study with only eight participants and the research lacks firm conclusions. Nonetheless, it is the first study to explore benefits received by a nurse/Reiki practitioner.

\section{Summary of the Benefits of Using Reiki}

The review of the literature on the benefits of using Reiki indicated that research has been undertaken on the efficacy of using Reiki for a variety of illness and conditions. In relation to pain management the majority of studies suggest that Reiki when used for different types of pain has a beneficial effect. The majority of these studies are robust in their design and reporting although the majority include small samples (majority $=<25$ participants). Psychological conditions such as anxiety, depression and stress were the most commonly evaluated types of condition. Studies that have reported on the psychological benefits of Reiki have tended to demonstrate positive results. However, the evidence in this area needs to be approached with caution as the existing studies are marred by a range of problems predominantly relating to the measures used within the studies and the validity of these measures. The role of Reiki in helping patients recover from varying illnesses has also been studied with mixed results. Some evidence exists to support the use of Reiki in patients recovering from acute coronary syndrome and cancer patients who had recently completed chemotherapy. However, there was little evidence to suggest the use of Reiki in patients recovering from coronary artery bypass graft surgery or stroke. There was also evidence of beneficial effects of Reiki when used with patients with mild cognitive impairment or mild Alzheimer's disease, patients with chronic illnesses and patients receiving chemotherapy.

A small number of studies explored the benefits of learning and self-use of Reiki. Predominantly, this has been with nurses or healthcare providers. The reported benefits of learning and self use of Reiki included a sense of spirituality, increased self-care, feeling a healing presence, increased personal awareness, lifestyle changes, better stress management, 
the ability to achieve clarity of thought and the ability to restore oneself to a tranquil state after learning Reiki.

\section{Concluding Comments}

This chapter has demonstrating the breadth, variable quality and indicative, but limited, evidence of the potential benefits of Reiki. Most importantly, given the focus of the $\mathrm{PhD}$ on Reiki self-use, the literature review demonstrated the limited, though supportive, evidence base, on self-use of Reiki. The thesis now progresses to examine the core theoretical concept of the $\mathrm{PhD}$, health literacy. It does this by providing a critical overview of the conceptual literature on health literacy. 
Table 3.12: Summary of Evidence for the benefits of learning and self-use of Reiki

\begin{tabular}{|c|c|c|c|c|c|}
\hline $\begin{array}{l}\text { Author and } \\
\text { Country }\end{array}$ & $\begin{array}{l}\text { Aim / Purpose of the } \\
\text { Research }\end{array}$ & Study Design & $\begin{array}{l}\text { Participants, } \\
\text { Sample Size, } \\
\text { Gender of } \\
\text { Sample }\end{array}$ & Main Findings & $\begin{array}{l}\text { Summary Evaluative } \\
\text { Comments }\end{array}$ \\
\hline $\begin{array}{l}\text { Brathovde } \\
(2006) \\
\text { USA }\end{array}$ & $\begin{array}{l}\text { To determine if Reiki energy } \\
\text { therapy level one, was taught } \\
\text { as a self-care practice to } \\
\text { healthcare practitioners would } \\
\text { their caring perceptions } \\
\text { change? }\end{array}$ & Descriptive & $\begin{array}{l}\text { Nurses and } \\
\text { Healthcare } \\
\text { providers } \\
\mathrm{N}=10 \\
10 \text { female } \\
\end{array}$ & $\begin{array}{l}\text { Statistically significance increase }(\mathrm{p}=0.028) \text { was } \\
\text { noted in participants response to a caring efficacy } \\
\text { scale after learning Reiki. Participants reported a } \\
\text { sense of spirituality, increased self care, feeling a } \\
\text { healing presence and increased personal } \\
\text { awareness after learning Reiki }\end{array}$ & $\begin{array}{l}\text { A small but roust study } \\
\text { There are no significant } \\
\text { weaknesses } t \text { this study }\end{array}$ \\
\hline $\begin{array}{l}\text { Whelan and } \\
\text { Wishnia } \\
\text { (2003) } \\
\text { USA }\end{array}$ & $\begin{array}{l}\text { To evaluate how nurses who } \\
\text { give Reiki therapy perceived } \\
\text { the benefit of this therapy on } \\
\text { themselves concurrently as } \\
\text { providers of the therapy }\end{array}$ & $\begin{array}{l}\text { Phenomenological } \\
\text { study }\end{array}$ & $\begin{array}{l}\text { Nurses who were } \\
\text { also Reiki } \\
\text { practitioners } \\
\mathrm{N}=8 \\
8 \text { female } \\
\end{array}$ & $\begin{array}{l}\text { Practitioner benefits included calmness, being } \\
\text { more grounded, spiritual addition to their lives } \\
\text { and gratitude in sharing. Potential benefits for } \\
\text { clients related to help in the healing process, } \\
\text { bringing relaxation and calmness and help in } \\
\text { reducing pain }\end{array}$ & $\begin{array}{l}\text { This was a small study with } \\
\text { only eight participants and } \\
\text { the research lacks firm } \\
\text { conclusions. }\end{array}$ \\
\hline $\begin{array}{l}\text { Vitale } \\
(2009) \\
\text { USA }\end{array}$ & $\begin{array}{l}\text { To explore the lived } \\
\text { experience of nurses who } \\
\text { practice Reiki for self-care }\end{array}$ & $\begin{array}{l}\text { Phenomenological } \\
\text { study }\end{array}$ & $\begin{array}{l}\text { Nurses who } \\
\text { practiced Reiki } \\
\text { for self-care } \\
\mathrm{N}=11 \\
11 \text { female } \\
\end{array}$ & $\begin{array}{l}\text { Benefits of using Reiki for self-care included } \\
\text { stress management, the ability to achieve clarity } \\
\text { of thought and to restore oneself to a tranquil and } \\
\text { 'centred' state. Feelings of having a sense of } \\
\text { connection with the self, others, and the universe } \\
\text { and a sense of spirituality were also reported }\end{array}$ & $\begin{array}{l}\text { A thoroughly conducted } \\
\text { study with the only } \\
\text { apparent weakness being } \\
\text { that it did not draw upon a } \\
\text { representative. }\end{array}$ \\
\hline $\begin{array}{l}\text { Cuneo } \text { et } \\
\text { al .(2011) } \\
\text { USA }\end{array}$ & $\begin{array}{l}\text { To assess the impact of Reiki } \\
\text { education, training, and } \\
\text { practice of work related stress } \\
\text { of the registered nurse }\end{array}$ & $\begin{array}{l}\text { Pre and Post-test } \\
\text { design }\end{array}$ & $\begin{array}{l}\text { Nurses } \\
\mathrm{N}=26 \\
\\
24 \text { female } \\
2 \text { male }\end{array}$ & $\begin{array}{l}\text { Statistically significant decrease in perceived } \\
\text { stress }(\mathrm{p}=.0063) \text {. Participants reported that they } \\
\text { slept better / well / fell asleep; felt relaxed, calm } \\
\text { and peaceful; felt warm / hot. }\end{array}$ & $\begin{array}{l}\text { The authors note that the } \\
\text { findings of this studymay } \\
\text { not be generalisable to } \\
\text { other nurses. }\end{array}$ \\
\hline
\end{tabular}

NB: Reiki was administered hands on in all studies. 


\section{Chapter Four: Conceptualising Health Literacy}

\section{Introduction}

This chapter provides a critical overview of the conceptual literature on health literacy. The rationale for the focus on this literature is provided first and the methods for selecting material to include in this chapter are explained. The clinical approach and the public health approach to defining and conceptualising health literacy are then explored in turn. One threelevelled approach to conceptualising health literacy (Nutbeam 2000) is then explained in detail and the rationale is provided as to why this approach to conceptualising health literacy was used as the underpinning theoretical framework within this $\mathrm{PhD}$ research.

\section{Rationale and Methods of Identifying the Literature}

The decision was taken to undertake a conceptual review of the health literacy literature due to the centrality of the concept to this thesis. A conceptual review 'aims to synthesise areas of conceptual knowledge that contribute to a better understanding of the issues' (Jesson, Matheson and Lacey 2011:15). This conceptual review of the health literacy literature therefore serves as an appropriate introduction to the concept. Furthermore the research question (how does learning and self-use of Reiki enhance health literacy?) and the fourth objective of the research (to confirm and refine the Reiki health literacy model) suggested the need to explicate how health literacy is defined and conceptualised. Beyond the conceptual literature there is a growing body of research / writing on other aspects of health literacy that is not critically reviewed here. For example, Paasche-Orlow and Wolf (2007) have identified the causal pathways linking health literacy to health outcomes. The measurement of health literacy has been explored by Ishikawa et al. (2008) and Baker (2006) and different types of health literacy have been proposed. For example, public health literacy by Freedman et al. (2009) and mental health literacy by Jorm (2000). Each of the latter draws out key features of health literacy relevant to the particular domain, that is, public health and mental health.

Key authors and texts referred to in this chapter were recommended by two researchers with knowledge and insight into the field of health literacy. All recommended papers were read and where appropriate citation tracking was undertaken. In total, 19 papers informed this conceptual review. These are listed in date order in figure 4.1 (below). The aim of each 
paper is stated to provide the reader with an indication of the area of health literacy addressed. The figure illustrates the expanding interest in health literacy with the majority of papers published after 2005. 


\section{Figure 4.1: Health Literacy Papers Included in the Conceptual Review}

\begin{tabular}{|c|c|c|}
\hline Author and Date & Title & Aims \\
\hline Williams et al. (1995) & $\begin{array}{l}\text { Inadequate Functional Health Literacy among } \\
\text { Patients at two Public Hospitals }\end{array}$ & $\begin{array}{l}\text { To report on a study to determine the ability of patients to complete successfully } \\
\text { basic reading and numeracy tasks to function adequately in the health care setting. }\end{array}$ \\
\hline $\begin{array}{l}\text { Ad Hoc Committee on Health } \\
\text { Literacy for the Council on } \\
\text { Scientific Affairs (1999) }\end{array}$ & $\begin{array}{l}\text { Health Literacy: Report of the Council on } \\
\text { Scientific Affairs }\end{array}$ & $\begin{array}{l}\text { To examine the scope and consequences of poor health literacy in the United States, } \\
\text { characterise its implications for patients and physicians, and identify policy and } \\
\text { research issues. }\end{array}$ \\
\hline Nutbeam (2000) & $\begin{array}{l}\text { Health Literacy as a Public Health Goal: A } \\
\text { Challenge for Contemporary Health Education and } \\
\text { Communication Strategies into the } 21 \text { st Century. }\end{array}$ & $\begin{array}{l}\text { To identify the failings of past educational programmes to address social and } \\
\text { economic determinants of health and trace the subsequent reduction in the role of } \\
\text { health education in addressing the social determinants of health }\end{array}$ \\
\hline Ratzan and Parker (2000) & $\begin{array}{l}\text { Current Bibliographies in Medicine: Health } \\
\text { Literacy }\end{array}$ & Part of the current bibliographies in medicine series. \\
\hline Kickbusch (2001) & $\begin{array}{l}\text { Health Literacy: Addressing The Health And } \\
\text { Education Divide }\end{array}$ & $\begin{array}{l}\text { To review concepts and definitions of literacy and health literacy and raise } \\
\text { conceptual, measurement and strategic challenges. }\end{array}$ \\
\hline Tones (2002) & Health Literacy: New Wine in Old Bottles. & $\begin{array}{l}\text { To explore definitions and conceptualisations of health literacy and question the } \\
\text { justification for extending basic definitions. }\end{array}$ \\
\hline $\begin{array}{l}\text { Nielsen-Bohlman and Institute } \\
\text { of Medicine . Committee on } \\
\text { Health (2004) }\end{array}$ & Health literacy: A Prescription to End Confusion. & $\begin{array}{l}\text { To explore what is known about the epidemiology of limited health literacy and } \\
\text { promising approaches for increasing health literacy. To offer a conceptual framework } \\
\text { for thinking about how society, culture, and the health and education systems } \\
\text { contribute to the problem and to possible solutions. }\end{array}$ \\
\hline Rootman and Ronson (2005) & $\begin{array}{l}\text { Health literacy and Health Research in Canada. } \\
\text { Where have we been and where should we go? }\end{array}$ & $\begin{array}{l}\text { To review current literature and research on literacy and health and identify priorities } \\
\text { for research on this topic in Canada. }\end{array}$ \\
\hline $\begin{array}{l}\text { Zarcadoolas, Pleasant and } \\
\text { Greer (2005) }\end{array}$ & $\begin{array}{l}\text { Understanding Health literacy: An Expanded } \\
\text { Model. }\end{array}$ & $\begin{array}{l}\text { To propose an expanded model of health literacy characterized by four domains: } \\
\text { fundamental literacy (reading, writing, speaking and numeracy), science literacy, } \\
\text { civic literacy and cultural literacy. }\end{array}$ \\
\hline Coulter et al. (2006) & $\begin{array}{l}\text { Patient-focused Interventions: A Review Of The } \\
\text { Evidence }\end{array}$ & $\begin{array}{l}\text { To produce an overview of the research evidence on the effectiveness of patient- } \\
\text { focused interventions. }\end{array}$ \\
\hline
\end{tabular}




\begin{tabular}{|c|c|c|}
\hline $\begin{array}{l}\text { Paasche-Orlow and Wolf } \\
\text { (2007) }\end{array}$ & $\begin{array}{l}\text { The Causal Pathways Linking Health Literacy to } \\
\text { Health Outcomes }\end{array}$ & $\begin{array}{l}\text { To provide an evidence based review of plausible causal pathways that could best } \\
\text { explain well-established associations between limited health literacy and health } \\
\text { outcomes. }\end{array}$ \\
\hline Ishikawa et al. (2008) & $\begin{array}{l}\text { Developing a Measure of Communicative and } \\
\text { Critical Health Literacy: A Pilot Study of Japanese } \\
\text { Office Workers }\end{array}$ & $\begin{array}{l}\text { To report on a study aimed to examine the psychometric properties of a brief measure } \\
\text { to assess major components of communicative and critical health literacy among } \\
\text { Japanese office workers. }\end{array}$ \\
\hline Nutbeam (2008) & The Evolving Concept of Health Literacy. & $\begin{array}{l}\text { To describe the two distinctive concepts that reflect health literacy, respectively, as a } \\
\text { clinical "risk", or a personal "asset". }\end{array}$ \\
\hline Pleasant and Kuruvilla (2008) & $\begin{array}{l}\text { A Tale of Two Health Literacies: Public Health } \\
\text { and Clinical Approaches to Health Literacy }\end{array}$ & To test a public health literacy knowledge scale. \\
\hline Freedman et al. (2009) & Public Health Literacy Defined & To outline a broad, new definition of public health literacy. \\
\hline Peerson and Saunders (2009) & $\begin{array}{l}\text { Health Literacy Revisited: What Do We Mean And } \\
\text { Why Does It Matter? }\end{array}$ & $\begin{array}{l}\text { To consider various definitions and measurements of health literacy in the } \\
\text { international and Australian literature, and discuss the distinction between the broader } \\
\text { concept of 'health literacy 'and 'medical literacy'. }\end{array}$ \\
\hline $\begin{array}{l}\text { Protheroe, Nutbeam and } \\
\text { Rowlands (2009) }\end{array}$ & $\begin{array}{l}\text { Health literacy: A Necessity For Increasing } \\
\text { Participation In Health Care }\end{array}$ & To discuss poor health literacy as a barrier to participation in health care. \\
\hline Berkman et al. (2011) & $\begin{array}{l}\text { Health Literacy Interventions and Outcomes: An } \\
\text { Updated Systematic Review }\end{array}$ & $\begin{array}{l}\text { To update a } 2004 \text { systematic review of health care service use and health outcomes } \\
\text { related to differences in health literacy level and interventions designed to improve } \\
\text { these outcomes for individuals with low health literacy. }\end{array}$ \\
\hline Chinn (2011) & $\begin{array}{l}\text { Critical Health Literacy: A Review and Critical } \\
\text { Analysis }\end{array}$ & $\begin{array}{l}\text { To examine the concept of "critical health literacy" in the context of the ever- } \\
\text { expanding corpus of research into health literacy. }\end{array}$ \\
\hline Sørensen et al. (2012) & $\begin{array}{l}\text { Health Literacy And Public Health: A Systematic } \\
\text { Review and Integration of Definitions and Models }\end{array}$ & $\begin{array}{l}\text { To systematically review existing definitions and conceptual frameworks of health } \\
\text { literacy. }\end{array}$ \\
\hline
\end{tabular}




\section{Defining and Conceptualising Health Literacy}

Nutbeam (2008) notes that the term 'health literacy' arose out of an interest in the established relationship between low levels of literacy and poor health. Health literacy is characterised by different approaches to the definition and use of the term (Kickbusch 2001; Rootman and Ronson 2005; Zarcadoolas, Pleasant and Greer 2005; Nutbeam 2008). Indeed, a recent systematic review of the definitions and conceptualisations of health literacy identified 17 definitions and 12 conceptual models (Sørensen et al. 2012). That said, two approaches to defining and conceptualising health literacy are prominent within the literature: the clinical approach and the public health approach both of which are now explored.

\section{i. The Clinical Approach to Health Literacy}

There are four defining features of a clinical approach to health literacy: emphasis on the use of functional literacy skills; emphasis on the individual (as opposed to the healthcare provider or wider society); focus on the clinical environment; and a construction of the individual as passive. These defining features are now discussed in turn.

Clinical approaches to defining health literacy tend to focus on the application of functional literacy skills such as reading, writing and understanding within the clinical environment. An early example of a definition that illustrates this is provided by Williams et al. (1995) that makes reference to reading labels on prescription bottles, completing health insurance forms and following instructions for diagnostic tests:

The ability of patients to perform basic reading tasks required to function in the healthcare environment, such as reading labels on prescription bottles, understanding information on appointment slips, completing health insurance forms and following instructions pertaining to diagnostic tests (1995:1677).

Another early example of a clinical approach to defining health literacy that draws attention to the use of functional literacy skills within the clinical environment is that used by the Ad Hoc Committee on Health Literacy for the Council on Scientific Affairs (1999). Similar to 
the above definition, the American Medical Association definition also refers to reading and comprehension but, in contrast, omits reference to writing;

The ability to read and comprehend prescription bottles, appointment slips, and the other essential health related materials required to successfully function as a patient (Ad Hoc Committee on Health Literacy for the Council on Scientific Affairs 1999:552)

In addition to drawing attention to the use of functional literacy skills in the clinical environment, the above two definitions also have in common another key feature of clinically oriented definitions of health literacy - emphasis on the patient or individual as having the main influence over, and responsibility for, making decisions about their own health. This is exemplified in the definition of health literacy below by Ratzan and Parker (2000):

The degree to which individuals can obtain, process, and understand the basic health information and services they need to make appropriate health decisions

(Ratzan and Parker 2000 vi)

This definition is one that has endured over the years. It was used by the Institute of Medicine (IOM) in their 2004 report Health Literacy: A Prescription to End Confusion and in a recent systematic review of health literacy interventions and outcomes (Berkman et al. 2011).

What is absent from the above three definitions is any reference to the role of the healthcare provider, the healthcare system or wider society as having any influence over health. Clinical approaches to defining health literacy are referred to thus because they bear reference to the individual within clinical situations. This rather assumes that health-related issues arise and are dealt with solely between the healthcare provider and the patient in a clinical environment. No consideration is given to other locations in which an individual might make health-related decisions, for example at home or the role of friends and family in health and illness decisions. This focus on the clinical environment is, in many ways, a reflection of the 
fact that the goal of conceptualising health literacy in this way was to ensure that patients adhered to treatment and complied with the advice of healthcare providers. As noted by Pleasant and Kuruvilla (2008), this approach to health literacy was intended to 'help physicians better communicate their prescriptions and to help patients better understand and comply with treatment regimens' (152).

One final characteristic of clinical approaches to defining health literacy is that the patient is typically constructed as passive: either 'having' or 'not having' the ability to function as a patient, the ability to comply with treatment regimens or to make appropriate health decisions; in other words, as either 'having' or 'not having' adequate health literacy. Furthermore, not possessing adequate health literacy to function as a patient is viewed as problematic from a clinical perspective. Pleasant and Kuruvilla (2008) argue that health literacy in a clinical context 'tends to characterise health literacy as a problem that patients have and physicians need to overcome' (Pleasant and Kuruvilla 2008:152). Similarly, Nutbeam has observed that within a clinical context 'poor literacy skills are seen as a potential risk factor that needs to be managed in the process of providing clinical care' (Nutbeam 2008:2073). This Nutbeam suggests emanated from 'concerns about the impact of low literacy on patient involvement in shared decision making, and effective self-care' (Nutbeam 2010).

\section{ii. The Public Health Approach to Health Literacy}

Definitions and conceptualisations of health literacy that arise from a public health approach are broader than those arising from a clinical approach (Nutbeam 2000; Rootman and Ronson 2005; Zarcadoolas, Pleasant and Greer 2005). Five defining features of a public health approach to health literacy can be identified: they highlight that health literacy is concerned with maintaining good health as well as dealing with ill health; they emphasise that health literacy is used outside of the clinical environment as well as within it; definitions encompass a broader range of skills in comparison to definitions based on a clinical approach; health literacy is associated with empowerment; and they explicate a connection between health promotion and health literacy. These defining features are now discussed in turn. 
Firstly, within a public health approach to health literacy, the context in which health literacy is used extends beyond the use of functional literacy skills within a clinical environment to include consideration of how literacy and other skills are also applied in everyday life and in the community more generally. Examples include having the knowledge to make healthy choices when buying food, reducing the amount of salt in cooking, and walking to work rather than driving or taking public transport. Implicit in this is an acknowledgement that health literacy is as much about keeping well as it is about dealing with ill health. Peerson and Saunders (2009:287) for example, has noted how clinically oriented definitions of health literacy fail to account for 'the many health related decisions that people make in the context of 'keeping well' in everyday life, rather than managing illnesses and conditions'.

Kickbusch and Magg (2008) emphasise a common theme amongst public health approaches to health literacy, that is, their assertion that health literacy is drawn upon outside of the clinical environment;

Health literacy is the ability to make sound health decision in the context of every day life - at home, in the community, at the workplace, the health care system, the market place and the political arena. It is a critical empowerment strategy to increase people's control over their health, their ability to seek out information and their ability to take responsibility.

(Kickbusch I and Maag D 2008:206)

Public health approaches to health literacy further differ from clinical approaches in the skills that are included in the concept. Whilst definitions of health literacy based on a clinical approach tend to focus solely upon the use of literacy skills, conceptualisations based on a public health approach encompass a broader range of additional skills;

Health literacy represents the cognitive and social skills which determine the motivation and ability of individuals to gain access to, understand and use information in ways which promote and maintain good health. [...] Health literacy 
means more than being able to read pamphlets and successfully make appointments. By improving people's access to health information and their capacity to use it effectively, health literacy is critical to empowerment.

(Nutbeam 2008:357)

Thus from the perspective of public health, health literacy is more complex than simply applying literacy skills in a clinical environment. The concept represents a myriad of skills and competencies, both cognitive and social, which are drawn on within the clinical environment and in everyday life.

The above definitions of health literacy provided by Kickbusch and Magg (2006) and Nutbeam (2008) also have in common the suggestion that health literacy is associated with empowerment. From a public health perspective, possessing a good level of health literacy is a means of enabling individuals to exert control over their health, to maintain health and take responsibility for health. As suggested by Nutbeam (2008) health literacy may be viewed as an 'asset', as something that can be developed as opposed to 'a potential risk factor that needs to be managed' (Nutbeam 2008:2073). Unlike the clinical approach to health literacy the notion of empowerment included within the public health approach inherently constructs the individual as 'active' as opposed to 'passive'.

Finally, public health approaches to health literacy acknowledge a connection between health literacy and health promotion (Pleasant and Kuruvilla 2008). Nutbeam (2008) further argues that health literacy can be viewed as an outcome of health promotion thus implying that health literacy is not a fixed concept but something that can be subject to influence by health education and communication. This idea contrasts markedly to the clinical approach whereby health literacy is represented by the dichotomy of 'having' or 'not having' adequate health literacy skills. Constructing health literacy as a fixed concept is problematic because it does not include scope for differing levels of health literacy and furthermore it does not suggest the possibility that an individual may change or enhance their health literacy. 


\section{iii. Nutbeam's Model of Health Literacy}

Reflecting the multi-dimensionality of health literacy from a public health perspective, Nutbeam (2000) has proposed a three-levelled model of health literacy which is summarised in figure 4.2 (below). Nutbeam (2000) has described broadly what each level of health literacy enables an individual to do however he does not specify the exact skills or competencies that are associated with each level.

\section{Figure 4.2: Nutbeams Model of Health Literacy}

\begin{tabular}{|l|l|}
\hline Basic/functional health literacy & $\begin{array}{l}\text { Sufficient basic skills in reading and writing to be } \\
\text { able to function effectively in everyday situations. }\end{array}$ \\
\hline literacy & $\begin{array}{l}\text { More advanced cognitive and literacy skills which, } \\
\text { together with social skills, can be used to actively } \\
\text { participate in everyday activities, to extract } \\
\text { information and derive meaning from different } \\
\text { forms of communication, and to apply new } \\
\text { information to changing circumstances. }\end{array}$ \\
\hline Critical health literacy & $\begin{array}{l}\text { More advanced cognitive skills which, together with } \\
\text { social skills, can be applied to critically analyse } \\
\text { information, and to use this information to exert } \\
\text { greater control over life events and situations. }\end{array}$ \\
\hline
\end{tabular}

(Nutbeam 2000: 263 - 264)

Nutbeam suggests that each level of health literacy represents 'greater autonomy and personal empowerment in decision making, as well as engagement in a wider range of health actions that extend from personal behaviours to social action to address the determinants of health' (Nutbeam 2008: 2075).

This model of health literacy has been used within this research as the underpinning theoretical framework. Choosing to base the model of Reiki health literacy on this model of health literacy was based on two particular features of the public health perspective that were considered to complement a Reiki philosophy. Firstly, the author (HG) is in agreement with 
Peerson and Saunders (2009) who draw attention to the fact that health literacy is as much about 'keeping well' in everyday life as it is about managing illness. Public health conceptualisations of health literacy reflect this by identifying a broad spectrum of contexts in which an individual might use their health literacy skills and knowledge. Whilst Reiki and Reiki health literacy can be used within a clinical environment, Reiki is frequently used outside of the clinical environment in everyday life, for example, self-use to prevent illness and maintain health. Secondly, the inclusion of notions such as empowerment and choice are consistent with the underlying philosophy of many complementary therapies including Reiki (Barrett et al. 2003; Long 2009). In selecting this particular model rather than others that are informed by a public health perspective (Zarcadoolas, Pleasant and Greer 2005; PaascheOrlow and Wolf 2007), it was felt that the three levels suggest that health literacy is not fixed but may be influenced by health education or intervention and potentially Reiki training and subsequent self-use. Furthermore Nutbeam's model is one of the most influential in the field. It is used worldwide and continues to be used in research (the extent of which can be viewed in chapter 4, figure 4.1) and policy.

\section{Concluding Comments}

The two prominent approaches to defining and conceptualising health literacy: clinical and public health have been explored in this chapter. Nutbeam's model of health literacy is an example of a public health approach to conceptualising health literacy and this model underpins the research presented in this thesis. The following chapter considers how the concept of health literacy might be applied within the context of Reiki and presents a model of Reiki health literacy informed by Nutbeam's model of health literacy. 


\section{Chapter Five: Developing a Model of Reiki Health Literacy}

\section{Introduction}

This chapter builds on Chapters Two and Three with the aim of considering how the concept of health literacy might be applied in the context of Reiki. The three-step process involved in developing the initial model of Reiki health literacy is described. This includes a discussion of the pre-reading, a discussion of the development of the content of each level of Reiki health literacy and a discussion of the development of the benefits of each level of Reiki health literacy. Finally, the initial model of Reiki health literacy is presented.

\section{Reiki and Health Literacy}

Pleasant and Kuruvilla (2008) have suggested that health literacy is associated with improving health and reducing inequalities in health. This, in combination with Nutbeam's (2008) suggestion that higher levels of health literacy are associated with personal empowerment, makes a compelling case for health professionals to seek out means of enhancing the health literacy of the population. Silenzio (2002) has suggested that ' $C A M$ may represent a substantial and largely untapped resource base' (2002:1562) when it comes to the health and well-being of the public. Two salient features of Reiki practice theoretically suggest its potential as a complementary modality to enhance health literacy: Reiki can easily be learned by anyone regardless of gender, ethnicity, health status or literacy levels and its emphasis on taking responsibility for one's own health through regular self-use. However, with the exception of Long's (2009) work on shiatsu and critical health literacy, the fields of CAM and health literacy have, to date, not merged.

\section{Process of Developing the Model of Reiki Health Literacy}

Prior to the empirical phase of this research, it was important to consider what health literacy might entail in the context of Reiki. To explore this, a model of the skills and knowledge that may comprise Reiki health literacy was constructed. This was a three-step process and each step is now described. 


\section{i. $\quad$ Preliminary Reading}

The mapping and review of the Reiki literature (Chapter Two) and the conceptual review of health literacy (Chapter Three) informed the thinking behind the development of the initial Reiki health literacy model. This work had been completed prior to constructing the model and therefore may be considered as part of the preliminary reading.

Having decided to use the Nutbeam model to underpin this research, a search was undertaken using MEDLINE and internet search engines (for example, Google Scholar) to identify studies that had also used the model. The aim was to examine how other authors had used Nutbeam's model in different health contexts and for different health conditions, specifically to identify the skills, knowledge and competencies that they had included in each level of health literacy.

Nine pieces of empirical research were identified. These were read and Figure 5.1 (below) was compiled. Figure 5.1 lists, in date order of publication, the author of each paper followed by a corresponding column that describes the context of the research (that is, the context in which the author (s) have used Nutbeam's framework). A further three columns comprise the skills and competencies that each author identified as being indicative of functional, interactive or critical health literacy. Some authors were specific in their identification of the skills that comprise each level of health literacy, for example, reading instructions or leaflets from hospitals (Ishikawa, Takeuchi and Yano 2008). Other authors identify the type of material or activity that could be used to enhance each level of health literacy, for example, traditional health education or, community based development programmes (Coulter et al. 2006). 
Figure 5.1: Interpretations of Nutbeam's levels of Health Literacy

\begin{tabular}{|c|c|c|c|c|}
\hline \multicolumn{5}{|c|}{ Interpretation of Skills Knowledge or Competencies } \\
\hline & & Functional & Interactive & Critical \\
\hline Author & Context & & & \\
\hline St Leger (2001) & $\begin{array}{l}\text { This paper examines } \\
\text { the role schools could } \\
\text { play in facilitating the } \\
\text { achievement of health } \\
\text { literacy as a public } \\
\text { health goal. It briefly } \\
\text { explores the } \\
\text { possibilities of schools } \\
\text { addressing and } \\
\text { achieving Nutbeam's } \\
\text { three levels of health } \\
\text { literacy. }\end{array}$ & $\begin{array}{l}\text { Transmission of basic } \\
\text { information about: } \\
\text { hygiene - nutrition - } \\
\text { safety - drugs - } \\
\text { relationships - sexuality - } \\
\text { parenthood } \\
\text { Example activity: } \\
\text { Classroom-based lessons } \\
\text { Reading books and leaflets }\end{array}$ & 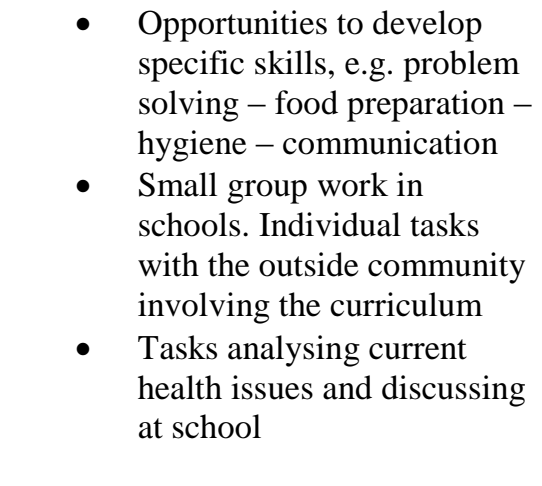 & $\begin{array}{l}\text { Classroom and community learning } \\
\text { opportunities which address social } \\
\text { inequities, determinants of health, } \\
\text { policy development and ways of } \\
\text { affecting change } \\
\text { Involvement in school-community } \\
\text { issues which students have chosen } \\
\text { and which confront current policies } \\
\text { and practices }\end{array}$ \\
\hline $\begin{array}{l}\text { Coulter } \text { et al. } \\
(2006)\end{array}$ & $\begin{array}{l}\text { This paper provides an } \\
\text { overview of the } \\
\text { research evidence on } \\
\text { the effectiveness of } \\
\text { patient - focussed } \\
\text { interventions. }\end{array}$ & $\begin{array}{l}\text { Examples of functional health } \\
\text { literacy activities } \\
\text { - Patient information leaflets } \\
\text { - Traditional health } \\
\text { education }\end{array}$ & $\begin{array}{l}\text { Examples of interactive health } \\
\text { literacy activities } \\
\text { - School health education } \\
\text { programmes }\end{array}$ & $\begin{array}{l}\text { Examples of critical health literacy activities } \\
\text { - Community-based development } \\
\text { programmes }\end{array}$ \\
\hline $\begin{array}{l}\text { Donelle and } \\
\text { Hoffman-Goetz } \\
\text { (2008a) }\end{array}$ & $\begin{array}{l}\text { This paper reports on } \\
\text { an investigation that } \\
\text { analysed health- } \\
\text { oriented Aboriginal } \\
\text { internet discussion } \\
\text { forum conversations. } \\
\text { The findings were } \\
\text { framed within } \\
\text { Nutbeam's model of } \\
\text { health literacy. }\end{array}$ & $\begin{array}{l}\text { Examples of posts in forums } \\
\text { reflecting functional health literacy; } \\
\text { - } \quad \text { Dissemination of } \\
\text { information } \\
\text { - Health news bulletins } \\
\text { (warnings etc) } \\
\text { - Recent research findings }\end{array}$ & $\begin{array}{l}\text { Examples of posts in forums } \\
\text { reflecting interactive health literacy; } \\
\text { - } \quad \text { Development of virtual } \\
\text { community } \\
\text { - } \quad \text { Virtual social support, self- } \\
\text { help e.g. the virtual } \\
\text { smoking cessation self-help } \\
\text { group } \\
\text { - Lifestyle coaching } \\
\text { - Tailored information }\end{array}$ & $\begin{array}{l}\text { Examples of posts in forums reflecting critical } \\
\text { health literacy } \\
\text { - Postings on the scope of health care } \\
\text { and healthcare services. } \\
\text { - Native health care traditions } \\
\text { - Aboriginal/government health care } \\
\text { negotiations } \\
\text { - Health issues of contention between } \\
\text { - Aboriginal and government leaders } \\
\text { Aboriginal health care philosophy }\end{array}$ \\
\hline
\end{tabular}




\begin{tabular}{|c|c|c|c|c|}
\hline $\begin{array}{l}\text { Donelle and } \\
\text { Hoffman-Goetz } \\
\text { (2008b) }\end{array}$ & $\begin{array}{l}\text { This pilot study } \\
\text { examined the use of } \\
\text { online chat rooms as a } \\
\text { potential health } \\
\text { promotion resource for } \\
\text { women of colour. } \\
\text { A codebook using } \\
\text { categories from } \\
\text { Nutbeam's health } \\
\text { literacy framework was } \\
\text { developed to guide the } \\
\text { directed content } \\
\text { analysis }\end{array}$ & $\begin{array}{l}\text { Examples of "factual health } \\
\text { information," information about } \\
\text { "health risks" and information } \\
\text { about "health services" and } \\
\text { "accessibility" of services } \\
\text { Examples include postings on; } \\
\text { - } \quad \text { specialised information } \\
\text { and services aimed at } \\
\text { individuals with personally } \\
\text { sensitive health issues, } \\
\text { such as sexually } \\
\text { transmitted diseases } \\
\text { - Nutrition and exercise. } \\
\text { - Information about dietary } \\
\text { salt reduction, healthy } \\
\text { dietary habits } \\
\text { Strategies to incorporate } \\
\text { physical activity into daily } \\
\text { life routines were included } \\
\text { in the online postings. }\end{array}$ & $\begin{array}{l}\text { Evidence of the terms } \\
\text { "encouragement," "social } \\
\text { interaction," "motivation," and "self } \\
\text { efficacy"/"self satisfaction". } \\
\text { Interactive health literacy was } \\
\text { evidenced as encouragement and } \\
\text { emotional support from other chat } \\
\text { room members. } \\
\text { The participants offered support to } \\
\text { each other through: } \\
\text { (1) spiritual expressions, } \\
\text { (2) Verbal encouragement } \\
\text { (3) Problem solving/goal } \\
\text { setting around health issues. }\end{array}$ & $\begin{array}{l}\text { Instances of "advocacy," "adversarial health } \\
\text { information," "determinants of health," and } \\
\text { "critical analysis" regarding a health issue or } \\
\text { concern. } \\
\text { Examples include postings on; } \\
\text { - Challenging readers to consider how } \\
\text { economic profitability influences } \\
\text { research and treatment of breast } \\
\text { cancer in the healthcare industry. } \\
\text { Political advocacy skills through the } \\
\text { use of an online petition. }\end{array}$ \\
\hline $\begin{array}{l}\text { Ishikawa and } \\
\text { Yano (2008) }\end{array}$ & $\begin{array}{l}\text { This paper provides a } \\
\text { literature review of } \\
\text { existing definitions and } \\
\text { measures of health } \\
\text { literacy }\end{array}$ & $\begin{array}{l}\text { From reviewing the findings of } \\
\text { various studies, skills associated } \\
\text { with Functional appear to be; } \\
\text { - Information seeking (e.g. } \\
\text { using physician as main } \\
\text { source of health } \\
\text { information rather than } \\
\text { other health care } \\
\text { providers) } \\
\text { Decision making (e.g. } \\
\text { likelihood of participating } \\
\text { in decision making. Low } \\
\text { functional health literacy } \\
\text { might be associated with }\end{array}$ & $\begin{array}{l}\text { Skills associated with Interactive } \\
\text { appear to be; } \\
\text { - Finding information before } \\
\text { consulting a healthcare } \\
\text { provider and applying } \\
\text { information to personal } \\
\text { concerns } \\
\text { - Identifying the best sources } \\
\text { of information, } \\
\text { - The ability to seek } \\
\text { personally adapted } \\
\text { information from a medical } \\
\text { team, } \\
\text { - The application of }\end{array}$ & $\begin{array}{l}\text { Skills associated with Critical appear to be; } \\
\text { - Judging the credibility of information } \\
\text { on a website and managing the } \\
\text { volume of information } \\
\text { - The ability to assess the quality of } \\
\text { information critically and to apply it } \\
\text { in various situations }\end{array}$ \\
\hline
\end{tabular}




\begin{tabular}{|c|c|c|c|c|}
\hline & & $\begin{array}{l}\text { letting family and friends } \\
\text { or healthcare providers } \\
\text { make final decisions on } \\
\text { their behalf) } \\
\text { - Health-care service use } \\
\text { (e.g. higher hospitalization } \\
\text { less use of preventative } \\
\text { services such as cancer } \\
\text { screening programs) } \\
\text { The functional use of basic } \\
\text { information and } \\
\text { understanding the } \\
\text { importance of self-care }\end{array}$ & knowledge on a daily basis & \\
\hline $\begin{array}{l}\text { Ishikawa, } \\
\text { Takeuchi and } \\
\text { Yano (2008) }\end{array}$ & $\begin{array}{l}\text { Measuring functional, } \\
\text { communicative, and } \\
\text { critical health literacy } \\
\text { in patients with } \\
\text { diabetes. }\end{array}$ & $\begin{array}{l}\text { Scale assessed the extent to which } \\
\text { patients had experienced difficulties } \\
\text { in reading the instructions or } \\
\text { leaflets from hospitals and } \\
\text { pharmacies } \\
\text { In reading instructions or leaflets } \\
\text { from hospitals/pharmacies, you. . } \\
\text { - Found that the print was } \\
\text { too small to read. } \\
\text { Found characters and } \\
\text { words that you did not } \\
\text { know. } \\
\text { Found that the content was } \\
\text { too difficult. } \\
\text { needed a long time to read } \\
\text { and understand them } \\
\text { Needed someone to help } \\
\text { you read them. }\end{array}$ & $\begin{array}{l}\text { Scale assessed the extent to which } \\
\text { patients had extracted and } \\
\text { communicated diabetes-related } \\
\text { information since they were } \\
\text { diagnosed with the disease. } \\
\text { Since being diagnosed with diabetes, } \\
\text { you have. . } \\
\text { - Collected information from } \\
\text { various sources. } \\
\text { Extracted the information } \\
\text { you wanted. } \\
\text { Understood the obtained } \\
\text { information. } \\
\text { Communicated your } \\
\text { thoughts about your illness } \\
\text { to someone. } \\
\text { Applied the obtained } \\
\text { information to your daily } \\
\text { life. }\end{array}$ & $\begin{array}{l}\text { Scale assessed the extent to which patients had } \\
\text { critically analyzed the information and used it } \\
\text { to make decisions. } \\
\text { Since being diagnosed with diabetes, you have } \\
\text {... Considered whether the information } \\
\text { - } \text { was applicable to your situation. } \\
\text { - Considered the credibility of the } \\
\text { information. } \\
\text { Checked whether the information was } \\
\text { valid and reliable. } \\
\text { Collected information to make health- } \\
\text { related decisions. }\end{array}$ \\
\hline $\begin{array}{l}\text { Ishikawa et al. } \\
\text { (2008) }\end{array}$ & $\begin{array}{l}\text { Study aimed to } \\
\text { examine the } \\
\text { psychometric }\end{array}$ & Not Applicable & $\begin{array}{l}\text { Items on the scale intended to } \\
\text { measure interactive health literacy } \\
\text { included the ability to; }\end{array}$ & $\begin{array}{l}\text { Items on the scale intended to measure critical } \\
\text { health literacy included the ability to; }\end{array}$ \\
\hline
\end{tabular}




\begin{tabular}{|c|c|c|c|c|}
\hline & $\begin{array}{l}\text { properties of a brief } \\
\text { measure to assess } \\
\text { major components of } \\
\text { communicative and } \\
\text { critical health literacy } \\
\text { among Japanese office } \\
\text { workers }\end{array}$ & & $\begin{array}{l}\text { collect health-related } \\
\text { information from various } \\
\text { sources } \\
\text { extract the information } \\
\text { wanted } \\
\text { understand and } \\
\text { communicate the obtained } \\
\text { information }\end{array}$ & $\begin{array}{l}\text { - Consider the credibility of the } \\
\text { information } \\
\text { Make decisions based on the } \\
\text { information, specifically in the } \\
\text { context of health-related issues. }\end{array}$ \\
\hline $\begin{array}{l}\text { Friedman et al. } \\
(2009)\end{array}$ & $\begin{array}{l}\text { Purpose of the study } \\
\text { was to explore the } \\
\text { implications of } \\
\text { applying Nutbeam's } \\
\text { multidimensional } \\
\text { health literacy } \\
\text { framework to } \\
\text { understanding of } \\
\text { African American } \\
\text { Men's Prostate Cancer } \\
\text { information. }\end{array}$ & $\begin{array}{l}\text { Ability to identify the following } \\
\text { risk factors for Prostate cancer; } \\
\text { dietary/nutritional factors, lack of } \\
\text { exercise, sexual behaviours, race, } \\
\text { age, heredity, and environmental } \\
\text { factors. }\end{array}$ & $\begin{array}{l}\text { Ability to identify their sources of } \\
\text { health and Prostate Cancer } \\
\text { information. This included } \\
\text { interpersonal, mass media, and } \\
\text { educational sessions. }\end{array}$ & $\begin{array}{l}\text { Ability to articulate how they would use } \\
\text { Prostate Cancer prevention education } \\
\text { information. This included sharing with family } \\
\text { and friends and making changes in their own } \\
\text { behaviours. }\end{array}$ \\
\hline
\end{tabular}




\section{ii. Development of the Definition of each Level of Reiki Health Literacy}

Having compiled Figure 5.1 and acquired an insight into how other researchers had conceptualised each level of health literacy across different health contexts, work began on compiling the definition of each level of Reiki health literacy. This was a twofold process. Firstly, it involved the author referring to Nutbeam's definition and then questioning in turn what each level would be in a Reiki context based on the reading undertaken for Chapter Two (Literature on Reiki) and her understanding of Reiki drawn on from personal knowledge and training as a Reiki practitioner. Secondly, it involved drawing on the reading regarding the skills, knowledge and competencies that other researchers who had used Nutbeam's model had included in each level of health literacy. At all stages of developing the initial model of Reiki health literacy, the skills, knowledge and competencies that comprised each level was discussed with the researcher's supervisors (May and June 2010 supervision meetings).

The researcher's thinking was influenced directly by Nutbeam's model and other researchers' interpretations of each level of the model. When compiling the definition of each level of Reiki health literacy Nutbeam's definition of functional, interactive and critical health literacy were considered, before looking at how other researchers had interpreted these definitions. In some instances, key words and phrases used by Nutbeam were drawn on. For example, Nutbeam uses the phrase 'sufficient basic skills in reading and writing' within his definition of functional health literacy. This led to the definition of functional Reiki health literacy including the phrase 'in a Reiki context having sufficient basic skills...'.

An example of how other researchers' interpretations of Nutbeam's levels of health literacy influenced the researcher's thinking can also be seen in the process undertaken when defining functional Reiki health literacy. The researcher deduced that functional health literacy is associated with possessing the very basic or minimum skills, knowledge or competencies in any given context. For example, in the context of online chat room discussion forums functional health literacy included 'posting' factual health information (Donelle and Hoffman-Goetz 2008b) and in the context of school lessons it included reading books or leaflets about, for example, hygiene, nutrition, safety and so forth (St Leger 2001). In the context of Reiki the basic or minimum skills, knowledge or competencies was deemed to be the ability to perform treatment on oneself and others. 
Similarly Nutbeam's definition of interactive health literacy and others' interpretations of it suggest the associated skills and competencies to be more advanced levels of thinking, reading and understanding which, in turn, implies that an individual is able to actively participate in a task as opposed to simply having the knowledge to do it. For example in the context of diabetes care, interactive health literacy was associated with obtaining information from a wide range of sources (Ishikawa, Takeuchi and Yano 2008) and in the context of prostate cancer information, interactive health literacy was associated with the ability to identify information interpersonally, in the mass media, and in educational sessions (Friedman et al. 2009). This led to the definition of interactive Reiki health literacy including knowing when to give oneself a Reiki treatment or visit a practitioner, possessing a more developed understanding of the concept of 'energy' and applying Reiki skills such as using energetic cleansing and protection and sending Reiki backwards and forwards in time, in everyday life. Nutbeam's model of health literacy suggests that critical health literacy is associated with critically analysing information and using information to exert control. Other authors using Nutbeam's model have translated this to include considering the credibility of information (Ishikawa, Takeuchi and Yano 2008) and in the case of the use of internet chat rooms (Donelle and Hoffman-Goetz 2008b) critically analysing a health issue or concern. This led to the definition of critical Reiki health literacy as involving the ability to 'see past' the biomedical model of health and apply a holistic perspective.

\section{iii. Development of the Potential Benefits of each Level of Reiki Health Literacy}

Nutbeam's model of health literacy incorporates the benefits of health literacy on both an individual and a social / community level. The model of Reiki health literacy also hypothesises about the benefits of Reiki health literacy; however this is primarily on an individual level. This is due to the fact that the benefits of Reiki tend to be on an individual as opposed to a social or community level. That is not to eliminate the possibility of Reiki having an effect at the community / social level. However, these effects will more likely be indirect as a result of individuals practising Reiki and thus more in the sense of 'as a sum of the whole'. An example might involve a group of Reiki practitioners or persons who have undertaken Reiki training and who actively use Reiki in their everyday lives, initiating a proactive, self-sustainable community based initiative to promote health and wellbeing. In 
smaller communities or groups the effects on the group or community may be more apparent. In turn, it is notable that increased wellbeing of the individual will have an impact upon the community.

The individual benefits of possessing each level of Reiki health literacy were defined in a similar manner to the above described process of defining the skills, knowledge and competencies associated with each level of Reiki health literacy. The process was twofold. Firstly, it involved the researcher referring to Nutbeam's description of the benefits of health literacy and then questioning in turn what this would be in a Reiki context. Secondly, it involved drawing on the body of academic and non-academic literature on Reiki described in Chapter Two, in particular, the material used to address the literature review question 'what are the benefits of using Reiki?' An example of how this process was followed is now provided for each level of Reiki health literacy.

An individual benefit of functional health literacy as identified by Nutbeam is improved knowledge of risks and health services'. In a Reiki context this translated to 'improved knowledge of risks and health services from an embodied perspective: 'how they apply to me as an individual'". This was derived from the assertion found in much of the non academic literature on Reiki regarding Reiki's emphasis on raising self awareness via self treatment as exemplified below by Mellowship and Chrysostomou (2008)

Reiki is a fascinating journey of self discovery and growth that starts with the attunements and continues through self healing. As awareness raises and understanding increases so too does happiness and fulfilment. Reiki is an empowering healing gift that absolutely anyone can possess and use to treat themselves and others for any and every condition. (4-5)

Tentative evidence for the ability of Reiki to raise self-awareness is also found within empirical research. Drawing on the review of the Reiki literature, one of the findings from Brathovde's (2006) study was that after being taught Reiki level one as a self-care practice participants reported feelings of increased personal awareness (Brathovde 2006). Similarly, 
another benefit of functional Reiki health literacy is that 'Relaxation is increased; stress is reduced'. This benefit was conceived of directly from the Reiki research literature where a number of studies noted a reduction in stress and or anxiety in participants who received Reiki either from a Reiki practitioner or via self use of Reiki (Miles 2003; Shore 2004; Thomas 2005; Vitale and O'Connor 2006; Meland 2009; Vitale 2009; Richeson et al. 2010; Hulse, Stuart-Shor and Russo 2010; Cuneo et al. 2011).

An example of how the benefits of interactive Reiki health literacy were defined by drawing on the Reiki research literature and the Reiki theoretical literature can be seen in the hypothesised benefit 'Increased sense of ability to self care'. As noted in chapter two (p XX) the emphasis on self use of Reiki makes this an obvious benefit and one which has also been noted by participants in Brathovde's (2006) study of healthcare providers who were taught Reiki level one.

\section{The Model of Reiki Health Literacy}

Figure 5.2 below presents the model of Reiki health literacy. The first column specifies each level of Nutbeam's model of health literacy: functional, interactive and critical. The second column includes a description of each level of health literacy according to Nutbeam and the third column describes the level of health literacy from a Reiki perspective. The two models are presented side by side to demonstrate how the levels of Reiki health literacy map on to Nutbeam's levels of health literacy. The final two columns describe the benefits of possessing each level of health literacy both from Nutbeam's perspective and from a Reiki perspective. The model presupposes that an individual is already aware of what Reiki is, has accessed a Reiki teacher and undertaken at least Reiki level one training. 
Figure 5.2: A Model of Reiki Health Literacy

\begin{tabular}{|c|c|c|c|c|}
\hline Health Literacy Level & Nutbeam's Description & Description as applied to Reiki & $\begin{array}{l}\text { Individual benefit of health } \\
\text { literacy }\end{array}$ & $\begin{array}{l}\text { Individual benefit of Reiki health } \\
\text { literacy }\end{array}$ \\
\hline Functional & $\begin{array}{l}\text { Sufficient basic skills in reading and } \\
\text { writing to be able to function } \\
\text { effectively in everyday situations }\end{array}$ & $\begin{array}{l}\text { In a Reiki context having } \\
\text { sufficient basic skills would be } \\
\text { the ability to perform treatment } \\
\text { on oneself and others. This } \\
\text { could be taught experientially } \\
\text { and visually } \\
\text { Because of Reiki's oral history } \\
\text { one would not need basic skills } \\
\text { in reading and writing to } \\
\text { become attuned to Reiki and } \\
\text { learn how to do this } \\
\text { Functional Reiki health literacy } \\
\text { reflects the practical side of } \\
\text { Reiki }\end{array}$ & $\begin{array}{l}\text { Improved knowledge of risks } \\
\text { and health services, compliance } \\
\text { with prescribed actions }\end{array}$ & $\begin{array}{l}\text { Improved knowledge of risks and } \\
\text { health services from an embodied } \\
\text { perspective. 'How they apply to me as } \\
\text { an individual' } \\
\text { By giving or receiving a Reiki } \\
\text { treatment a range of physical health } \\
\text { problems may be improved } \\
\text { Relaxation is increased; stress is } \\
\text { reduced as a result } \\
\text { Feeling peaceful and nurtured - all } \\
\text { have an indirect affect on well being }\end{array}$ \\
\hline Interactive & $\begin{array}{l}\text { More advanced cognitive and literacy } \\
\text { skills which, together with social } \\
\text { skills, can be used to actively } \\
\text { participate in everyday activities, to } \\
\text { extract information and derive } \\
\text { meaning from different forms of } \\
\text { communication, and to apply new } \\
\text { information to changing } \\
\text { circumstances }\end{array}$ & $\begin{array}{l}\text { Knowing when to use Reiki, that } \\
\text { is, knowing when to give } \\
\text { oneself a treatment or visit a } \\
\text { practitioner } \\
\text { More developed understanding } \\
\text { of the concept of 'energy' for } \\
\text { which basic reading skills would } \\
\text { be necessary } \\
\text { Using Reiki to not only benefit } \\
\text { health but by applying it in daily } \\
\text { life. For example using } \\
\text { energetic cleansing and } \\
\text { protection. }\end{array}$ & $\begin{array}{l}\text { Improved capacity to act } \\
\text { independently on knowledge, } \\
\text { improved motivation and self- } \\
\text { confidence }\end{array}$ & $\begin{array}{l}\text { Improved capacity to act } \\
\text { independently on knowledge, } \\
\text { improved motivation and self- } \\
\text { confidence } \\
\text { Increased sense of ability to self care } \\
\text { Daily self use of Reiki helps to } \\
\text { maintain good health. Reiki used pro- } \\
\text { actively rather than re-actively. } \\
\text { Sending Reiki backwards induces } \\
\text { 'healing at a deeper level'. } \\
\text { Sending Reiki forwards improves } \\
\text { confidence in situations (not } \\
\text { necessarily related to health i.e. when }\end{array}$ \\
\hline
\end{tabular}




\begin{tabular}{|c|c|c|c|c|}
\hline & & $\begin{array}{l}\text { Send Reiki forwards and } \\
\text { backwards in time (Reiki level } 2 \\
\text { required) }\end{array}$ & & $\begin{array}{l}\text { one might feel anxious or when one } \\
\text { may need to attend the doctors or the } \\
\text { hospital) }\end{array}$ \\
\hline Critical & $\begin{array}{l}\text { More advanced cognitive skills which, } \\
\text { together with social skills, can be } \\
\text { applied to critically analyse } \\
\text { information, and to use this } \\
\text { information to exert greater control } \\
\text { over life events and situations. }\end{array}$ & $\begin{array}{l}\text { Critically analyse information } \\
\text { from a Reiki perspective would } \\
\text { equate to the ability to see past } \\
\text { the biomedical model of health } \\
\text { and apply a holistic perspective } \\
\text { to health. This expanded } \\
\text { perspective of health enables an } \\
\text { individual to exert greater } \\
\text { control over their health. } \\
\text { Reiki epitomises critical health } \\
\text { literacy because it provides us } \\
\text { with another 'way of knowing' / } \\
\text { body of knowledge from which } \\
\text { to analyse information. This is } \\
\text { empowering and thus enables } \\
\text { the individual to exert more } \\
\text { control over life events and } \\
\text { situations. } \\
\text { In this sense it may be } \\
\text { considered a threat to the } \\
\text { dominant model of health and } \\
\text { health care as consumers chose } \\
\text { complementary and alternative } \\
\text { therapies over conventional } \\
\text { treatment. }\end{array}$ & $\begin{array}{l}\text { Improved individual resilience } \\
\text { to social and economic adversity } \\
\text { This type of health literacy can } \\
\text { be more obviously linked to } \\
\text { population benefit, alongside } \\
\text { benefits to the individual. Health } \\
\text { education in this case would be } \\
\text { directed towards improving } \\
\text { individual and community } \\
\text { capacity to act on these social } \\
\text { and economic determinants of } \\
\text { health. }\end{array}$ & $\begin{array}{l}\text { All information gathered regarding } \\
\text { health and knowledge applied from } \\
\text { both a traditional (biomedical) and } \\
\text { complementary (Reiki) perspective. } \\
\text { Judgement made from a balanced } \\
\text { perspective. } \\
\text { Freedom of choice. }\end{array}$ \\
\hline
\end{tabular}




\section{Concluding Comments}

This chapter observed that there is a lack of research around CAM and health literacy and suggested that Reiki may potentially enhance health literacy. Prior to exploring this suggestion with empirical research, a model of what constitutes health literacy in the context of Reiki was constructed and is presented in this chapter. The model of Reiki health literacy also suggests the individual benefits of this type of health literacy. The following Chapter presents the first underlying principle of the research, the methodology. 


\section{Chapter Six: Methodology}

\section{Introduction}

This chapter outlines the methodological approach used to underpin this research (qualitative methodology). The chapter begins by briefly exploring understandings surrounding the term 'methodology'. It continues by identifying some of the key characteristics of qualitative methodology. A rationale for using qualitative methodology within this research is then provided. The final two sections of this chapter include an account of how the researcher's biography may have influenced the research and an account of how the participants were treated ethically throughout the research in this research were treated ethically in accordance with ethical standards.

\section{Defining Methodology}

Methodology has been defined by Silverman (2000) as 'how one will go about studying any phenomenon' (Silverman 2000:79). However, this straightforward definition to some extent masks the complexity behind the term; within the social science and healthcare research literature 'methodology' is subject to a diverse range of connotations. Furthermore, how a researcher goes about studying a phenomenon (to borrow Silverman's phrase) is not always discussed under the banner of 'methodology'. Terms such as 'strategies of inquiry' or 'traditions of inquiry' (Carter and Little 2007:1318) have also been used to denote how a researcher goes about studying a phenomenon.

The 'methodology', 'strategy' or 'tradition' of inquiry used to underpin a research project is further characterised by diversity. A methodology may be characterised broadly or generally; for example as qualitative or quantitative (Silverman 2000) or more narrowly and/or specifically such as grounded theory or conversation analysis (Silverman 2000), symbolic interactionism or feminism (Carter and Little 2007: 1318) to provide but a few examples. A common misconception surrounding the term 'methodology' appears to be its interchangeable use with the term 'method'. Whilst 
method and methodology are intrinsically linked (see below) each term in actuality refer to different aspects of the research process (Willig 2008).

\section{Characterising Qualitative Methodology}

\section{Meaning}

Central to a qualitative methodological approach to research, lies an emphasis on the concept of 'meaning'. For example acquiring an understanding of how people experience and make meaning (or sense) of the social world and how they experience the world around them. As noted by Pope and Mays:

[Qualitative Research] tries to interpret social phenomena (interactions, behaviour etc) in terms of the meanings people bring to them; because of this it is often referred to as interpretive research. (Pope and Mays 2006:4)

This objective of understanding the meanings that social actors attach to events and experiences leads to a focus within qualitative research on 'quality and texture of experience rather than with the identification of cause - effect relationships' (Willig 2008:8). Within the endeavour of striving to understand the meanings that participants bring to their experiences is also the understanding that 'meaning' itself is socially constructed and is influenced firstly by context:

No phenomena can be understood out of relationship to the time and context that spawned, harboured and supported it (Lincoln and Guba 1985:189)

And secondly by the researcher:

Meanings are seen to be negotiated between researcher and researched within a particular social context so that another researcher in a different relationship will unfold a different story (Finlay 2002:531) 


\section{Natural Settings}

A second distinct feature of a qualitative methodology is the preference for studying people in their natural settings (Denzin and Lincoln 2003; Pope and Mays 2006; Willig 2008). Such settings may include the home, restaurants, schools, hospitals, on the street: in short, settings or places that people are familiar with as opposed to artificial and unfamiliar settings such as laboratories or experimental situations. Such choice of setting is underpinned by the belief (and intertwined with the emphasis on meaning) that meaning is something that is shaped by participants' environment, and furthermore between participants and the researcher (Lincoln and Guba 1985; Finlay 2002)

\section{Textual data}

It was previously noted that the terms method and methodology are often used interchangeably despite the fact that they refer to differing aspects of the research process. Silverman (2000) notes that a methodology 'shapes which methods are used and how each method is used' (Silverman 2000: 88). This has been echoed by Carter and Little (2007) who state that 'methodology provides justification for the methods of a research project' (Carter and Little 2007: 1317). Denzin and Lincoln (2003) have asserted that qualitative research does not 'have a distinct set of methods or practices that are entirely its own' (p10). Indeed, most research methods can be used both qualitatively and quantitatively (see for example Siverman 2000). Methods that are strongly associated with qualitative research include observation and interviews and whilst bearing in mind that there is the potential for each of these methods to be used in a quantitative or qualitative fashion, the data that these methods produce when used within qualitative research have one thing in common. That is they aim to produce a record of participants 'words and action' (Pope and Mays 2006; Willig 2008) as opposed to numerical data. This is concordant with the emphasis within qualitative methodology on understanding and making meaning of peoples experiences of the social world. As observed by Avis (2005) 'the importance of textual data is that they allow people to express their thoughts and beliefs in their own words and in their own terms' (Avis 2005:5) 


\section{Reflexivity}

An emphasis on reflexivity is a further distinct characteristic of qualitative research (Ahern 1999; Green and Thorogood 2009). Finlay (2002) has defined reflexivity as follows:

Reflexivity can be defined as thoughtful, conscious self-awareness. Reflexive analysis in research encompasses continual evaluation of subjective responses, intersubjective dynamics, and the research process itself. It involves a shift in our understanding of data collection from something objective that is accomplished through detached scrutiny of "what I know and how I know it" to recognizing how we actively construct our knowledge. (Finlay 2002: 532)

Thus issues linked to reflexivity permeate all aspects of the research process from design, to the writing up of research. There exist many approaches to demonstrating reflexivity (Gough 2008) and one such way is through consideration of how aspects of the researcher's persona impacts upon the research (see influence of researchers biography below).

\section{Rationale for the use of Qualitative Methodology within this Research}

A qualitative approach was selected for this research as the most appropriate way to explore the research question. Primarily this was influenced by the emphasis within qualitative research on obtaining a deep understanding of meaning and experience attached by people to events and actions (Saks and Allsop 2007). In relation to health research and specifically research into CAM, Richardson and Saks (2007: 328) note:

Qualitative studies provide an understanding of the complexity of the patient experience including how the experience of the intervention impacts on the patients' self-knowledge, and important self directed changes in behaviour and lifestyle (Richardson and Saks 2007: 328 in Saks and Allsop 2007) 
This emphasis on the ability of qualitative studies to provide insight into the impact of patients' self-knowledge and self-directed changes in behaviour and lifestyle was highly relevant to this project.

\section{Influence of Researchers Biography}

The researcher's academic background includes an undergraduate degree in gender studies and an interest in feminist research methodology. Whilst this research was not designed to be a 'feminist' piece of research per se, the influence of the researcher's academic background and interests could not be overlooked when conducting the interviews, analysing the data and writing up the research. The researcher approached each interview in agreement with Oakley:

[...]in most cases, the goal of finding out about people through interviewing is best achieved when the relationship between interviewer and interviewee is non-hierarchical and when the interviewer is prepared to invest some of his or her own personal identity in the relationship (Oakley 1981:41)

Whilst concerns with establishing non-hierarchical (equal) relationships and investing oneself in the research have historically been features of feminist research, it could be argued that today they represent features of good ethical practice within all qualitative research as opposed to the sole concern of feminist researchers. The aim when conducting the interviews was to foster a non-hierarchical relationship with all the research participants, not just the female ones. One means by which non-hierarchical relationships may be encouraged within the interview encounter is through the reciprocal sharing of personal stories (Dickson-Swift et al. 2007) or through researcher self-disclosure which is reminiscent of Oakley's (1981) notion of the interviewer investing his or her own personal identity in the interview relationship. 
The issue of researcher self-disclosure has been discussed in both the feminist and non -feminist literature on interviewing. In her study of clergymen's wives, Finch (Finch 1993) reported that participants 'became warm and eager to talk to me' (Finch; 172: 1993) once they became aware that she herself was a clergyman's wife. Similarly, in their study of the experiences of qualitative researchers Dickson-Swift et al. (2007) found that qualitative health researchers reported 'perceiving a need to create some sort of 'level playing field', acknowledging that self-disclosure could enhance rapport, show respect for the participants and validate the participants' stories' (Dickson-Swift et al.: 332).

\section{Wellbeing of participants during and after interviews}

Corbin and Morse (2003) note that 'The dynamic nature of qualitative interviews makes it impossible to predict with certainty what will transpire' (Corbin and Morse 2003:341). Whilst the subject of Reiki in itself may not be considered a sensitive subject, participants often demonstrated an awareness of how strangers to Reiki found the subject 'weird'. The subject of health, however, does have the potential to be a highly personal and sensitive subject. Given that health and the use of Reiki for selfcare were key topics to be addressed in the interviews, the researcher had to consider in advance the possibility that the interviews might be construed by participants as dealing with 'sensitive' subjects. In an effort to protect participants' wellbeing, participants were informed in advance of the interview that they did not have to answer any questions if they did not wish to and they were reminded that they could take a break from the interview or terminate it at any time without having to give a reason.

Some participants talked about health conditions that required the researcher to respond in a sensitive manner, for example one participant was living with Crohn's disease and another with bi-polar disorder. On occasion participants talked of family members who were experiencing ill health; one participant's wife was recovering from breast cancer and another participant's mother was extremely ill with Multiple Sclerosis and dementia. Whilst these participants did not outwardly display any signs of distress during their interview, a sensitive approach was still employed. For 
example, one participant became tearful towards the end of the interview when talking about a health condition. In this instance the researcher drew on her interpersonal skills expressing empathy. Following transcription of the interviews, all participants were allocated a pseudonym to protect anonymity. Care was also taken to disguise circumstances or events that might have revealed the participants' identity.

\section{Concluding Comments}

This chapter presented and provided a rationale for the methodology underpinning the exploration of the thesis research question. It is essential that the thesis is based on choice of both a methodology and methods that are appropriate to explore and address the research question and objectives. The methodological approach used to underpin this research was based on qualitative methodology and some of its key characteristics were explored. Attention was also drawn to the approach adopted in order to conduct the interviews and the importance of possible self-disclosure of the researcher being a Reiki level two self-user. Attention now turns in Chapter Seven to the methods employed in the thesis and thus how the methodological principles were followed through in practice. 


\section{Chapter Seven: Methods}

\section{Introduction}

This chapter will describe the methods used to generate data for this study. It will present descriptions of the method of sampling, the sample participants and the size of the sample. An account of where the sample was recruited from and the methods used to do this are also presented. An account is given of the design and refinement of data collection instruments before finally describing the approach to data analysis.

\section{Background}

Prior to commencing the empirical phase of this research, a review of the literature on the effects of Reiki was undertaken and a conceptual review of the literature on health literacy. This initial work led to the development of a conceptual model of Reiki health literacy and the identification of the following research question;

- How does learning and using Reiki for self-use enhance health literacy?

And the formulation of the following six objectives;

1. Review the literature on Reiki

2. Identify key concepts associated with health literacy

3. Develop a model of Reiki health literacy

4. Confirm and refine the Reiki health literacy model

5. Uncover the specific effects of learning and self-use of Reiki on health literacy

6. Explore how Reiki health literacy is used in the context of health in daily life

To address the research question and meet the specified objectives a two-phased qualitative study was undertaken. Ethical approval for both phases of the research was secured from the School of Healthcare Research Ethics Committee (SHREC) on $30^{\text {th }}$ September 2009 (ref SHREC/RP/167). 


\section{Methods}

It is generally accepted that the most important consideration when deciding upon methods is to choose those that will generate relevant data to address the research question (Willig 2008). Due to the fact that both phases of the research involved exploring participants' lived experience with Reiki, the decision was made to collect data using face-to-face interviews. The immediate and exploratory nature of face-toface interviews was considered to be the most effective way of exploring the Reiki health literacy model. In particular, arguably the most effective way to explore the knowledge-based skills --for example, the ability to critically analyse information from a Reiki perspective -- was to ask questions about the experiences, preferences, choices and so forth of experienced Reiki practitioners. In phase one of the research an unstructured interview was used and in phase two a semi structured interview. Vignettes were also incorporated into the semi structured interviews in phase two.

When considering the array of qualitative research methods that could potentially be used to generate data relevant to the research question and objectives, some qualitative methods were deemed unsuitable. For example, the collection and analysis of written documents or audiovisual data would have been unsuitable simply because the oral history of Reiki suggests that very few, if any, raw data of this type exist. Some elements of the Reiki health literacy model reflect practices that it would be possible for a researcher to observe such as a Reiki student carrying out a selftreatment. However, the decision not to use observation as a research method was twofold. Firstly, Reiki self-treatment is often a private activity, and observing a person using Reiki on themselves may constitute an invasion of privacy and unwillingness on behalf of Reiki students to participate in the research. Secondly, a Reiki self-treatment is also a silent activity. Simply observing this silent activity would not yield meaningful data or data relating to the benefits a person derives from this activity. Similarly, it would be possible to observe the teaching of a Reiki class but observation on its own would not generate meaningful data on how Reiki is subsequently used in everyday life. 


\section{Phase One: Unstructured Interviews}

Unstructured interviews (sometimes referred to as in-depth interviews) are defined by Bowling (2009:407) as 'a face-to-face interview using an interview schedule with the topics listed but with few specific questions and no fixed questions'. Three main reasons informed the decision to use unstructured interviews in phase one instead of other types of interview such as the semi-structured interview. The first reason related to the type of data that was sought from the interviews with Reiki Master Teachers. As noted by Johnson (2001), a purpose of conducting unstructured interviews is to generate 'rich' data and achieve a 'deep' understanding of the participant's experience

A researcher who uses 'in-depth interviewing' commonly seeks 'deep' information and knowledge - usually deeper information and knowledge than is sought in surveys, informal interviewing, or focus groups for example. This information usually concerns very personal matters, such as the individuals self, lived experience, values and decisions, occupational ideology, cultural knowledge or perspective. (Johnson 2001:104)

Generating 'deep' or in-depth data was consistent with the aim of exploring the various components that comprise the Reiki health literacy model with a view to confirming and refining it. In the above quotation, Johnson also draws attention to some of the potential subject matters for which a researcher might want to generate in-depth data. In particular, his notion of data concerning participant's self and their lived experiences, values and decisions are reflective of the data that the interviews with aimed to elicit.

The second consideration that influenced the decision to use unstructured interviews related to issues of reflexivity. The initial Reiki health literacy model was developed from a theoretical and conceptual review of both the Reiki and health literacy literature by the researcher. The researcher is also a Reiki practitioner herself who practices self-use of Reiki. It has been suggested by Johnson (2001) that the use of 
unstructured interviews may be beneficial in instances where the researcher has firsthand knowledge and / or experience of the subject of the research;

If the interviewer happens to be a current or former member or participant in this activity, he or she may use in depth interviews to explore or check his or her understanding to see if they are shared by other members or participants. (Johnson 2001:106)

Whilst it was beneficial to explore whether the meaning of Reiki as inherent in the Reiki health literacy model was shared between researcher and participant, the reasons for choosing this type of interview went beyond simply 'exploring' and 'checking' shared meanings. In addition, there was the desire to prioritise the views of the participants. Due to the fact that the researcher possessed firsthand knowledge and experience of Reiki, unstructured interviews allowed for the possibility of reducing any bias and subjectivity in the model that resulted from this firsthand knowledge and experience. The absence of a rigid set of questions within unstructured interviews allows the interview to be guided by the interviewee, providing a fuller representation of the interviewee's perspective (Bryman 2008; Low 2007; Mason 2002). In this respect, data to inform the Reiki health literacy model was generated from the viewpoint of what participants believed to be important as opposed to what the researcher believed to be important. The choice to use unstructured interviews was not intended to suggest that this removed the researcher's influence entirely; it was simply one of many measures taken to minimise any subjectivity on behalf of the researcher.

The third reason underlying the decision to use unstructured interviews was that openended interviews are 'useful when exploring research areas where little is known or which are complex' (Low in Saks and Allsop 2007:75). The Reiki health literacy model is new and complex and the fourth objective of the research was to refine it. In this respect self-use of Reiki as a means of enhancing health literacy may be conceived of as a topic where little is known within the fields of public health or CAM thus lending itself to exploration using an unstructured approach to data collection. 


\section{Phase Two: Semi-Structured Interviews}

Semi structured interviews were used in phase two and are defined by Bryman (2008) as follows;

The interviewer has a series of questions that are in the general form of an interview schedule but is able to vary the sequence of questions [...]. Also the interviewer usually has some latitude to ask further questions in response to what are seen as significant replies. (Bryman 2008: 196)

As Bryman suggests, the order in which questions are asked during a semi-structured interview may vary between participants as well as the actual questions asked of each participant. This is in contrast to structured interviews whereby 'the wording and order of all questions are exactly the same for every respondent' (Denzin 1989:104) and also to unstructured interviews where there are no fixed questions.

The key difference between the types of interview used in phase one and two of the research is one of 'openness' and degree of structuring. The interview schedule used within phase one had some questions determined in advance however; the interview was in theory 'open', allowing participants to raise topics as they deemed appropriate. Within phase two more questions were determined in advance than was the case with phase one. Whilst the participant was still free to raise topics, the questions on the interview schedule were still adhered to.

The flexibility in terms of structure that is characteristic of semi structured interviews is purported to enable the participant to speak more widely on the subjects raised by the interviewer (Denscombe 2003) which can result in participants raising 'important issues not contained in the schedule' (Denzin 1989:106). Another advantage arising from the flexible nature of the semi-structured interview is that the interviewer is free to probe beyond and into interviewees' responses (May 2001; Bryman 2008). 
Semi-structured interviews were appropriate for use in phase two for three reasons. Firstly, some data had already been collected in phase one and as implied by Wengraf (2001) semi structured interviews are an appropriate choice in the more advanced stages of a research project;

The research focus at the start of the research cycle is that of building a theory or model of a particular reality typically requiring an unstructured or lightly structured interview. Once the model has been built, it is then tested by a more heavily structured or fully structured interview. (Wengraf 2001:60)

Wengraf's suggestion that the focus at the start of a research project is building a theory or model was analogous with the aim of phase one: to confirm and refine a model (of Reiki health literacy). Once the model of Reiki health literacy had been refined, the aim was then to explore its applicability with Reiki level one and two selfusers. Thus, suggesting semi-structured interviews to be an appropriate choice.

Secondly, it was anticipated that using semi-structured interviews would help to achieve focus on the applicability of the Reiki health literacy model. As Kelly notes:

[Semi structured interviews] are thus appropriate in research situations in which the researcher intends to focus on specific research interests rather than to examine an individuals experiences more holistically. (Kelly 2010:318)

Part of the rationale for using in-depth interviews with only light structuring in phase one was that the model of Reiki health literacy was new and complex and therefore in-depth interviews were appropriate for confirming, refining and further exploration of the model of Reiki health literacy. However, in the second phase of the research this was not the case. The researcher had a clearer idea of the various components comprising Reiki health literacy and the aim was to explore the applicability of this 
model, that is, a greater focus was needed in phase two. Exploring the applicability of the Reiki health literacy model involved looking at the effects of Reiki on health literacy and considering how Reiki health literacy is used in the context of daily life (objectives 5 and 6). Phase two of the research therefore represented a shift from the general (exploring health literacy in the context of Reiki) to the more specific (exploring the effects of Reiki on health literacy and its use in the context of daily life).

Thirdly, the flexible nature of semi-structured interviews made them an appropriate choice for use in phase two of the project. Based on the review of the literature, it was anticipated that a method that would permit the researcher to probe would be useful when exploring participants' experience of self use of Reiki. In their interview based study of the experience of receiving Reiki, Engebretson and Wardell (2002) observed that participants stated it was difficult to describe their experience of Reiki or 'put it into words'. Using a semi-structured interview design allowed the researcher to probe and enter discussion with the interviewee and facilitate the interviewee putting into words their experiences of Reiki.

\section{Phase Two: Vignettes}

Vignettes 'consist of text, images or other forms of stimuli to which research participants are asked to respond' (Hughes and Huby 2002:382). Vignettes can be incorporated into a variety of research methods; most commonly they are used as a stimulus for discussion during interviews or focus groups (Hughes and Huby 2002). Vignettes were used in phase two and were incorporated into the semi-structured interviews. They were presented to participants towards the end of the semistructured interviews, before the closing questions. Two of the vignettes consisted of text and one consisted of an image. Inserting a photo or other visual image into an interview is also known as photo elicitation (Harper 2002:13). The technique can 'facilitate the interview process, bringing greater depth to topics discussed, and enhancing the quality of data gathered' (Liebenberg 2009:444). According to Harper, this is because images 'evoke deeper elements of human consciousness that do words' (2002:13). 
All three vignettes were used as a way of generating additional and supplementary data to that generated by the interview questions. They were also designed to address objectives 4, 5 and 6 (see above). In relation to the fourth objective to confirm and refine the Reiki health literacy model, there were specific elements of the Reiki health literacy model that it was believed the vignettes would generate data on. Firstly, functional Reiki health literacy involves possessing a basic level of knowledge about various aspects of Reiki. In addition to the interview questions that were aimed at generating data around this aspect of functional Reiki health literacy, the vignettes also provided an indication of what participants knew about Reiki. This data was therefore supplementary as opposed to new. However, in relation to interactive Reiki health literacy where one of the key competencies involves the ability to put Reiki knowledge into practice, the vignettes were a way of stimulating the participant to think about how they did this. One of the questions within the interview schedule aimed to explore this issue:

- Can you think of any times when you have used Reiki on yourself for health reasons or to help with a health problem?

The vignettes were intended to elicit supplementary data around this issue; however, they also served as a way of ensuring that some data were generated in the event of the participant responding in the negative to the above question. Furthermore, the fact that the vignettes described both physical and mental ailments for which Reiki could potentially be used, meant that data was generated on different aspects of health.

The third pictorial vignette was intended to generate data relevant to objectives four, five and six but specifically its aim was to generate data around the issue of making meaning from Reiki knowledge in different formats which is an interactive Reiki health literacy competency. This vignette was intended to explore if a participant could make meaning from information in different formats, that is, recognising and making meaning from visual (non-verbal) information. Participant responses to the pictorial vignette also provided supportive data on the participants' level of functional 
Reiki health literacy. When participants responded during the interview that they learnt about chakras in their Reiki course(s) the fact that they could recognise the chakras in the third vignette offered further evidence of them possessing a functional Reiki health literacy competency (having knowledge of chakras) and also that they possessed some interactive Reiki health literacy competencies (putting Reiki knowledge into practice and the ability to make meaning from Reiki knowledge in different formats). Finally, the three vignettes directly helped to address objective six of the research: explore how Reiki is used in the context of health in daily life.

One other factor informed the decision to incorporate the vignettes into the semi structured interview schedule. Liker (1982) notes that 'vignettes do not necessarily require participants to have in-depth knowledge of the topics under study' (cited in Hughes and Huby 2002:384). This was considered to be advantageous when interviewing participants who were attuned to Reiki level one or who had only been practising for a short period of time and who may not have as in depth knowledge or experience of self-using Reiki as participants who had been self-using Reiki for longer periods of time.

\section{Description of Vignettes}

Each of the vignettes is presented below in figures 7.1, 7.2 and 7.3. The first vignette related to physical pain / discomfort and required the participant to consider what they would do if they were in such a situation (see figure 7.1) The second vignette related to mental health issues such as worry, stress and the ability to 'switch off' or relax (see figure 7.2). The participant was asked to imagine themselves in the situation and then asked what they would do. The third vignette differed from the previous two in that it did not contain text; instead an image of the chakras 'out of line' (intending to convey a sense of feeling unbalanced) was presented to the participant who was asked 'what do you see?', followed by 'have you ever felt like this, if so what did / would you do?' (See figure 7.3). The vignettes were based on data extracted from the Reiki Masters' interview transcripts, and is presented in each of the figures below. The rationale for basing the vignettes on interview data is presented in the following section (below). 
Figure 7.1: Vignette One

\begin{tabular}{|l|l|}
\hline \multicolumn{2}{|c|}{ Vignette One } \\
\hline \multicolumn{1}{|c|}{ Interview Data Informing } & \multicolumn{1}{c|}{ Actual Vignette } \\
\hline $\begin{array}{l}\text { I did a lot of Reiki on it then and I never } \\
\text { have any problem with my ankle or I } \\
\text { have no pain. I have no swelling, I've got } \\
\text { full movement it's really well healed and } \\
\text { I would attribute that to the Reiki practice } \\
\text { as well. (Ruth on using Reiki on an ankle } \\
\text { that has been broken twice) }\end{array}$ & $\begin{array}{l}\text { You broke your ankle a few years back } \\
\text { and it has healed well, however, } \\
\text { had to walk a bit further than usual and } \\
\text { this has made your ankle ache today. } \\
\text { What do you do? }\end{array}$ \\
\hline
\end{tabular}


Figure 7.2: Vignette Two

\begin{tabular}{|c|c|}
\hline Interview Data Informing Vignette & Actual Vignette \\
\hline $\begin{array}{l}\text { If I'm going through a bit of a difficult time for } \\
\text { some reason or the another, maybe my energy } \\
\text { levels have dipped a bit or I'm not feeling a } \\
\text { hundred percent or I've had a hard day or my } \\
\text { car's broken down on a motorway or something } \\
\text { like that, I will immediately place my hands } \\
\text { somewhere on myself and just try and quieten } \\
\text { my breathing down a bit and feel the flow of that } \\
\text { energy re-balancing me (Annie) }\end{array}$ & \\
\hline $\begin{array}{l}\text { When you feel absolutely ... sometmes you feel } \\
\text { tired, so it can be a physical thing but it can also } \\
\text { be a bit of an emotional thing as well you know } \\
\text { where people keep going round and round in } \\
\text { your mind and you know you feel a bit full up } \\
\text { and it's so you sort of place your hands on } \\
\text { yourself and a feeling of sort of peacefulness, } \\
\text { sometimes warmth [...] But it's a feeling of sort } \\
\text { of comfort and peacefulness you know, } \\
\text { settlement.....funny words I'm using here but ... } \\
\text { (Annie) } \\
\text { It might be a deadline, your boss might come to } \\
\text { you and say look I need this piece of work doing, } \\
\text { its Tuesday today, I need it doing by Thursday } \\
\text { and you've got all your other work to do and that } \\
\text { fight or flight response can come in and go from } \\
\text { nought to ten immediately and you haven't, you } \\
\text { can't run away because it's your job, you can't } \\
\text { fight your boss because you'd get the sack!! So } \\
\text { you're stuck with this adrenaline ... see where } \\
\text { I'm going? So if at that point you can just } \\
\text { remember your Reiki, you can do your } \\
\text { breathing, you can just take five minutes just to } \\
\text { do a bit of a treatment, its going to deal with that } \\
\text { adrenaline that's floating around in the body and } \\
\text { bring you back down (Grace) }\end{array}$ & $\begin{array}{l}\text { You are at work and you have a meeting to } \\
\text { attend at } 11 \text { am. It's 10am and your boss } \\
\text { comes to you wanting something doing in } \\
\text { preparation for the meeting which leaves you } \\
\text { an hour to do it. It's not really enough time! } \\
\text { Your adrenaline is pumping as you begin to } \\
\text { worry that you won't have enough time to } \\
\text { meet the deadline. On top of all this, you are } \\
\text { anxious about the meeting anyway because it's } \\
\text { very formal and there's someone there that you } \\
\text { want to impress as you are looking for a } \\
\text { promotion. The meeting goes well however } \\
\text { when you get home from work the events of } \\
\text { the day keep going round and round in your } \\
\text { mind. It's been a difficult and demanding day } \\
\text { and you feel that your energy levels have } \\
\text { dipped a bit. }\end{array}$ \\
\hline $\begin{array}{l}\text { Yes you can send Reiki forwards but I haven't } \\
\text { done it that much, only in situations like being, } \\
\text { meetings, if I've had a meeting I think please } \\
\text { you know send the Reiki forward to that } \\
\text { meeting so it goes smoothly (Hazel) } \\
\text { If I know, if I go into a situation where I feel } \\
\text { nervous or whatever you can interpret that to } \\
\text { calm yourself down (Hazel) }\end{array}$ & \\
\hline
\end{tabular}

NB: Text in bold indicate key words, phrases or ideas used to inform vignette 


\section{Figure 7.3: Vignette Three}

\begin{tabular}{|c|c|}
\hline \multicolumn{2}{|c|}{ Vignette Three } \\
\hline Interview Data Informing Vignette & Actual Vignette \\
\hline $\begin{array}{l}\text { I've just finished a Reiki one course and what I } \\
\text { do with a Reiki one when I'm teaching groups I } \\
\text { do it over four weeks. The first night - it's just } \\
\text { one night a week - the first week is me just sat } \\
\text { with my folder, my file out and I draw pictures } \\
\text { of what the chakras, they say they look like } \\
\text { from books I've read (Laura) } \\
\text { Like when you're waiting for an interview, you } \\
\text { know things can become out of balance and its } \\
\text { finding that balance between having that little } \\
\text { bit of pressure to make you perform but then } \\
\text { it's going over the top so you don't actually } \\
\text { perform so it's about [...] that's your root } \\
\text { chakra, feeling grounded isn't it so it's about, } \\
\text { thinking about your root chakra you know } \\
\text { maybe putting your hands there, or maybe just } \\
\text { thinking about getting things in balance, } \\
\text { grounding yourself, tree roots coming out your } \\
\text { feet, whatever it is to make yourself feel better } \\
\text { so incorporating it like that all the time (Grace) } \\
\text { happening you'll get an illness [...] it'll tend to } \\
\text { droop and clog and tear and spin the wrong }\end{array}$ & 准 \\
\hline
\end{tabular}




\section{Design and Development of Vignettes}

Both realism and plausibility have been cited as key factors to consider when constructing vignettes (Hughes and Huby 2002; Jenkins et al. 2010). The more realistic and plausible vignettes appear to research participants the richer the data is likely to be. Using data from the Reiki Masters interview transcripts to base the vignettes on helped to ensure their realism as they were grounded in another Reiki practitioners 'real' experience as opposed to one fabricated by the researcher. The rationale for using pain and discomfort as the subject of the first vignette was based on the supposition that most people have experienced physical pain, however mild, at some point in their lives. The rationale for choosing a mental health issue in the second vignette was similarly based on the supposition that most people have felt under pressure or experienced worry at some point in their lives. The rationale for selecting an image of the chakras for the third vignette was that when an individual is taught Reiki, the Master Teacher will often illustrate the teaching of the chakras with images. Pictures of the chakras are readily available in many Reiki books (see, for example, Honervogt 2001; Quest 2002). Thus, it was likely that the image would be familiar to participants.

The textual vignettes were designed based on examples of self use of Reiki extracted from the transcripts of the Reiki Master Teacher interviews. Once the subject of each vignette had been decided the Reiki Masters' interview transcripts were searched for examples of self-use of Reiki relating to these issues and used as a guide to the text that might be included in each vignette. For vignette one, an example provided by Ruth of how she had used Reiki on a broken ankle was used as a base for the vignette. For vignette two, key phrases from relevant extracts of the interviews with Reiki Master Teachers were incorporated into the vignette. For vignette three, keywords or phrases relating to chakras informed the vignette.

\section{Sample}

Within qualitative research, sampling is considered one of the key ways in which quality and rigor of the research is evaluated (Coyne 1997; Curtis et al. 2000; Gibbs et 
al. 2007). Specific approaches to and methods of constructing a sample are likely to differ between studies because as noted by Coyne:

The researcher should find out what information is most needed and most useful in a given situation, and then employ the most suitable methods. (Coyne 1997: 630)

Whilst sampling in qualitative research studies is guided by principles such as what is needed and most useful as noted above by Coyne, as opposed to rigid methods employed in quantitative research, it is generally considered good practise to thoroughly describe the sample and the ways used to obtain it. This section aims to provide a description of the sample as well as a transparent account of how and why sampling decisions were made.

The broad aim of sampling in qualitative research stands in contrast to the broad aim of sampling in quantitative research (Kuzel in Crabtree and Miller 1999). Whilst sampling strategies in quantitative research aim to be statistically representative, sampling strategies in qualitative research aim to 'select information rich cases for studying in depth' (Liamputtong and Ezzy 2005: 45). Two main approaches to sampling are prominent within qualitative research: theoretical and purposive (sometimes referred to as purposeful) (Coyne 1997). Theoretical sampling is a central tenant of grounded theory. Within a theoretical approach to sampling, the collection, coding and analysis of data are undertaken simultaneously (Coyne 1997; Draucker et al. 2007). Choices about whom or what to sample are ongoing and dependent on what emerges from the coded and analysed data. The process of collecting, coding and analysing data is therefore non-linear. A researcher using a theoretical approach to sampling will begin by making an initial decision on what or whom to sample, for example two female general practitioners. Data from these interviews will then be coded and analysed and then, as a direct result of what transpires from these data, further sampling decisions will be made with the aim of developing or challenging the theory or concepts arising from the previous interviews. The decision may be taken 
to continue sampling female general practitioners or to sample male general practitioners. This contrasts with purposive sampling whereby decisions about whom or what will comprise the sample are decided upon in advance and rarely amended or deviated from throughout data collection. As Silverman states;

Purposive sampling allows us to choose a case because it illustrates some feature or process in which we are interested (Silverman 2000:104).

Data is generally coded and analysed after the entire sample has been collected and as such a purposive approach to sampling represents a more linear process than theoretical sampling.

\section{Phase One and Two: Method of Sampling}

A purposive approach to sampling was employed for this study as the research design suggested in advance who would shed light on the research problem (Reiki Master Teachers and Reiki level one and two practitioners) and the concept(s) that it was hoped they would illustrate (the various elements of the Reiki health literacy model, the effects of learning and self use of Reiki and how Reiki health literacy is used in the context of health in daily life).

\section{Phase One: Participants}

Target participants were individuals who had been practising Reiki at Master Teacher level for at least one year and whose main occupation was as a practitioner and / or teacher. A minimum of one year practising at Master Teacher level was set as an inclusion criterion as it was hypothesised that this length of time would provide sufficient experience. Reiki Masters acted as key informants, defined by Holloway (2008) as:

Individuals who have special knowledge about, and are experts on, the history and culture of a group, about interactions and processes in it and cultural 
rules, rituals and language, or who have special knowledge in the topic being researched [...] They have spent more time in the culture or community and have more experience of the setting than other informants (Holloway 2008:139)

Given that the overall focus of the research was on learning and self-use of Reiki, Reiki Master Teachers were deemed the most appropriate key informants as due to their role as teachers they

a) Teach newly trained Reiki practitioners how to self-use Reiki

b) Would be knowledgeable about the benefits one might obtain from learning Reiki and its self-use

c) Would be able to draw on their knowledge of how others to whom they had taught self-use of Reiki had benefited

d) Would be able to draw on their own experience of Reiki self-use

These characteristics gave Reiki Masters advantageous knowledge that one would not expect to be present in level one or two practitioners. Using Reiki Master Teachers as key informants was also consistent with the purposive approach to sampling, that is, they were selected for their potential to illustrate some of the key features of the research; the model of Reiki Health literacy and the use of Reiki for self-care.

\section{Phase Two: Participants}

Target participants were individuals who had undertaken Reiki level one or Reiki level one and two training and who viewed themselves as regular self-users of Reiki. In the original research design, 'regular' self-use of Reiki was defined as at least once per week. However, in the early stages of recruitment to phase two it became clear that this definition was problematic. Telephone conversations with potential participants indicated that whilst some participants used Reiki daily or weekly, others informed the researcher that while they did not use it on a weekly basis they used it if 
they were stressed or unwell for example. Therefore the definition of the term 'regular self-use of Reiki' was modified to be whatever the participant considered to be regular self-use of Reiki.

Participants at level one Reiki were appropriate for inclusion in phase two due to the emphasis within level one training on self-use of Reiki. Level two practitioners were also appropriate participants as there is an expectation underpinning the theory and philosophy of Reiki that level two practitioners will also self-treat. Sampling level two practitioners also provided a contrast in length of Reiki practice within the phase two sample. Whilst comparison between Reiki level one and two was not a key concern of this research, it was anticipated that including participants qualified to level two might provide information as to whether level one training is sufficient to enable a person to achieve all three levels of Reiki health literacy or whether higher levels of training are necessary. As with the decision to sample Reiki Master Teachers, including Reiki level one and two practitioners in the sample was consistent with a purposive approach to sampling, that is, Reiki level one and two practitioners were chosen based on the belief that they would be able to illustrate issues related to self-use of Reiki.

\section{Sample Size}

The literature on sampling in qualitative research tends to focus on the array of sampling strategies and procedures (see for example Coyne 1997) as opposed to determining an acceptable size sample for a qualitative research project. This is likely a reflection of the widely accepted principle within qualitative research that 'the number of participants is less important than the richness of the data' (Liamputtong and Ezzy 2005:49). Reflecting this idea Mason (2002) recommends that when deciding upon how many interviews to include in a sample 'the key question to ask is whether your sample provides access to enough data, and with the right focus, to enable you to address your research questions' (2002: 134). This was the key principle guiding the choice of how many participants to sample. 


\section{Phase One}

The aim was to conduct interviews with ten Reiki Master Teachers who regularly self-used Reiki. When determining the number of Reiki Master Teachers to sample, three considerations relating to the method of data collection, the focus of data collection and the aims of the first phase of the research informed the decision to sample 10. Firstly, Morse (2000) has suggested that methods of data collection influence the number of participants:

The greater the amount of useable data obtained from each person (as number of interviews and so forth), the fewer the number of participants. (Morse 2000:4)

The 'rich' and 'deep' data that unstructured interviews aim to produce and the characteristic absence of a rigid set of questions can often generate high volumes of data. With this in mind, the decision was made to sample 10 Reiki Master Teachers as it was necessary for the researcher to consider how many interviews she could transcribe and analyse single handed within the delineated time of doctoral study. Discussion with the researcher's supervisors resulted in the decision that sampling 10 Reiki Master Teachers was realistic and achievable in the allotted time. Secondly, with reference to Mason's suggestion that the sample should achieve 'the right focus, to enable you to address your research questions' (ibid); the fact that Reiki Master Teachers with at least one year experience of practising at Master Teacher level were to comprise the sample arguably helped to ensure a high degree of focus relevant to the research questions and as such negated the need for a larger sample. Thirdly, phase one of the research was concerned with refinement as opposed to constructing a model that was characteristic of all Reiki practitioners which also negated the need to sample more than 10 .

\section{Phase Two}

The aim was to conduct interviews with 30 Reiki level one and two practitioners who regularly self-used Reiki, however, the final sample comprised 25 participants due to 
difficulties with recruitment (see below). Three factors influenced the decision to sample 30 Reiki level one and two practitioners. Firstly the population from which the sample of Reiki level one and two practitioners was to be drawn was likely to be larger than the population of Reiki Master Teachers. This was based on the hypothesis that it would be uncommon for Reiki Master Teachers to have only one student. Given the size of the population, the aim of achieving variation as well as rich and focussed data suggested a larger sample size. Secondly, the inclusion criteria of having undertaken level one or one and two Reiki and that the participant self-used Reiki on a regular basis helped to achieve focus and ensure that data relevant to the research questions, would be generated. Thirdly, within the context of doctoral research, practical issues of time and human resources had to be considered. After discussing the issue with her supervisors, the researcher was advised that a maximum of 30 level one and two participants could realistically be recruited and interviewed and their interviews transcribed in the allotted period of time.

\section{Sample Diversity}

Data representing a variety of perspectives and from a diverse sample can help to enhance the credibility of findings by demonstrating that the researcher has sought to present a balanced picture and not favoured one particular viewpoint or perspective (Rubin and Rubin 2005). The decision was taken to recruit as diverse a sample as possible in terms of level of Reiki practice, length of Reiki practice, gender, ethnicity and practice setting however doing so was not without its challenges. Reiki as a profession is not formally regulated (that is, it relies on voluntary self-regulation) and because Reiki can be learned for self-use, learning is no indication that a person will go on to practise professionally and therefore register with a professional body. As such, there was no definitive list of Reiki practitioners from which to draw a sample. In the absence of a comprehensive sampling frame, key characteristics such as gender, age or ethnic composition of the Reiki population were unknown in advance of the study. Nonetheless, there were no grounds for suspecting that Reiki Master Teachers or Reiki level one and two practitioners comprised a homogenous group. Reiki can potentially be practised by anyone, and in a variety of settings, for example, private practice and holistic / complementary health centres or clinics. Also, it is practised in 
more innovative settings such as prisons (Rand 2009), residential care and nursing homes (UK Reiki Federation 2009) and cancer care settings (Lorenc et al. 2010). With this in mind, the aim when sampling both Reiki Master Teachers and Reiki level one and two practitioners was to recruit samples that included at least one male practitioner, one practitioner of ethnic origin other than white British and one practitioner working in an 'innovative setting' for each phase of the research. Given that it was determined prior to commencing sampling that the phase two sample as a whole would include participants at different levels of Reiki practice, the researcher was required to think about how this characteristic would be distributed within the sample. A recruitment grid was compiled to help the researcher think about how level of Reiki practice might be distributed within the sample (see table 7.1 below).

Table 7.1: Recruitment Grid for Phase Two Sample

\begin{tabular}{|c|c|c|c|c|}
\hline \multicolumn{2}{|c|}{ Level one Reiki Training } & \multicolumn{2}{|c|}{ Level two Reiki Training } & $\begin{array}{c}\text { Total } \\
\text { Participants }\end{array}$ \\
\hline $\begin{array}{c}\text { More than a } \\
\text { year of } \\
\text { experience }\end{array}$ & $\begin{array}{c}\text { Less than a } \\
\text { year of } \\
\text { experience }\end{array}$ & $\begin{array}{c}\text { More than a } \\
\text { year of } \\
\text { experience }\end{array}$ & $\begin{array}{c}\text { Less than a } \\
\text { year of } \\
\text { experience }\end{array}$ & \\
\hline 8 & 7 & 8 & 7 & 30 \\
\hline
\end{tabular}

The recruitment grid represented an ideal and was intended to provide an approximate indication of the numbers of practitioners at each level of Reiki that needed to be recruited so as to ensure a variety of perspectives. It was acknowledged that in reality the population may not be equally dispersed; and that it might only have been possible to recruit a small number of participants with less than a year's experience but a larger number with more than a year's experience at level one. 


\section{Procedure for Recruitment}

\section{Phase One}

In phase one, the interview schedule was piloted with the researcher's own Reiki Master Teacher (discussed below) who was contacted by telephone and asked to take part in an interview. At the end of this interview the Reiki Master Teacher was asked if he or she knew of other Reiki Master Teachers who might also be willing to participate in an interview. Within the following week, the pilot participant telephoned the researcher with a list of eight names and telephone numbers of Reiki Master Teachers who had given permission to be contacted by the researcher regarding receiving more information about the research. All eight of these Reiki Master Teachers were contacted by telephone over the space of two days and briefed about the research. With their permission, an information sheet was then posted to them. The researcher followed up this letter after one week with a second phone call inviting them to participate and arrange a mutually convenient date and time to meet. During this second phone call, the participant was given the opportunity to ask any questions regarding the research before he or she agreed to participate. Of the eight potential participants provided by the pilot participant, seven agreed to an interview. One Reiki Master Teacher agreed to participate but subsequently withdrew on the grounds of ill health. Two further participants were identified by one of the seven participants. The same procedure was followed when recruiting these two participants to the study, that is, permission was sought to contact them via the original participant. A telephone call was made, an information letter sent and a follow-up phone call made to negotiate a suitable time and date to meet.

\section{Phase Two}

Recruitment to phase two of the research was by seven methods. Table 7.2 (below) summarises for each method of recruitment the total number of potential participants contacted and the actual number who participated in an interview. 


\section{1) Reiki Masters from Phase One}

Six of the ten Reiki Master teachers from phase one were teaching Reiki at the time of interview. One of these six mentioned during their interview that they were not currently in touch with any of their students. Another of these six Reiki teachers stated that they were open to teaching Reiki but had not done so for a number of years. Therefore out of a potential six, four were re-contacted via telephone and asked if any of their students might be interested in participating in an interview. Between these four Reiki Masters, a total of five of their students gave their permission to be contacted by the researcher. Each of the five participants were then contacted by telephone and briefed about the research. During the telephone call the researcher sought permission to post an information sheet to them (see appendix 2). Within a week of posting the information sheet the researcher then telephoned the participant again and invited them to participate. A mutually convenient date and time to meet was then arranged at the end of the telephone call. During this second phone call the participant was given the opportunity to ask any questions regarding the research before he or she agreed to participate. Of the five participants, three agreed to participate in an interview. Agreeing a mutually convenient interview time and date and an illness within the family were the reasons for non-participation of the other two Reiki practitioners.

\section{2) The Reiki Association}

The Reiki association is a community organisation for people who are attuned to Reiki, regardless of whether or not they are a public practitioner. It produces a quarterly magazine which is distributed free of charge to members. Two methods were used to recruit participants via the Reiki Association. Firstly, the regional representative for Yorkshire of the Reiki association was contacted via email. An information sheet was attached to the email and it was requested that she forward the information sheet to anyone she knew who met the inclusion criteria who might be willing to participate. Two individuals contacted the researcher via email expressing a willingness to participate in the research. Both were re-sent the participant information sheet via email and if having read it they were still happy to participate, were asked to contact the researcher via email or telephone to arrange a mutually 
convenient time and date to conduct the interview. One participant went on to attend an interview. Unfortunately a mutually convenient time could not be negotiated with the other interested individual. The Reiki association representative also emailed the contact details of a friend who had consented to her details being passed to the researcher and who was interested in participating in the research. However, when the researcher tried to contact the individual it became apparent that the telephone number was incorrect. The Reiki association representative did not respond to a request from the researcher for the correct telephone number.

Secondly, an advert for the research requesting that potential participants contact the researcher was placed in the Reiki Association Summer 2010 magazine. The advert can be viewed in appendix 3. One individual emailed the researcher after seeing the advert. This participant was emailed a participant information sheet. They then responded, providing their mobile phone number and requested that the researcher telephone them to arrange a mutually convenient time and date for the interview.

\section{CAM Clinic One}

The majority of participants were recruited through a complementary therapy clinic in the South West of England. Whilst presenting this research at a conference in April 2010 the researcher was approached by the manager of CAM clinic one with the offer of visiting the clinic at a later date to conduct interviews. The researcher emailed the participant information sheet to the manager who then forwarded the information sheet to clients that she knew had undertaken Reiki training. The manager of the CAM clinic then made appointments for participants to attend an interview over a 2day period in September 2010. Because the researcher had not had any prior contact with participants before the interview, the researcher provided an overview of the research, checked that the participant had received the information sheet and gave the opportunity for the participant to ask questions or change their mind before commencing the interview. All participants had received the information sheet and were happy to participate. 


\section{CAM Clinic Two}

A colleague of the researcher was previously employed at CAM clinic two and provided the researcher with the contact details for the manager. The researcher telephoned the manager, briefed her about the research and requested assistance with recruiting potential participants. A member of staff at the clinic contacted clients who she knew had undertaken Reiki training and obtained permission for the researcher to contact them. This member of staff supplied the names and contact details of four Reiki practitioners all of whom were then telephoned by the researcher and briefed about the research. Three of the four potential participants agreed to participate however, one withdrew in advance of the interview citing that she did not feel she used Reiki on herself very much and another withdrew on the day of the interview due to ill health. The fourth Reiki practitioner was unable to participate due to a holiday at the time of interview. One participant was interviewed at 'CAM clinic two' in March 2011.

\section{Reiki Masters Who Did Not Participate in Phase One}

To maximise recruitment at CAM clinic two (see above) two Reiki Master Teachers identified using the internet who worked in the area surrounding CAM clinic two were contacted via email and asked if they could suggest any of their students who might be interested in participating in the research. One responded and provided contact details of one of their students who had agreed to be contacted. An information letter was emailed to this potential participant who subsequently agreed to take part in an interview. In addition, a member of staff at CAM clinic one recommended the researcher contact a family member who was a Reiki Master Teacher and who had given permission to be contacted. This Reiki Master Teacher was contacted by telephone and provided the contact details for one of their students who had agreed to participate. Contact was made with this individual who agreed to participate and was interviewed in their own home. 


\section{Personal Contacts}

Throughout the empirical phase of the research it was common for family, friends or colleagues of the researcher to inform her that they knew someone who might be willing to participate in an interview. In all such cases it was stressed that the potential participant must give express permission to be contacted by the researcher. In all cases where permission to contact had been granted, potential participants were contacted either by telephone or letter and briefed about the research. They were informed of the inclusion criteria and, provided they met it, were mailed an information sheet. They were then telephoned a week later and invited to participate. Seven potential participants were identified in this manner and all seven agreed to participate.

\section{Other}

Attempts were made to recruit a final five participants with the aim being to recruit male level one practitioners as a means of adding diversity to the sample. Nine Reiki Master Teachers based in the Yorkshire area who advertised their business online were contacted via email explaining the research and requesting assistance with recruitment. Five Reiki Master Teachers responded to this request and two male level one practitioners volunteered to be interviewed. However, despite the researcher emailing the details relating to the interviews and a request to meet, responses were not received from either potential participant. 
Table 7.2: Method of Recruitment, Potential Participants Contacted and Total Participated

\begin{tabular}{|l|c|c|}
\hline \multicolumn{1}{|c|}{ Method of Recruitment } & $\begin{array}{c}\text { Potential Participants } \\
\text { Contacted* }\end{array}$ & Total Participated \\
\hline $\begin{array}{l}\text { Reiki Masters from Phase } \\
\text { one }\end{array}$ & 5 & 2 \\
\hline The Reiki Association & 4 & 10 \\
\hline CAM Clinic 1 & 10 & 2 \\
\hline CAM Clinic 2 & 4 & 7 \\
\hline Reiki Masters who did not & 2 & 25 \\
\hline Participate in Phase One & 7 & 2 \\
\hline Personal Contacts & & \\
\hline Total & & \\
\hline
\end{tabular}

* Not all participants contacted about the research went on to participate in an interview (see above)

It can be seen from Table 7.2 above that recruitment from CAM clinic one followed by recruitment via personal contacts were the most fruitful methods of recruitment. The least fruitful methods of recruitment were via CAM clinic two and via Reiki Masters who did not participate in phase one of the research. The latter, however, was only used in two specific circumstances rather than throughout the recruitment phase, therefore its usefulness as a method of recruitment cannot be generalised. It was disappointing that similar numbers of participants could not be recruited via CAM clinic two as were recruited via CAM clinic one. It can be speculated that this might have been due to the fact that the researcher had established a pre-existing relationship and rapport with the contact at CAM clinic one, whereas with CAM clinic two the researcher was mediated by a mutual colleague of the researcher and the clinic. Personal contact that already been established in the case of clinic one whereas it was established by telephone with clinic two. 


\section{Sampling Difficulties}

As previously reported, a comprehensive sampling frame for Reiki practitioners does not exist. When sampling Reiki Master Teachers for phase one this did not present a problem; a relatively small sized sample was required and key informants proved happy to assist with the recruitment by recommending other Reiki Master Teachers. In phase two, however, some sampling difficulties became apparent and whilst the intended sample size was 30, it was only possible to recruit 25 Reiki level one and two practitioners to the research in the time available. Additionally, the sample was not as diverse in terms of level of Reiki practice or gender as was initially hoped. The final sample comprised three men (all of whom were Reiki level two practitioners) and three level one Reiki practitioners thus the sample comprised mainly of female level two practitioners with the implication being that the results of this research are potentially reflective only of female level two practitioners (see Chapter Eight for full description of sample).

\section{Interview Process}

Taking on board the approach of self-disclosure as discussed in Chapter Six, the researcher shared with participants that she herself was attuned to Reiki level two and was a $\mathrm{PhD}$ student. It was felt that sharing this information with participants from the outset would enhance rapport and present the researcher as an 'insider' rather than an 'outsider'. The following exchange with Grace, a Reiki Master Teacher, demonstrates the benefit of this self disclosure. In the exchange Grace implies that knowing that the researcher is attuned to Reiki puts her at ease with the conversation and with referring to herself as a Reiki 'Master' which she states most people find 'weird':

INT: Do you prefer the term Reiki teacher or Reiki Master - you said earlier that you're a bit mmmm with Master?

Grace: I use when I'm in general conversation, with you I'm okay with the Master bit because I assume you understand it but with people who don't 
understand it, it can sound a bit grandiose and it can sound a bit weird, I mean Reiki's a weird subject to most people anyway so I don't want to come across as any more weird than I have to.

In some instances, the knowledge that the researcher was herself attuned to Reiki led the participant to assume shared understandings. For example, one participant commented 'You being attuned will realise that it alters your life completely'. In many instances, participants' experiences and understandings were shared by the researcher and this indeed facilitated rapport between interviewer and interviewee. Rubin and Rubin note that:

Openness on the part of the interviewer not only helps the interviewee feel more protected, less exposed, but also helps build empathy. [...] On the other hand, the interviewer needs to be cautions not to hijack the interview and turn it into a self-examination. (Rubin and Rubin 2005:83)

It could be argued that caution not to 'hijack' the interview extends beyond the interview encounter. When transcribing the interviews and when analysing the transcripts the researcher was careful not to assume that due to her status as someone attuned to Reiki, an 'insider', her knowledge and beliefs about Reiki practice were imposed on the participants. This was achieved through reflection and discussion of interview transcripts with supervisors.

It was also common that interviewees asked the interviewer questions relating to her own experiences with Reiki; questions they would not have been able to ask had they not been aware of her status as someone attuned to Reiki:

Natalie: while I was doing him he obviously had a bad shoulder that I didn't know about because you can feel it can't you, you know and erm I do touch, 
I'm a touch - not hard but I do touch and erm I felt things moving - have you ever had that experience?

INT: I haven't no

If and when participants asked the researcher questions during the interviews the researcher answered them as fully and truthfully as possible.

\section{Interview Schedule}

Interview schedules were developed for both phase one and two interviews. In phase one, due to the nature of unstructured interviews, the interview schedule did not function as a rigid set of questions but as a guide to the topics to be addressed along with suggested questions. In phase two, the interview schedule was adhered to more strictly but as is the nature of semi structured interviews the interviewer was free to deviate from the schedule and ask further questions (probes) if appropriate. A summary of the interview schedule used in phase one is presented in Figure 7.4 and the full schedule can be viewed in appendix 4. A summary of the interview schedule used in phase two is presented in Figure 7.5 and the full schedule can be viewed in appendix 5. 
Figure 7.4: Summary of Interview Schedule for Phase one

\begin{tabular}{|c|c|}
\hline Type of Question & Subject \\
\hline \multicolumn{2}{|l|}{ Introductions } \\
\hline \multirow[t]{4}{*}{ Opening / Beginning Questions } & $\begin{array}{l}\text { Length of Reiki practice, Level of } \\
\text { Reiki practice }\end{array}$ \\
\hline & $\begin{array}{l}\text { How participant became involved in } \\
\text { Reiki }\end{array}$ \\
\hline & $\begin{array}{l}\text { Reasons for becoming a Reiki } \\
\text { Master / Teacher? }\end{array}$ \\
\hline & $\begin{array}{l}\text { Main occupation (Reiki Teacher or } \\
\text { other) }\end{array}$ \\
\hline \multirow[t]{4}{*}{ Main questions } & $\begin{array}{l}\text { About being a Reiki Master/ } \\
\text { Teacher }\end{array}$ \\
\hline & Self Use of Reiki \\
\hline & Health \\
\hline & Learning Reiki \\
\hline \multirow[t]{2}{*}{ Closing Questions } & $\begin{array}{l}\text { Anything else about Reiki that we } \\
\text { haven't talked about }\end{array}$ \\
\hline & $\begin{array}{l}\text { Permission to telephone at a later } \\
\text { date if I need to clarify anything } \\
\text { from interview }\end{array}$ \\
\hline
\end{tabular}




\section{Figure 7.5: Summary of Interview Schedule for Phase two}

\begin{tabular}{|c|c|}
\hline Type of Question & Subject \\
\hline \multicolumn{2}{|l|}{ Introductions } \\
\hline \multirow{2}{*}{$\begin{array}{l}\text { Opening / Beginning } \\
\text { Questions }\end{array}$} & Length of Reiki practice, Level of Reiki practice, Length of time at current level \\
\hline & Reasons for learning Reiki \\
\hline \multirow[t]{5}{*}{ Main Questions } & Knowledge of what to expect from Reiki course \\
\hline & What participant learned on course(s) \\
\hline & Self-se of Reiki; frequency, reasons for, disadvantages of \\
\hline & $\begin{array}{l}\text { Health; changes made since learning Reiki, perceived benefits of Reiki to health, use specifically for health, control over health, } \\
\text { views of own health, views of allopathic medicine and mainstream medical views }\end{array}$ \\
\hline & Reiki with others; explaining to others, treating others, participation in Reiki groups \\
\hline Vignettes & $\begin{array}{l}\text { Vignettes } 1 \text { and 2; Knowing when to use Reiki } \\
\text { Vignette } 3 \text {; Recognising chakras }\end{array}$ \\
\hline \multirow[t]{3}{*}{ Closing Questions } & Main advantages of learning Reiki \\
\hline & Anything else about Reiki not covered by interview \\
\hline & Permission to telephone at a later date to clarify anything from interview \\
\hline
\end{tabular}




\section{Piloting and Refinement of the Interview Schedules}

\section{Phase One}

The interview schedule for phase one was piloted with the researcher's own Reiki Master Teacher and amendments resulting from the pilot interview can be seen in figure 7.6. Only one amendment relating to a prompt aimed at exploring the level of skill involved in performing a Reiki treatment was made. Figure 2 shows this post pilot amendment.

Figure 7.6: Amendment made to interview schedule post pilot

\begin{tabular}{|c|c|}
\hline $\begin{array}{rrr}\text { Pilot } & \text { Interview } & \text { Schedule } \\
\text { Questions } & & \\
\end{array}$ & $\begin{array}{r}\text { Final } \\
\text { Questions }\end{array}$ \\
\hline $\begin{array}{l}\text { Can you tell me some more about using } \\
\text { Reiki on yourself? } \\
\text { PROMPT: How would you describe the } \\
\text { level of skill involved in giving either } \\
\text { yourself or someone else a Reiki } \\
\text { treatment? For example is it a basic skill, } \\
\text { advanced? Why is this? }\end{array}$ & $\begin{array}{l}\text { Can you tell me some more about using } \\
\text { Reiki on yourself? } \\
\text { PROMPT: How would you describe the } \\
\text { level of skill involved in giving either } \\
\text { yourself or someone else a Reiki } \\
\text { treatment? For example is it a basic skill, } \\
\text { an easy thing to do? Why is this? }\end{array}$ \\
\hline
\end{tabular}

N.B Amendment is indicated by italics

When the question was asked in the original format (see above) the pilot participant responded by saying 'how do you mean?' Thus within the final topic guide the prompt was more direct and instead probed whether giving a Reiki treatment was an easy thing to do. Because the interviews with Reiki Master Teachers were unstructured, the exact questions posed to each participant varied and questions were tailored to each participant's circumstances. For example if it became apparent in an interview that the participant did not currently teach Reiki, the questions relating to what they teach at each level of Reiki were modified to explore what they themselves learned at each level of Reiki. Similarly, some questions were tailored for individuals 
who worked with Reiki in specialist fields to include specific questions about Reiki in their field of work.

\section{Phase Two}

The interview schedule for phase two was piloted with four participants. The first pilot interview was carried out with a former colleague of the researcher who is attuned to Reiki level one and employed as a research assistant. Piloting the interview schedule with this individual meant that it was possible to gain feedback on the understanding and acceptability of the questions both from the point of view of a Reiki practitioner and an experienced researcher. Given that the researcher was also recruiting Reiki level two practitioners, the decision was taken to treat a further three interviews as pilots. Doing so enabled piloting of the interview schedule with practitioners at level two and who had been practising Reiki for longer than the first pilot participant. All pilot interviews were included in the final analysis.

During the phase two piloting, a process was put in place to explore if the interview questions were 'working', that is, that they were capturing different elements of the Reiki health literacy model. A grid was constructed with the items from the health literacy model down one side and the participant's interview code number across the top. Ticks or examples from the interviews as appropriate were then placed in the boxes if participants made reference to each skill within their interview. This helped to identify if there were any areas of the model of Reiki health literacy that participants were consistently not addressing. (See appendix 6 for 'grid')

Following the pilot interviews amendments were made to five questions. Three amendments were made to aide clarity; one question was changed from being a closed question to an open question. These four amendments can be seen in Figure 7.7 (below). 
Figure 7.7: Amendments Made to Interview Schedule Post Pilot

\begin{tabular}{|l|l|}
\hline Pilot Interview Schedule Questions & Final Interview Schedule Questions \\
\hline $\begin{array}{l}\text { Do you have any friends or family that do } \\
\text { Reiki? If so do you talk to them about } \\
\text { Reiki - share ideas/ help each other? }\end{array}$ & $\begin{array}{l}\text { How do you explain Reiki to family and } \\
\text { friends? }\end{array}$ \\
\hline $\begin{array}{l}\text { Do you feel that using Reiki on yourself } \\
\text { has helped you to prevent ill health or } \\
\text { maintain good health? }\end{array}$ & $\begin{array}{l}\text { Talk me through what sort of things you } \\
\text { do to keep yourself healthy }\end{array}$ \\
\hline $\begin{array}{l}\text { Do you have any friends or family that do } \\
\text { Reiki? If so do you talk to them about } \\
\text { Reiki - share ideas/ help each other? }\end{array}$ & $\begin{array}{l}\text { Do you give Reiki to anyone else? } \\
\text { ill health? }\end{array}$ \\
\hline $\begin{array}{l}\text { Vignette 3: Picture } \\
\text { Have you ever been in a situation similar } \\
\text { to this? } \\
\text { If so what did you do? }\end{array}$ & picture? \\
\hline
\end{tabular}

In addition to the above noted amendments to the interview schedule resulting from the pilot phase, one further amendment was made to the interview schedule after the ninth interview. It became clear that the question Talk me through the sorts of things you do to keep yourself healthy was not generating relevant data. This question was intended to generate data relating to whether participants felt able to take steps to prevent ill health from occurring by self-treating with Reiki; however participants tended to give examples not relating to Reiki such as healthy eating or exercise. It was therefore amended to read would you give yourself a treatment even if you were in good health? 


\section{Data Analysis}

\section{Phase One and Phase Two}

Content analysis was undertaken on the data from the unstructured interviews in phase one and the semi-structured interviews from phase two. As a method, content analysis can be applied to both quantitative and qualitative data (Elo and Kyngas 2008) and with a variety of different types of data; written, verbal or visual data (Cole 1988 in Elo and Kyngas 2008). Hsieh and Shannon (2005) define qualitative content analysis as follows:

a research method for the subjective interpretation of the content of text data through the systematic classification process of coding and identifying themes or patterns. (Hsieh and Shannon 2005:1278)

The authors also identify three specific approaches to content analysis: conventional, directed and summative. When using a conventional approach to content analysis, codes are not predetermined; rather, they are based on and emerge from the data. In comparison, a directed approach to content analysis uses existing knowledge or theory as the basis for initial coding categories. The third approach to content analysis, a summative approach, involves counting keywords. These keywords reflect the interest of the research or may be derived from the literature (Hsieh and Shannon 2005). Two approaches to content analysis were used for each of the different phases of the research. A directed content analysis approach was used to analyse the Reiki Masters' interview transcripts because it was conducive to the aim of confirming and refining the Reiki health literacy model. As noted by Hsieh and Shannon, the use of directed content analysis is useful when the goal 'is to validate or extend conceptually a theoretical framework or theory' (Hsieh and Shannon 2005:1281). In this case the theoretical framework was the Reiki health literacy model. Within phase two a combination of directed content analysis and conventional content analysis was used. 


\section{Process}

All interviews from both phases of the research were tape recorded and then fully transcribed by the researcher. Pseudonyms were also assigned to each transcript. The interview transcripts were then proof-read for typographical errors before being reread and summarised. Reading the transcripts numerous times ensured familiarity and facilitated immersing oneself in the data (Elo and Kyngas 2008). Summaries of each transcript were then compiled wherein demographics and seemingly relevant or interesting points were noted (relevant or interesting points were defined as anything that was in line with aims of the research, for example self-use). The unit of analysis was the interview transcript and the summaries were intended as a quick reference guide for the researcher.

\section{Phase One}

A distinct feature of a directed approach to content analysis is that an initial coding scheme is derived from existing theory. Consistent with this, an initial coding scheme was devised consisting of words or phrases that reflected or summarised key concepts included in the Reiki health literacy model (Figure 7.8). 
Figure 7.8: Initial Codes for Phase one

\begin{tabular}{|l|l|}
\hline \multicolumn{1}{|c|}{ Code } & \\
\hline Skills & a) Practical \\
& b) Theory / Knowledge \\
& c) Pre-existing \\
\hline Benefits & a) Health Physical \\
& b) Health Mental \\
& c) Health Emotional \\
& d) Relaxation \\
\hline Feelings associated with self - treatment & e) Empowerment \\
\hline Knowing when to self-treat & f) Self-Care \\
\hline Energy & g) Health Maintenance \\
\hline
\end{tabular}

Using this initial coding scheme, the researcher coded two transcripts using the review / comment facility in Microsoft Word. This process was repeated twice for each transcript to ensure nothing had been missed. Sections of the text that had been coded were highlighted yellow and then transferred into a separate document and arranged under coded headings. Text that had not been coded (that is, any text not highlighted in yellow) that did not appear to reflect the existing codes was reexamined to determine if it represented a new code or a sub-category of an existing code. The coded text was then checked to ascertain that the assigned codes accurately represented the text that had been assigned to it and, where necessary, code names where adjusted. 


\section{Phase Two}

For phase two, five interview transcripts were read and the first impressions were noted and recorded along with the participants' field notes. Each interview transcript was then re-read and notes were made on the document using the review / comment facility in Microsoft Word.

One of the objectives of the research was to confirm and refine the mode of Reiki health literacy, therefore some of the notes that were made on the transcripts reflected the codes used in the phase one coding scheme, that is, they were codes that reflected the initial model of Reiki health literacy. For example, when a participant spoke of learning about chakras on their course this was coded as FRHL (an abbreviation of functional Reiki health literacy). Where a participant spoke of using Reiki on themselves this was coded as IRHL (an abbreviation of interactive Reiki health literacy). The full coding scheme can be viewed in appendix 7 and an abridged version can be viewed in figure 7.9.

\section{Figure 7.9: Initial Codes for Phase two (abridged)}

\begin{tabular}{|l|l|}
\hline \multicolumn{1}{|c|}{ Code } & \multicolumn{1}{c|}{ Sub-Code } \\
\hline Functional Reiki Health Literacy & Eight sub-codes see Appendix 7 \\
\hline Interactive Reiki Health Literacy & Fifteen sub-codes see Appendix 7 \\
\hline Critical Reiki Health Literacy & Six sub-codes see Appendix 7 \\
\hline Background & \\
\hline Health Literacy & \\
\hline Stress & \\
\hline Context & \\
\hline Combining & \\
\hline Meditation & \\
\hline Spirituality & \\
\hline Lineage & \\
\hline Reiki Principles & \\
\hline Effects & \\
\hline Visualisation & \\
\hline $\begin{array}{l}\text { Examples of participant asking questions } \\
\text { of interviewer }\end{array}$ & \\
\hline Awareness & \\
\hline Intuition / Sensing & \\
\hline
\end{tabular}


Sections of text that could not be coded according to the model of Reiki health literacy were coded using exact words or phrases used by the participant, for example when a participant spoke of practising meditation, a new code called 'meditation' was created. Additionally when a suitable word or phrase did not capture what the participant was talking about, a generic code was created. For example, when a participant spoke of how they had a background in chemistry and had worked in laboratories, this was coded as 'participant background'.

\section{Trustworthiness of Researchers Interpretations}

In an attempt to ensure the credibility of the researcher's interpretations of the data and to minimise researcher subjectivity, the supervisory team were involved in the early stages of coding the interview transcripts. For phase one, the researcher independently coded two interview transcripts and a meeting was held with the supervisory team to discuss whether the researcher's interpretation of what was being said or implied by the interviewee was the same as the supervisor's interpretation. On the whole, the supervisor's interpretations were consistent with the researcher's, with some minor variations noted. These variations were incorporated into the final coding scheme which was then uploaded onto Nvivo (v8) and applied to all of the ten transcripts. The lead supervisor also independently applied the coding scheme to one transcript as a way of verifying that the coding scheme 'worked'. For phase two, one transcript was coded by the researcher and the same transcript was also coded independently by two members of the supervisory team. A meeting was then held to discuss the transcript and both members of the supervisory team agreed that the coding scheme appeared to be working well and they had not encountered any problems in applying the codes to the transcript. The coding scheme was then uploaded onto Nvivo (v8) and applied to all 25 transcripts.

\section{Concluding Comments}

This chapter presented and provided insight into the way the empirical phase of the $\mathrm{PhD}$ research was undertaken, including methods of recruitment of participants, data collection tools and the process of data analysis. In the spirit of qualitative research, 
the researcher has tried to make the processing, analysis and interpretation of data phases open to external scrutiny, to enable the reader to come to an understanding of why things were done as they were and how they were done. Throughout, emphasis lay on ensuring that the fieldwork was undertaken in a rigorous and ethical manner. The thesis now turns to exploring the findings from the empirical phase, beginning in Chapter Eight which reports on the analysis and interpretation of the unstructured interviews with Reiki Master Teachers. 


\section{Chapter Eight: Exploration of the Reiki Health Literacy Model with Reiki Master Teachers}

\section{Introduction}

The aim of phase one of the research was to confirm and refine the model of Reiki health literacy. This chapter will report on the analysis and interpretation of the unstructured interviews with Reiki Master Teachers. Discussion of the interview data will be guided by the three levels of the Reiki health literacy model (presented in Chapter Five), specifically the skills and knowledge that comprise each level. Structuring the results in such a way is in line with a directed approach to content analysis (Hsieh and Shannon 2005). Attention will be drawn to confirmatory and disconfirming evidence for the components of each level within the initial model and the additional components suggested by the data that refine the model. Prior to discussing the data, however, key characteristics such as ethnic origin, age group, field of work ${ }^{3}$ and length of Reiki practice of the sample are described.

\section{Participants}

Ten Reiki Master Teachers were interviewed and their details are summarised in Table 8.1. With the exception of a non-white British practitioner, the aim of sampling at least one male practitioner and one practitioner working in an 'innovative setting' was met.

${ }^{3}$ The field of work rather than the specific occupation of participants is presented here to protect anonymity. 
Table 8.1: Key Characteristics of the Sample

\begin{tabular}{|l|l|l|c|c|}
\hline Name & $\begin{array}{l}\text { Age } \\
\text { Group }\end{array}$ & Field of work & $\begin{array}{l}\text { Length of Reiki Practise } \\
\text { Years })\end{array}$ & $\begin{array}{l}\text { Current } \\
\text { Teacher }\end{array}$ \\
\hline Karen & $70+$ & $\begin{array}{l}\text { Retired CAM } \\
\text { Practitioner }\end{array}$ & 16 & No \\
\hline Ruth & $51-59$ & Retired Healthcare & 12 & Yes \\
\hline Annie & $60-69$ & CAM Practitioner & 11 & Yes \\
\hline Wendy & $31-40$ & CAM Practitioner & 10 & No \\
\hline Hazel & $51-59$ & Healthcare & 9 & Yes \\
\hline Deborah & $51-59$ & Healthcare & 7 & Yes \\
\hline Laura & $41-50$ & CAM Practitioner & & No \\
\hline Anthony & $41-50$ & CAM Practitioner & 5 & Yes \\
\hline Natalie & $60-69$ & Retired Healthcare & & \\
\hline Grace & $51-59$ & Healthcare & & \\
\hline
\end{tabular}

Participants were all of white British background and a range of ages. The youngest Reiki Master Teacher was in the age group 31- 40 and the eldest Reiki Master teacher was in the 70+ age group. Longer length of Reiki practice was not necessarily associated with increased age. The eldest Reiki Master Teacher had been practising Reiki for the longest length of time (16 years) and the youngest participant had been practising Reiki for 11 years. There was little variation between participants' field of work, with Reiki Master Teachers being employed as either a CAM practitioner or within the field of healthcare. In some respects, it is unsurprising to find that half of the sample comprised CAM practitioners (or retired CAM practitioners) given that target participants were Teachers of Reiki. However, it is interesting that the other half of the sample comprised Reiki Teachers who worked in the healthcare field. 


\section{Interpretation of Interview Data}

\section{Functional Reiki Health Literacy}

The commonly accepted definition of functional health literacy is;

'Sufficient basic skills in reading and writing to be able to function effectively in everyday situations'. (Nutbeam 2000:263)

This definition was first used within the field of literacy studies and has been applied to the context of health. Functional health literacy involves the use of the same basic skills (that is, reading and writing); however, the context in which they are applied is different. Rather than everyday situations, basic reading and writing skills are applied in the context of everyday health decision making (Nutbeam 2010). Functional Reiki health literacy involves acquiring the basic skills that are specifically taught within a Reiki course. These basic Reiki skills are the 'essentials' that enable a person to use the Reiki system effectively and make everyday health decisions informed by basic knowledge of Reiki philosophy and practise.

The interview data will now be explored firstly in relation to the initial model of functional Reiki health literacy and then in relation to the refined model. Two skills reflecting functional Reiki health literacy were initially derived from a reflection of the underlying theory, philosophy and practise of Reiki. An additional seven skills and competencies emerged from the data that together with one of the initial two, it will be argued, comprise functional Reiki health literacy. Figure 8.1 summarises the components of functional Reiki health literacy that will now be discussed. 
Figure 8.1: Summary of Components of Functional Reiki Health Literacy

\begin{tabular}{|l|l|}
\hline $\begin{array}{l}\text { Functional Reiki Health Literacy: } \\
\text { Initial Model }\end{array}$ & $\begin{array}{l}\text { Functional Reiki Health Literacy: } \\
\text { Refined Model }\end{array}$ \\
\hline $\begin{array}{l}\text { Ability to self- treat with Reiki and ability } \\
\text { to give a Reiki treatment to family or } \\
\text { friends }\end{array}$ & $\begin{array}{l}\text { Knowledge of how to self- treat with } \\
\text { Reiki and knowledge of how to give a } \\
\text { Reiki treatment to family or friends. }\end{array}$ \\
\hline $\begin{array}{l}\text { Functional Reiki Health literacy reflects } \\
\text { the practical aspects of Reiki }\end{array}$ & $\begin{array}{l}\text { Receiving a Reiki attunement and } \\
\text { knowing what to expect from the } \\
\text { attunement }\end{array}$ \\
\hline & Basic knowledge of what Reiki is \\
\hline & Basic knowledge of energy \\
\hline & Knowledge of protection \\
\hline & Kasic knowledge of chakras \\
\hline & Knowledge of grounding \\
\hline
\end{tabular}

\section{Functional Reiki Health Literacy: Initial Model}

- Ability to Self-treat with Reiki and Ability to Give a Reiki Treatment to

\section{Family or Friends}

The main skill associated with functional Reiki health literacy within the initial model was the ability to self-treat with Reiki and the ability to give a Reiki treatment to family or friends. When constructing the initial model, this skill was identified as being a functional Reiki health literacy skill simply because it is a basic Reiki skill and functional health literacy is a basic level of health literacy. However, it is noteworthy that autonomy or action is not implied within definitions of functional 
health literacy. Rather, the emphasis is on acquiring or having knowledge more than actively applying the knowledge to participate in an activity. Self treating with Reiki or treating a family member or friend is not a passive activity; it is an active application of knowledge. Referring to this skill as having the ability to self treat with Reiki or treat family and friends suggests ambiguity as to whether a person actively self treats or performs a treatment on others. This component of functional Reiki health literacy will therefore be more accurately referred to in the refined model as knowledge of how to self- treat with Reiki and knowledge of how to give a Reiki treatment to family or friends.

\section{- Knowledge of How to Self-treat with Reiki and Knowledge of How to Give a Reiki Treatment to Family or Friends.}

Interviews with Reiki Master Teachers confirmed that teaching their students how to self treat and how to give a Reiki treatment to others was part of their Reiki training. All of the eight participants who at the time of interview taught Reiki said that they taught students how to give themselves a Reiki treatment. This was described by Reiki Master Teachers in differing ways; sometimes as 'how to give themselves a Reiki treatment', sometimes 'the hand positions', 'how to self treat', or 'how to use it on themselves'. Two examples are provided below to illustrate this;

\footnotetext{
'When you're first taught Reiki [...] in level one, you're taught about the hand, the twelve hand positions' (Hazel)
}

'Well the first level of Reiki we teach people how to do a hands-on treatment for themselves and other people' (Ruth)

Reiki Masters were also asked how they would describe the level of skill involved in giving oneself a Reiki treatment. As the interview extracts below demonstrate, self 
treatment with Reiki was considered by the Reiki Master Teachers as 'easy', 'simple' and involving little or no skill;

'Very very little skill to give yourself Reiki' (Grace)

'Oh it's very easy; there's no skills, no skill involved at all, you just literally lay your hands on and wait for the Reiki it's as simple as that' (Laura)

Just over half $(n=6)$ of the Reiki Master Teachers said that showing their student how to give a Reiki treatment to another person was a feature of their level one teaching. It was only with reference to their level one course that Reiki master teachers discussed this issue. The quote from Wendy (below) addresses the issue of giving a Reiki treatment to another person. Wendy does not encourage her students to give Reiki to too many people other than family and friends and places emphasis on self treatment rather than treating others;

People go away from the weekend knowing how to use it on themselves, how to do it basically on a friend or a family member, I don't really encourage them to do it on too many other people at that stage although obviously they can get insurance but you know, I think it's best ... from my point of view I started doing it for me and I always say that to everyone else - just do it for you and see where you get to because not everyone's destined to be a Reiki teacher (Wendy)

There was variation amongst the Reiki master teachers as to 'who' Reiki could be given to by the Reiki level one student. Similar to Wendy (above), Anthony and Karen spoke of showing their level one student how to give a Reiki treatment to friends or family only;

Just doing it on friends and family (Anthony) 
If they wanted they could maybe practise on a family member and see what happened (Karen)

Other Reiki Master Teachers did not specify to whom a Reiki level one student could give a Reiki treatment and in the case of Annie and Ruth (below), instead used generic terms such as 'someone' or 'other people';

How to give a Reiki session to someone (Annie)

Well the first level of Reiki we teach people how to do a hands-on treatment for themselves and other people. (Ruth)

In summary, two reasons suggest that knowledge of how to self-treat with Reiki and knowledge of how to give a Reiki treatment to family or friends is a functional Reiki health literacy competency. Firstly, functional health literacy is characterised by possessing 'basic' skills; it therefore follows that functional Reiki health literacy is also characterised by possessing 'basic' skills. Self treatment and treating others is taught within the first level of Reiki training wherein the most 'basic' Reiki skills are taught. Secondly, self-treating with Reiki was frequently described by Reiki Master Teachers as easy or simple, adding strength to the suggestion that it is a basic and therefore functional Reiki health literacy skill.

\section{- Functional Reiki Health Literacy Reflects the Practical Aspects of Reiki}

The initial model of Reiki health literacy suggested that functional Reiki health literacy reflects the practical aspects of Reiki as opposed to the theoretical or knowledge-based aspects. However, it became apparent when examining the Reiki Masters' data that whilst many practical skills are taught within the first level of Reiki training, many more basic competencies are taught that are knowledge-based 
competencies, for example: knowing what to expect from having a Reiki attunement, knowing what Reiki is and its history, knowledge of chakras, knowledge of grounding and how to ground oneself, knowledge of protection and how to protect oneself, and knowledge of symbols (all discussed below).

Whilst much of this knowledge does have a practical application --for example, grounding oneself is a practical application of knowing how and why it is important to ground oneself -- it is important to distinguish between knowing how to apply knowledge and actively doing so. This distinction between possessing knowledge and putting knowledge into practice is an important one in defining functional Reiki health literacy. Functional Reiki health literacy, as with functional health literacy, emphasises the passivity of the individual as a 'receiver' of information as opposed to an individual who 'acts' upon that information.

\section{Functional Reiki Health Literacy: Refined Model}

In addition to the two components of functional Reiki health literacy discussed above, the interviews helped to identify the following seven areas that refined the initial model.

\section{- Receiving a Reiki Attunement and Knowing what to Expect from the} Attunement

The process by which a person acquires the ability to practise Reiki is called 'attunement.' This was reinforced by Deborah and Wendy; Deborah pointed out that an attunement is the only way that the ability to 'do' Reiki can be acquired and Wendy similarly notes that the sole reason for receiving an attunement is to enable a person to 'do it' (Reiki);

'You can only become to Reiki if you attune yourself through a Reiki master, that's the only way you can do it' (Deborah) 
'I get people coming you know who think oh will I be able to do it [...] you say to them 'look the whole point of an attunement is that you will be able to do it' and then you give them this attunement which takes -- what? -- three minutes, something like that and bingo, it's coming through their hands [...]' (Wendy)

All but one Reiki Master Teacher (Natalie was not currently teaching) stated that having an attunement was part of their Reiki level one teaching. Two examples illustrate this; both Grace and Ruth pointed out that Reiki level one involves receiving four attunements;

'Reiki one consists of four attunements' (Grace)

'There are four attunements to Reiki one so we do two attunements on the first day and two on the second' (Ruth)

Hazel stated that she discusses the attunement with her students although she did not specify the exact nature of that discussion;

'We discuss the attunement, we discuss all the ethics, professional issues, charging and all things like that in our ... we take it back to the basic level basically’ (Hazel)

The actual process of attunement is only learned by a Reiki student if and when they reach the Master level. Level one and two students are requested to keep their eyes closed during their attunement (Quest 2002). However, one other Master Teacher talked about what to expect from a Reiki attunement after the student had received it. Karen noted that although everyone experiences an attunemet differently, a student of level one Reiki might expect that their life 'alters' completely. In the quote below, Karen refers to the interviewer and her knowledge that the interviewer herself is attuned to Reiki; 
'So we just had a general chat and then I told them really what to expect when they were attuned, I mean everyone experiences it differently but I had to ... you being attuned will realise that it alters your life completely and I said if you're not willing for that to happen you know then forget it'" (Karen)

Karen was the only Reiki Master teacher to state that she discusses what to expect after an attunement with her students. Whilst none of the Reiki Master Teachers explicitly stated so, it is possible that they may talk to their students about the attunement when they discuss with their students 'what Reiki is' (below).

In summary, receiving a Reiki attunement is a component of functional Reiki health literacy because it is an inherent part of learning Reiki - it is the sole means by which a person is able to channel Reiki energy. This in itself suggests it is a basic skill. Receiving a Reiki attunement enables a person to function within the Reiki system just as possessing basic skills in reading and writing enable a person to function in everyday health situations.

\section{- Basic Knowledge of What Reiki Is}

Most of the Reiki Masters stated that they teach their Reiki level one student what Reiki is. Often this included the history of Reiki. To Laura, the history of Reiki is a 'basic' and to Annie talking about the history of Reiki is a means of putting the first degree course into a framework;

'I give out their handouts, all the information is in there for chakras, obviously about Reiki, the history of Reiki, about Usui, what it's used for, I cover all the basics' (Laura) 
'In the first degree Reiki there is an introduction to Reiki and a little talk about what exactly Reiki is [...] and then we talk a little bit about the history of Reiki just to sort of put it into a particular framework because I think people like frameworks' (Annie)

None of the Reiki Master Teachers elaborated on exactly what they taught students that Reiki was; indeed, this was not a component of the interview schedule. However, Annie volunteered this information unprompted. Annie explained that Reiki is a universal principle and that human beings have the ability to 'tap' into a life force energy;

'People think that Reiki is Japanese [...] but actually it isn't at all. It's a universal principle that sort of ascribes to the theory that there is, that we are part of the whole and that there is a wonderful sort of life force energy that we can tap into and we do it unknowingly $99.9 \%$ of the time' (Annie)

Notably, however, there is a potential difference between a Reiki Master such as Annie's interpretation of what Reiki is and the understanding of what Reiki is from the perspective of a level one or two student. Potentially, understandings of Reiki as outlined in the above quote may reflect a more in-depth and sophisticated understanding of Reiki and therefore higher levels of Reiki health literacy.

In summary, for an individual to function effectively, that is, use the Reiki system, it follows that one of the first and most basic competencies that the individual needs is a basic knowledge of what Reiki is. Within the Reiki Master Teachers' interviews, teaching 'what Reiki is' included information on chakras, the history of Reiki, Dr Usui, uses of Reiki, and what 'exactly' Reiki is. The fact that this information forms part of the first level of Reiki teaching (the most basic level) suggests that a basic knowledge of what Reiki is as being a functional Reiki health literacy competency. 


\section{- Basic Knowledge of Energy}

The word 'energy' was often used by Reiki Master Teachers as a distinct concept to be understood and taught. Wendy said that she teaches the ideas behind energy such as the fact that not being able to see or feel energy does not negate its existence;

'You've got to be able to understand how energy works so I teach quite a lot about the ideas that are behind it, you know the idea that we might not be able to see it and some people can't even feel it but it doesn't mean it doesn't exist. So that's the kind of thing I would go into [at level one Reiki]' (Wendy)

The concept of energy appeared multifaceted within the interviews. Whilst Reiki itself is a specific type of energy, participants also talked about teaching their students how to protect their 'own energy' from 'negative energies' and about energy being 'dense' (see Hazel below).

In summary, energy is one of the key concepts underpinning the Reiki system, thus suggesting it to be a functional Reiki health literacy competency.

\section{- Knowledge of Protection}

Hazel explained that people who are attuned to Reiki are more open to 'dense' energies and that using protection enables a person to prevent such energies from entering the aura. Hazel also specified some techniques that may be used to protect oneself, such as putting oneself into a golden bubble or cloak or asking Saint Michael for protection;

'If you're a Reiki person and you're developing yourself and you get lighter and lighter, you're more open to dense energies as it were. So by putting yourself into a golden bubble or a cloak or Saint Michael or whatever you'd like to do for that protection, it protects you and you won't be affected so much by somebody who's an argumentative sort or whatever you know, you're 
able to see it. But and if you go into a room or you've had a busy day or whatever as I've said before you go home absolutely shattered that's because you've absorbed all the energies. But if you could protect yourself you can rid yourself of a lot of ... you're not exposed to those energies or...well you're exposed but it doesn't come into your aura as it were' (Hazel)

Three other teachers also spoke of teaching students how to protect themselves and emphasised the importance of doing this. Laura even suggests that protecting oneself is a 'massive tool' that could be taught to people prior to learning Reiki;

'You teach people how to protect themselves before anything else, before they've even... there's one massive [participant's stress] you know tool before you've even started, and if you learn the Reiki on top of that it's... it doesn't cure problems but it certainly helps' (Laura)

In summary, the importance that Reiki Master Teachers attached to knowing how to protect oneself suggests it to be a functional Reiki health literacy competency. Functional health literacy enables a person to function effectively within the health system, which may involve for example making decisions. Not knowing how to protect oneself and subsequently doing so (actually doing so being an interactive Reiki health literacy competency) impairs an individual's ability to function effectively within the Reiki system as they may be more 'open' to dense energies and affected by argumentative people.

\section{- Basic Knowledge of Chakras}

Both Grace and Annie talked about the chakras in relation to Reiki. Annie pointed out how the chakras relate to Reiki and Grace noted that learning Reiki facilitates self development and awareness and how learning about the chakras in level one Reiki is a part of this; 
'I say it's about self development as well learning Reiki even if it's just your own self development and self awareness. So that's the benefits there and people just, because they're learning about the chakras and how, how the chakras are affected by different things and then the knock on effect of that' (Grace)

'Most of the hand positions will lock in to the positions of the chakras but you don't need to know that. My Reiki master didn't know one chakra from another, she hadn't a clue' (Annie)

Not all Reiki Master Teachers spoke of teaching about the chakras and, among those who did, there were differences between the levels of Reiki that this information was taught with Laura teaching it at level one and Hazel at level two;

'I get my folder, my file out and I draw pictures of what the chakras, they say they look like from books I've read and [...] all the information about ... and I give out their handouts, all the information is in there for chakras' (Laura)

'If the person takes it to the second degree because not everybody wants that at all we just develop that knowledge really and then we talk about the distance healing and then we teach the symbols, we still go through the ethics, maybe the chakras' (Hazel)

Reiki Master Teachers who did not talk about teaching their students about the chakras often talked about the chakras in other contexts; for example, Deborah spoke of her chakras being in balance (or not), Karen spoke of clearing her own chakras and Wendy spoke factually of the chakras, thus demonstrating knowledge and awareness of them. Upon close examination of the interview transcripts, neither Ruth nor Anthony spoke at all of the chakras. 


\section{Knowledge of Grounding}

Grounding was mentioned by three out of the ten Reiki Master Teachers. Annie uses the idiom 'keep your feet firmly planted on the ground', meaning maintaining a practical and realistic outlook, to express why a person who practises Reiki may want to ground themselves;

'Sometimes when you're working, sort of energy things and you're working on sort of a different level there can be an airy fairy sort of feeling with it you know, can get quite high with these things and I think you know like the old saying you need to keep your feet firmly planted on the ground, you know be of the world and so it's quite good to use the Reiki in that way to keep yourselffirmly in a really good place and not you know allowing yourself to get too spacey and over there...' (Annie)

Furthermore, she describes a specific technique that may be used for grounding oneself;

'If you're feeling wobbly, you know just by sort of holding, cupping a foot, it sort of helps to just bring you back down a bit if you're feeling a little bit up there or a bit spaced out for any reason at all, it's very good for grounding' (Annie)

Wendy placed great emphasis on teaching her students how to ground themselves using the 'tree' method;

' [...] right from level one I introduce people to the tree [a technique for grounding] and I say to them that is the most important thing you can do, even if you never do anything else do the tree, be a tree, because you're giving yourself Reiki while being a tree you're mending your aura, you're mending your energy system, it's flowing through you better, your whole energy system 
is being repaired by being a tree then it lends itself to you being a better channel as well' (Wendy)

In summary, knowledge of grounding is seen as important for a number of reasons. It helps to prevent 'airy fairy' and 'spacey' feelings that may be a side effect of working with Reiki, as noted by Annie. Grounding is also beneficial to the self and helps to channel Reiki more effectively as noted by Wendy. It is therefore a competency that helps a person to function effectively in the Reiki system. As with knowledge of protection (above), knowledge of grounding also has an obvious practical application. However, functional Reiki health literacy, in line with Nutbeam's (2000) conceptualisation of health literacy, does not promote interactive communication or autonomy. Actually putting knowledge of grounding into practice would represent more of an interactive Reiki health literacy skill.

\section{- Knowledge of Symbols}

Three symbols are taught at level two Reiki and a fourth symbol is taught at Master level Reiki. Acquiring knowledge of the symbols and the ability to draw the symbols appeared to be viewed by Reiki Master Teachers generally as an 'add - on' to Reiki level one teaching. Both Annie and Wendy note that at Reiki level two, when a Reiki student would first encounter the symbols, the student is working in the same way, building on Reiki level one with the symbols being 'introduced' or 'added on';

'Here [level two Reiki] we're working in exactly the same way as with the first degree but we have the introduction of the symbols which move the level of the Reiki up just a little bit' (Annie)

'It's really about building on the level one so you don't, it's not as if we're changing anything because that still all stands and then it's just adding on the symbols' (Wendy) 
Having knowledge of symbols was demonstrated by all the Reiki Master Teachers that were interviewed. It is an example of a functional Reiki health literacy competency because it involves the communication of factual information. As with grounding and protection, knowledge of symbols also have a practical application, that is they can be drawn and used for a variety of purposes and in a variety of situations. However, drawing them and using them would indicate an interactive level of Reiki health literacy, whereas simply possessing knowledge of them represents a functional Reiki health literacy competency.

\section{Summary of Functional Reiki Health Literacy}

Interviews with Reiki Master Teachers confirmed that functional Reiki health literacy involves acquiring the knowledge of how to give a Reiki treatment to oneself and to family or friends. However, there was no evidence to support the idea that functional Reiki health literacy reflects the practical aspects of Reiki.

The interviews helped to identify a further seven competencies, many of which involved the acquisition of knowledge (for example, knowing what Reiki is and its history). Furthermore, there were some skills that appeared to be practical skills and knowledge or theoretical based skills for example knowledge of grounding and how to ground oneself is a knowledge based competency that has a practical application. The interviews thus suggested a need to refine the initial model to include the following skills and competencies;

- Knowledge of how to self- treat with Reiki and knowledge of how to give a Reiki treatment to family or friends

- Receiving a Reiki attunement and knowing what to expect from the attunement

- Basic knowledge of what Reiki is

- Basic knowledge of energy

- Knowledge of protection

- Basic knowledge of chakras 
- Knowledge of grounding

- Knowledge of symbols

The notion of functional Reiki health literacy thus involves acquiring the ability to channel Reiki energy by attending a Reiki course and receiving an 'attunement'. It involves acquiring knowledge of the 'basic' Reiki skills. Acquiring knowledge of these skills equips the Reiki student with the basic skills and knowledge they will need to function effectively within the Reiki system, that is, 'use' Reiki. Moreover, functional Reiki health literacy suggests a relatively passive role on the part of the Reiki student. Whilst a person may acquire these skills and knowledge, they may choose not to use them. The difference between passively acquiring these skills and actively putting them to use is what differentiates between functional and interactive Reiki health literacy.

\section{Interactive Reiki Health Literacy}

The commonly accepted definition of interactive health literacy is;

More advanced cognitive and literacy skills which together with social skills, can be used to actively participate in everyday activities, to extract information and derive meaning from different forms of communication, and to apply new information to changing circumstances. (Nutbeam 2000: 263-4)

Interactive Reiki health literacy skills are more advanced than those that comprise functional Reiki health literacy. They involve the use of basic and advanced Reiki skills in addition to existing cognitive, literacy and social skills. Together, these skills are actively used to participate in everyday activities which within the context of Reiki health literacy involve actively using the Reiki system. Reiki skills, cognitive, literacy and social skills are used to extract information about Reiki and health, to derive meaning from different forms of communication, and to apply Reiki information to changing circumstances. The interactive Reiki health literacy equivalent of 'changing circumstances' includes changing health circumstances. 
Actively participating in the use of the Reiki system and applying Reiki to personal health therefore involves the individual not only possessing Reiki knowledge and skills but also actively using them.

The interview data will now be discussed firstly in relation to the initial model of interactive Reiki health literacy and then in relation to the refined model. Four skills reflecting interactive Reiki health literacy were initially derived from a reflection of the underlying theory, philosophy and practice of Reiki. Of these, three were partially supported by the interview data and one was fully supported. A further three emerged as being components of interactive Reiki health literacy that refined the model. Figure 8.2 summarises the components of interactive Reiki health literacy that will now be discussed. 
Figure 8.2: Summary of Components of Interactive Reiki Health Literacy

\begin{tabular}{|c|c|}
\hline $\begin{array}{l}\text { Interactive Reiki Health Literacy: } \\
\text { Initial Model }\end{array}$ & $\begin{array}{l}\text { Interactive Reiki Health Literacy: } \\
\text { Refined Model }\end{array}$ \\
\hline Knowing when to use Reiki & $\begin{array}{l}\text { Putting Reiki knowledge into practice } \\
\text { - Self treating with Reiki } \\
\text { - Giving a Reiki treatment to family } \\
\text { or friends } \\
\text { - Using energetic protection to } \\
\text { benefit health }\end{array}$ \\
\hline $\begin{array}{l}\text { Using Reiki to not only benefit health but } \\
\text { by applying it in daily life. For example, } \\
\text { using energetic cleansing and protection. }\end{array}$ & $\begin{array}{l}\text { Using energetic protection to benefit } \\
\text { health } \\
\text { Refined to sub-competency of putting } \\
\text { Reiki knowledge into practice (above) }\end{array}$ \\
\hline $\begin{array}{l}\text { Send Reiki forwards and backwards in } \\
\text { time }\end{array}$ & $\begin{array}{l}\text { Using the Reiki symbols } \\
\Rightarrow\end{array}$ \\
\hline \multirow[t]{3}{*}{$\begin{array}{l}\text { More developed understanding of the } \\
\text { concept of 'energy' }\end{array}$} & $\begin{array}{l}\text { More developed understanding of the } \\
\text { concept of 'energy'4 }\end{array}$ \\
\hline & $\begin{array}{l}\text { Applying Reiki knowledge to own health } \\
\text { Making changes to life (style) that as a } \\
\text { result of learning Reiki are beneficial to } \\
\text { health }\end{array}$ \\
\hline & $\begin{array}{l}\text { Deriving meaning from Reiki knowledge } \\
\text { in different formats (written, verbal non- } \\
\text { verbal) }\end{array}$ \\
\hline
\end{tabular}

4 Supported 


\section{Interactive Reiki Health Literacy: Initial Model}

\section{- Knowing when to use Reiki}

Within the initial model of Reiki health literacy, one of the key interactive competencies identified was knowing when to use Reiki. This was considered to be an interactive Reiki health literacy competency because it involved the Reiki student actively putting into practice the skills and knowledge that they have learnt from a Reiki Master Teacher. However, a detailed analysis of the Reiki Master's interview data in combination with a deeper understanding of Nutbeam's model of health literacy led to the thinking that knowing when to use Reiki is in fact only one element of a person actively putting into practice the Reiki skills and knowledge that they possess. Thus, rather than phrasing this component of interactive Reiki health literacy as knowing when to use Reiki it will now be more appropriately referred to as putting Reiki knowledge into practice; the emphasis being on actually using Reiki rather than knowing when to use it.

\section{- Putting Reiki Knowledge into Practice}

Components of functional Reiki health literacy include knowing how to give a Reiki treatment to oneself, family or friends; grounding and how to ground oneself; energetic protection and how to protect oneself; and knowledge of the Reiki symbols. It was previously noted that performing a Reiki treatment is a practical application of knowing how to do so. The same is also the case for grounding oneself, protecting oneself and using the Reiki symbols. There was supporting evidence from the data that Reiki Master Teachers used Reiki on themselves and on family and friends. Whilst Reiki Masters appeared knowledgeable about grounding, there was no evidence to suggest that they themselves put this knowledge into practice. Therefore, knowledge of grounding is a component of the refined model of Functional Reiki health literacy but not a component of the refined model of interactive Reiki health literacy. Using energetic protection and using the Reiki symbols are discussed later in this section. 


\section{Self Treating with Reiki}

Performing a Reiki treatment on oneself is taught within level one Reiki and eight Reiki Master Teachers spoke of carrying out treatments on themselves. Of the two Reiki Master Teachers who did not speak of treating themselves, one felt it was important but did not speak of their personal experiences of doing so. The other Reiki Master Teacher who did not speak of their personal experiences of self treating noted that she felt that by giving Reiki to other people she was herself benefitting from Reiki. The Reiki Masters who did speak of their own experiences spoke of various aspects relating to their self use of Reiki. Annie and Natalie (below) note that they self treat with Reiki everyday;

I do recommend when I teach Reiki and I definitely do this for myself to [...] give myself Reiki at least once a day on some level (Annie)

Its routine, I do it every day unless there's something drastic that I get leapt out of bed because the phone's ringing or something like that (Natalie)

Wendy and Laura expressed the fact that they self-treat with Reiki with reference to where they carry out their self treatments;

I mean I've done it on the bus; I've done it on the train. I don't do it in the car (Wendy)

I do it in bed on a night because it's comfortable to do (Laura)

Ruth provided a specific example of a situation in which she had used Reiki on herself to help with a broken ankle. In the extract below she talks of how, on two occasions, she broke her ankle and on both occasions used Reiki on it. Ruth attributes the full recovery of her ankle to the fact that she used Reiki on it; 
Last year I broke my ankle. I was on a walk because I belong to a walking group and I slipped in some mud and I broke my ankle and I did an awful lot of Reiki on that, an awful lot and, I'm 66 so you would expect really at that age to have some, probably some repercussions but... and I broke it again at the Christmas time so and I did a lot of Reiki on it then and I never have any problem with my ankle or I have no pain, I have no swelling, I've got full movement it's, it's really well healed and I would attribute that to the Reiki practice as well (Ruth)

Self treating with Reiki may be considered an interactive Reiki health literacy skill as it represents active use of the Reiki system. In addition, when the purpose of self treating with Reiki is to help with a health problem (such as a broken ankle) it involves actively applying information learned within a Reiki course. In this respect performing a self treatment may be considered the Reiki health literacy equivalent of active participation in an everyday activity and also applying new information.

\section{Giving a Reiki Treatment to Family or Friends}

Although six of the ten Reiki Master Teachers spoke of showing their students how to give a Reiki treatment to another person, only two of them gave examples of instances when they themselves had done so. Karen spoke of using Reiki on her late husband and Natalie on her grandson;

I did Reiki on him [husband] and certainly when he was so ill and dying I did Reiki on him every day and he didn't need any painkillers until about three days before he went into hospital (Karen)

My grandson, who's 14, if he has earache, if he has anything, the phone's ringing 'can Grandma come across please?' [Laughs] (Natalie) 
As with self treating with Reiki, giving a Reiki treatment to family or friends may be considered an interactive Reiki health literacy competency because it represents active use of the Reiki system and active application of information learned within a Reiki course. Furthermore, it involves the use of social skills that are characteristic of interactive health literacy.

\section{Grounding Oneself}

None of the Reiki Master Teachers spoke of actually grounding themselves and only three spoke of it in their interviews as being something they teach their students. Therefore, whilst there was limited evidence to suggest that this skill represents a functional Reiki health literacy skill, there was no evidence to support it being an interactive Reiki health literacy skill.

- Using Reiki to not only benefit health but by applying it in daily life. For example, using energetic cleansing and protection.

After a detailed examination of the data, it was decided that this component of Reiki health literacy could be more appropriately worded than it was within the initial model. The wording of this component within the initial model suggested that the use of energetic cleansing and protection in daily life is in addition to using Reiki to benefit health. There was no evidence within the Reiki Masters' interview data to suggest that using energetic cleansing was a skill that the participating Reiki Master Teachers actively used. However, the use of energetic protection appeared to be inextricably linked to benefitting one's health, rather than being something that was done for reasons separate to health. Therefore, this component of the initial model of Reiki health literacy in the refined model is referred to as Using energetic protection to benefit health. Furthermore, reflection of the skills and knowledge that comprise interactive Reiki health literacy suggest that using energetic protection is in fact an additional sub-competency of putting Reiki knowledge into practice. This is because as with self treating with Reiki and treating family and friends with Reiki, using Reiki to protect oneself is a practical application of knowing how to do this. 


\section{- Using Energetic Protection to Benefit Health}

Laura, Hazel and Ruth spoke of how they used Reiki for protection. Laura spoke extensively of using one of the Reiki symbols for protection and about the differing ways in which she used it. In the extract below, she speaks of protecting her car whilst driving, protecting her own and neighbouring houses and protecting her personal safety whilst walking in public;

I always draw the power symbol and then ask for how many power symbols, a hundred or whatever to surround my car and get me safely on my journey always do that. I ask for, I don't do just this house I do the block, all to be protected from burglary and things like that - I don't do it every day but you know [...] it's mainly protection I do it but in all the different little ways, walking down the street for example if there's a big gang of kids or something and I've got to walk past them I'll always draw it really big, walk into, protect myself like that it's that kind of thing (Laura)

Like Laura, Ruth also spoke of using Reiki to protect herself on journeys and a Reiki symbol to protect her home in her absence;

Well if I'm going on a journey I would protect my house before I go. When I shut the front door I would protect my house and I would place my car in a Reiki bubble and I would do the power symbol for the journey and I would ask that the journey be a safe one without any hold ups or anything untoward happening and I would just ask that the journey be safe (Ruth)

Using the Reiki symbols is not the only means by which people can protect themselves. Ruth (above) speaks of placing her car in a 'Reiki bubble'. In the extract below, Laura describes how experiencing negative effects from treating clients with Reiki prompted her to put her knowledge of protection into action. Like Ruth, she also speaks of putting herself in a 'bubble' and also envisioning herself in a cloak; 
When I first got really going with the Reiki and I started working at the clinic [...] some days I'd have five or six clients all Reiki, because I do ear candles as well, but at the time it was all Reiki. And I'd been taught, quite heavily by both of my Reiki Masters to protect yourself. I used to think 'yeah right!' and I, it took, me being me, it took me a while to sort of click but every Wednesday morning up until about [...] I'd wake up in a morning and up until about lunchtime I'd feel as though my glands were swelling up, I'd just think 'oh I'm coming down with something I feel a bit blaggghh' always this area, bit heady as if I'm about to get some heavy cold and then it would clear. This went on for about six weeks before I realised it was every morning and I thought 'right well that means it's after a Tuesday when I've done lots of Reiki, I've had lots, I've been opening up to a lot of energy there, plugging in to lots of energies' I thought 'I'm not protecting myself' so I started I thought 'well just do it, just start protecting yourself' and it, I mean I teach these in my classes it amazes me, it amazed me because I was like oh my god it wasn't airy fairy! I started putting myself in a big cloak, in a bubble and all the rest of it, never ever, ever happened since ever, so I had to experience that to believe it (Laura)

Hazel admitted that she was 'bad' at remembering to protect herself. However, in the extract below, the researcher asks Hazel if she notices the difference on the occasions she does remember to protect herself. She responds in the affirmative but also notes that doing a Reiki session can counteract any negative effects resulting from not using protection;

HG: Do you notice the difference between when you do it and you don't do it [protect yourself]?

RM: The protection? Yes I can do yeah [...] but the thing is that if you realise that you haven't protected yourself [...] by going home and doing a Reiki 
session or thinking 'well look, while I'm asleep will you pull all this together for me' in a morning you'll feel a lot more refreshed so you can do it either way really (Hazel)

Using Reiki for protection may be considered an interactive Reiki health literacy competency because it is an example of actively using the Reiki system. Using Reiki to protect oneself, home or car also has health benefits as it protects one's own physical health when treating others and, in the case of travel, promotes a 'safe' journey. Using energetic protection represents the Reiki student applying Reiki information to their health.

\section{- Send Reiki Forwards and Backwards in Time}

Within the initial model of Reiki health literacy, the ability to send Reiki backwards and forwards in time was identified as an interactive Reiki health literacy skill based on the fact that doing so actively involves the Reiki student putting to use their knowledge of symbols to induce healing on a physical and emotional level. However, sending Reiki backwards and forwards in time is not the only way in which the symbols can be used. The symbols are also used for protection (as above), focussing the Reiki energy, inducing healing on deeper levels to name but a few uses. Therefore, this component of interactive Reiki health literacy may be more accurately referred to as using the Reiki symbols.

\section{- Using the Reiki Symbols}

As one of the previous sections showed, Reiki symbols can be used for protection; however, within their interviews, Reiki Master Teachers also spoke of 'sending' Reiki. Reiki is not 'sent' arbitrarily; rather, Reiki Master Teachers talked about why a person might want to send Reiki and what the anticipated effect would be. For example, in the extract below Hazel implies that sending Reiki to traumatic situations such as divorce, stillbirth or breakdown can help a person to resolve the issues or 'move forward' as Hazel describes it; 
Say you had something like you'd got divorced or something like this [...] and it was really horrible or you had a stillbirth or something like that, something that's really, could affect you or whoever or a breakdown or anything. You could send healing back to that situation that you know about and that's where it comes in... and it perhaps wouldn't, unless you're at a certain level it perhaps wouldn't get rid of it all, the energy, but at that you could move forward. (Hazel)

Wendy spoke of 'sending' Reiki to events that had occurred in childhood in order to benefit the present / adult self. In the extract below, Wendy speaks of using the Reiki symbols to eradicate habits and thought patterns that are a result of childhood events;

\begin{abstract}
'Well for example you know when you send it backwards - let's say you had an incident in childhood that you felt was still making you act in a certain way or think in a certain way so basically, psychologically we've got inner child work. So if you're doing inner child work you're trying to eradicate habits and thought patterns that were built up through what happened to you in your childhood, you can enhance that letting go of those thoughts and feelings by sending symbols to it so what you, for example, you don't necessarily have to meditate on it you can say right, let's say on ... I don't know...when I was 12 I was bullied...so I remember the incident in my head so I'm going to send the symbols to it and send some healing to it and ask that that trauma and the negativity that it brought forward is then dissolved.' (Wendy)
\end{abstract}

Using the Reiki symbols may be considered an interactive Reiki health literacy competency because it reflects actively using one's knowledge of symbols, that is, actively participating in use of the Reiki system. Using the Reiki symbols is also reflective of applying information to personal health circumstances as in the examples above where use of the symbols is believed to assist with mental or emotional health issues. 


\section{- More Developed Understanding of the Concept of 'Energy'}

Having a basic understanding of the concept of energy is a functional Reiki health literacy competency, whereas having a more developed understanding of the concept of energy was identified within the initial model of Reiki health literacy as an interactive competency. Those Reiki Master Teachers who spoke of energy were specifically asked if they thought that a person's knowledge and understanding of energy would change over the course of learning Reiki. Both Annie and Hazel agreed that a person's understanding of energy would develop as they progressed through the levels of Reiki training. Both participants also put forward similar explanations as to how a person's understanding of energy might change. Below, Annie suggests that understanding energy is linked to perception. She explains that students of Reiki often experience a shift in their perceptions of the world. This shift in perception involves developing the ability to look below the surface of 'exterior appearances' and 'sense different levels of understanding';

'Hmmmm, that's an interesting question, yes....yes it has to. It has to because from my own experience, and that's where I can come from but the experiences of students you know that I stay in touch with and they ring up with experiences and things, to chat over them with me, and it's almost as if there's a shift in the way that you perceive the world and its sort of that you're looking below of the surface of exterior appearances [...] it's almost as if you can, in a way, as you work with this more and more it's almost as if you can sense different levels of understandings so if for example, there's an argument going on between two people or someone is stressed about something, working in this way gives you the opportunity, I think is a good word, to see below the surface of what's happening.' (Annie)

Similar to Annie, Hazel agreed that a person's knowledge of energy would change throughout the course of learning Reiki and also linked this to perception. As the dialogue below shows, Hazel found it difficult to articulate exactly how a person's 
understanding of energy changes but used words associated with the idea of perception such as 'sensitive' and 'sense';

[Can you explain how that changes?]

No [Laughing] I can't no!! Energy... I can feel the energy, you know like I've always been sensitive to... you can go into a room full of people and you think 'oh my god!'. You can work with people - I work in a small team and sometimes that team - the energy is heavy. I go home and I'm drained. So I'm used to working with energies and people's energies whether they're light, whether they're all... got all problems, the heaviness. So and throughout your Reiki progression as it were or whatever you like to call it you're more sensitive, you're more open to people's energies to the point of fact that you can sense if perhaps if they're ill or, or whether they're worried or that type of thing, it can bring you closer to a person if you want to be' (Hazel)

Neither Hazel nor Annie explained exactly how changes in perception come about or how a person becomes more sensitive to energy; however, their utterances appear to suggest that it is a result of experiential learning. Conversely, whilst Wendy believed a person's understanding of energy would change it was on the condition of a person researching energy and practising meditation, not solely practising Reiki;

'I think it would if you researched it and you meditated and you used it but just by doing it no' (Wendy)

Annie (above) does not talk about developing one's understanding of energy in relation to health. Hazel (above) relates developing understanding of energy to health when she says 'you can sense if a person is ill', however she is referring to other people rather than herself. Nonetheless, there is no reason to suspect that this skill is not transferable to a personal health context considering that possessing a basic 
knowledge of energy (as in functional Reiki health literacy) involves learning that one has one's own energy and that a person's own energy is something to be protected. Thus, in theory, the ability to see below the surface of situations may be applied in the context of personal health. Likewise, developing an understanding of one's own energy may be applied to a personal health context. Doing so would emphasise the individual benefit that is associated with Nutbeam's (2000) notion of interactive health literacy.

Having a more developed understanding of energy may be interpreted as an interactive Reiki health literacy competency because it is representative of a more advanced Reiki skill. It may be compared to possessing more advanced cognitive and literacy skills that are associated with interactive health literacy. A functionally Reiki health literate individual would have a basic understanding of the nature of energy and the ideas behind the concept of energy, whereas an interactive Reiki health literate individual is able to progress to be able to sense energy. Another reason for a more developed understanding of energy being considered an interactive Reiki health literacy competency is that the data suggests the potential for an individual to apply this competency to their own health.

\section{Interactive Reiki Health Literacy: Refined Model}

In addition to the four areas above, the following four competencies emerged from the interview data as being at an interactive Reiki health literacy level.

\section{- Applying Reiki Knowledge to Own Health}

A key reason as to why participants self-used Reiki and advocated their students doing so was to prevent ill health from occurring. Below, Karen describes how by self-using Reiki, a person can prevent a range of ailments such as high blood pressure and heart problems; 
'You can prevent yourself getting high blood pressure; you can prevent heart problems obviously if you manage blood pressure. A lot of things, you know, people can get real uptight about things you know you've seen them, their faces go red, they get angry, you can prevent yourself...you gradually lose your anger because anger...two of the biggest causes, well the two biggest causes of disease are anger and fear and with dealing with and doing Reiki you can clear a lot of anger out especially self treating which you know obviously could lead to other problems. I mean I don't know what a person's pre-disposition to illness is but if you can get rid of the anger or the fear of doing something then a whole host of illnesses just will never appear [...] but I think the main thing is that if you're treating yourself you can calm down and you can relax and your body says thank you. The anger and the fear dissipate so therefore you are preventing any kind of disease occurring' (Karen)

Similarly, Wendy notes how using Reiki on oneself to reduce stress may prevent headaches;

'What I sometimes find with people when they do it on themselves is they don't do it until they do feel bad. So a lot of people will say to me 'oh I had a headache but I did it on myself and it went away' and that's great but if they maybe had realised that they were getting stressed the three days prior to the headache, if they started doing it then they would never have actually got the headache if you see what I mean? So that's why it's good to do it constantly because you're preventing stuff from actually...' (Wendy)

Interlinked with the idea of self using Reiki to prevent ill health was the idea of self using Reiki to maintain good health. Eight of the ten Reiki Master Teachers noted that using Reiki when a person was in good health would help to maintain their good health. The exchange below is illustrative of how Reiki Master Teachers responded to being asked if a person could use Reiki if they were in good health; 
[Do you think it's beneficial using it when you're in good health as well as if you've got something wrong like a broken ankle?]

Yes, saying prevention is better than cure so yes definitely

[So it's a preventative?]

You could look at it like that yes, to keep maintenance, to keep yourself maintained, yes and in the right mindset

Reiki is used pro-actively to prevent ill health and maintain good health. It is an example of an interactive Reiki health literacy skill as it is reflective of actively using the Reiki system and it involves applying Reiki information to one's own health.

In addition to using Reiki to prevent ill health and maintain good health, many of the Reiki Master Teachers that were interviewed gave further examples of how they had used their knowledge of Reiki and applied it to their own health. Sometimes these examples related to the participant's physical health. Karen (below) spoke of using Reiki on an aching back;

If I'm wandering around sometime in the day and my back hurts I'll stick a hand on it and give it five minutes Reiki, that kind of thing (Karen)

Sometimes Reiki Masters gave examples of how they had used their Reiki knowledge and skills to benefit their mental or emotional health. In the examples below, both Deborah and Annie talk about how using Reiki on themselves helped them through bereavement. In addition, Annie describes how using Reiki helped to keep her 'buoyant' when her daughter was ill; 
Because that's an important tool [self-use of Reiki] for you to work on to bring you out the other side because grief at the end of the day there's no way round it there's only through it, isn't there? (Deborah on Mother dying)

I am absolutely convinced it helps [self use of Reiki], it's helped me through the most difficult periods, daughter being diagnosed with cancer, you know, mother dying slowly and this that and the other and just walking round going 'Reiki on, Reiki on, Reiki on' and keeping yourself buoyant, I can't tell you how much it helps. (Annie)

However, there was a sense within the data that for the Reiki Master Teachers, the mind and body are to some extent inseparable. Wendy demonstrates an awareness of how the mind and the body are linked and talks of how using Reiki on oneself can help the two function together effectively. In the quote below, Wendy describes the effect that Reiki has on inducing a sense of calmness and how in turn this benefits the adrenal glands and the respiratory and the circulatory system;

Well definitely that sense of calmness. I mean immediately it slows the breathing rate down and the heart rate down so immediately it's improving the functioning of the physical body because in a state of stress you're adrenal glands are obviously going nuts and you're releasing far too much adrenaline which then tires the body. So immediately you've got the effect of calming the adrenal glands down, the respiration and the circulatory system, even on a very basic level it will do that for somebody within minutes. So immediately then... obviously everything is physically flowing a lot better and mentally and emotionally. I think it's sometimes difficult isn't it because in this world we're still at that stage where you've got psychologists saying your mental and emotional state is important, and you've got the physical side saying 'oh it's all about the physical function of the body' and we are getting to the stage where they are trying to come together. So I guess to sit here and say if you're 
emotionally calmer and more at peace then physically you're going to be better (Wendy)

Acknowledging a relationship between the mind and the body was also evident when participants related their self use of Reiki to their own health. Whilst some participants spoke of physical and mental and/or emotional problems separately some participants spoke of them as being interlinked. Natalie (below) spoke of how using Reiki on herself helps her to 'deal' physically and mentally with pain that is the result of a chronic illness;

It does help me with the pain definitely. It helps me with dealing with the pain which is more important [...] I don't take pain killers unless I'm absolutely... I think it's a mind thing and I think people get reliant on pain killers. I do have to take heart tablets, you know I mean I recognise that and I don't ever want to be there in that situation again but I very rarely, rarely take pain killers and you know my doctor says if you took them six hourly you wouldn't have the pain but then I would have the side effects from the pain killers. So I think it helps me in dealing physically and mentally and probably the mental is more important (Natalie)

Applying Reiki knowledge to one's own health involves taking action such as applying Reiki to an aching back or a broken ankle. It involves taking action such as continuing to give oneself Reiki as a means of supporting good mental and emotional health in situations that are typically associated with a decline in mental or emotional health, like bereavement. Actively applying Reiki knowledge to one's own health is an interactive Reiki health literacy skill which is comparable to the interactive health literacy skills of participating in an everyday activity (using the Reiki system) and applying new information to changing circumstances. 


\section{- Making Changes to Life (style) that as a Result of Learning Reiki are Beneficial to Health}

Participants frequently described how learning Reiki and practising it on oneself facilitated the person making changes that were beneficial to health. The changes that Reiki Masters speculated might take place as a result of learning and using Reiki, or the changes that they had observed in themselves or their students, were many and varied. On one level Reiki Master Teachers suggested that a person who learnt Reiki and used it on themselves might put more thought into various aspects of their health. In the quote below, Annie uses words such as 'thinking' and 'examining' and 'readdressing' to describe the different types of changes that a person might make to their life after learning Reiki;

When you begin to work with an energy medicine or an energy system of some kind it does have a knock on effect because then you begin to think more about your lifestyle, you begin to think more about your diet and things that you are taking into your body to fuel it and all the rest of it you know. If you want to take it that step further then it comes into mind to examine your emotional responses and you know, what things in your life are not working and need to be readdressed on some level. So I feel that once you get into that framework then you begin to... it spreads outwards and you begin to examine and think about all different levels of your physical existence as well as your emotional existence and your mental existence and everything else. (Annie)

Similarly, Wendy implies that when people learn Reiki they experience a change in the way they think about their health. She describes this as 'getting into other ideas about health' and talks of how people begin to 'correlate' their health with other aspects of daily life;

I think a lot of people from the people I've seen and from my experience get into other ideas about health and about how your body actually works. They 
seem to want to know more about what's actually going on rather than just going down the doctors and letting him or her tell you. It's much more 'well hang on a minute what is actually going on for me? How does it actually link in emotionally?' as well. A lot of people get into that whole body mind thing; Louise Hay [author] all that kind of thing. People start thinking about the correlation between their lifestyle and their health, their emotions and their health, their mental attitude and health, people around them and their health, their environment and their health. So it, that's why it becomes holistic because you start to see yourself not in isolation anymore but as a reaction to everything that's going on. [...] And then obviously it leads people to the interest in crystals, often people get into things like homeopathy, reflexology, more into the massage thing, Bach flower remedies, everything out there and it just leads you down the path of 'oh well if this is this then what else is there?!', 'what else can I do' and I think that's the word isn't it 'what else can I do to help me' [participants stress] rather than 'what can the doctor do to help me?' or ' what can my husband do to help me?' it's 'what can I do?'. (Wendy)

Some examples that Reiki Masters gave involved actually making changes in their life as opposed to simply just thinking more about their health. Karen talked at length about her own experiences of having changed her diet after she learned Reiki. In the two extracts from her interview below, she describes how this involved eating more fruit, giving up meat, drinking more water and drinking less tea and coffee;

I eat a lot more fruit, I always did eat a lot of fruit and vegetables but I eat a lot, lot more now [...] I went off all sorts of things. I think really the biggest change that I noted was giving up you know, giving up meat, I just couldn't stand it anymore it just made me feel so ill so I just, but that was the biggest thing I noted really (Karen) 
I think you learn to look at things in a different way...do I really want that? No. You find you drink a lot more water, as just water you know not tea and coffee. You go off tea and coffee quite a bit, you drink more herbal tea'. (Karen)

Participants also spoke of making changes that related to their attitudes or their mental and emotional health. One example included the development of a more relaxed and 'laid back' attitude. Natalie (below) talks of feeling calmer and laid back, whilst Ruth (below) speaks of becoming more relaxed. Similarly Karen (below) notes that her self use of Reiki has had a calming effect on her temperament;

I think it's changed me as a person, if that's as I said I feel I'm calmer about situations, I'm laid back, I don't let things hassle me. I just think it makes you a different person. (Natalie)

You look at life in a different way, you become more relaxed about life and you become less fearful about things. (Ruth)

I used to have a filthy temper, I really did when I was younger and I found that it's just calmed me right down doing Reiki on myself. (Karen)

Laura (below) credits learning Reiki with having made 'gentle changes' to her emotional wellbeing. She describes how she has 'cleared' negativity that was associated with a destructive relationship. Furthermore she implies a link between doing this and her emotional wellbeing when she says she is more balanced;

I was in a very quite destructive relationship, as in mental, you know there was a lot of, a lot of jealousy's and things like, all the negative side... I've cleared all that negativity. There's still, I'm not saying it you know there isn't any at all but it's, it's made all these gentle changes and it's made me stronger 
because I'm more balanced and when you're like that you attract what's good for you rather than what's bad for you (Laura)

A person making changes to their life or lifestyle that is beneficial to their health may be considered an interactive Reiki health literacy competency because it represents active use of the Reiki system. Furthermore, when an individual becomes interested in other holistic approaches to health such as homeopathy or reflexology (see Wendy above) this is reflective of seeking or extracting information on health.

\section{- Deriving meaning from Reiki knowledge in different formats (written, verbal non-verbal)}

Within the context of Reiki, the ability to derive meaning from different forms of communication was frequently related to aspects of non-verbal communication. One example from the data involves deriving meaning from circumstances. Hazel suggests that the underlying meaning of an unpleasant situation may be Reiki providing the opportunity to address issues;

If somebody's not got on with their sister or brother or for whatever reason they don't get on with them sometimes this will come to the fore. Situations will happen for that person to deal with and I think the Reiki puts you in a position to deal with these issues. You know if you don't get on with somebody at work, that person, for whatever, I don't know why it happens, but that person will create circumstances or you ...circumstances will be created between the two people so say 'well look, you've got a chance here. You either deal with it and work through it or forget it and you don't move on'. Does that make sense? [...] throughout your life I think that situations do occur like that and spirit's very good in giving you second chances and third chances and things will keep bumping in to you, you'll be bumping into things throughout your life until you say 'well look I want to deal with this or I don't want to deal with this'. Does that make sense? (Hazel) 
Deborah also spoke of making meaning from non-verbal communication. In the extract below, she speaks of 'tuning into' her own body to listen to what it is telling her and to detect imbalances;

On a day to day level you know all sorts of things happen to us, we all have to deal with stress on a day to day level and it varies. So what you can do and as much as you possibly can, if you tune yourself into your own body you're listening to what it's telling you because it will be telling you. Sometimes you, sometimes in a morning you'll want to draw towards a dress that's red or a blouse that's blue and then you think well why am I drawn to that colour? Because your body is all the time trying to tell you there's an imbalance perhaps in the throat chakra which is blue or ...so my job is to decide what my body is trying to tell me (Deborah)

Participants also spoke of how they understood and derived meaning from physical health problems. Very often the meaning of physical ailments was attributed to the concept of energy or 'blockages' or damage to the chakras;

I think the physical thing is the final manifestation of a disruption of energy within the energy body so forth. (Annie)

Physical health problems are around a blockage somewhere in the body and I think, you know just by calming the body down, by calming the mind down, calming everything down, it just encourages the homeostasis, the flow of, helping the body to heal itself. If there's no blockage there, there's more chance of it healing (Grace)

You can get knocks as well and chakras can droop and clog and tear and spin the wrong way and when anything like that starts happening you'll get an illness. And we've all got Achilles' heels, we've all got our weak spots and it'll 
tend to go to your weak spot or to the area of the body where that mental and emotional problem is (Laura)

Making meaning from Reiki knowledge in different formats appeared to be primarily associated with making meaning from non-verbal communication. It may be considered an interactive Reiki health literacy competency because it involves the Reiki student extracting information and making meaning from circumstances, making meaning from one's own body or from physical ailments. Use of verbal communication is a component of using social skills which are used in the competency Giving a Reiki treatment to family or friends (discussed above).

\section{Summary of Interactive Reiki Health Literacy}

In addition to active use of many of the functional health literacy competencies, interactive Reiki health literacy also comprises a number of more advanced competencies. Interactive Reiki health literacy suggests a more active role on behalf of the Reiki student than is characteristic of functional Reiki health literacy and involves actively participating in the use of the Reiki system. This involves putting knowledge into practice that has been learned on a Reiki course and applying what one has learned during a Reiki course to one's health (and to a greater extent one's own life, own concerns, own circumstances).

Interactive Reiki health literacy also involves the ability to make meaning from different forms of communication, particularly non-verbal communication as Reiki practitioners often talk of understanding what their body is telling them or what a particular chakra is telling them all of which is non-verbal. Interactive Reiki health literacy comprises the following skills and competencies;

- Putting Reiki knowledge into practice

- Self treating with Reiki

- Giving a Reiki treatment to family or friends

- Using energetic protection to benefit health 
- Using the Reiki symbols

- More developed understanding of the concept of 'energy'

- Applying Reiki knowledge to own health

- Making changes to life (style) as a result of learning Reiki that are beneficial to health

- Making meaning from Reiki knowledge in different formats (written, verbal, non-verbal)

\section{Critical Reiki Health Literacy}

The commonly accepted definition of critical health literacy is;

More advanced cognitive skills which, together with social skills, can be applied to critically analyse information, and to use this information to exert greater control over life events and situations (Nutbeam 2000:264)

Critical Reiki health literacy involves the use of Reiki skills in tandem with more advanced cognitive and social skills to critically analyse information and use this information to then exert control over the life events and situations that have the potential to impact upon health. Within the context of Reiki, more advanced cognitive skills may include, for example, the ability to critique the practice of Reiki and health information arising from a biomedical perspective. More advanced social skills, applied to a Reiki context, might include joining or forming a Reiki group.

The interview data will now be discussed firstly in relation to the initial model of critical Reiki health literacy and then in relation to the refined model. Figure 8.3 summarises the components of critical Reiki health literacy. 
Figure 8.3: Summary of Components of Critical Reiki Health Literacy

\begin{tabular}{|c|c|}
\hline $\begin{array}{l}\text { Critical Reiki Health Literacy: Initial } \\
\text { Model }\end{array}$ & $\begin{array}{l}\text { Critical Reiki Health Literacy: Refined } \\
\text { Model }\end{array}$ \\
\hline $\begin{array}{l}\text { Critically analyse information from a } \\
\text { Reiki perspective }\end{array}$ & $\begin{array}{l}\text { Critically analyse information about } \\
\text { Reiki, medicine and health }\end{array}$ \\
\hline $\begin{array}{l}\text { Ability to 'see past' the biomedical } \\
\text { model of health and apply a holistic } \\
\text { perspective to health }\end{array}$ & $\begin{array}{l}\text { Ability to apply a holistic perspective to } \\
\text { health } \\
\text { - Making decisions and choices } \\
\text { informed by multiple perspectives }\end{array}$ \\
\hline \multirow[t]{4}{*}{$\begin{array}{l}\text { All information gathered regarding health } \\
\text { and knowledge applied from both a } \\
\text { traditional (biomedical) and } \\
\text { complementary (Reiki) perspective. } \\
\text { Judgement made from a balanced } \\
\text { perspective. Freedom of choice. }\end{array}$} & $\begin{array}{l}\text { Not supported fully therefore moved } \\
\text { above } \\
\Rightarrow\end{array}$ \\
\hline & $\begin{array}{l}\text { Exerting control over physical, } \\
\text { psychological and emotional health }\end{array}$ \\
\hline & $\begin{array}{l}\text { Identify the wider social and political } \\
\text { benefits of Reiki }\end{array}$ \\
\hline & Forming or joining a Reiki group \\
\hline
\end{tabular}

\section{Critical Reiki Health Literacy: Initial Model}

The initial model of critical Reiki health literacy comprised three components: critically analyse information from a Reiki perspective; the ability to 'see past' the biomedical model of health and apply a holistic perspective to health; and the ability to apply biomedical and complementary health perspectives to personal health. 


\section{- Critically Analyse Information from a Reiki Perspective}

The first component of critical Reiki health literacy as identified within the initial model was the ability to critically analyse information from a Reiki perspective. The wording of this component does not specify the type of information that is analysed by an individual. Therefore in an effort to add clarity, it will be referred to in the refined model as critically analyse information about Reiki, medicine and health.

\section{- Critically Analyse Information about Reiki, Medicine and Health}

Rather than passively accepting what they had been taught about Reiki, some Reiki Master Teachers demonstrated the ability to question or critique the practise of Reiki. Annie (below) demonstrated this ability by acknowledging the possibility that any changes a person who has learned Reiki experiences may be coincidental. The extract below begins with Annie stating that she observes subtle changes 'all the time' in people who learn Reiki but that she still 'examines' whether the changes in fact relate to Reiki;

Do you know you see it all the time; it's a very subtle process. Okay might have happened anyway... I'm not so caught up in all of this not to still have this little you know thing going on in my head - 'examine this Annie, examine this' (Annie)

Another example of how Reiki Master Teachers critically analysed Reiki was by being realistic about the extent to which self use of Reiki could help them with their health. This became apparent within Natalie's interview when she recollected how 20 years ago after a stay in hospital she had returned home with a large number of prescribed medications but had gradually weaned herself off these medications. When the interviewer asked her about whether she would do the same now, she responded as follows; 
I think there's some times when you've got to think am I risking too much? Is maybe the answer to that [...] because I'm not a person who likes taking you know [tablets] but this time I thought, I'm a lot older and is it worth the risk so you've got to be sensible I think and consider the risks (Natalie)

Another means by which Reiki Master Teachers demonstrated their ability to critically analyse information was in relation to allopathic medicine and health. With reference to a recent outbreak of swine flu, Karen was critical of the government and pharmaceutical companies by saying that she didn't 'buy into it'. In the extract below, Karen implies that making 'us' [the population] fearful of swine flu is a way of controlling the population. She speculates that self treating with Reiki dissipates this fear;

Unfortunately at the moment the government and the pharmaceutical companies want us to live in a climate of fear you know with the swine flu and the flu and everything else and I don't buy into it but an awful lot of people do. But it's the easiest way of controlling the population, but the more people who can learn to heal themselves and see through it the better, but I think the main thing is that if you're treating yourself you can calm down and you can relax and your body says thank you. The anger and the fear dissipate so therefore you are preventing any kind of disease occurring (Karen)

Hazel critiqued both conventional medicine and complementary medicine (Reiki). In the extract below she states her belief that many of the allopathic drugs used today are destroying our bodies but that 'we're not there yet' with our ability to self heal or 'get ourselves well' (with Reiki);

Conventional medicine, in my opinion, is brilliant. Having said that [laughs] all this gets complex doesn't it really. I believe [inaudible] we've got the, the ability to get ourselves well right, but we're not there yet, no more than conventional medicine has got it all singing and dancing because a lot of the 
drugs we use right, are destroying our bodies anyway but that doesn't take away the fact that you don't use conventional medicine you've got the two. Neither right at the top of the tree as yet, in my opinion (Hazel)

In summary, the interviews with Reiki Master Teachers identified two forms that the ability to critically analyse information within the context of Reiki health literacy takes. Firstly, it is apparent in the ability to question or critique the practise of Reiki and, secondly, the ability to critique information that arises from a biomedical perspective. These abilities represent critical Reiki health literacy abilities because they arguably represent the use of advanced cognitive skills. The ability to critically analyse information within the context of Reiki is also reflective of critically analysing information and then using this information to exert greater control over health; the ability to apply an analytical perspective to health information (Reiki or biomedical) leads to the individual making an informed decision about their own healthcare.

\section{- Ability to Apply a Holistic Perspective to Health}

The ability to apply a holistic perspective to health was confirmed by the interview data and emerged as being a key theme. Deborah (below) demonstrated this by stating explicitly that learning Reiki is a 'holistic approach'; however, she also expressed the view that conventional medicine should be used in addition to complementary medicine;

You find it's a very holistic approach. I work very much with crystals and don't, believe me as well, I work very much with medicine as well, don't think that I pooh pooh it at all because I really don't. You do need, you do need your GPs and you do need medicine... I'm a cardiac rehab and I'm only too aware of beta blockers and how they're needed so I'm not coming from a place where, I'm coming from a place where everything can complement everything else so I fully understand the need for the orthodox medicine but also complementary medicines like homeopathy, and crystals, they are again a 
wonderful way of complementing things there, so no I am open to absolutely everything (Deborah)

Similarly, Hazel talked about how Reiki practice can act as a catalyst for helping a person to think about holistic approaches to health. In the extract below she speaks of reflexology and balancing the body but also the need for conventional medicine. Hazel also demonstrated another critical Reiki health literacy skill; identifying the wider social and political benefits of Reiki (see below) by critiquing the amount of money spent on conventional medicine as opposed to preventative medicine;

I'm not saying its Reiki that would be everything all singing all dancing. It, to me, Reiki is to kick start you into thinking about holistic stuff you know and things like, I believe in other alternative ways, reflexology, balancing the body. But I equally think at this moment in time that we do need conventional stuff but I think they're going at it from a different angle and we are you know, all the amount of money that is spent on the drugs for breast cancer or whatever thing because cancer is a biggy. I think if a lot of money was spent equally on the preventative, on getting the health and wellbeing then I think we'd be a damn sight better society to be honest, I think too much money is wasted in conventional medicine (Hazel)

In her interview Wendy spoke of taking into account both biomedical knowledge and knowledge of Reiki in relation to taking over-the-counter and prescription medication thus demonstrating her ability to apply a holistic perspective to health. Wendy begins by noting the importance of modern medicine;

I think from my point of view it's important not to dismiss traditional medicine. Well not traditional, no ours is traditional! But modern medicine [Both laugh] because I mean don't get me wrong I mean goodness me where would we be without Neurofen and Paracetamol or Aspirin (Wendy) 
However, she continues to note that in people who practise Reiki, the decision to take such medication is pre-empted by a desire for more information about the medication;

But I would say, like see it more as okay, so what is this chemical actually going to do to me, what is it that I'm taking? Just a little bit more wanting to know a bit more rather than going oh yeah it's called whatever and I take it everyday. I think Reiki people tend to say 'and how does it work? And what is it exactly?' just want that little bit more information (Wendy)

Furthermore, Wendy also draws on her knowledge of Reiki to suggest that in people who practise Reiki, the decision to take medication is also informed by the knowledge that there may be another (complementary) solution to the problem;

and also I think from my point of view I've suffered with depression, really badly and obviously was offered pills but I think if you can come at it from a Reiki point of view this belief that you can alter your cellular make up, you can alter your DNA then why take pills that are only holding you in a false state of security because as soon as you come off them you'll be buggered if you haven't looked at the problem. So I think you see it more as a long term and a cyclical thing of well if I take this is this only short term, is this going to cure it, is this how is this going to actually affect me? Whereas I think when you're not in that mindset you think 'oh well I'll take these pills, I might have to take them for the rest of my life' and I think with Reiki you don't have to be resigned to that, you can use them as a tool, but be much more aware of how you're using them (Wendy)

In summary, having the ability to apply a holistic perspective to health may be considered a critical Reiki health literacy skill because thinking about Reiki in terms of lifestyle as opposed solely to a system to be used for health demonstrates a more 
expanded view of Reiki, that is, the use of more advanced cognitive skills. Furthermore, the ability to apply a holistic perspective to health entails possessing knowledge of how both biomedicine and complementary medicine might assist with a health problem. Having the ability to draw on duel knowledge increases an individuals control over their health as the choice then exists to use one type of medicine or a combination.

\section{Critical Reiki Health Literacy: Refined Model}

In addition to the three competencies outlined above, the following three also emerged from the data as being critical Reiki health literacy competencies that refine the initial model.

\section{- Exerting Control over Physical, Psychological and Emotional Health}

The ability to use information to exert control over health is a key feature of critical health literacy. Likewise, a feeling of being in control of one's health was also noticeable within the Reiki Masters' interview data and was directly attributed by most of the interviewees to their knowledge and/or practice of Reiki. One example of this was evident within Karen's interview when she specified how as a result of self treating with Reiki she is better able to control her food intolerances;

I found that it's easier to control my intolerances you know with doing Reiki, much easier. (Karen)

However, the means of expressing feeling in control of overall health as distinct from feeling in control of a specific health problem differed between participants. In the extract below Wendy expressed control of health by emphasising the 'I', the first person singular, as opposed to a third person as the person responsible for managing health; 
It just leads you down the path of 'oh well if this is this then what else is there?!' 'what else can I do' and I think that's the word isn't it 'what else can I do to help me' [participants emphasis] rather than 'what can the doctor do to help me?' or 'what can my husband do to help me?', it's 'what can I do?' (Wendy)

Similarly, Annie also emphasised the first person singular when she talked about what she can do for herself with regards health;

'You know thank goodness that the medics are there do you see what I mean? Thank goodness they're there but it [knowing about Reiki] does stimulate the fact well okay you know this is the diagnosis or this is if I take those tablets blah de blah that's great but what can I do for me and I think that's immensely empowering. I think it has to alter the whole framework of rather than feeling you know you're handing over your health and wellbeing to someone else' (Annie)

It is noteworthy that in the above extract, Annie uses the term 'immensely empowering' to express her belief that she is able to think about what she can do for herself in health situations. It could be argued that exerting control over one's health as opposed to passively accepting health status is empowering and as argued by Nutbeam 'improved health literacy is critical to empowerment' (Nutbeam 2000:259).

In summary, having the ability to exert control over health may be considered a critical Reiki health literacy competency because it is akin to using information to exert greater control over life events and situations. In the context of critical Reiki health literacy, it is Reiki information that is used for this purpose. 


\section{- Identify the Wider Social and Political Benefits of Reiki}

Some participants were able to identify benefits of Reiki that extended beyond personal use. For example, Wendy speculated how her home town would be a healthier town with a better atmosphere if everyone learned Reiki;

Ah, this is my pet one as well because I always think if, can you imagine if the whole of [town] if everybody had Reiki and they were all healing themselves everyday how much better would the health of [town] be, how much better atmosphere would it be because of it [both laugh] I just think if only everyone could just realise that the power to heal themselves is in their own hands I think it would be great. (Wendy)

Participants also identified the wider social and political benefits of Reiki by speculating upon the how Reiki could be integrated into the NHS and also other health or social care organisations.

\section{Integration with $\mathrm{NHS}$}

Both Ruth and Hazel spoke of the potential for Reiki to be integrated into the health service. In the extract below, Ruth suggested that doing so would assist with what she referred to as 'total healing';

I would never advocate that you ignore traditional medicine. You can't take responsibility for what other people do but I would always advocate that you do a mixture of the two. That's why I would like to see Reiki integrated into the health service and as a help towards, you know, total healing because total healing isn't just an operation or a medicine to alter the chemical or the biological state of things. You've got to have a spiritual aspect to it as well and I think people in hospices have found this to be very relevant (Ruth) 
Hazel also spoke of the potential for Reiki or Eastern medicine more generally, to be integrated into the NHS;

I wish the two would entwine. We should more... have more of an Eastern, and I think that the whole concept of health is coming, should come from a preventative rather than a, what's the other word? Not preventative - do you know what I'm saying? [INT: Reactive?] Reactive to illness, if the NHS concentrated on preventative medicine then I think we'd be in a damn sight better state than what we are (Hazel)

\section{Integration into Other Organisations}

Teaching and practising Reiki within a drug and alcohol treatment service, Grace was the only participant who practised Reiki in an 'innovative setting'. In the extract below she spoke of how practising Reiki within such a setting has many benefits. She suggested it raises the profile of the organisation and results in better outcomes for service users;

Well I think it raises the profile of the organisation, I mean its certainly raised the profile of the organisation I work for because the clients want it and ask for it and then they go to other agencies and ask for it and they're not doing it and they say well [names organisation] are and all that sort of thing. So it raises the profile, it gives better outcomes because the service users who engage in it seem to do better - they definitely do better, I know they do. (Grace)

In summary, the ability to identify the wider social and political benefits of Reiki was apparent where Reiki Master Teachers speculated on the benefits of Reiki to the population in general and to integrating Reiki into the NHS and other health and social care organisations. It can be argued that it is a critical Reiki health literacy competency as it involves the use of more advanced cognitive skills. Further support 
for the argument that the ability to identify the wider social and political benefits of Reiki is a critical Reiki health literacy skill may be gained when Nutbeam's suggestion that critical health literacy 'may involve the communication of information, and development of skills which investigate the political feasibility and organisational possibilities of various forms of action to address social, economic and environmental determinants of health' (Nutbeam 2000:265) is considered in relation to this competency.

\section{- Forming or Joining a Reiki Group}

Within the Reiki Masters' interview data it became clear that there was a sense of 'community' amongst Reiki practitioners. Frequently this became apparent when Reiki Master Teachers spoke of joining or forming a Reiki group $(n=4)$. The main function of Reiki groups appeared to be for members to practise Reiki on each other as explained by Deborah;

As Reiki Masters a lot of us get together regularly and have healing sessions for each other because we're healing as well. We still need to make sure our vibrations are as clear as they can be so we're still on our healing journeys as well (Deborah)

In addition to Reiki practice, Ruth also noted that the 'Reiki days' served as a time for talking about 'spiritual things';

Karen was very good she used to have what she called Reiki days and about once or twice a year she would gather all her friends together and we'd all go to her house and do Reiki treatments, talk about spiritual things and experiment with crystals and cards and whatever so that was very nice and then that became so big that we had to hire the church hall in the village to have the days so that was very nice [...] We started just a group of five or six of us, would alternate months, we would go to each others' houses and do 
Reiki swaps in that, on each other so we'd do, as well as doing Reiki on ourselves we do keep up the practice of helping other people as well (Ruth)

Reiki groups then, serve as a forum for practising on one another, by practising on one another Reiki Masters are also helping or healing one another. There appeared also to be a social element to such groups. Hazel (below) noted a further dimension of Reiki groups which emphasised the role of other Reiki practitioners in continued learning. For Hazel, Reiki groups help practitioners to 'bring each other on', that is, develop or improve their skills and knowledge;

It's important, I think, for Reiki people to try and get a group together as it were. Even if it's once a month, every two months it's where like minded people... and you can bring each other on as well (Hazel)

The notion of community as it relates to health literacy appears in Nutbeam's (2000) work wherein he notes that the goal of critical health literacy is "personal and community empowerment.' The Reiki Masters' data suggested the existence of a community, however the extent to which it could be argued that the Reiki community was empowered through critical Reiki health literacy was unclear. What it does suggest is the potential for the Reiki community to play a role in enhancing critical Reiki health literacy. In summary, forming or joining a Reiki group may be considered a critical Reiki health literacy competency because it reflects the use of advanced social skills. Using these social skills to form or join a Reiki group supports all levels of Reiki health literacy.

\section{Summary of Critical Reiki Health Literacy}

Critical Reiki health literacy is the most advanced with regards the use of Reiki skills, cognitive skills and social skills. This level of health literacy enables a person to apply a holistic approach to their health and make health related judgments or decisions from a standpoint informed by multiple perspectives. To possess critical 
Reiki health literacy skills may be considered empowering as it promotes greater control and freedom of choice over health and health care. It comprises the following skills and competencies;

- Critically analyse information about Reiki, medicine and health

- Ability to apply a holistic perspective to health

○ Making decisions and choices informed by multiple perspectives

- Exerting control over physical, psychological and emotional health

- Identify the wider social and political benefits of Reiki

- Forming or joining a Reiki Group

\section{Concluding Comments}

This Chapter presented the findings from the first phase of the empirical part of the $\mathrm{PhD}$ Research. The interview data was explored in relation to each of the three levels of the initial model of health literacy which enabled further refinement of each of the three levels. Empirical data generated through interviews with Reiki Master Teachers helped to construct a refined model of Reiki health literacy; the first level of which, functional, largely involved the acquisition of knowledge. Progressing to interactive Reiki health literacy, interviews suggested a more active role on behalf of the Reiki student that involved putting Reiki knowledge into practice. The most advanced level of Reiki health literacy, critical, suggested a level of personal empowerment characterised by the ability to exert greater control and freedom of choice over health and health care. The following Chapter presents the findings from the second phase of the empirical part of the $\mathrm{PhD}$ whereby the applicability of the Reiki health literacy model is explored with Reiki level one and two self users. 


\section{Chapter Nine: Exploring the Applicability of the Reiki Health Literacy Model with Level One and Two Self-Users}

\section{Introduction}

The results of the first phase of the research were presented in Chapter Eight and were aimed at confirming and refining the model of Reiki health literacy first presented in Chapter Five. This chapter reports on the analysis and interpretation of the data generated during the second phase of the research. The overarching aim of the second phase of the research was to explore the applicability of the Reiki health literacy model with Reiki level one and two self users as a means of establishing if the Reiki health literacy model accurately captures people's experiences of using Reiki for selfcare. In doing so, it involved further exploration, conferment and refinement of the Reiki health literacy model.

The process of further confirming and refining the Reiki health literacy model during phase two involved comparing the data from phase two with the data from phase one. Confirmation of the version of the model presented in Chapter Eight, was accomplished when the data generated during phase two corresponded with that generated in phase one (that is, there was evidence that Reiki one and two self-users were in agreement with Reiki master teachers). Conversely, where data from phase one was not supported by data from phase two, this was noted. Data that arose from phase two that suggested skills, knowledge or competencies not identified by phase one participants, and therefore not a component of the model of Reiki health literacy presented in Chapter Eight, refined the model further.

The chapter begins with a description of the key characteristics of the participants such as age group, level of Reiki practice and length of Reiki practice. The remainder of the chapter focuses on an interpretation of the data from interviews with Reiki level one and two practitioners in relation to each level of the Reiki health literacy model. 


\section{Participants}

Twenty-five Reiki level one and two practitioners were interviewed between July 2010 and March 2011 and their details are summarised below in Table 9.1.

Table 9.1: Key Characteristics of the Sample

\begin{tabular}{|c|c|c|c|c|c|}
\hline \multirow[t]{2}{*}{$\begin{array}{l}\text { Level of Reiki } \\
\text { Practice }\end{array}$} & \multicolumn{3}{|c|}{$\begin{array}{l}\text { Approximate Length of } \\
\text { Reiki Practice (Years) }\end{array}$} & \multirow{2}{*}{$\begin{array}{c}\text { Proportion } \\
\text { Female }\end{array}$} & \multirow{2}{*}{$\begin{array}{c}\text { Median Age } \\
\text { group }\end{array}$} \\
\hline & $\begin{array}{c}\text { Short } \\
(<2)\end{array}$ & $\begin{array}{r}\text { Medium } \\
(2-9)\end{array}$ & $\begin{array}{l}\text { Long } \\
(10+)\end{array}$ & & \\
\hline Level One & 1 & 2 & 0 & $3 / 25$ & $31-40$ \\
\hline Level Two & 3 & 14 & 5 & $19 / 25$ & $51-59$ \\
\hline
\end{tabular}

Participants length of Reiki practice is an approximation due to the fact that it was common for participants to state their length of practice in approximate terms rather that absolute terms, for example 'roughly 4 years' or 'getting on for 4 years'. For ease of reading, participants' length of Reiki practice has also been divided into three groups representing short term use (less than 2 years), medium term use (between 2 and 9 years) and long term use (10 years or more).

Participants were predominantly of white British background with the exception of two participants, one of whom was of 'other' white background and the other was of 'other' black background. Participants were of a range of ages with two participants in the youngest age group $(20-30)$ and two participants in the oldest age group (60 69). The aim of recruiting at least one male practitioner and one practitioner of ethnic origin other than white British was met. As discussed Chapter Six (methods), the sample was not as diverse in terms of level of Reiki practice as hoped with the sample comprising only three Reiki practitioners at level one and 22 at level two. Whilst it is acknowledged that this may be a reflection of a weak sampling strategy, it may alternatively suggest that people who learn Reiki do not remain at level one, rather they tend to progress to level two. Indeed, two of the level one practitioners expressed their intention to progress to level two in the near future. The sample 
comprised participants with a good range of experience (in terms of length of Reiki practice) from participants who were relatively new to Reiki, for example Lucy with less than 1 year experience of Reiki practice, Samantha with approximately 1 year experience and Christine and Jackie with 1.5 years experience to participants who had practised Reiki for more than 10 years, for example Denise (12 years), Annabel (13 years) and Rosie and Kate (15 years).

\section{Interpretation of Interview Data}

The interpretation of the interview Data is structured around the model of Reiki health literacy. There are three main headings within this section (functional, interactive and critical Reiki health literacy) and these represent the three levels of Reiki health literacy. The subheadings represent the various components of each level. Whilst the headings are indicative of the levels and components of Reiki health literacy they are simultaneously themes that arose when interpreting the data. The data was analysed as a whole, that is, within the analysis the data was not differentiated by level of Reiki practice or length of Reiki practice or any other variable. However, within the following interpretation of the data attention is drawn to any significant differences relating to level of Reiki practice or length of Reiki practice.

\section{Functional Reiki Health Literacy}

Chapter seven tentatively concluded that functional Reiki health literacy comprises eight competencies. With the exception of receiving a Reiki attunement, these competencies are knowledge-based. The passivity implied within functional Reiki health literacy does not involve the Reiki student translating any of this knowledge into practice.

\section{- Knowledge of how to self- treat with Reiki and knowledge of how to give a Reiki treatment to family or friends.}

All but one participant demonstrated within their interviews that they possessed knowledge of how to self treat with Reiki. In common with the Reiki Masters 
interviewed in phase one, the Reiki level one and two practitioners discussed this using a variety of terms that included 'how to give myself a treatment', the 'hand positions', the 'hand movements' and 'self healing'. Most frequently, participants learned how to self treat on their Reiki level one course. Participants also explicitly stated that they had been taught how to give a Reiki treatment to another person. The following quote from Susan is typical of the way in which many participants expressed their knowledge of treating others with Reiki:

She [Reiki Master] showed me how to give myself a treatment and how to give somebody else a treatment (Susan, level one, medium term user)

When participants talked about the 'the hand positions', it was apparent that this term was one frequently used to express knowledge of how to self treat and treat another person. The following exert from Alice's interview illustrates this:

I remember learning the positions of the hands.

[Was that for use on yourself or on other people?]

Both really (Alice, level two, medium term user)

Similarly for Phillipa, the 'hand positions' were for self treatment and treating others:

Yes, we had the set hand positions for self treatment as well as giving, you know, treatment to somebody else, a friend or family (Phillipa, level two, medium term user)

Only one participant explained that she had not been taught how to self-treat with Reiki. In the following extract, Jackie explains how this was due to the fact that her Reiki Master teacher had geared the course more towards people who wanted to treat others: 
[Did she tell you about the positions of self-treating then, you know, for using it on yourself?]

No. I would say it was more; she was looking at people wanting to treat others (Jackie, level two, short term user)

Despite not being taught by her Reiki Master how to self treat with Reiki, it became apparent throughout her interview that Jackie did in fact possess the knowledge of how to self treat when she provided concrete examples of incidences when she had used Reiki for self treatment.

\section{- Receiving a Reiki Attunement and Knowing What to Expect from the} Attunement

All participants who took part in the research volunteered to do so on the understanding that they had been attuned to level one or two Reiki. The wording of the information letter read you are being asked to participate in this research because you are attuned to Reiki level one or two. Therefore the act of volunteering to participate in the research was taken as evidence that they had received a Reiki attunement. Furthermore, when participants were questioned about whether they knew what to expect from their Reiki attunement(s), many referred to their experience of receiving it thus confirming that they had indeed received an attunement.

In terms of knowing what to expect from an attunement, responses were mixed. Three participants stated that they did know what to expect from an attunement. Clara was one of these three and stated that she knew what to expect from her attunement through a combination of reading and discussion with her Reiki Master teacher:

Yes, I've read up about it and when I spoke to [Reiki Master Teacher] about it and she explained everything, any concerns or worries I had she just seemed to say the right things to me (Clara, level two, medium term user) 
Clara also recalled how on the day of her Reiki attunement her Reiki teacher also explained about the attunement:

She explained, you know, about how she was going to do the attunement, so everything we were doing that day she gave us a brief, she talked us through it well so you knew what to expect (Clara, level two, medium term user)

Some participants stated that they did not know what to expect from having a Reiki attunement, whilst some had a 'vague', 'slight' or 'rough' idea or knew what to expect 'a little bit':

Slightly, yeah she sort of outlined what happens and things like that ... not in any depth (Cheryl, level two, medium term user)

Well vaguely, vaguely, because by then I met people who had done Reiki or received Reiki, so vaguely but no. To be honest no. (Faye, level two, medium term user)

Whilst Clara (quoted above) knew what to expect as a result of reading and discussing it with her Reiki Master Teacher, for others there was not necessarily a correlation between reading about Reiki in advance of the attunement and knowing what to expect. Despite having undertaken prior reading about Reiki on the internet and in books, Lucy still stated in her interview that she did not fully know what to expect from her Reiki attunement:

No, all I knew to expect was what I'd looked up on the internet and I'd read the book before I went (Lucy, level one, short term user) 
The data generated during phase two confirmed that receiving a Reiki attuemnt was a component of functional Reiki health literacy. With regards to knowing what to expect from the Reiki attunement, the evidence generated during phase two was ambivalent. Within phase one, only a small number of Reiki Master Teachers stated that they discuss what to expect from the Reiki attunement. In phase two, there were a small number of participants who wholly knew what to expect, but the majority did not.

\section{- Basic Knowledge of What Reiki Is}

Most participants were able to express some basic knowledge relating to what Reiki is. However, the means by which participants expressed this varied. Some participants such as James and Naomi offered a concrete definition of what Reiki is using the phrase 'universal energy':

I mean the Reiki energy is a universal energy (James, level two, medium term user)

There was a bit of context because obviously, you know, discussing Reiki and trying to understand what is Reiki in the sense of its universal energy, it's a kind of thing that you're a channel and [Reiki Master Teacher] was very clear about saying 'you're not the healer', you're just purely a channel for the healing (Naomi, level two, medium term user)

Other participants expressed their knowledge of what Reiki is using phrases such as 'where it comes from', 'origins', 'how it came about / came to this country'. These participants were expressing their knowledge of what Reiki is using the history of Reiki as a frame of reference. Both Heather and Cheryl referred to the founder of Reiki, Dr Usui, as the starting point to how Reiki became the system that it is today: 
She[Reiki Master] just went through the history with Dr Usui and he started in eighteen something and it was passed on through generations and then an American lady brought it to America, she brought it to America and then it sort of finally came over here. But, it sort of evolved to what it is today, it was very different then. (Heather, level two, medium term user)

She [Reiki Master] very much went through the background to Reiki, Dr Usui and how it developed (Cheryl, level two, medium term user)

Similarly, Alan and Faye also referred to the history of Reiki. Alan supplemented this by stating that he learned what Reiki 'is' or 'isn't' and Faye implies her knowledge of the history of Reiki whilst simultaneously expressing her knowledge that Reiki is a 'form of healing':

I mean you learn a little bit about the history of Reiki, what it actually is or isn't (Alan, level two, medium term user)

I have this thing in my mind that it's a very, very old Japanese form of healing dating back 5,000 years old and that really stuck in my mind (Faye, level two, medium term user)

The fact that most participants possessed a basic knowledge of what Reiki is corresponds with the data generated from interviews with the Reiki Master Teachers, that is, most Reiki Master teachers explained that they teach their Reiki level one student what Reiki is. Often this is placed within the context of the history of Reiki.

\section{- Basic Knowledge of Energy}

Level one and two Reiki practitioners demonstrated their knowledge of energy in a variety of ways. It was common for participants to discuss energy as being something 
that humans possess. In the quotes below, Bella explains how people 'give out' energy and Naomi explains how energy is 'around the body':

She [Reiki Master] gave an example about energy coming out of the body; yes she said everybody gives out energy from the body (Bella, level one, medium term user)

I've been doing energy work, as in Yoga, for years [...] so I understood the idea of energy around the body (Naomi, level two, medium term user)

Similarly, including the notion of the human being within their accounts of energy, Lucy referred to energy as being something that flows from the universe through the body and Faye explained that we (human beings) are energy:

People get blockages and then they'll treat the blockage with medication, but if you treat the mind and whole body just getting the energy flowing from the universe through the body. (Lucy, level one, short term user)

We all are energy, and that you, you know its energy of kindness, who you are, what you do has an energy. (Faye, level two, medium term user)

Another way in which participants demonstrated their knowledge of energy was with reference to their experiences with energy, usually during their first Reiki course. Lilly and Phillipa recalled their experiences of 'feeling' energy during their Reiki training:

What we did do with the energy, we had quite a large group - there were about two of us I think, and we continually swapped partners [...] and realised that swapping partners everybody's energy feels different. And then we 
discussed as a class what we felt, you know, people said they felt hot, felt tingling, felt pins and needles, you know, just cold even and like lots of different feelings. (Lilly, level two, medium term user)

She [Reiki Master] taught us how to feel the energy in the palms of our hands, and to actually recognise that it can be different for each person. (Phillipa level two, medium term user)

A further example of the way in which participants discussed energy is illustrated by Christine who described learning about energy on her Reiki level one course and how Reiki works on an 'energy level':

That was all done at Level 1 [learning about energy] she obviously talked about that and that was all to do with the history and how it worked, so it was explaining that basically Reiki works on energy levels, so all that was covered in Level 1. (Christine, level two, short term user)

There was ample evidence from the interviews with Reiki level one ad two practitioners to confirm this element of the Reiki health literacy model, that is, knowledge of energy is a functional Reiki health literacy competency.

\section{- Knowledge of Protection}

The majority of participants was able to demonstrate knowledge of protection and was able to explain a range of techniques that they had been taught. Two of the most frequently cited methods of protection were using a 'bubble' and using 'light'. Two quotes by Alice and Kate are typical of how participants described the 'bubble' technique: 
I would sort of visualise myself in a sort of bubble and that would be how I would protect myself, yes. (Alice, level two, medium term user)

Well, I sort of, I try to imagine myself in a bubble and then fill it with love, it tends to be like a sort of a something that fits round the body and then I imagine love filling it out sort of thing. I can't quite, I can't quite visualise myself in a bubble, it's like visualising something coming down over my body and then filling it out when I fill it with love sort of thing. (Kate, level two, long term user)

James described how using the medium of meditation, he 'brings in' light to protect himself:

I always use the light now, I can bring in light and focus light and I can heal with light [...] Yeah, you've got to meditate, that means you've got to really calm down, so you've got to do a breathing meditation, and I wait till my minds clear of all thoughts. You've got to have an empty, you've got to go into like a, what you call an emptiness almost and then you bring in the light by imagining like loads of global lights [...] and so I just bring it in and then it just sort of goes round me and covers me. (James, level two, medium term user)

Light, as a method of protection, was also described by Cheryl and Denise. Other methods described by participants included the use of angel wings (Phillipa) and cloaks (Patricia). It was apparent within the analysis of the phase one data that Reiki Masters attached great importance to protection. However, this sense of importance did not appear to be shared by Reiki level one and two practitioners with some questioning the need for protection. Bella and Alan dismissed the need for protection on the grounds that they did not feel they needed it and Alice disliked the idea of protection questioning the need for protection: 
Personally, because I do it on some of my friends now, I don't personally feel I need to protect when doing it (Bella, level one, medium term user)

As far as I'm concerned, I don't actually need protection. I don't feel I need protection. I mean, I know there is something in my Reiki manuals about protection and locking yourself with love and light, but I don't actually, I don't really feel ....I mean I obviously, going though different stages and different emotional changes, I've had periods were I've suddenly felt some fear about something. And then gone with it and its dissipated, so that's why I don't really need it (Alan, level two, medium term user)

I don't like the idea of having to protect myself I don't see, you know, I don't see what I am protecting myself from (Alice, level two, medium term user)

Furthermore, some participants, whilst possessing knowledge of protection, stated that they did not put that knowledge to use by actually protecting themselves, further suggesting that the importance of protection was not shared with the Reiki Master Teachers. This issue of putting (or not putting) knowledge into practice is discussed later under the interactive components of the Reiki health literacy model (see pages $16-23)$.

\section{- Basic Knowledge of Chakras}

All participants were able to either talk about the charkas or recognise a picture of them when presented with vignette three (see Chapter Six). Participants were able to offer a range of information relating to the chakras including what they are, how they relate to Reiki, how they relate to the human body and the feelings a person might experience when their chakras are out of balance. In describing what the chakras are, participants provided some basic descriptions using words such as 'wheels', 'intense energy centres' and 'portholes': 
The chakras are the wheels, so you want to keep them balanced and moving. (Denise, level two, long term user)

Just that they are very intense energy centres and about perhaps just being aware of the fact that there's quite a strong energy pull over certain parts of the body. (Naomi, level two, medium term user)

Oh gosh, she [Reiki Teacher] said that they were portholes in your body. (Heather, level two, medium term user)

Alice demonstrated knowledge of the chakras with reference to how many chakras there are:

My understanding is you know that we have seven different chakras you know and some people debate it as being eight actually I think. (Alice, level two, medium term user)

Two participants described how the chakras relate to Reiki; Heather noted that chakras are the means by which Reiki enters and leaves the body and Cheryl described how Reiki can be used to 'balance' chakras:

[...] you know, that Reiki can come and go from these portholes (Heather, level two, medium term user)

They [chakras] can become out of balance and stuff like that and that Reiki, you know, can be one way of actually balancing it all out again (Cheryl, level two, medium term user) 
Participants also related their knowledge of the chakras to the human body and Phillipa and Christine provided examples of how they had eased a range of ailments using Reiki on the chakra that corresponded with the ailment:

In the winter I suffer with chest infections since I've had meningitis and I use Reiki for them as well to stop the coughing in the night. It doesn't totally stop it, but it does ease it and I tend to use the throat chakra and I'll beam into my throat chakra for that. (Phillipa, level two, medium term user)

I might be feeling a bit stressed, I might have a sore throat, I might just generally be a bit run down, [...] I will know which point to go to, either Reiki my throat or I'm gonna go straight to the temples or I am gonna do my heart. Because really the chakras are little bits of the body, so if my legs are aching I'll go to the base and treat them. (Christine, level two, short term user)

The third vignette that was shown to participants during their interview comprised a picture of a person with their chakras out of balance. This vignette generated much discussion through which participants demonstrated their knowledge of the chakras. All but one participant was able to identify the picture as being of the chakras 'out of balance'. When asked how he would feel if his chakras were out of balance, James gave the following response:

I would feel totally wrong, I would not be with it at all and this base chakra is miles out, so you wouldn't have the ability to sort of like, this represents going to work and like the ground building like a survival working, the second chakra is fine, I would say maybe it's in the right place, so that's ok, the solar plexus is miles out so your emotions are probably, that has a lot of intelligence but also a lot of emotions there, but it's also to do with the mind and 
intelligence, there are a lot of thinking and thoughts go there. The heart chakra is ok, it might be a bit low that. (James, level two, medium term user)

Alan responded in a similar manner referring to both physical and emotional sensations when asked how he would know if his chakras were out of balance:

Well I feel like I'm either pulled over to the right or pulled over to the left, you know, I'm not totally within myself.

[HG: Ok. Is that a physical feeling or is it a knowing kind of?]

Yeah, it can be physical or emotional - they're seriously out of balance (Alan, level two, medium term user)

It was noted within the previous analysis of the Reiki Masters' data that all but two Reiki Masters spoke of the chakras. In contrast, all Reiki level one and two participants spoke of the chakras thus confirming a basic knowledge of the chakras as being a functional Reiki health literacy competency.

\section{- Knowledge of Grounding}

Within the interviews, grounding was associated, literally, with the ground or the earth and the most common method of grounding described by participants was visualising roots stemming from the body into the ground. This method is described below by Alice, Naomi and Denise:

I would visualise sort of roots going down into the ground (Alice, level two, medium term user) 
I mean we used to kind of do stuff about kind of roots going into the ground and getting that real sense of being very, you know, very grounded, very much of the earth (Naomi, level two, medium term user)

I just sit and close my eyes and visualise light going all through my body down and like roots down into the ground and I anchor those down to my feet (Denise, level two, long term user)

Phillipa also demonstrated an awareness of using roots to ground herself, yet she also described another technique that she had been taught that involved visualising coloured chords coming out of the body and into the earth:

She taught us the technique of visualising roots coming out the sides of our feet into the ground. She also taught us the technique of sending, using our base chakra and our solar plexus, and sending the coloured chords down our legs and also down into the earth, into the centre of the earth and wrapping them round like a boulder and keeping yourself grounded (Phillipa, level two, medium term user)

Within the interviews there was evidence that Reiki level one and two practitioners possessed knowledge of grounding and those who did had the ability to describe the technique that they had been taught to ground themselves.

\section{- Knowledge of Symbols}

The Reiki symbols are not taught at Reiki level one, therefore, it is unsurprising that they were not talked about by Reiki level one participants. Reiki Level two participants' knowledge of symbols became apparent when they discussed the content of their Reiki course(s). Some participants simply recalled the fact that they had been taught about the symbols. Two extracts from Christine's and James's transcripts illustrate this: 
So we went through the three symbols, distance healing and psychological, physical, we worked through all that (Christine, level two, medium term user)

Reiki two was focusing on distance healing on the symbol for distance healing (James, level two, medium term user)

Other participants such as Jackie were able to express more factual information about the symbols. When discussing what she was taught about the symbols she noted the fact that they are to be kept secret, that each one has a meaning and that they can be drawn:

They're a secret but they may appear differently because of the carrying down through history and they may change. But also, she went through, not so much what they meant, but trying to get us to draw them (Jackie, level two, short term user)

Some participants also demonstrated knowledge about how the symbols are used; this included how to say the corresponding mantra and how to draw them as exemplified by Faye and why they are used (or for what purpose) as described by Naomi (opening up a session) and Phillipa (sending to the past or the future, to people or situations):

We learned how to use them, to say them, to draw them, all kind of things really, how to use them and why (Faye, level two, medium term user)

She obviously explained them and described the kind of layout of them and what they're about and about how you can open up, you open up a session with them and the strength and power associated with them (Naomi, level two, medium term user) 
You can use them in different ways, so rather than just putting the Reiki symbols into somebody, you can use them in reverse to draw things out in certain areas as well. Yes, she explained all that about, you know, how the symbols and also she, I learnt about the symbol for the sending and also past, present and future, not just to people, but to situations as well (Phillipa, level two, medium term user)

Within the interviews there was evidence to confirm that Reiki level two participants possessed knowledge of the Reiki symbols. This included factual knowledge about the symbols and knowledge about how and why the symbols are used.

\section{Summary of Functional Reiki Health Literacy}

Interviews with Reiki level one and two self users largely confirmed that the skills knowledge and competencies identified within the initial model of Reiki health literacy and as further confirmed and refined within phase one, were at the level of functional Reiki health literacy. That is, the skills, knowledge and competencies were applicable and captured people's experiences of self using Reiki. The exception to this was the knowledge of what to expect from a Reiki attunement whereby the evidence to confirm this was limited. Interviews with Reiki level one and two self users did not suggest any additional competencies that further refined the model.

\section{Interactive Reiki Health Literacy}

Chapter Seven tentatively concluded that Interactive Reiki health literacy comprises six competencies. These competencies were more advanced than those identified as being functional competencies and generally suggested a more active role on behalf of the Reiki student than was characteristic of the functional Reiki health literacy competencies. 


\section{- Putting Reiki Knowledge into Practice}

Within this competency there are three pieces of Reiki knowledge that can be translated into practice: the ability to self treat with Reiki, the ability to give a Reiki treatment to family or friends and the ability to use energetic protection

\section{Self treating with Reiki}

As previously noted, all but one participant demonstrated their knowledge of self treatment. Furthermore, all participants discussed actually performing self treatment with Reiki within their interviews. Participants self use of Reiki may be characterised in two ways. It became apparent when interpreting the data that there was one group of participants who described themselves as using Reiki regularly and a group who indeed used Reiki but not what they described as regularly.

Participants who described themselves as using Reiki on themselves regularly often expressed this by stating that they used Reiki 'nightly', 'every night' or 'everyday'. Extracts from Annabel's, Phillipa's and Clara's interviews illustrate this:

Unless I'm really tired I try to do just like, you know, generally nightly, unless I'm so exhausted (Annabel, level two, long term user)

Every night [...] when I say every night I mean obviously there is an odd night I don't do it here and there (Phillipa, level two, medium term user)

Every day [...] I do miss the odd day but I rarely do, if I don't, especially in my job, I really can feel the difference if I don't. (Clara, Level two, medium term user)

Alan also stated that he used Reiki on himself every day but followed this up by stating that due to the amount of time involved, daily self treatment wasn't easy: 
Try to do it every day, but sometimes it's not that easy. [...] You know, I go that deep that, you know, by the time I get finished it might be an hour and a half later (Alan, level two, medium term user)

Participants who did not use phrases that indicated they self treated with Reiki on a daily basis described their frequency of Reiki self use as a couple of times a week or three or four times a week as illustrated by Patricia and Paula:

About 3 or 4 times a week (Patricia, level two, long term user)

I try and do it a couple of times a week (Paula, level two, medium term user)

Participants who did not describe themselves as using Reiki on themselves regularly 5 were nonetheless active in their self use of Reiki. For this group of participants, their self use tended to be dependent upon them having a health complaint. Susan sums up this pattern of self use by using the phrase 'if there's something not right':

Normally if I can't sleep, if I've got head ache, if I've got stomach... if there's something not right. I don't tend to just do it as a regular (Susan, level one, medium term user)

Other participants noted having the inability to sleep, menstrual pain, anxiety, and a hip problem as being factors that influenced whether or not they self treated with Reiki as exemplified by Jennifer, Faye and Kate:

Regular self use of Reiki was an inclusion criterion for the research, however at interview it was common for participants to state that they did not self use Reiki regularly. 
I tend to use it when I'm not sleeping well [...] so I will often use it at night before I go to bed or something like that (Jennifer, level two, medium term user)

I do it when I've got, it's quite rare, but sometimes I have a bit of period pain, so I do it then, and I would do it when I'm anxious. So I do use Reiki on myself, but not as much as I'd like to, but I do it specifically, more for the anxiety (Faye level two, medium term user)

For Kate self use of Reiki was influenced by her hip problem but also by the availability of time:

I've been doing it more recently because I've hurt my hip and so [...] I'm trying to do my exercises for my hip as regularly as I can and I try to do Reiki on my hip as regularly as I can, so sometimes I might do the Reiki on my hip every day or it might be every 2 or 3 days, it just depends what I'm doing in the week as to what time I've got to do things. (Kate, level two, long term user)

The above cited extract from Faye's interview, describes how she self uses Reiki specifically for anxiety. However, stress levels were cited by Christine as being a factor that influenced her self use of Reiki. In the following extract, Christine begins by stating that she self treats with Reiki as often as she needs to. When asked for clarification on this Christine elaborates that on some occasions there is no specific reason behind her decision to use Reiki on herself:

[How often do you give yourself Reiki then?]

As often as I need it. 
[As often as you need it. How would you know when you need it?]

I tend to... there are days when I take myself off, maybe I'll come home from work and think 'oh I'll give myself a bit of Reiki' for no other reason than I think I'll do a bit of Reiki. (Christine, level two, short term user)

However, Christine follows this up by explaining that despite often not having a reason for self treating with Reiki, in fact, her level of stress is often a factor:

Because maybe I'm having a peaceful moment and I want to enjoy the time even more, a lot of it is based on my stress levels [...] If I'm quite stressed and need to calm myself down I will think 'right I'll go for a 10 minute Reiki', but 'no', it's a bit random really (Christine, level two, short term user)

Another way in which participants demonstrated the fact that they self used Reiki was within their descriptions of how they used Reiki on themselves. This was in one of two ways: either a full treatment using the traditional hand positions or doing a 'spot' treatment that is, placing their hands in one single position on the body.

\section{Giving a Reiki treatment to family or friends}

Many participants stated that they had given Reiki to family or friends. Among the family members that participants described treating were:

- Son / Daughter

- Sister

- Husband

- Mother-in-law

- Partner

- Father 
- Stepson

Participants provided examples not only of whom they had practised Reiki on but also the method of doing so (hands on or distance). Susan, Paula and Jackie recalled instances when they had practised hands on Reiki on family members. For Susan, this was on her son, for Paula her sister and for Jackie, her Dad:

I've done it on [son] [...] It's just if he's had, you know if I know he's got stomach ache or something I might just place my hands, so whether it makes a difference or not I don't know. It's similar to giving them a cuddle; it's that sort of calming touch (Susan, level 1, medium term user)

We were at a dinner and dance once and my sister, she suffers with lupus and so her joints are quite bad and she was up dancing and her ankle went and she came over and sat next to me and I put her foot on my lap and said 'go on please' and then danced the rest of the night (Paula, level two, medium term user)

I tell you what did surprise me when I first started doing it, my Dad who's like in his, well it's his birthday tomorrow and he's 79 and he'd got a poorly knee, he stumbled, this was when I'd done my Level 1 and I said I'd been learning Reiki. I explained it to him and he actually let me do it, I said 'you'll have to put your foot up there' and I said 'would you mind if I do it' and I was so surprised he let me treat his knee (Jackie, Level two, short term user)

James and Kate provided examples of when they had provided distance Reiki for family (James) and a friend (Kate):

Yes for my sister I've done distance healing and [partner's son] distance healing and I think I did some for Susan (participant) once as well, so quite a few distance healing sessions (James, level two, medium term) 
I have a friend with terminal cancer [...] she started with breast cancer about 8 years ago, so I do sometimes send her distance healing (Kate, level two, long term user)

In contrast to the previous participants who had provided Reiki treatments to family members, Heather talked about how her husband had refused a hands-on Reiki treatment and that she does not offer Reiki to her children:

Well I have offered it to my husband, but he's flatly refused, but I'm allowed to send, but I can't put my hands on him and do it, because he thinks its mumbo jumbo. [...] and to be honest I haven't with my children because they would probably think I was bonkers (Heather, level two, medium term user)

Patricia and Kate provided examples of treating friends with Reiki. Both participants used the term 'exchanges' or 'swap' to indicate that in exchange for giving Reiki to that particular friend, the friend would respond by providing something (nonmonetary) in exchange:

I do a few of my friends, like I do exchanges, I do a reflexology exchange, facial exchange, the other therapists I know don't do Reiki (Patricia, level two, long term user)

I've got a friend and she's a massage therapist and does reflexology and we get together about every 3 weeks and we do a swap, so sometimes I do Reiki for her, sometimes I do reflexology (Kate, level two, long term user)

\section{Using Energetic Protection to Benefit Health}

Previously within this chapter it was noted that the majority of participants was able to demonstrate knowledge of protection and was able to explain a range of techniques 
that they had been taught. However, the importance attached to protection by Reiki Master Teacher's did not appear to be shared with Reiki level one and two self users; this was evident in participants questioning the need for protection.

Under the discussion of functional Reiki health literacy competencies, examples illustrating participants' knowledge of protection were provided by Alice, Kate and James (see pp 9 - 11). Their examples may also be considered as evidence to suggest that they translate this knowledge into practice (that is, they use protection) as their quotes refer to what 'I' do or 'would do'. Phillipa was another participant who used protection and provided the following example of how she uses angel wings to protect herself:

Yes, she taught us, yet again, she gave us suggestions of how ... things that we could do for protecting ourselves and she explained some of the things she used. She felt particularly close to angels and using angel wings, which is something I do, I use archangel Michael wings to protect myself (Phillipa, level two, medium term user)

Those participants who actively used protection were able to discuss the reasons why they used it and, in contrast, those who did not use protection were often able to explain why they should. In the two extracts that follow, Clara describes using protection to help in her job and Denise due to her practice of mediumship (communication between the dead and the living):

Yes, so she sort of talked to us about, especially in my job 'cos I work in a care home and it really helped me, you know, before she taught me these techniques, I used to pick up on everyone else's like energy and things, so she talked about putting yourself in a bubble or a cloak (Clara, level two, medium term user) 
Well every morning anyway, I know she did talk about protection and about a cloak or a light around you, but I automatically, 'cos I work in that sort of ... I do practise a bit of mediumship, so I always have to, I always do protection every morning (Denise, level two, long term user)

Participants demonstrated that they were able to use energetic protection and the reasons for doing so. As such, the idea that using energetic protection to benefit health is a component of interactive Reiki health literacy was supported by data generated during phase two.

\section{- Using the Reiki Symbols}

Rosie stated that she used the symbols 'all the time'. In the following extract from her interview she describes using the symbols on herself and also to send Reiki to herself

When I wake up every morning, before I get up, I use the [names the mantra] and the [names the mantra] Reiki on myself just for a few minutes to start my day

[OK and you do this every day do you?]

Pretty much, unless I've overslept and then I have to mutter them on the way to work in the car, but pretty much every day and particularly if I know that I'm going to have a particularly tough day, because I very often do have a very tough day and if I can see one coming sometimes I do what [Reiki Master Teacher] suggests which takes a little bit more application; I send it forward to meet me at the other end to ease the way it's going to be. (Rosie, level two, long term user) 
The idea of sending Reiki ahead of time to help with the day ahead was also discussed by Clara. Clara described how she found it helpful to send Reiki to the future if she knew that a difficult day was imminent:

I always seem to do it when I go to sleep, it just feels right for me, but if I've had a particularly bad day or, what I use it for a lot is it helps me, I send it into the future if I know I'm going to have a difficult day and I've got a bad meeting or I know I've got a difficult resident, just to try and calm it and help me (Clara, level two, medium term user)

Lilly was another participant who talked about sending Reiki to situations that she was going to be in including meetings or more generally difficult days at work. In the following excerpt from her interview she describes the effects that sending Reiki has on her mental wellbeing and confidence:

Oh I'm just trying to think how I can explain it, it's just really comforting. If I go through a challenging time or I know I've got a challenging situation it might almost be like a little bit like a placebo but when I send Reiki to a situation I always feel comforted and I feel more confident (Lilly, level two, medium term user)

In addition to sending Reiki to herself, Rosie also talked about using the Reiki symbols to self-treat her Irritable Bowel Syndrome (IBS). In the following extract from her interview she discussed how she uses the symbol that is linked to metal and emotional healing due to her belief that her IBS is linked to stress. The extract below begins with the researcher asking Rosie to talk her through how she uses Reiki to treat her IBS: 
Well, I'll just literally draw the symbols onto my hand and [...] I usually, because of the [mental / emotional symbol] being the emotional one, I usually go for the solar plexus and [power symbol] for the physical.

[Right, OK. How do you find, does it help at all do you think?]

I think a lot of it with my IBS is emotional or stress and I think a lot of it is spending the time to calm yourself down. I don't get the many problems I used to have anyway because I manage it so well, I think I should write a book about controlling IBS, but I think it's the calmness and the feeling of the energy coming into you and accepting it.

[Accepting the energy or accepting the....?]

Accepting the energy. (Rosie, level two, long term user)

The Reiki symbols were not only used to treat physical health problems such as IBS as described by Rosie, they were also used to address mental or emotional problems. Alan spoke of using the Reiki symbols on himself to look at childhood issues:

Well I've used the symbols on myself [...] because I wanted to look at things going back through time, going back to my childhood [...] There was always some issues there, so I've actually done that (Alan, level two, medium term user)

Christine described her use of one of the symbols to avoid conflict with her manager during meetings: 
My contracts manager, she's a nightmare and I've physically sat there in the meeting and sent the emotional symbol, drawn the emotional symbol [...] she can be very condescending, bad tempered and she's a business woman. She wants result for the money, which is fair enough, however, she has the fantastic ability to make people feel that big, so I'll quite often draw the symbol, but it wouldn't be known to anybody (Christine, level two, short term user)

Phillipa noted that she did not often use the distance symbol to send Reiki to herself. However, she had done on occasion in the past. In her interview, she described a situation whereby she had sent Reiki to the past and as a result self 'healing' had taken place:

I had a very big sort of, healing situation and I believe that a lot of that was down to me sending to the situation in the past. [...] So it ties in with major illness - my daughter was very very ill and a lot of the sending that I done was to do with my past marriage between me and my ex husband. And when she became ill we were in intensive care for a long time with her, and my ex husband and I had to spend time shut in a room with her, literally just him and I, so actually, in those 10 days there was a massive massive healing went on.

The impact of this healing had been immense and this was evidenced by her choice of language. When Phillipa was asked whether she believed that the Reiki helped to bring herself and her ex-husband together to resolve the situation, her response was 'oh definitely'. Furthermore when asked if she felt better for having healed the situation Phillipa responded:

My god yes, massively, because I was very bitter and angry about a lot of things and to the point where just before she was transferred to, out of intensive care, he apologised for lots of stuff and actually said 'sorry' and that was just like a huge clearing really, so yes, I think a lot of that. (Phillipa, level two, medium term user) 
In summary, Reiki symbols can be used in different ways and for different reasons including easing a difficult day and providing comfort and confidence in situations, easing physical medical problems and addressing problems from the past. There was ample evidence from Reiki level two self users ${ }^{6}$ to confirm use of the Reiki symbols as being an interactive Reiki health literacy competency.

\section{- More Developed Understanding of Energy}

A basic understanding of energy as described in the above section on functional Reiki health literacy entailed characterising energy as being something that humans possess, something that can be felt, or the observation that Reiki 'works' on an energy level. In contrast a more developed understanding of energy is characterised by the ability to make links between energy and wellbeing and to understand energy as something that can be influenced or controlled by a person. In the extracts below, both James and Naomi, suggest a link between energy and wellbeing. James links energy to wellbeing when he discusses the feelings a person might experience if they did not take steps to prevent negative energy entering their environment and Naomi makes a link between having a better understanding of energy and increased wellbeing:

The result would be, in my opinion, would be feeling out of balance, would be anxious and aggravated and not being able to concentrate and, you know, I'd get into negative situations, because you feel negative, you draw negative towards ... what's called 'the law of attraction'. So if you feel, you know when it's one of those days when you get out of bed the wrong side and think 'oh blimey, that's gone wrong and that's gone wrong' I think it's because you're in that frame of mind, you can be drawing things into you that are equally as bad. (James, level two, medium term user)

${ }^{6}$ Regular self use of Reiki was an inclusion criterion for the research, however at interview it was common for participants to state that they did not self use Reiki regularly 
I think it's [Reiki] helped me to kind of understand energy more and understand how to work in a much more measured, [...] measured way with myself in the sense of, thinking about what I do that helps to engender a more positive energy, being more aware of the negative energies, being very aware of the negative energies that you pick up. I'm quite a sensitive person, so I realise that a lot of the times its because I'm in a very negative environment and I've not always realised what that's about, so it's just becoming much more aware of that and the power of sort of looking at life on an energetic level. I think it did wonders for my whole sense of wellbeing and my mental wellbeing. (Naomi, level two, medium term user)

The above extract from Naomi's interview draws attention to the notion of 'action'. When Naomi talks about what I do that helps to engender a more positive energy she is essentially recognising that she can actively influence energy. There was a theme of energy as something that can be changed or manipulated as opposed to energy simply being there. The following exerts from Alice's interviews further illustrate this. Alice describes the technique that she uses to clear her energy and how action changes (for the better) her energetic field:

I mean I would probably - I have been in situations like that and I've just literally gone to the loo and sort of tried to clear my energy and what works for me is sort of flapping my arms around literally. [...] No doing that it sort of changes my energy and then I do sort of visualisation

[Okay. Just when you say clearing your energy, can you explain to me?]

Well like for instance, you know if I was feeling very anxious with a lot of adrenalin that simple physical action would distribute [...] all the adrenalin. 
But on another level for me it would change my energetic field as well and I would feel better. (Alice, level two, medium term user)

\section{- Applying Reiki Knowledge to own Health}

As with the Reiki master teachers, Reiki level one and two self users frequently talked about how they applied their knowledge of Reiki self treatment to their own health conditions. This included a range of physical and mental / emotional health conditions. Examples of physical ailments that participants had used their knowledge of Reiki to treat included wisdom tooth pain; sinus pain; food poisoning; falls; colds; back problems; shoulder problems; foot problems; constipation; tiredness / fatigue and headaches. Typical examples of how participants talked about applying their knowledge of Reiki to their own health are exemplified by extracts from Christine's, Lilly's and Lucy's interview:

I used it when I had my wisdom teeth out. [...] It helped with the pain, it helped ease the pain. (Christine, level two, short term user)

If I get a cold or anything like that I always find Reiki's really good around the sinuses, around my ears ... (Lilly, level two, medium term user)

And it's really helped me, that's another thing it's helped me with, I've always struggled with going to the toilet, always, and it's helped me with that, just made me more regular.

[Has it. Now do you think that's from learning it or is it from your selftreatments?]

I think it's from the self-treatments. [...] Yes, definitely from the self-treatments. (Lucy, level one, short term user) 
In addition to physical health problems, a small proportion of participants described how they had applied their knowledge of Reiki to assist with emotional or mental health problems such as nerves and anxiety. In the extract below, Alice describes two ways in which she applied her knowledge of Reiki to help with an occupational health interview that she was nervous about attending. Firstly, she notes how she used her knowledge of Reiki and applied this to herself and secondly she applied the knowledge that Reiki can be sent by asking another person to send her Reiki:

I had an appointment about three weeks ago that I was quite nervous about. I did use Reiki on myself but also asked someone else to send me some Reiki and that's not strictly your area of research but I did give myself Reiki at the same time as well [...] I was going into this interview, very very nervous and I said to this person can you give me ...can you send me some Reiki? (Alice, level two, medium term user)

One condition that was discussed frequently by Reiki level one and two self users was stress and it was clear within this phase of the research that applying knowledge of Reiki resulted in reduced levels of stress. The association between a purported reduction in stress and applying Reiki knowledge became apparent throughout the interviews in differing ways. Sometimes participants were explicit about what Reiki knowledge they had applied to help with stress, for example Annabel discussed how applying her knowledge of self treatment helped her to 'focus', induced feelings of 'calmness' and helped her to sleep:

It's just the calmness, you just seem to be able to focus better after it [Reiki self treatment]. [...] it's hard to pin point really, because I am a worrier, you know I am one of these people that just worries for nothing and I think it really helps like that, it helps you focus, calms you down, helps you sleep. I think it makes you more tuned in with what's out there. (Annabel, Reiki level two, long term user) 
Denise was also explicit about the type of Reiki knowledge (symbols) she applied to 'take away' stress and induce a feeling of peacefulness:

I love the feeling of it, it's just, it's so special and I mean I use it with my meditation, I start off with the power symbols and then I work my meditation from there, so I just love that.

[What does it feel like, can you describe the feeling?]

It's a peaceful, its being at peace and it takes all that terrible stress away and there's nothing quite like it, I want to say that sacred space, but that's the feeling, it's a nice warm, it's a lovely energy. (Denise, Level two, long term user)

Clara described applying much of the Reiki knowledge that she possessed including self treatment, putting herself in a 'white light' and 'golden cloak', and sending Reiki to herself. When asked if she thought that doing such things helped her, she responded as follows:

I really do think its [Reiki] made a different to me because before I had it I used to find it [job] quite stressful and I was thinking of leaving you know

[Your job, that was?]

Yes, so it's really helped me to be a lot stronger and when I come home I can just come home and just say lie on the bed for five minutes and just do a small treatment and then I'm not turning my thoughts over (Clara, level two, medium term user)

For Clara, the result of applying various facets of Reiki knowledge had had a dramatic effect. She cited Reiki as helping her to stay in her current job when she was thinking of leaving it: 
It's helped me in my job as well, I feel I would have left this job as I was finding it really hard, you know, so I think it's helped me [...]

[And do you enjoy your job now?]

Yeah I love it

Within some participants' interviews it was unclear which specific Reiki knowledge they had applied that resulted in less stress. Participants often used the generic term 'it' to refer to the Reiki system and within this, there was the implication that since learning 'it', and since using / applying 'it' they had experienced less stress. For example, when asked what had been the main advantages of learning Reiki, Cheryl responded that it provided her with 'inner peace':

I think probably, a very straight forward way of getting inner peace [laughs]. [...] it doesn't require equipment, okay you pay for the attunements but its not excessive and you're paying for somebody's time and expertise so that's fair enough and its a very flexible thing to do so yeah... (Cheryl, level two, medium term user)

Lilly noted that Reiki was the only thing that helped her to relax and Lucy noted how Reiki helped her to focus and deal with stress:

It's the only thing that makes me relax [...] I've got a very stressful job, and it's the only thing that brings me down and grounds me. (Lilly, level two, medium term user)

I've put focused and stress relief, so it's helped me deal with stress and negativity with things. (Lucy, level one, short term user) 
Paula described how she had attained physical benefits as a result of applying her knowledge of Reiki to reduce her stress. Similar to Cheryl, Lilly and Lucy (above), Paula used the generic phrase 'since I've done Reiki' to indicate that she had applied her Reiki knowledge. In the extract below Paula describes how she visited a GP regarding her neck and shoulder problem and learned that the problem was a result of stress. She subsequently describes how this was a recurrent problem until two years ago when she learned Reiki and has only experienced this problem on three occasions since:

So I went to the doctors and he checked me over and I haven't got the blood flow or the movement in my neck or any of that and I said 'what can I do to get rid of that?' and he said 'unless you want to get rid of your children, your husband, your shop, there's not a lot'. My stress comes out in my shoulders and before I did Reiki I used to walk around like that most of the time [hunches shoulders], because a lot of the time it would go and then I would be just like that. Since I've done Reiki, it used to go about once a month maybe even more than that sometimes, since I've done Reiki I've had it about three times. [...] So it has taken the stress factor away from me. (Paula, level two, medium term user)

\section{- Making Changes to Life (style) as a Result of Learning Reiki that are Beneficial to Health}

Over half of Reiki level one and two self-users discussed changes they had made to their life or lifestyle after learning Reiki. The types of changes that participants had made were wide ranging from changes to the types of food and drink consumed to changes in their relationships with people. Some participants had made many changes to their life or lifestyle and when interpreting individual interview transcripts it was on occasion difficult to isolate one or two major changes. It was felt by the researcher that extracting examples of individual changes from some transcripts would dilute the issue of the participant actually having made a multitude of changes. Therefore the extracts presented below begin with those that illustrate that a variety of 
changes can be made after people learn Reiki. Following this, the extracts are grouped together thematically representing particular types of changes.

Phillipa talked about the many and wide-ranging changes she had made including having her mercury fillings removed, changing her diet, reducing her alcohol intake and accepting her illness:

I then learned Reiki 1 really to try and sort of help my own health. After Reiki 1, when I was waiting to do my Reiki 2 I decided to make a major change and had all the mercury fillings removed from my mouth. [...]And changed my diet drastically, so no caffeine, no wheat, you know, I drink very little alcohol or anything like that and also, I suppose the biggest change is I've accepted I've got an illness now, and my job is that I've got to rather than keep worrying about the fact that I'm not working, how can I get back to work, I've actually now decided that my job is to get well. (Phillipa, level two, medium term user)

Similarly, Lucy used the phrase 'just in general, everything' when she talked about the many changes that had occurred in her life since learning Reiki including drinking less alcohol, taking more time for relaxation, being less 'obsessive' with regards her exercise regime and better relationships with family and friends:

I am health conscious anyway and I do eat really healthy, but my only downfall was ... I hardly eat any sugar... but then I can drink two bottles of wine, so I kind of think I work all week. So I don't know if that's the Reiki because I've always been of that mindset and I just thought, I'm trying for a baby, so I'm going to cut down on the alcohol, but I don't know whether that's linked to that. Relaxation, didn't take any time out for me, so that's a biggy. I probably do have my work balanced quite good anyway, but I kind of think 'well I'm a bit more', with the gym I was a bit more, I got a bit obsessive, I would kind of beat myself up if I didn't go whereas now I'm just like 'oh well, it's ok'. I'm not going to put on two stone if I don't go, so just in general, 
everything, work, relationships, I mean I have a good relationship with my husband in any case, but friends and family and stuff like that. (Lucy, level one, short term user)

Both Phillipa and Lucy talked about drinking less alcohol and Phillipa talked about making changes to her diet. Indeed, one of the most frequently cited changes participants had made related to what they put into their body. Sometimes these were dietary changes such as reducing (and in some cases increasing) their intake of certain foods or drinks. Other participants discussed eating more organic food or drinking filtered water. Extracts below from Jennifer's, Alan's and Clara's interviews are typical examples of how other participants discussed making changes to what they took into their body:

I think I'm probably more aware of my health and there's certain things that I've just sort of like gradually stopped doing so much because I think they have a detrimental effect on me like too much coffee or tea, I've definitively cut down on those. [...] I don't think I drink as much alcohol and that's just things that I feel have happened to me, probably since Reiki, but it could have something to do with factors, like my life progressing (Jennifer, level two, medium term user)

Well, I think that's what I'm actually doing, changing diet and so on and as far as going to [...] I mean drinking, pubs I don't really bother anymore, I don't want those things anymore, I don't want those things in my life now [...] When I was a lot younger I was a drug taker as well. Not anymore. What seems to be happening is that I want more of these experiences in my life, more of this sort of thing [Reiki] (Alan, level two, medium term user)

I've started eating a lot healthier [...] Sort of going over to more organic things if I can, buy a water filter. (Clara, level two, medium term user) 
Some participants noted that they had made changes regarding their relationships with other people. In the extract below from Faye's interview she talks about how she realised her argumentative behaviour was influenced by her parents and that this was unpleasant. The result of modifying her behaviour to include the qualities instilled in her by her grandmother (kindness, softness, gentleness and positivity) resulted in an improvement in her relationship with her partner and with other people:

... both my parents are very angry people and Reiki made me realise that some of my behaviour was not my stuff, it was not myself, you know, it was stuff I've learned from my parents, stuff, stuff, stuff and also because my grandmother, was a very catholic person, but in a really nice way, she always taught me to be kind, be soft, be gentle, be positive, which I had in my personality, but it got lost over the years, and Reiki has made me touch myself back and it's helped me to see that 'yes' actually it is unpleasant to, you don't want to argue with people, you might as well let it go and so it's really helped me to change my make-up, my mental and emotional make-up. I have Reiki a lot in my life, you know, my relationship with my partner was really bad, but now we get on really well, we're good friends and I have that ongoing relationship with people you know. (Faye, level two, medium term user)

Clara also talked about a change in her relationships with people noting that she felt more connected to people that are similar ('on the same wave length') to her:

[...] it's like people you have around you, I think there's some people, you don't feel as connected to [...]I think some people you can feel maybe more connected to, and it's like a recognition of people on the same wave length in a way. (Jennifer, level two, medium term user) 
Participants also discussed changes that had occurred in their attitudes and the way that they viewed difficulties in life (James), and viewed other people (Rosie). Notably the two extracts below have in common the fact that both James and Rosie both refer to being (or having the ability to make themselves) calmer:

I think I'm a lot calmer and at ease and I see things in a different way. I see things as, like difficulties as sort of as positive. I understand now what difficulties are in that we are here for a reason and its part of our learning, our spiritual learning, you know, some people aren't here to have a happy time they're here to learn but some newcomers are maybe just starting off and having such a hard time, but in essence we're all here to have a bit of a hard time otherwise there would be no point in coming onto the earth. [...]I see things, I try to help people who say 'I can't believe I'm having such a bad time', this has happened, that has happened and 'cos I can see maybe what's happening but they can't, in some ways that is important to them, that part of their life is more important than winning the lottery, but they don't see it like that.

[Do you think it almost makes you feel a bit wiser?]

Yes, I see it in a totally different perspective, all of a sudden another door opens, another path that you've never really realised. I mean I don't like seeing suffering and I think we have to help people on their journeys and reducing suffering is good, but it doesn't mean they don't have to have difficulties in the road that they are taking because those are the sort of things, it's like a tree, if you support it too much the roots never grow, so you've got to let it blow in the wind. (James, level two, medium term user)

I think I have a different attitude, I'm not somebody who makes massive changes, but I've got an extremely different attitude. I can pull myself up from being intolerant of people a lot more than I used to be able to and I can, 
probably if, it's probably more of a psychological thing with me, I can make myself calm a lot quicker than I used to and I can also phase down a difficult situation with it. And I am conscious when, after I'd had my attunement s in 2006, I don't work Mondays, I went to work on the Tuesday and our manager, she is quite an intimidating women, and I'd not gone in 'specially on the Monday for something she'd wanted me to be there for, but I don't have to. Now I would have probably, but I wanted the day to go on soaking up how marvellous I was feeling and she came over and sat next to me and took me on about it, but because I don't have to work on that day, she was on very slim ground. But normally she would have intimidated me even if I'd try not to show it and I absolutely didn't care. I sat there and I listened to her and I asked her lots of questions and I was ever so smiley and you could tell it fazed her completely and I just felt a wonderful bubble of safety all around me and she couldn't do anything about it and she knew she couldn't and that was the biggest proof to me that something had massively changed, that she couldn't intimate me and she can intimidate almost anybody. (Rosie, level two, long term user)

\section{- Deriving meaning from Reiki knowledge in different formats (written, verbal non-verbal)}

Participants demonstrated that they were able to derive meaning when knowledge was presented to them in varying formats. This included making meaning from knowledge presented to them by the researcher (that is the picture depicted in vignette three). It also included making meaning or deriving knowledge from other non-verbal sources of communication such as physical pain or discomfort or intuitive feelings.

It was noted above under the section on functional Reiki health literacy that all participants were able to either talk about the charkas or recognise a picture of them when presented with vignette three (see chapter six). This ability to correctly identify the picture as being of the chakras was taken as evidence that participants had knowledge of the chakras and furthermore in relation to this component of interactive 
Reiki health literacy, that they had the ability to recognise and derive meaning from non-verbal communication (that is, derive meaning from a picture).

When participants correctly identified that the picture was indeed of the chakras 'out of balance' they were asked to imagine that the picture represented themselves and to think about what it would feel like if they were out of balance. This generated much discussion that suggested that participants were able to derive meaning from the nonverbal 'feeling' of being out of balance. Jackie noted that if her chakras were out of balance this would signify that she was feeling mixed up and stressed:

Well, definitely mixed up, I'd feel as if I'd want to practise my Reiki to balance, you know, as you say place the hands perhaps on the throat chakra that's out of place. Yes that person looks quite stressed. (Jackie, level two, short term user)

For Naomi 'out of balance chakras' signified the need for healing, overactive chakras or chakras that had too much energy or points of weakness:

I suppose on an energetic level, I mean it seems like there's a beautiful shining very bright crown chakra, a lot of energy happening there, I mean maybe if I were looking at it I'd think well are those points that need healing and I might zoom in on that, I mean, I'm more of a feeler than I'm a see-er when I do Reiki, I don't kind of see colours, it's much more of a feel [...] so they could either be for me, if I were looking quite quickly, it could either be points that need healing, they're either overactive chakras, too much energy or they're points of weakness. (Naomi, level two, medium term user)

Within the context of Reiki, both physical and intuitive feelings are all forms of communication that have the potential to convey meaning. It was common for participants to discuss how they understood and derived meaning from physical health 
problems. In the extracts below from Phillipa's transcript, she talks about how she associates her back pain with relationship issues and how a sore throat may be associated with verbal communication:

I suffer a lot with lower back pain; I now associate that with, maybe some issues with sort of relationships. So sometimes, actually now, it's probably making me think about okay if I've got a pain in my throat, is it that I've got a sore throat or is it that actually I'm not saying something to somebody or I've said too much? [...] so actually I think about my health as my mind, my body and my soul. (Phillipa, level two, medium term user)

Faye talked about the physical feelings she would expect to experience if her chakras were out of balance:

My breathing is not the same. I've been going through a major trauma with my parents lately and I'm still recovering from it and I feel, you know, my back is tense and the shoulder and my breathing not right and my energy levels not right and 'yes' I would also get pain and anxiety. [...] And also just the way I feel emotionally and mentally. (Faye, level two, medium term user)

A further way in which participants demonstrated that they had the ability to make meaning from information in different formats was associated with making meaning from non-verbal communication. This was centred on the idea that meaning could be derived from what was 'felt' physically or 'sensed' intuitively. Christine talked about how she could feel if a chakra was out of line and how this may indicate that a chakra was blocked:

You know when a chakra is out of line anyway because you can feel it and you can draw it back into line [...] if something's off line it would not be quite vibrating in the right place, or maybe I don't feel anything at certain points, 
which would be a sign. [...]It could be a chakra that's blocked or not quite where it should be. [...] I just keep treating it until it starts to feel right. (Christine, level two, short term user)

James was another participant who demonstrated the ability to make meaning from non-verbal communication. In the extract below he discussed how physically feeling heat around certain chakras meant that he needed Reiki in that particular area:

It's like a spot treatment, it's mainly the middle chakras, you know, the solar plexus, I get an intense amount of heat, sometimes I have to take my hand away.

[Right, so why do you choose to do your middle ones then, rather than, is there a reason?]

I think it's probably because I get more heat there, I don't get any heat up here and I always associate that if you need it you get the heat. (James, level two, medium term user)

Similarly, Naomi talked about a feeling of being 'pulled' to certain areas of the body being an indication that there is a need for healing in that area:

When I do treatments on myself and on others for me I get a sense that, there's a requirement for energy or healing by a pulling on a certain point in the body. So it's a sense of really pulling me in - if everything feels kind of fairly in an equilibrium I just get a sense of, you know, so for me it's like if there is a real sense of pull, yes, that's kind of, yes that's how I get a sense of whether I need to focus on a particular area. (Naomi, level two, medium term user) 
Pain, intuitive feelings, and physical feelings are all forms of communication that carry meaning within the context of Reiki. Within this, participants demonstrated how they derived meaning from various feelings or sensations such as heat, vibrations, pulling, pain, or discomfort thus confirming that the ability to derive meaning from Reiki knowledge in different formats is an interactive component of Reiki health literacy.

The following interactive Reiki health literacy competencies were derived from the themes that became apparent when interpreting the data from phase two and serve to further refine the model of Reiki health literacy.

\section{- More Advanced Cognitive Skills}

The interactive Reiki health literacy competencies outlined above are more advanced than those that comprise functional Reiki health literacy and therefore they inherently involve drawing on more advanced cognitive skills. In this respect advanced cognitive skills need not be a stand-alone competency of interactive Reiki health literacy; rather it may be viewed as a theme that runs through all of the competencies that are included in interactive Reiki health literacy. However, it is useful to consider what exactly is meant by advanced cognitive skills within the context of Reiki. Nutbeam's (2000) model of health literacy includes the use of more advanced cognitive skills at both the interactive and critical level yet the nature of these skills is not well explicated within Nutbeam's model of health literacy.

Examples of the use of advanced cognitive skills or thinking included statements from participants that referred to what $I$ think (with the emphasis on the first person). This is in contrast to simply recounting what they have been told (by a Reiki teacher) which arguably involves only basic cognitive skills. To illustrate this, extracts are provided below from Cheryl and Phillipa's interviews. Cheryl made two statements relating to her thoughts about Reiki practice; the first related to what one actually does with Reiki being less important than actually doing Reiki and the second related to using the symbols: 
I think that's the interesting thing for me that the more you sort of go along, I think the what you actually do is less important than the fact you do it (Cheryl, level two, medium term user)

I think the symbols are a mental way of getting you into a certain place and I think to be dogmatic about them and say this is how you must do it every single time is missing the point, anyway that's just me but....(Cheryl, level two, medium term user)

Similarly, Phillipa challenged the idea of using the hand positions and stated her belief that Reiki will go to where it needs to go regardless of the placement of the hands:

I'm very aware that you don't have to be in a certain place for you to get Reiki. I'm a big believer that Reiki will go to where it needs to go wherever your hands are. (Phillipa, level two, medium term user)

The use of more advanced cognitive skills is briefly discussed at this point in the chapter as they are a prerequisite for many of the following interactive Reiki health literacy competencies not previously identified, that further refine the model.

\section{- Adapting Reiki practice to meet own needs}

Whilst advanced cognitive skills may be characterised by statements referring to what $I$ think, a participants ability to tailor their Reiki practice to meet their own needs may be characterised by the phrase 'what $I$ do' which contrasts with the idea of simply doing what one has been taught to do. Reiki practice is flexible and this was reflected within interviews with Reiki level one and two self-users. One example of how participants adapted Reiki to meet their own needs was outlined earlier in this chapter under the discussion of active self treatment. It was noted that some participants used Reiki on themselves if and when they had a health complaint. Rather than routinely 
carrying out Reiki self treatments, these participants were adapting their Reiki practice to meet their health needs. Furthermore, adapting Reiki to meet ones needs was also reflected in the previous discussion of how participants used Reiki on themselves that is, undertaking either a full treatment using the traditional hand positions or doing a 'spot' treatment by placing their hands in one single position on the body.

Following on from the idea that there are different ways in which a person might self treat with Reiki a proportion of participants discussed using Reiki for their own benefit in ways other than the traditional hands-on or distance mode of use. Paula described how she used Reiki to benefit her in stressful situations simply by asking for the Reiki energy 'to enter':

I try to stand back, take a few deep breaths, that's usually when I ask for help, go to a quiet corner and say 'right I need it now'. [...] Yes, I just sort of talk to myself and ask for the Reiki energy to enter. (Paula, level two, medium term user)

Other participants spoke of visualising Reiki as opposed to using the hands on or distance approach. Phillipa described how she visualises Reiki falling over her like a shower to ease hot sweats:

I use Reiki on myself because I suffer an awful lot with sweats, hot sweats. Now that could be because I'm about to start the menopause, but it could be also that with my health condition, chronic fatigue, you do suffer with fluctuation of body temperature, so I can actually visualise switching Reiki on and that almost acts like a shower running over me and cooling me (Phillipa, level two, medium term user) 
Some participant's spoke of how they had modified some of the Reiki techniques they had been taught. Cheryl used the phrase gone my own way with it when she spoke of how she had adapted the technique that she had been taught for grounding:

I think subsequently I've sort of gone my own way with it [grounding technique] I suppose because I always imagine it going through the soles of my feet and then into the earth and grounding that way (Cheryl, level two, medium term user)

Similarly, Alan used the phrase I do other things myself now when he described the techniques he uses for grounding. In the extract below Alan begins by describing the techniques his Reiki Master teacher had taught him for grounding, he then describes the technique he uses;

Well, because like your solar plexus is your centre, you know, I mean that deep breathing, you know, working yourself into your solar plexus and giving you balance and I do other things myself now.

[What do you do then yourself?]

Well I do breathing exercises, I do locking into the earth's energies. Yes, I do, it comes from the feet, the roots come from the feet. Yes, I take my shoes and socks off as well as my slippers. (Alan, level two, medium term user)

In addition to the fact that Reiki could be used on the self in a variety of ways, it became apparent that a person could self treat at a time that met their needs. There was not one prescribed time of day that Reiki self treatment had to be undertaken; rather it was something that the practitioner could adapt to their needs and preferences. Some participants such as Beth preferred to self treat with Reiki in a 
morning, whilst others such as Clara and Denise favoured the evening before going to sleep:

I usually do that in the morning when I wake up. [...] At night I'm too tired. [...] If I started I would just fall asleep. In the morning I usually wake up early so I just do a bit then. (Beth, level two, medium term user)

Just on a night before I go to sleep, you know[...]I place them on my heart, but once or twice a week I do go through the full, you know. (Clara, level two, medium term user)

Well usually I do it at night [...] To get me off to sleep really.[...] Well I do the, I do my own little sort of technique really because the absence healing, I send it to myself. I send that to myself, and then I just place my hands here, I don't bother with the eyes unless, of course, if I've got neck trouble I might go here, but tend to go here like that and then I usually go here and then here and then by that time I'm usually asleep. (Denise, level two, long term user)

A final method of adapting Reiki to meet a person's individual needs became apparent when participants described how they used Reiki in combination with other techniques including exercises prescribed by a physiotherapist and meditation as described by Samantha and Cheryl:

So how I've been doing that is I've got into, because I have a problem with my shoulder. I think that was something to do with my past, and so that a physiotherapist told me to do some exercises, so what I've been trying to do is link them all in the morning before I go to work. [...] So I do my exercises and then I go on to do my mantras and I also do just for today, so I do all three and also my friend gave me a little booklet so I've been trying to do a meditation as well. (Samantha, level two, short term user) 
The way that I use Reiki, I think that it's probably closer to doing a daily meditation and just using the structure of Reiki to structure the different meditations, but yeah as I say it's probably sort of threeish, two or three times a week (Cheryl, level two, medium term user)

\section{Summary of Interactive Reiki Health Literacy}

Interviews with Reiki level one and two self users largely confirmed that the skills knowledge and competencies identified within the initial model of Reiki health literacy and as further confirmed and refined within phase one, were at the level of interactive Reiki health literacy and thus applicable to Reiki level one and two self users. However, a further two competencies were identified within the phase two data (More Advanced Cognitive Skills and Adapting Reiki practice to meet own needs) and these further refined and enhanced the applicability of the model.

\section{Critical Reiki Health Literacy}

Chapter seven tentatively concluded that critical Reiki health literacy comprises five competencies. This level of Reiki health literacy is the most advanced with regards the use of Reiki skills, cognitive skills and social skills.

\section{- Critically Analyse Information about Reiki, Medicine and Health}

Participants demonstrated critical thinking regarding their experiences with Reiki. This included an awareness of the critique commonly directed at Reiki and many other complementary and alternative modalities, that it is a placebo. This awareness was implied rather than explicitly stated and was apparent when participants recounted any changes that had occurred since learning Reiki. Some participants were prepared to acknowledge the possibility that there may be factors other than Reiki such as their age, their life progressing, coincidence or less stress that were responsible for the changes. 
Susan noted that since learning Reiki she had become more relaxed and laid back and Jennifer noted that she drank less alcohol. Both participants noted that this might be because of Reiki; however, they were aware that it might also be due to other factors:

I don't know if it's because of Reiki or I don't know if its age but I'm a lot more relaxed about things, I'm just a lot more laid back [...] like I say I don't know if that's Reiki or not (Susan, level one, medium term user)

I don't think I drink as much alcohol and that's just things that I feel have happened to me, probably since Reiki, but it could have something to do with factors like my life progressing (Jennifer, level two, medium term user)

Cheryl had a health condition that required her to take immunosuppressant drugs. Since learning Reiki she had managed to significantly reduce her dose of these drugs due to her concerns about their potential side effects. In the following extract from her interview, Cheryl describes how this was a 'scary' step to take as these drugs were effective. However, she acknowledges the possibility that it would have happened anyway or that it might be a 'coincidence':

I don't know if its relevant or not but my initial dose of the immunosuppressant that I take, the dose is actually based on body weight and about three years ago, I started on a particular dose but over the past year, two years I've managed to half the dose. This is in negotiation with the specialist and she said yeah. I said, at one point I said look, because it's quite, the immunosuppressant drugs are not particularly nice they're associated with increased rates of cancer, the sort of thing that they give to people who have had kidney transplants so I was keen to try and reduce the dose if I could. And she said yeah you know we'll try and get it down and so, now whether that's just a correlation, a coincidence that you know the Reiki, 
I've done the Reiki and managed to reduce the dose but having said that I think possibly something like, doing the Reiki has enabled me to consider reducing the dose because it's quite a scary thing to do and it works, it certainly works [the immunosuppressant's]. I'm maintaining it at half the original dose so whether that would have happened anyway or whether the Reiki has sort of [inaudible] something so that I can you know my body can actually responds better to it I don't know, there's all sorts of interesting thoughts (Cheryl, level two, medium term user)

Denise stated that her health had improved as a result of her Reiki self treatments; however, in the following extract she noted that she had considered whether this was in fact a result of Reiki or whether it was a result of less stress due to her recent retirement:

[Do you think that your health benefits from giving yourself Reiki treatments?]

Well let's put it this way, since I've retired I haven't been to the doctors for 4 years. [...] Before then it was always back trouble. Always coming down with colds and flu and everything.

[OK, so would you say that that's Reiki?]

I knew you were going to say that. [...]I thought that myself. [...] Well it could be because I haven't got the stress of working, but if I do Reiki everyday and I'm doing Reiki there must be some benefits in that, so maybe a bit of both, a bit of both. (Denise, level two, long term user)

In addition to the ability to critique Reiki, there was also evidence that participants were able to critique orthodox approaches to healthcare. Participants' critiques of orthodox healthcare practices centred on their belief that they were in some way 
lacking. For Annabel, there was too much prescribing within orthodox medicine and not enough talking to get to the 'root of the problem':

I think there's room for both [complementary and orthodox healthcare practices], but I think they prescribe far too many sometimes and I don't think there's enough talking to people, you know, in like mental health, it's too much prescribing. Or just jumping in there with things, we should be letting people know more about Reiki to try it on themselves and talking to people to get to the root of the problem, well teaching them to get to the root of the problem and making them more aware rather than just pills. There's a place for pills, definitely, to control the situation, but it has to be a bit of everything, so I think rather than, I think it's going to get more and more popular in time, especially young ones, there's far too many young ones that just, you know, that I see coming through and we try and tell them there's more. (Annabel, level two, long term user)

Similar to Annabel's reference to getting to the root of the problem, Jennifer also believed that doctors treat the symptoms of illness rather than the causes. Instead, Jennifer advocated looking 'a bit deeper':

I've never been a great believer in just running to the doctors for, you know... because I think the medical profession, although it's obviously, I mean there'll always be room for drugs and that side of things, I think they're treating the symptoms of illness, rather than the causes of illness. So I think you have to look sometimes, depending on what it is, sometimes you have to look a bit deeper, so I would always try to cure myself initially, depending on what it was of course. If it was a broken arm or something like that then you can't. (Jennifer, level two, medium term user)

The ideas expressed by Annabel regarding the 'root' of the illness or problem and Jennifer's idea of looking a bit deeper for the cause of ill health were reinforced by 
Alan when he referred to what was lacking in orthodox medicine as being a holistic view of the cause of illness:

A lot of the time things are happening for a reason, you know, there's some sort of imbalance. [...] Emotional, physical, you know, spiritual and that's one thing doctors don't do, they don't look at things in a holistic way, they just go 'oh'. [...] People go in and say 'well, you know, this is happening', they don't say 'can you have a look at why this is happening' [...] they don't ask you what's happening in your life, you know, there's a possibility that that may be the reason why this sufferings occurred like. [...] So you see there's no holistic approach whereas in the east that's it, the holistic approach, they look at the mind, body and spirit, you know, whereas here they don't, it's just physical, they don't look at your mental wellbeing or spiritual wellbeing. (Alan, level two, medium term user)

Alice also demonstrated the ability to critique orthodox medicine, however, in contrast to some of the other participants, this was not since she became aware of Reiki rather, she stated that she had always had some degree of scepticism towards orthodox medicine:

I think, because I've always been a bit of a sceptic to be honest, my Mum was a doctor so I kind of you know I'm not very never been a great believer in the medical thinking it was the answer (Alice, level two, medium term user)

Two participants noted that they did not trust, or had less confidence in doctors. Heather recalled how she had been to the doctor with a complaint and felt like he was not listening to her; however there was nothing within Heather's transcript to suggest that her negative views of doctors were linked to the fact that she was attuned to Reiki. Denise also stated that she did not have much faith in the medical profession anymore. In contrast to Heather however, her interview transcript implies that this 
lack of faith in doctors had evolved since learning Reiki. Denise was a retired nurse; in the extract below she begins by talking about how she began to drift away from the 'physical medical world' and the Reiki 'world' took over. Her use of the word 'anymore' suggested that this lack of faith in the medical profession had arisen subsequent to learning Reiki:

I felt I was drifting away from the physical medical world and the Reiki was taking over

[OK so do you think your views of your own health have changed at all since learning Reiki?]

Yes, quite honestly and I know this is confidential but I haven't much faith in the medical profession anymore. Well let me just put it this way, I always say to my clients 'always carry on with the doctors, always carry on with the medicine', you've got to, but I just feel that if I can stay positive and do my Reiki I can stay healthy and that's my mindset, I can stay healthy. (Denise, level two, long term user)

\section{- Making Decisions Informed by Multiple Perspectives}

A person who has undertaken Reiki training has the choice of using Reiki or orthodox medicine to treat health complaints. Within the course of individual interviews it became apparent that many participants were discussing how and why they made their health management choices by drawing on their beliefs, knowledge and experiences of a complementary approach (Reiki) and an orthodox approach (for example the use of pain killers). That is, decision making was informed by multiple (Reiki and orthodox medicine) perspectives. 
For some participants such as Jackie there were distinct characteristics of Reiki that influenced the decision to use it for health complaints over orthodox medicine. For others such as Alan and Naomi, their beliefs, opinions and experiences on or with orthodox medicine influenced this decision. Jackie reported that she had a headache prior to the interview and talked about using Reiki to treat the headache. When asked why she had chosen to use Reiki over medicinal pain killers, Jackie suggested that for her, there were certain favourable characteristics of Reiki (and other complementary modalities) such as the fact that it was portable, it didn't involve taking tablets and was 'easy to use' that influenced her decision to use Reiki as opposed to any orthodox medicine. This was further influenced by her experience and belief that 'it [Reiki] works':

Well because you can do it anywhere, you can take it on a bus [...] yes, you can take it anywhere really, and I suppose it works, it works for me and I don't like taking tablets really. I mean that's the idea of alternative therapy, you know I mean I particularly liked it when I did my aromatherapy course, learning about the oils, the essential oils and what is best to use them for different things, so that's why I'm into it, I don't want to, I think there must be some alternative to taking, I'm not saying that if you've got cancer or something like that, don't take drugs and I wouldn't ever say that to anybody, stop taking them. [...] But Reiki is easy to use. (Jackie, level two, short term user)

Alan noted that he tried to avoid taking medication that doctors prescribed due to his belief that doctors didn't 'know anything about' what they were prescribing:

I avoid medicines from doctors. [...] Because I think a lot of the time a lot of the stuff that they give you they don't really know anything about it whatsoever. They just go 'oh I've got this catalogue here, I'll just [...], you can take this, this will be alright' side effects, you know, they don't really know anything about it. 
He continued on this subject by discussing how he made dietary changes and used Reiki to treat his arthritis. This was counterbalanced by his perception that the doctor who diagnosed his arthritis did not help him in a way that he found acceptable:

In fact, I was diagnosed with arthritis, this is a few years ago, and the x-rays, you know, 'oh yeah, problems from [inaudible] blah de blah'. Right what do I do about it? Can't do anything about it. I've got painkillers. Painkillers. And I said 'well that's absolute rubbish, you're a doctor, you tell me what I can do about it, but you can't, I'm not having that, that's rubbish'. Well here take this Arthritic Society leaflet; they might be able to help you sort something. Take it back, it's absolutely no use whatsoever, I want you to tell me what I can do about it. Yeah, nothing, you can have stronger painkillers. Ok see you 'bye' and I went straight round the health food stores, asked them to print me any information they had on Osteoarthritis and I started to have dietary change and different other things like and now I've got my Reiki. (Alan, level two, medium term user )

When managing her health Naomi stated her preference for homeopathy, Reiki or preventative measures such as yoga and 'energy stuff'. Naomi was employed by the NHS and when asked why she chooses a complementary approach she drew on her knowledge of a traditional medical approach to health which she conceptualised as being 'quite destructive', 'invasive', as not working and focussing on isolated ailments. She also drew on her knowledge of the 'whole body' approach used within homeopathy, Reiki and yoga as a rationale for favouring this approach to managing her health

I do believe in the NHS and I'm pleased that we have it, however, I, if I have something wrong with me I go to a homeopath or I give myself Reiki and I find anyway that if I do my Yoga and I do kind of energy stuff I'm fairly healthy 
anyway. And well, [...] working in the industry [NHS], seeing the kind of traditional medical approach to things, I do find quite destructive.

[Can I ask why you choose to do that? Can you explain your thinking behind doing that?]

I think it's just, I mean it's the whole body approach to something. I think also because medicine, a lot of the medicines are so invasive and I don't find they work well [...] And also, you know, I think you know you go to the doctors and its wham bam, they're very focused on a little bit here, they're not really interested in what's going on and I know with me it's sometimes just a small thing and it's quite nice to actually talk about the other things (Naomi, level two, medium term user)

\section{- Exerting Control over Physical, Psychological and Emotional health}

Participants expressed that they felt they were able to exert control over various aspects of their health ranging from the perceived ability to 'doing something' for their health to controlling their levels of stress and frequently this was directly attributed to their knowledge and/or practise of Reiki. As with Reiki Master Teachers one the means by which Reiki level one and two self-users expressed feeling in control of their health differed between participants. However, there were some overall themes. One of the most frequently occurring ways in which participants expressed their feeling of control over their health was by stating their belief that they could (and did) take responsibility for their health. There was a firm belief among participants that they were responsible for their own health and wellbeing and this responsibility clearly placed the individual in a position of control. Jennifer noted that she felt both in control of her health and responsible for it rather than simply expecting it to 'land in her lap': 
I'm aware that I am in control of my health if you know what I mean and it is sort of my responsibility, you know you can't sort of just expect good health to land in your lap and I think obviously as you get older it's more important to do stuff that keeps you healthy. (Jennifer, level two, medium term user)

Similarly, Phillipa stated her belief that Reiki engendered a feeling of being in control of your health as a result of firstly accepting responsibility for it:

First of all I think accepting responsibility for it [health], that was a big thing because I think prior to that you're looking for someone else to cure you or to make you feel better or something else, like taking a tablet or something like that. Whereas with Reiki you're in control of that (Phillipa, level two, medium term user)

However, as acknowledged by Naomi, talking responsibility or accepting responsibility for oneself was not necessarily an easy thing to do. She described how there are 'cruel lessons' involved and that the realisation of your own responsibility can be fearful. She followed this up by stating that once this was overcome the reward is liberation and empowerment:

Its always that dual thing isn't it, I think when you get into spirituality and stuff, its, there's some cruel lessons because it's very easy to sort of think 'oh it's not my fault' and everybody else is to blame so the dual thing about it is that you have to take responsibility for yourself and responsibility for what's going on in your life. However, once you get past that and the fear of that the realisation, the liberation that actually I am the one that makes my life and I, therefore, I can make my life better is quite liberating and quite empowering. So once you can get over the 'oh my god' I'm responsible for things that are wrong or right, actually once you kind of get into that you realise that you can actually make things more right. (Naomi, level two, medium term user) 
Another way in which participants expressed an ability to exert control over their health centred on a belief that in practicing self-use of Reiki, they were 'doing something' or 'offering themselves something' to benefit their health. This is exemplified in the extracts below from Susan and Christine:

It [Reiki self-use] quietens me down, it quietens my head, it relaxes me, it gives me a sense of I'm doing something about it as well. You know I think a lot of the time you think well what can...you know I've got stomach ache, what can I take, what .... and sometimes you just can't do anything for it. But you know if you can just do that, I feel like I'm trying to do something and it just, even if it relaxes me it's going to help me because it takes the tension away headaches, quite often it helps (Susan, level one, medium term user)

The thing is, the beauty with Reiki is that you've always got that feeling that I'm in control, I can control my feelings, my health, because I can offer myself this (Christine level two, short term user)

In terms of specific conditions that participants discussed exerting control over some such as Susan (above) specified physical ailments such as stomach ache or headache however, one of the most frequently referred to condition related to the ability to exert control over stress levels. Simply 'doing' Reiki on a daily basis was viewed by Cheryl as preventative and a way to manage stress:

So there's a like a preventative aspect to it so that I, if, I feel as though it helps me manage stress better if I'm doing the Reiki every morning (Cheryl, level two, medium term user)

In the following extract from his interview, James describes a situation in which he used a Reiki technique (grounding) to help alleviate stress. In the first part of the 
extract, James uses the example of a situation he was in to illustrate his point that he is in control of negative emotions. James' choice of language was strongly associated with the concept of control; he described 'having the authority', 'being the master' (of negative thoughts) and 'being in charge':

I remember when I'd done the Reiki course, I can't remember what happened but I was stressed out with something at work, I think there had been an argument with someone, about the way it was going and that and I remember being stressed out like you do get stressed. So I came back and grounded myself, I grounded the roots and brought in the light and I did feel better, it sort of welled up in me and pushed all the negative emotions out because I'm sure I had a cloud of negativity around me that day, so I did wash it out and that helps you to realise that it does really work and you can, you know, switch off those negative thoughts because if you're not careful those negative forces will get the better of you if you're not careful. You've got to be master of them. We have the authority to be master over those negative forces. You don't realise how much power we have and so you've got to remember we're in charge they're not. We have the authority to, you know, send them packing so you've just got to make sure that you do that (James, level two, medium term user)

Paula described how, in standing up to her husband, she had found she was a stronger person. In turn, this had helped her reduce her levels of stress because she felt she was no longer 'taking everything on board':

My Reiki Master, she did say when you do Reiki 1, you'll probably start arguing with people a lot more, because I've always been a pushover, I've always been 'yes ok I'll do that' and 'I'll sort that out', 'don't worry I'll sort that out' and she did say, you know, once you've done it you'll probably notice the difference, you'll probably start arguing with your husband more, it's not him it's you. [...] I did come away and people were saying to me 'I've never 
heard you speak to him like that before', all of a sudden I was standing up for myself and I was actually, 'I'm a person and I'm here'. [...] So in that way I found I was a stronger person. [...] before I would just cry or say 'yeah, alright I'll sort it out', 'don't worry I'll sort that out'

[Has that minimised your stress levels then?]

It's helped, definitely helped because I'm not taking everything on board anymore. I am standing up for myself more (Paula, level two, medium term user)

\section{- Identify the Wider Social and Political Benefits of Reiki}

A significant proportion of participants were able to articulate what they viewed as benefits of Reiki that extended beyond personal use. This included the wider social and political benefits that could potentially be realised if Reiki could be integrated into the NHS and other health or social care organisations. It also included how participants believed their Reiki skills or knowledge could help others and in some cases how participants own Reiki knowledge and usage had in actuality helped others either directly or indirectly.

In contrast to participants from phase one, only one participant suggested that Reiki could potentially be integrated into the NHS or other health or social care organisations. This was surprising given that three of the Reiki Master Teachers suggested that this could or should be the case. It is also surprising, given the theoretical benefits of Reiki to health; the NHS would be an obvious place for participants to suggest its use. Annabel was employed as a nurse and suggested two areas where there was potential for Reiki to be used within the NHS. In the first excerpt below she notes particular clinical areas where Reiki could be used such as mental health or intensive care and in the second, she draws on her own experience in 
practice suggesting specific conditions such as sports injuries for which Reiki could be used:

It's quick and fast, but I think if you were in, especially mental health, intensive care or on wards and things like that, I think it fits in really well. (Annabel, level two, long term user)

We do get a lot of people with sports injuries, people with chronic problems and 'yes' it [Reiki] would be great for that. (ibid)

It was common for participants to express a desire to help others (defined as people unknown to them) such as the public or wider community in the future. Some participants for example, Jackie talked about 'passing on' their knowledge of Reiki to others, something that emanated from their belief that Reiki had helped them:

I think it has helped me as a person, but I also want to pass it on to other people.

[When you say pass on, you say you're interested in passing it on, do you mean teaching it?]

No, just the knowledge for them to learn. (Jackie, level two, short term user)

Other participants such as James and Naomi expressed a wish to help others by offering Reiki within their community. James discussed his plans to establish a Reiki business which was motivated by the fact that he himself was in good health and wanted to help people who were not in such good health:

Well, touch wood, I don't suffer from anything apart from my back, you know, I've been blessed with good health and I'm very grateful for that. But that's why I want to help others, because I've got good health, I want to try and help 
people with their suffering and suffering that might be necessary [...] but they might not have to suffer quite so much, you know what I mean, so we can ease, we can all help to ease pain. (James, level two, medium term user)

Naomi expressed an interest in volunteering to provide Reiki treatments to people with cancer. In the excerpt below Naomi speculates that the provision of complementary therapies to patients with cancer can be empowering. Whilst she is referring to complementary therapies in general rather than Reiki specifically, it is nonetheless an example that is suggestive of the potential wider benefits of Reiki:

I'm looking to volunteer to give Reiki, but they'll say it's not for healing it's for relaxation, but ok [...] you're not allowed to say healing and that's in cancer. And actually cancer is much more advanced than they're thinking because they realise that actually, cancer is obviously such a hugely invasive thing and the treatment is very invasive and people feel so disempowered. And they're thinking that complimentary therapy, maybe not so much about healing, but it does give that patient a of feeling of getting some empowerment back that they're helping to manage in between treatments and their sense of wellbeing and they learn to relax. And actually then they don't take up the services much because they are feeling much more in control, so it's not such a poisonous word (Naomi, level two, medium term user)

Naomi (above) also suggests a further benefit of Reiki that has political and financial implications, that is, cancer patients who receive complementary therapies use less services. Whether this is in fact proven remains to be seen however, it once again points to potential benefits of Reiki that extend beyond personal use by the individual.

Whilst the desire expressed to offer Reiki to others as an integrated part of orthodox health and social care organisations was in evidence, Faye raised the issue within her interview of this being problematic. Faye worked voluntarily as a homeopath for a faith based drugs charity. Despite the fact that she practiced homeopathy, she was not 
permitted within her work to practice Reiki:

There's still a huge amount of people against it out there. I've volunteered for a charity here; we look after persons with drugs basically. [...] but the charity, the people who have set it up are Christian, highly Christian. Ok right, so I remember during my first interview they said 'are you a Christian?' and I said 'look my background is catholic, I believe in god but I have to be honest with you that the catholic god is tricky for me, I believe in god whether I can call myself a Christian or not, I'm not happy with the label' and she liked the honesty. But anyway I kind of got on with the stuff and obviously seeing a woman been through a huge amount of trauma from childhood and I said to my supervisor 'I'm dying to give them some Reiki', because some of them had been raped and this and that, awful, awful and she said 'you're not allowed, you can't use Reiki' and I said 'why?' and she turned round to me and she was speaking on behalf of the head of the charity, she said 'no the head, they only think that Jesus can heal that' and I was completely taken back by that, I didn't completely get it because Jesus is probably the top guy in terms of a top healer, but I was so shocked, I was quite upset about it [...]I'm not allowed to use Reiki. (Faye, level two, medium term user)

Faye's account of her experiences of offering Reiki within established health and social care organisations illustrates that whilst the desire to integrate Reiki is well meaning, it is not welcomed by all organisations especially in Fay's case by ones providing services within a religious ethos.

Despite, experiences such as Faye's, examples of participants offering Reiki within the wider community or using Reiki in ways intended to help others, were apparent. Adam (level two, medium term user) for example was a volunteer at a local hospice, offering Reiki to patients. However, some participants such as Rosie and Kate used Reiki in more discreet ways to try to benefit others. Rosie worked within a medical 
environment and described how she had on occasion used the Reiki symbols on patient's files:

I have drawn the symbols on patient's files before now just to give them a little bit extra something (Rosie, level two, long term user)

Kate described how she had sent Reiki to 'troubled spots' in the world:

I've not done it very often but I have tried to send Reiki to troubled spots in the world [...] you know, to the Middle East. I've got a globe, so I sometimes send distance healing (Kate, level two, long term user)

Identifying the wider social and political benefits of Reiki was not always linked to what participants could offer others in practical terms (that is, Reiki treatments). Clara talked at length about how learning and self-use of Reiki had helped her confidence and had helped her to become less fearful of death. This had been to such an extent that she felt she was better equipped to help others within the remit of her job in a care home for the elderly. Thus the benefits that Clara had experienced cascaded to the residents of her workplace:

I was really worried about it because my boss came to me one day and he said, 'I'd like you to be the activities co-ordinator manager' and I thought 'I can't do that' and then I thought 'well I can do that', you know, so I just feel like I'm getting the residents out and I can contribute towards their lives more, you know, instead of them sitting there, we take them all over and I wouldn't have had the confidence to do that before. (Clara, level two, medium term user)

I know it's not a very nice subject but I used to find the dying side really hard.[...] And now I find it really helps me, I feel quite privileged now when 
I'm with someone whereas I was frightened before [...] and people, it's really strange people have said to me, I don't know why, but I always feel really comfortable. They say things like that or they've even said that they feel really at peace and things like that and I'm sure it helps [...] it's hard, you know, but since I've had my Reiki I've found it a lot easier, you know, I used to try and avoid it really. (Clara, level two, medium term user)

Whilst some of the participants cited within this section were not at the time of interview actually undertaking any of the work they discussed, the fact that the issue of helping others was raised suggests that those who possess critical Reiki health literacy skills may potentially use Reiki to incite benefits on the wider social and political levels.

\section{- Forming or Joining a Reiki Group}

More than half of participants had attended a Reiki group however; none of the participants had themselves formed one. Descriptions of the groups and the activities that took place varied slightly depending upon the particular group that the participant attended. However, the following description provided by Alice is typical of the groups described by many of the other participants:

So we gather round, you know gather together, sort of tune in so to speak and maybe do a bit of meditation, group meditation, and then it just kind of depends you know what the format of the share can follow. [...] Sometimes there are Reiki students who are needing to do requirements with other Reiki students, so they pair off and go off. Sometimes it's sort of group. [...] it's all sort of negotiated at the beginning and then there's usually a social aspect as well at some point you know, tea, cake or something. (Alice, level two, medium term user) 
In addition to group meditation and opportunities to share Reiki in pairs or in a group (as noted above) Alice also noted that there was a 'social element' to her group. This was common among other groups however the nature of the social element varied. Naomi (level two, medium term user) noted that 'we talk about things' and Heather described the interaction within her group thus:

Sometimes she'll say [Reiki master teacher], you know, have you had any experiences lately, is there anything that's bothering you, or, you know, can you tell us something what's happened (Heather, level two, medium term user)

One activity that was unique to the group that Beth attended was that attendee's received a further attunement during the group's meeting. In the Japanese tradition this is referred to as $R e i-j u$ and is not something commonly practiced within the western version of Reiki:

We have a Reiki share and we try and have a regular attunement as well.

[Ah right, so you redo your attunement over and over, yes, it's got a name hasn't it, yes].

Yes it has - I've forgotten what it is.

[Rei-ju].

Yes. (Beth, level two, medium term user)

Participants often spoke of the benefits they derived from attending a Reiki group, with many agreeing that the group was 'supportive'. However, there were other 
distinct benefits that participants who attended groups described and these involved the sharing of information, knowledge and skills to benefit health. Paula described how she had learned how to treat wounds using essential oils when attending her Reiki group:

Even down to that, [shows interviewer cut on finger] it wasn't healing and I went to Reiki share last week and they said 'have you tried lavender oil?' [...] And so I went home and took all the plasters off and the strips all over it put the lavender oil on and in the morning it had all dried up. So from going to Reiki share I am learning because most of the people that go to Reiki share do reflexology and aromatherapy, a lot of them are in that trade I suppose. And so, I feel every time I go there I'm learning something new either about myself or about the world in general. They've always read different books and they've always got different ideas - that doesn't mean I'm going to believe everything (Paula, level two, medium term user)

Beth described the positive benefits she derived from attending her Reiki group including feeling energised, looked after and cared for:

And then we all do one treatment on one person at a time so you are sort of laying there with six pairs of hands on you, which is a bit stunning sometimes. It makes you feel very energised afterwards, looked after and cared for (Beth, level two, medium term user)

Whilst on the whole, those who had attended a Reiki group viewed them positively this was not the case for all participants. Lucy's Reiki Master Teacher had held a Reiki share however having attended once, Lucy did not want to return due to differences in personality between attendee's:

[Do you go to that regularly?] 
No, no it's just a one off and to be honest I don't know if I'd go to it again anyway. I think he is going to run it again, but I didn't really feel I got any benefit out of it.[...] we were all really different personalities and there was one personality there who was quite strong minded and I felt quite negative, I don't think she felt she was, but I felt she gave a bit of a bad vibe in the group and when we were leaving she said 'oh thanks, I feel so much better' and I thought 'I don't I feel drained' (Lucy, level one, short term user)

There was evidence from the phase two data to support the notion that joining or forming a Reiki group is a component of critical Reiki health literacy. Such groups provide an opportunity to treat other members of the group either individually or as part of the group. They are an opportunity for those attuned to Reiki to socialise and were largely considered as supportive. They also serve as a forum for the sharing of health information and advice. However, it appears that attendance at a group is dependent upon the complementary personalities of those within the group.

\section{Summary of Critical Reiki Health Literacy}

Interviews with Reiki level one and two self users largely confirmed that the skills knowledge and competencies identified within the initial model of Reiki health literacy and as further confirmed and refined within phase one, were at the level of critical Reiki health literacy and applicable to Reiki one and two self users. Interviews with level one and two self-users did not uncover any additional skills, knowledge or competencies that could be considered to be at a critical level of Reiki health literacy.

\section{Concluding Comments}

This chapter presented an analysis and interpretation of the data generated during the second phase of the empirical part of the research. Within this chapter, the model of Reiki health literacy presented in Chapter Eight was further confirmed and refined, 
and two further skills (More Advanced Cognitive Skills and Adapting Reiki practice to meet own needs) were added. The model of Reiki health literacy is applicable to Reiki level one and two self users, evidence for this was found in the similarity in perspectives between Reiki Master Teachers and Reiki level one and two self users however, the addition of two competencies at the level of Interactive Reiki health literacy serve to further enhance its applicability. The following, and final Chapter of this thesis moves on to discuss the empirical and theoretical contributions of the research in relation to the objectives of the thesis. 


\section{Chapter Ten: Discussion}

\section{Introduction}

This $\mathrm{PhD}$ research arose out of the observation that despite a barrage of public health campaigns encouraging the nation's population to take better care of themselves people are still not making as many healthy choices with regards to health and wellbeing as they could. The consequences of this are evident in high levels of stress and psychological ill-health, sickness absenteeism and crises of obesity and the increasing prevalence of long-standing illness. This research has been situated within the wider context of increasing interest in CAM amongst the general public (Frass et al. 2012) and an emerging interest in the potential contribution that CAM might make to population health (Long 2009). The researcher's experience of self-using Reiki and her observation that there is a lack of high quality research into Reiki, particularly self-use of Reiki, served as the impetus behind the research.

The research aimed to explore how learning and self-use of Reiki enhances health literacy and this final Chapter draws together the work that was undertaken to meet this aim and address the specific objectives of:

1. Review the literature on Reiki

2. Identify key concepts associated with health literacy

3. Develop a model of Reiki health literacy

4. Confirm and refine the Reiki health literacy model

5. Uncover the specific effects of learning and self-use of Reiki on health literacy

6. Explore how Reiki health literacy is used in the context of health in daily life

The Chapter begins with a short overview of the argument within the previous Chapters, in order to present a picture of how the thinking in relation to the research progressed and developed. This is followed by a section drawing out the empirical and theoretical contributions of the research in relation to the six research objectives 
of the thesis. The subsequent section draws out some key strengths and possible limitations of the research and future research possibilities.

\section{Overview of the Thesis Argument}

To demonstrate how the argument of the thesis evolved, this section divides the thesis into three 'parts'. The first part of the thesis may be considered as the theoretical and conceptual foundations and provides an overview of the arguments as informed by Chapters Two through to Five. The second part of the thesis may be considered the principles underlining the work and provides an overview of Chapters Six (methodology) and Seven (methods). The third part of the thesis is the empirical part of the thesis and provides an overview of Chapters Eight and Nine, the analysis and interpretation of the empirical data, aimed at refining and applying the initial theoretically-based model of Reiki health literacy.

\section{Part One: Theoretical and Conceptual Foundations}

Chapters Two to Five presented the theoretical and conceptual foundations. Chapter Two highlighted self-use as a key feature of the Reiki system and the potential, 'in theory' benefits of Reiki, for example, helping to alleviate pain, releasing negative thoughts and a sense of deep relaxation. Chapter Three presented the evidence in relation to the effects of Reiki, demonstrating its breadth, variable quality and indicative, but limited, evidence of perceived potential benefits of Reiki when applied as a CAM treatment modality. Most significantly in the context of this thesis, the review indicated both the limited corpus of research on Reiki self-use but also positive effects of such use. Chapter Four examined the concept of health literacy by providing a critical overview of the conceptual literature on health literacy and explored the potential of the Nutbeam model of health literacy to be applied in the context of Reiki. Chapter Five drew out key aspects of the discussion within the previous three Chapters to develop and present an initial and novel theoretical and conceptually based model of Reiki health literacy. 


\section{Part Two: Underlining Principles of the Research}

Chapters Six and Seven presented the methodology and the methods, that is, the underlining principles of the research. These Chapters highlighted how the empirical research was undertaken rigorously and ethically in pursuit of refining and applying the model of Reiki health literacy drawing on key features of qualitative research.

\section{Part Three: Refinement and Application of the Reiki Health Literacy Model}

Chapters Eight and Nine presented an analysis and interpretation of the empirical data generated through the research. Chapter Eight presented the process of confirming and refining the model of Reiki health literacy through discussion with 'experts' (Reiki Master Teachers). Chapter Nine explored the application and relevance of the refined model of Reiki health literacy through interviews with self-users of Reiki. This third part of the thesis thus represented the culmination of the research: evidence of the effects of Reiki self-use; a model of Reiki Health Literacy; and the presentation of evidence suggesting the potential of Reiki to enhance health literacy.

Thus, the thesis has drawn together and presented: evidence on the effects of Reiki, both from theory and as found in research, and the effects of Reiki self-use; a critical engagement with the literature on health literacy leading onto the novel development of a model of Reiki health literacy; the refinement of this model; and demonstration of its value in exploring the potential of Reiki self-use.

\section{Empirical and Theoretical Contributions}

The second section of this Chapter draws out how the thesis has met its aim and objectives and how it contributes to the empirical and theoretical literature. Links to other literature have been drawn in where appropriate, in particular in relation to discussion of objectives three to six. 


\section{Objective One: Review the Literature on Reiki}

The evidence and findings presented in Chapters Three and Four addressed the first objective of the research. The mapping of the Reiki literature included 67 documents and the critical review of the empirical research into Reiki included 27 studies, but only four of these focussed on self-use of Reiki. This range of evidence, in the first instance, demonstrates that the subject of Reiki has sparked considerable interest among the academic CAM community. This is against a backdrop of an increasing quantity, and potentially quality, of research into the effectiveness of complementary and alternative medicine, with research in areas such as herbal medicine, acupuncture and homoeopathy dominating the field. The volume of documents identified by the mapping and included in the critical review is testimony to this academic interest and demonstrates that the subject of Reiki is not solely the domain of Reiki practitioners who write books or manuals on the subject or write about their work in specialist publications (for example, Touch the Reiki Association Community Magazine).

A picture of Reiki therapy emerged from the review of the literature as one of emerging evidence that, at least in theory, is flexible enough to be used with a variety of people in a variety of different settings and with a variety of ailments. Given the range of studies in which its use has been explored, one might also tentatively infer that treating people with Reiki is perceived by its recipients as an acceptable form of treatment, given the participation and completion rates in the studies. The area of the acceptability of Reiki as a CAM modality however requires explicit and further study in future research. The varied use and acceptability of Reiki notwithstanding, the evidence to support Reiki (when administered to a recipient) as an effective form of treatment is extremely limited.

Most importantly, given the core interest of the $\mathrm{PhD}$ on Reiki self-use, the literature review demonstrated the limited, though supportive, evidence base, on self-use of Reiki. As to why research into self-use of Reiki has been so lacking is unclear.

\section{Objective Two: Identify Key Concepts Associated with Health Literacy}

Chapter Four of the thesis addressed this objective. Chapter Four identified two key approaches to conceptualising health literacy, the clinical and the public health 
approach. Making explicit the differentiation between these two approaches to health literacy served to help identify which conceptual framework would best enable exploration of what health literacy would entail in the context of Reiki. Conceptualisations of health literacy are largely situated within a biomedical discourse; however, public health approaches to health literacy, in particular Nutbeam's three levelled model, are underpinned by a philosophy that is compatible with a wider, both individually focused and community relevant, complementary discourse of health. Key elements include the notion of health literacy being about 'keeping well' as opposed to solely managing illness, or adhering to prescribed treatments, and the inclusion of notions such as empowerment and choice. All of these are consistent with the underlying philosophy of many complementary therapies including Reiki (Fulder 1998).

\section{Objectives Three and Four: Develop a Model of Reiki Health Literacy and Confirm and Refine the Model}

Chapters Five and Eight respectively address these two objectives. The starting point of the formation of the model of Reiki health literacy was the critical review of the Reiki and health literacy literature. The model was refined using unstructured interviews with a purposive sample of 10 Reiki Master Teachers. The end-result was a 'refined' model of Reiki health literacy for use in the final stage of the thesis' fieldwork, aimed at exploring the relevance and applicability of the model with a sample of persons who regularly self-use Reiki. The final, refined model of Reiki health literacy is presented in figure 10.1 (overleaf). Differences between, and thus important revisions/additions to the initial model of Reiki health literacy and the refined model can be seen in columns three (Description as applied to Reiki) and five (Individual benefits of Reiki health literacy). 
Figure 10.1: A Refined Model of Reiki Health Literacy

\begin{tabular}{|c|c|c|c|c|}
\hline $\begin{array}{l}\text { Health } \\
\text { Literacy } \\
\text { Level }\end{array}$ & Nutbeam's Description & Description as applied to Reiki & $\begin{array}{l}\text { Individual benefit of health } \\
\text { literacy }\end{array}$ & $\begin{array}{l}\text { Individual benefit of } \\
\text { Reiki health literacy }\end{array}$ \\
\hline Functional & $\begin{array}{l}\text { Sufficient basic skills in reading } \\
\text { and writing to be able to function } \\
\text { effectively in everyday situations }\end{array}$ & $\begin{array}{l}\text { In a Reiki context having sufficient basic } \\
\text { skills involves acquiring the ability to } \\
\text { channel Reiki energy by attending a Reiki } \\
\text { course and receiving an 'attunement'. It } \\
\text { involves acquiring knowledge of the } \\
\text { 'basic' Reiki skills such as how to self- } \\
\text { treat with Reiki and how to give a Reiki } \\
\text { treatment to family or friends. It involves } \\
\text { acquiring a basic knowledge of what } \\
\text { Reiki is, of energy, of protection, of the } \\
\text { chakras, of grounding and of the Reiki } \\
\text { symbols. } \\
\text { Functional Reiki health literacy suggests } \\
\text { a relatively passive role on the part of the } \\
\text { Reiki student. Whilst a person may } \\
\text { acquire these skills and knowledge, they } \\
\text { may choose not to use them. }\end{array}$ & $\begin{array}{l}\text { Improved knowledge of risks and } \\
\text { health services, compliance with } \\
\text { prescribed actions }\end{array}$ & $\begin{array}{l}\text { Acquiring functional Reiki } \\
\text { health literacy equips the } \\
\text { individual with the basic } \\
\text { skills and knowledge they } \\
\text { need to function } \\
\text { effectively within the } \\
\text { Reiki system, that is, 'use' } \\
\text { Reiki. } \\
\text { The individual acquires } \\
\text { knowledge of an additional } \\
\text { means by which health } \\
\text { conditions and complaints } \\
\text { can be managed. }\end{array}$ \\
\hline Interactive & $\begin{array}{l}\text { More advanced cognitive and } \\
\text { literacy skills which, together with } \\
\text { social skills, can be used to actively } \\
\text { participate in everyday activities, to } \\
\text { extract information and derive } \\
\text { meaning from different forms of } \\
\text { communication, and to apply new } \\
\text { information to changing }\end{array}$ & $\begin{array}{l}\text { Interactive Reiki health literacy involves } \\
\text { the use of more advanced cognitive skills. } \\
\text { It involves actively participating in the } \\
\text { use of the Reiki system which includes } \\
\text { putting knowledge into practice that has } \\
\text { been learned on a Reiki course and } \\
\text { applying what one has learned during a } \\
\text { Reiki course to one's health (and to a } \\
\text { greater extent one's own life, own }\end{array}$ & $\begin{array}{l}\text { Improved capacity to act } \\
\text { independently on knowledge, } \\
\text { improved motivation and self- } \\
\text { confidence }\end{array}$ & $\begin{array}{l}\text { By self-treating with Reiki } \\
\text { a range of physical health } \\
\text { conditions may be } \\
\text { improved. Relaxation is } \\
\text { increased and stress is } \\
\text { reduced. } \\
\text { Reiki is used pro-actively } \\
\text { rather than re-actively with }\end{array}$ \\
\hline
\end{tabular}




\begin{tabular}{|c|c|c|c|c|}
\hline & circumstances & $\begin{array}{l}\text { concerns, own circumstances). This may } \\
\text { involve self-treating with Reiki, giving a } \\
\text { Reiki treatment to family or friends, using } \\
\text { energetic protection to benefit health, } \\
\text { using the Reiki symbols, making changes } \\
\text { to life (style) that are beneficial to health } \\
\text { and adapting ones Reiki practice to meet } \\
\text { own needs. } \\
\text { Interactive Reiki health literacy also } \\
\text { involves acquiring a more developed } \\
\text { understanding of the concept of 'energy' } \\
\text { and the ability to make meaning from } \\
\text { different forms of communication, } \\
\text { particularly non-verbal communication. }\end{array}$ & & $\begin{array}{l}\text { frequent self-use helping } \\
\text { to maintain good health. } \\
\text { Use of the Reiki symbols } \\
\text { can be used to ease a } \\
\text { difficult day and providing } \\
\text { comfort and confidence in } \\
\text { situations. Their use can } \\
\text { ease physical medical } \\
\text { problems and assist in } \\
\text { addressing problems from } \\
\text { the past. } \\
\text { Changes made to lifestyle } \\
\text { impact positively on } \\
\text { health. }\end{array}$ \\
\hline Critical & $\begin{array}{l}\text { More advanced cognitive skills } \\
\text { which, together with social skills, } \\
\text { can be applied to critically analyse } \\
\text { information, and to use this } \\
\text { information to exert greater control } \\
\text { over life events and situations. }\end{array}$ & $\begin{array}{l}\text { Critical Reiki health literacy involves the } \\
\text { ability to critically analyse information on } \\
\text { a range of health related subjects } \\
\text { including Reiki and medicine and health. } \\
\text { It involves acquiring the ability to apply a } \\
\text { holistic perspective to health, an } \\
\text { antecedent of which may include the } \\
\text { ability to make health related decisions } \\
\text { and choices informed by multiple } \\
\text { perspectives. Critical Reiki health } \\
\text { literacy also involves a person being able } \\
\text { to exert control over physical, } \\
\text { psychological and emotional health; to } \\
\text { identify the wider social and political } \\
\text { benefits of Reiki and to form or join a } \\
\text { Reiki group. }\end{array}$ & $\begin{array}{l}\text { Improved individual resilience to } \\
\text { social and economic adversity } \\
\text { This type of health literacy can be } \\
\text { more obviously linked to } \\
\text { population benefit, alongside } \\
\text { benefits to the individual. Health } \\
\text { education in this case would be } \\
\text { directed towards improving } \\
\text { individual and community } \\
\text { capacity to act on these social and } \\
\text { economic determinants of health. }\end{array}$ & $\begin{array}{l}\text { Critical Reiki health } \\
\text { literacy can be regarded as } \\
\text { empowering as it promotes } \\
\text { greater control and } \\
\text { freedom of choice over } \\
\text { health and health care. } \\
\text { A person who has } \\
\text { undertaken Reiki training } \\
\text { has the choice of using } \\
\text { Reiki or orthodox } \\
\text { medicine to treat health } \\
\text { complaints. }\end{array}$ \\
\hline
\end{tabular}


Comparing the initial model with the final model it can be seen that the descriptions of functional health literacy as applied to Reiki are more elaborate. The most striking elaboration is that the description of functional health literacy as applied to Reiki now includes an additional seven components. These seven additions were identified as a direct result of interviews with Reiki Master Teachers. Furthermore, a change in the wording of the components can be seen to more accurately capture the essence of functional Reiki health literacy. For example, the notion of sufficient basic skills in the context of Reiki originally included the ability to perform treatment on oneself and others, with the inference being that functional Reiki health literacy reflected the practical aspects of Reiki. However, based on the observation that autonomy or action is not implied within definitions of functional health literacy that are based on Nutbeam's model, the ability to perform treatment on oneself and others was referred to in the final model as knowledge of how to self- treat with Reiki and knowledge of how to give a Reiki treatment to family or friends.

In terms of the individual benefit of functional Reiki health literacy (column five), again the refined model more clearly differentiates and elaborates its possible components. Whilst the benefits of Reiki health literacy in the initial model are relatively specific, for example, the improvement of a range of physical health problems and stress reduction, the benefits in the refined model are more general, for example, the individual is equipped with skills and knowledge to use Reiki. Refining the individual benefits of Reiki health literacy to become general as opposed to specific takes into account the varied benefits that individuals may derive from Reiki practice.

In terms of interactive Reiki health literacy, the notion of actively applying knowledge is included at the level of interactive Reiki health literacy in both versions of the model. However exploring the initial model with the study participants further developed, elaborated and thus refined the elements of interactive Reiki health literacy. The initial description of interactive health literacy as applied to Reiki comprised specific skills for example, more developed understanding of the concept of energy and using energetic cleansing and protection however, the description of 
interactive health literacy as applied to Reiki in the refined model was added to, to include not only the specific skills but also the types of skills for example advanced cognitive skills. Refinements are also observed between the individual benefits of interactive Reiki health literacy in the initial and refined model. Given that the refined model accounts for the active use of skills and knowledge, the associated benefits are more closely related to the active use of these skills.

The level of Reiki health literacy whereby the most similarities can be seen between the initial and the more elaborative, refined versions of the model is critical Reiki health literacy with the main difference being that the refined model contains more sophisticated wording. In addition, the refined model now includes the ability to identify the wider social and political benefits of Reiki and to form or join a Reiki group. This description embraces components that extend beyond the individual, leading to it's closer alignment with Nutbeam's notion of critical health literacy. The refinement, arising from testing and exploring the initial model in the empirical work, now demonstrates a more obvious and closer link to population benefit.

The initial model of Reiki health literacy and thus the refined model presented above were based on Nutbeam's model of health literacy. Other authors have used this model across a range of health/public health contexts including school lessons, online chat room discussion forums and diabetes (St Leger 2001; Donelle and HoffmanGoetz 2008b; Ishikawa, Takeuchi and Yano 2008). One problem inherent in Nutbeam's approach to conceptualising health literacy is that whilst his model describes broadly what each level of health literacy enables an individual to do, it does not specify the exact skills, knowledge or competencies that are associated with each level. This PhD study, following studies by St Leger (2001), Donnell and Hoffman-Goetz (2008), Ishikawa, Takeuchi and Yano (2008) and others, helps to clarify what the skills, knowledge and competencies of functional, interactive and critical health literacy include. Looking at the skills, knowledge and competencies that comprise Reiki health literacy and those included in other studies that have used Nutbeam's model, the similarities and differences between different types of health literacy become apparent, a topic returned to below in relation to objective 5, effect 4 . 
This reinforces the notion that health literacy is context specific and mediated by a variety of factors.

Very little research has been undertaken on CAM and health literacy and none that specifically conceptualises health literacy in the context of specific CAM modalities. This has remained the case throughout the duration of this study with two exceptions. The first exception is Bains and Egede (2011) who report on a cross-sectional survey from an outpatient primary care clinic exploring CAM use and its relationship with health literacy. However, while seemingly a potentially highly relevant reference, the way that health literacy in the study was interpreted and measured is highly problematic. Despite referring to Rootman and Gordon-el-Bihbety (2008) comprehensive definition of health literacy with its components of understanding, evaluating and communicating information, the authors use a narrow literacy (as opposed to health literacy) measure, the Revised Rapid Estimate of Adult Literacy in Medicine (REALM-R), itself oriented to medicine as opposed to the theory and philosophy of CAM. Moreover, REALM-R is predominantly a measure of reading and writing, rather than understanding or applying knowledge to health choices.

The second exception is the work of a team at Western Institute of Nursing, Montana State University (USA) who have an on-going project that aims to develop an instrument to measure health literacy, specifically in the context of CAM for older rural residents. However, this team have not, to date, published any of their findings, only two short conference abstracts being available (Shreffler-Grant 2009a; ShrefflerGrant 2009b). The first abstract (Shreffler-Grant 2009a) points to their emerging definition of CAM health literacy as '... the essential information about CAM needed to make informed self management decisions regarding health.' The abstract also reports that the team have identified 'the antecedents to CAM health literacy, the concepts that comprise CAM health literacy and the overall outcome of CAM health literacy'. However, this abstract does not make explicit the methods used in elucidating these dimensions of CAM health literacy. The abstract is clear however, on the purpose of developing this conceptual model which is 'to develop an 
instrument to measure CAM health literacy'. This is reinforced in the second abstract (Shreffler-Grant 2009b) on adapting a health literacy measure to a CAM context.

Thus the work of the team at Montana State University differs to both the approach adopted in this thesis and the aim of the Reiki health literacy model, where the focus lay on conceptualising Reiki health literacy grounded on theoretical and research evidence of Reiki and possible effects. Building on Nutbeam's conceptual work, the Reiki health literacy model draws out particular elements of the learning (knowledge and skill acquisition, via teaching, reading and the process of attunement), the ownership of this learning and the application of this knowledge and skills into participant's lives, all of which amalgamate into a three-level model of Reiki health literacy (functional, interactive and critical).

\section{Objective Five: Uncover the Specific Effects of Learning and Self-use of Reiki on}

\section{Health Literacy}

The findings of this research suggest there to be four main effects of learning and selfuse of Reiki on health literacy: promoting and maintaining health through Reiki self use; the acquisition of an additional body of knowledge and understanding regarding health; a catalyst for making positive health related changes; and the acquisition of Reiki health literacy. Each is now discussed in turn.

\section{- Effect One: Promoting and Maintaining Health through Reiki Self Use}

The first and most prominent effect of learning and self-use of Reiki on health literacy is the provision of an additional way of promoting and maintaining good health. This is in addition to the ways that non-Reiki health literacy is promoted, for example, through taking regular exercise, eating healthy food, reducing alcohol intake and so forth. In Chapter Two it was noted that many Reiki Master Teachers consider selftreatment with Reiki to be of paramount importance. Consistent with this, interpretation of the Reiki Master Teachers interview data presented in Chapter Seven found that all of the eight participants, who at the time of interview taught Reiki, taught their students how to give themselves a Reiki treatment. The majority of Reiki 
Master Teachers themselves practised Reiki self-treatment as did the majority of Reiki level one and two self users.

As the findings in Chapters Eight and Nine demonstrated, supplementing the very limited set of appraised evidence on Reiki self-use in Chapter Three, Reiki selftreatment can be employed to treat a variety of physical ailments including: colds; tiredness / fatigue; constipation; and pain stemming from a variety of ailments. Participants also pointed to its actual and potential use to treat mental or emotional problems such as bereavement, worry, nerves, anxiety and stress. Reiki Master Teachers specifically discussed using Reiki self-treatment to prevent health problems from occurring and also using Reiki self-treatment as a means of maintaining health.

Reiki self-treatment emerged as a flexible technique for managing health. As demonstrated by participants' reports, self-treating with Reiki can be in the form of using either the full sequence of hand positions described in Chapter Two or by simply placing their hands in one position (referred to as a spot treatment). Furthermore, it was evident that Reiki self-treatment can be tailored to meet a person's own needs, in terms of both available time, time of day and situations where they knew they needed Reiki self-treatment to manage or cope. Moreover, as is the case for other CAMs, Reiki techniques can be adapted and combined with other (biomedical or complementary) treatments and therapies.

In summary the first effect of learning and self use of Reiki on health literacy is that doing so provides a complementary and flexible means of treating physical, mental and emotional ailments. Learning and self use of Reiki encourages the maintenance of good health and may also be used as a preventative measure against ill health.

\section{- Effect Two: The Acquisition of an Additional Body of Knowledge and Understanding Regarding Health}


The second effect of learning and self use of Reiki on health literacy is that it provides the individual with an additional body of knowledge and understanding of how to promote and maintain good health. This body of knowledge is characterised by nonWestern techniques, underpinned by the notion of energy, that are used for personal health promotion, health maintenance and well-being, and attempts to prevent or reduce the impact of ill-health. Included in this body of knowledge is knowledge and understanding of energy, of energetic protection and the Reiki symbols. For example, an individual who possesses interactive health literacy skills is able to use their knowledge that an analgesic will assist with a headache. She/he may self treat their headache with Reiki using one of the three Reiki symbols. This may be in addition to taking a biomedical (over the counter, drug) treatment such as an analgesic or as a replacement to the analgesic. Similarly, such an individual may take measures to manage their stress such as by taking exercise, or getting adequate sleep. Yet another may use energetic protection to guard against the negative effects of stressful situations. This may be in addition to taking exercise or getting adequate sleep or as a standalone measure when the latter is not possible.

In summary, the second effect of learning and self use of Reiki on health literacy is that the individual acquires knowledge and skills that are in addition (and complementary) to the knowledge and skills promoted by traditional health literacy initiatives.

\section{- Effect Three: A Catalyst for Making Positive Health Related Changes}

The third effect of learning and self-use of Reiki on health literacy is that it appears to prompt the individual to make positive health related changes in their life. Participants in both phases of this research described a range of changes that they had made since learning and self using Reiki. These changes included putting more thought into health or as described by Wendy (Reiki Master Teacher) 'getting into other ideas about health'. One predominant change that learning and self use of Reiki appears to facilitate is that of making dietary changes and this was evident within this research with participants at all three levels of Reiki practice. Learning 
and self-use of Reiki also appears to engender feelings of calmness and relaxation which has an impact upon an individual's mental and emotional wellbeing. This finding coheres with studies by Vitale (2009) wherein nurses who self-used Reiki reported the ability to achieve a state of relaxation and calmness and Cuneo (2011) whose study demonstrated a mean 5.9 point decrease on a stress measurement scale in nurses who self-used Reiki. This more 'laid back' attitude towards life and other people has an effect on individuals' relationships with other people including those in their immediate circle (family, partners) and other members of the community more generally who are not necessarily close acquaintances.

In summary, the third effect of learning and self use of Reiki on health literacy is that it acts as a catalyst for a variety of health related changes that benefit physical, mental and emotional health and wellbeing.

\section{- Effect Four: The Acquisition of Reiki health Literacy: a Complementary Addition to Health Literacy}

The fourth effect of learning and self use of Reiki on health literacy is the acquisition of 'Reiki health literacy'. The definition of Reiki health literacy that has emerged through this research is of a distinct set of skills and knowledge drawn upon and used by those who are attuned to Reiki in the context of health. Reiki health literacy need not be viewed as a replacement to health literacy as defined by Nutbeam (2000) nor necessarily as a form of health literacy entirely distinct from Nutbeam's definition of health literacy. Indeed some health literacy knowledge and skills such as the functional health literacy competency of possessing 'sufficient basic skills in reading and writing' are a prerequisite for many of the Reiki health literacy competencies. Reiki health literacy can perhaps most accurately be considered as an addition to or an extension of health literacy.

Reiki health literacy also complements health literacy. At one (theoretical) level, it has the potential to accomplish the same outcomes. For example, both health literacy and Reiki health literacy can facilitate the management of a long term condition. At 
another level, health literacy and Reiki health literacy diverge, in particular in relation to the means by which the outcomes are accomplished. For example, Nutbeam suggests that an outcome of interactive health literacy is improved capacity to act independently on knowledge, improved motivation and self-confidence' and this is achieved by 'tailor[ing] health communication to specific need; facilitation of community self-help and social support groups; combin[ing] different channels for communication'. Interactive Reiki health literacy may also realise this outcome; however the means of doing so differ and instead rely upon: self-treatment; using energetic protection; using the Reiki symbols; a developed understanding of the concept of 'energy'; applying Reiki knowledge to one's own health; making changes to life (style); and making meaning from non-verbal communication.

Yet another area of divergence of health literacy and Reiki health literacy is at the level of critical health literacy. Nutbeam's model of health literacy is located within a biomedical discourse that relies on orthodox understandings of how health is promoted, supported and maintained. In contrast, the model of Reiki health literacy relies on an alternative view of these actions. Indeed, one competency that many participants in this research had developed was the ability to critique orthodox medicine and views of health. Critical health literacy encourages the critical analysis of information and using information to exert control. The irony of developing critical Reiki health literacy skills and in particular the ability to 'see past' the biomedical model of health is that the individual is critiquing the biomedical discourse in which Nutbeam's and many others' conceptualisations of health literacy are located.

In summary, the fourth effect of learning and self use of Reiki on health literacy is the acquisition of an additional and complementary form of health literacy: Reiki health literacy. This form of health literacy theoretically has the potential to achieve the same outcomes as health literacy. However, the two models diverge and cease to harmonise at the critical level whereby critically Reiki health literate individuals also have the ability to critique biomedical approaches to health. 


\section{Objective Six: Explore how Reiki Health Literacy is used in the Context of Health in Daily Life}

The emphasis of this objective lies on 'using' Reiki health literacy, that is, actively putting skills and knowledge into practice. Here focus falls predominantly on the interactive and critical levels of Reiki health literacy. It is beneficial to briefly consider foremost what is meant by the 'context of health in daily life'. This phrase is used herein to refer to the actions that individuals take for themselves (potentially on a regular basis) that have an effect on their health. Two types of action are apparent when considering this in relation to the data generated during this research. Firstly there are those actions that may be considered as a 'means to an end'. That is, they are the actions that those individuals who are attuned to Reiki can utilise for health reasons. Primarily these actions relate to self use of Reiki. Secondly, there are those actions that may be considered as being part of an overall health strategy. These actions also involve, but are not limited to, self-use of Reiki and may include, for example, changing diet, taking more exercise or even changing employment to a less stressful working environment and better work-life balance.

A particular aspect to return to is the level of critical health literacy. In the pursuit of enhancing health literacy, the background aim is to enable individuals to operate at a 'critical health literate' level, while recognising that a person can be critically health literate, in the context of one illness and/or CAM therapy, but not another. It is notable that the empirical findings presented within Chapters Eight and Nine point to both the potential and experienced effect of Reiki self-use in enabling critical health literacy. In contrast to Long's (2009) study of shiatsu where Nutbeam's interpretation of critical health literacy was used as a lens to make sense of findings related to the take-up of advice given by shiatsu practitioners and their clients' self-perceptions of the changes they made as being due to the shiatsu they have received, the $\mathrm{PhD}$ data demonstrate Reiki-specific elements operating at a critical health literacy level. This comes almost full circle back to addressing at least part of Bodeker's (2002) suggestion (Chapter One) of the need for better understanding of the '... the public health dimensions of traditional and complementary medicine.' The model of Reiki health literacy developed, refined and applied in this thesis, points to Reiki, and also 
other CAMs (cf. Long 2009), as having a potential both to enhance the population's health and critical health literacy, the level at which Nutbeam's model most directly proposes public health benefits for a community and/or wider population.

\section{Strengths and Limitations of the Research}

A number of strengths can be identified in the approach and its application used in this thesis.

- Comprehensive, systematically conducted mapping and critical appraisal of published research on evidence of the effects of Reiki and Reiki self-use.

- Adoption of a highly influential model of health literacy (Nutbeam) to provide the conceptual framework to guide the development of a model of Reiki health literacy.

- Making explicit the way that the model of Reiki health literacy was developed and refined.

- Undertaking of the empirical phases of the research in a thorough, rigorous and ethical manner.

Notwithstanding, as in any research study, there are potential limitations in the way the work was conducted.

The sample of this study comprised participants who volunteered to participate in the study based on the requirement that they regularly self-used Reiki. This method of sampling potentially led to a sample of Reiki-self users who have experienced benefits of Reiki. The sample thus did not include individuals who have learned Reiki yet have not experienced any benefits of Reiki self use. Furthermore, the research did not include individuals who have sought Reiki training but who subsequently never use any of their Reiki skills and knowledge. In looking to overcome this, further research may consider an intervention based design whereby participants are taught Reiki self treatment and followed up over a period of time. Such an approach was not feasible within this $\mathrm{PhD}$ study. 
The use of a directed approach to content analysis whereby codes are derived from existing knowledge or theory potentially may have 'blinded' the researcher to elements within the data that were not derived from the existing theory, that is, the initial model of Reiki health literacy. However, a directed approach to content analysis was logical within the context of this $\mathrm{PhD}$ research, giving the focus on refining a model. Furthermore the process of data analysis involved continual selfchecking and discussion with the $\mathrm{PhD}$ supervisors to ensure that the researcher was not selectively analysing the data. Moreover, the purpose of analysis was also to refine the model of Reiki health literacy thus inciting the researcher to be 'open' to new areas.

\section{Concluding Comments and Recommendations for Further Research}

This thesis has aimed to develop and refine a model of Reiki health literacy and to explore its relevance and applicability to individuals who self-use Reiki. A number of key messages emerge from the research. At a theoretical and conceptual level, an original model of Reiki health literacy has been developed. This model is unique in the CAM literature. It is suggested that the way that the model was developed can be utilised in other CAM therapy. In addition, through the development of such a model, this $\mathrm{PhD}$ research has provided an initial contribution to wider discussions about the potential of CAM in promoting and enhancing health and well-being in general through the development of critical health literacy. At an 'empirical' level, the research has provided insight into a number of effects of Reiki self-use, for persons trained at levels one and two. This adds a new dimension to the existing research base on Reiki, where there is both a highly limited set of studies on self-use and most focusing on the effects of receiving Reiki treatment.

A number of areas can be suggested to take forward and build on the current research. Firstly, there is a need to explore further the potential of the model of Reiki health literacy with a wider and larger sample of Reiki self-users, including Reiki Masters. Secondly, the model represents a theory of how Reiki might enhance health literacy. 
The next step is to explore whether learning and self-use of Reiki can indeed enhance health literacy and characteristics associated with those whose health literacy is enhanced. This would involve measuring health literacy, and CAM or more specifically Reiki health literacy, before and after Reiki training. Thirdly, as noted above, there is a need to examine ways in which other CAMs conceptualise health literacy and their potential to enhance health literacy. Fourthly, as individuals often use different CAM therapies in combination with one another, it would be valuable to explore what health literacy might entail in the general context of CAM (commonalities and differences between CAM therapies) as opposed to one particular therapy and/or medicine.

In conclusion, this PhD study has developed, refined and applied a novel model of Reiki health literacy. In doing so, the thesis has provided supportive evidence of the potential of learning Reiki and its regular self-use to enable a pro-active approach to health and well-being. Wider implications of this research include the use of Reiki as a supportive intervention for enhancing health literacy. Because anyone can learn and practise self-use of Reiki it may be a useful intervention for enhancing the health literacy skills of disadvantaged populations who are least likely to have highly developed health literacy skills. 


\section{Bibliography}

AD HOC COMMITTEE ON HEALTH LITERACY FOR THE COUNCIL ON SCIENTIFIC AFFAIRS, A. M. A. 1999. Health literacy: report of the Council on Scientific Affairs. . JAMA : the journal of the American Medical Association, 281(6), pp.552-7.

ADAMS, G. 2002. Shiatsu in Britain and Japan: Personhood, holism and embodied aesthetics. Anthropology \& Medicine, 9(3), pp.245-265.

AHERN, K. J. 1999. Ten Tips for Reflexive Bracketing. Qualitative Health Research, 9(3), pp.407-411.

ASSEFI, N., A. BOGART, J. GOLDBERG and D. BUCHWALD. 2008. Reiki for the Treatment of Fibromyalgia: A Randomized Controlled Trial. Journal of Alternative and Complementary Medicine, 14(9), pp.1115-1122.

AVEYARD, H. 2007. Doing a literature review in health and social care : a practical guide. Maidenhead; New York: Open University Press.

AVIS, M. 2005. Is there an epistemology for qualitative research? In: I. HOLLOWAY, ed. Qualitative Research in Health Care. Berkshire, England: Open University Press.

BAINS, S. S. and L. E. EGEDE. 2011. Association of health literacy with complementary and alternative medicine use: a cross-sectional study in adult primary care patients. BMC complementary and alternative medicine, 11.

BAKER, D. W. 2006. The meaning and the measure of health literacy. J Gen Intern Med Journal of General Internal Medicine, 21(8), pp.878-883.

BALDWIN, A. L., A. VITALE, E. BROWNELL, J. SCICINSKI, M. KEARNS and W. RAND. 2010. The Touchstone Process: An Ongoing Critical Evaluation of Reiki in the Scientific Literature. Holistic Nursing Practice, 24(5), pp.260-276 10.1097/HNP.0b013e3181f1adef.

BARRETT, B., L. MARCHAND, J. SCHEDER, M. PLANE, R. MABERRY, D. APPELBAUM, D. RAKEL and D. RABAGO. 2003. Themes of holism, empowerment, access, and legitimacy define complementary, alternative, and integrative medicine in relation to conventional biomedicine. J Altern Complement Med, 9(6), pp.937-47.

BERKMAN, N. D., S. L. SHERIDAN, K. E. DONAHUE, D. J. HALPERN, A. VIERA, K. CROTTY, A. HOLLAND, M. BRASURE, K. N. LOHR, E. HARDEN, E. TANT, I. WALLACE, M. VISWANATHAN, R. UNITED STATES. AGENCY FOR HEALTHCARE, QUALITY and R. T. I. I.-U. O. N. C. E.-B. P. CENTER. 2011. Health literacy interventions and outcomes : an updated systematic review. [Rockville, Md.]: Agency for Healthcare Research and Quality.

BODEKER, G. 2002. A public health agenda for traditional, complementary and alternative medicine. American journal of public health., 92(10).

BOWLING, A. 2009. Research methods in health : investigating health and health services. Buckingham: Open University Press.

BRATHOVDE, A. 2006. A pilot study: Reiki for self-care of nurses and healthcare providers. Holist Nurs Pract, 20(2), pp.95-101.

BREWITT, B., T. VITTETOE and B. HARTWELL. 1997. The Efficay of Reiki Hands on Healing: improvements in spleen and nervous system function as quantified by electrodermal screening. Alternative Therapis, 3(4), p89. 
BRYMAN, A. 2008. Social research methods. Oxford; New York: Oxford University Press.

CARTER, S. M. and M. LITTLE. 2007. Justifying knowledge, justifying method, taking action: epistemologies, methodologies, and methods in qualitative research. Qualitative Health Research, 17(10), pp.1316-28.

CATLIN, A. and R. L. TAYLOR-FORD. 2011. Investigation of standard care versus sham Reiki placebo versus actual Reiki therapy to enhance comfort and wellbeing in a chemotherapy infusion center. Oncol. Nurs. Forum Oncology Nursing Forum, 38(3), pp.E212-E220.

CHINN, D. 2011. Critical health literacy: A review and critical analysis. Social Science \& Medicine, 73(1), pp.60-67.

CORBIN, J. and J. M. MORSE. 2003. The Unstructured Interactive Interview: Issues of Reciprocity and Risks when Dealing with Sensitive Topics. Qualitative Inquiry, 9(3), pp.335-354.

CORNER, J., J. YARDLEY, E. J. MAHER, L. ROFFE, T. YOUNG, S. MASLINPROTHERO, C. GWILLIAM, J. HAVILAND and G. LEWITH. 2009. Patterns of complementary and alternative medicine use among patients undergoing cancer treatment. European Journal of Cancer Care, 18(3), pp.271-279.

COULTER, A., J. ELLINS, Q. HEALTH FOUNDATION . QUEST FOR, P. IMPROVED and I. PICKER. 2006. Patient-focused interventions : a review of the evidence. London: Health Foundation.

COYNE, I. T. 1997. Sampling in qualitative research. Purposeful and theoretical sampling; merging or clear boundaries? Journal of Advanced Nursing, 26(3), pp.623-630.

CRABTREE, B. F. and W. L. MILLER. 1999. Doing qualitative research. Thousand Oaks [etc.]: Sage.

CRAWFORD, S. E., V. W. LEAVER and S. D. MAHONEY. 2006. Using Reiki to decrease memory and behavior problems in mild cognitive impairment and mild Alzheimer's disease. Journal of Alternative and Complementary Medicine, 12(9), pp.911-913.

CUNEO, C. L., M. R. CURTIS COOPER, C. S. DREW, C. NAOUM-HEFFERNAN, T. SHERMAN, K. WALZ and J. WEINBERG. 2011. The effect of Reiki on work-related stress of the registered nurse. Journal of holistic nursing : official journal of the American Holistic Nurses' Association, 29(1), pp.33-43.

CURTIS, S., W. GESLER, G. SMITH and S. WASHBURN. 2000. Approaches to sampling and case selection in qualitative research: examples in the geography of health. Social Science \&amp; Medicine, 50(7-8), pp.1001-1014.

DENSCOMBE, M. 2003. The good research guide for small-scale social research projects. Maidenhead; Philadelphia: Open University Press.

DENZIN, N. K. 1989. The research act : a theoretical introduction to sociological methods. Englewood Cliffs, N.J.: Prentice Hall.

DENZIN, N. K. and Y. S. LINCOLN. 2003. Collecting and interpreting qualitative materials. 2nd ed. Thousand Oaks, CA ; London: Sage.

DEPARTMENT OF HEALTH. 2011. Healthy Lives, Healthy People: A call to action on obesity in England. United Kingdom.

DICKSON-SWIFT, V., E. L. JAMES, S. KIPPEN and P. LIAMPUTTONG. 2007. Doing sensitive research: what challenges do qualitative researchers face? Qualitative Research, 7(3), pp.327-353. 
DONELLE, L. and L. HOFFMAN-GOETZ. 2008a. An exploratory study of canadian aboriginal online health care forums. Health communication, 23(3), pp.27081.

DONELLE, L. and L. HOFFMAN-GOETZ. 2008b. Health Literacy and Online Health Discussions of North American Black Women. Women \& Health, 47(4), pp.71-90.

DRAUCKER, C. B., D. S. MARTSOLF, R. ROSS and T. B. RUSK. 2007. Theoretical Sampling and Category Development in Grounded Theory. Qualitative Health Research, 17(8), pp.1137-1148.

DRESSEN L. J SINGG, S. 1997. Effects of Reiki on Pain and Selected Affective and Personality Variables of Chronically Ill Patients. Subtle Energies and Energy Medicine, 9(1), pp.51-82

ELO, S. and H. KYNGAS. 2008. The qualitative content analysis process. Journal of Advanced Nursing, 62(1), pp.107-15.

ENGEBRETSON, J. and D. W. WARDELL. 2002. Experience of a Reiki session. Alternative Therapies in Health and Medicine [online]. (2), pp.48-53. Available

from: http://www.mrw.interscience.wiley.com/cochrane/clcentral/articles/694/CN00378694/frame.html.

FEDERATION, U. R. 2009. Reiki Pioneers [online]. [Accessed 22/8/2009]. Available from: http://www.reikifed.co.uk/pub/activ/pion/index.shtml\#settings.

FINCH, J. 1993. 'Its Great to Have Someone to Talk to': Ethics and Politics of Interviewing Women. In: M. HAMMERSLEY, ed. Social Research: Philosophy, Politics and Practice London: Sage Publications.

FINLAY, L. 2002. "Outing" the researcher: the provenance, process, and practice of reflexivity. Qualitative Health Research, 12(4), pp.531-45.

FRASS, M., R. P. STRASSL, H. FRIEHS, M. MULLNER, M. KUNDI and A. D. KAYE. 2012. Use and acceptance of complementary and alternative medicine among the general population and medical personnel: A systematic review. Ochsner J. Ochsner Journal, 12(1), pp.45-56.

FREEDMAN, D. A., K. D. BESS, H. A. TUCKER, D. L. BOYD, A. M. TUCHMAN and K. A. WALLSTON. 2009. Public Health Literacy Defined. American Journal of Preventive Medicine American Journal of Preventive Medicine, 36(5), pp.446-451.

FRIEDMAN, D. B., S. J. CORWIN, G. M. DOMINICK and I. D. ROSE. 2009. African American men's understanding and perceptions about prostate cancer: Why multiple dimensions of health literacy are important in cancer communication. J. Community Health Journal of Community Health, 34(5), pp.449-460.

FRIEDMAN, R. S. C., M. M. BURG, P. MILES, F. LEE and R. LAMPERT. 2010. Effects of Reiki on Autonomic Activity Early After Acute Coronary Syndrome. Journal of the American College of Cardiology, 56(12), pp.995996.

FULDER, S. 1998. The Basic Concepts of Alternative Medicine and Their Impact on Our Views of Health. The Journal of Alternative \& Complementary Medicine, 4(2), pp.147-158.

GALLOB, R. 2003. Reiki: a supportive therapy in nursing practice and self-care for nurses. J N Y State Nurses Assoc, 34(1), pp.9-13. 
GARRA, G., A. J. SINGER, B. R. TAIRA, J. CHOHAN, H. CARDOZ, E. CHISENA and H. C. THODE. 2010. Validation of the Wong-Baker FACES Pain Rating Scale in Pediatric Emergency Department Patients. Academic Emergency Medicine, 17(1), pp.50-54.

GIBBS, L., M. KEALY, K. WILLIS, J. GREEN, N. WELCH and J. DALY. 2007. What have sampling and data collection got to do with good qualitative research? Australian and New Zealand Journal of Public Health, 31(6), pp.540-544.

GOUGH, B. 2008. Deconstructing Reflexivity. Reflexivity. Blackwell Science Ltd, pp.21-35.

GREEN, J. and N. THOROGOOD. 2009. Qualitative methods for health research. London: SAGE.

GROTH-MARNAT, G. 2009. Handbook of psychological assessment. Hoboken, N.J.: John Wiley \& Sons.

HALL, M. 1999. Reiki for common ailments : a practical guide to healing. London: Piatkus.

HARPER, D. 2002. Talking about pictures: a case for photo elicitation. Visual Studies, 17(1), pp.13-26.

HART, C. 1998. Doing a literature review : releasing the social science research imagination. London: Sage Publications.

HEALTH AND SOCIAL CARE INFORMATION CENTRE (HSCIC). 2012. Statistics on Smoking: England, 2012. United Kingdom.

HERRON-MARX, S., F. PRICE-KNOL, B. BURDEN and C. HICKS. 2008a. A Systematic Review of the Use of Reiki in Health Care. Alternative \& Complementary Therapies, 14(1), pp.37-42.

HERRON-MARX, S., F. PRICE-KNOL, C. HICKS and B. BURDEN. 2008b. A systematic review of the use of Reiki in health care. Altern. Complement. Ther. Alternative and Complementary Therapies, 14(1), pp.37-42.

HOLLOWAY, I. 2008. A-Z of qualitative research in healthcare. Chichester, UK; Ames, Iowa: Wiley-Blackwell.

HONERVOGT, T. 2001. Inner reiki : a practical guide for healing and meditation. Stroud: Gaia.

HOUSE OF LORDS SELECT COMMITTEE ON SCIENCE \& TECHNOLOGY. 2000. House of Lords Select Committee on Science \& Technology : sixth report. Houses of Parliament

HSIEH, H.-F. and S. SHANNON. 2005. Three Approaches to Qualitative Content Analysis. Qualitative Health Research, 15(9), pp.1277-1288.

HUGHES, R. D. and M. D. HUBY. 2002. The application of vignettes in social and nursing research. Journal of Advanced Nursing, 37(4), pp.382-386.

HULSE, R. S., E. M. STUART-SHOR and J. RUSSO. 2010. Endoscopic Procedure With a Modified Reiki Intervention: A Pilot Study. Gastroenterology Nursing, 33(1), pp.20-26 10.1097/SGA.0b013e3181ca03b9.

ISHIKAWA, H., K. NOMURA, M. SATO and E. YANO. 2008. Developing a measure of communicative and critical health literacy: a pilot study of Japanese office workers. Health promotion international, 23(3), pp.269-274.

ISHIKAWA, H., T. TAKEUCHI and E. YANO. 2008. Measuring Functional, Communicative, and Critical Health Literacy Among Diabetic Patients. Diabetes care., 31(5), p874. 
ISHIKAWA, H. and E. YANO. 2008. Review Article: Patient health literacy and participation in the health-care process. Health Expectations, 11(2), pp.113122.

JACKSON C. 2010. Promoting informed decision-making for diet and physical activity in disadvantaged women. (PB-PG-0906-10231.).

JACKSON, C., F. CHEATER, W. HARRISON, R. PEACOCK, H. BEKKER, R. WEST and B. LEESE. 2011. Randomised cluster trial to support informed parental decision-making for the MMR vaccine. BMC public health, 11(1), p475.

JENKINS, N., M. BLOOR, J. FISCHER, L. BERNEY and J. NEALE. 2010. Putting it in context: The use of vignettes in qualitative interviewing. Qual. Res. Qualitative Research, 10(2), pp.175-198.

JESSON, J., L. MATHESON and F. M. LACEY. 2011. Doing your literature review : traditional and systematic techniques. London: SAGE.

JOHNSON, J. 2001. In Depth Intrviewing. In: J. A. H. J. F. GUBRIUM, ed. Handbook of Interview Research. Thousand Oaks, Calif. ; London ; New Delhi : Sage, cop. 2001.

JORM, A. F. 2000. Mental health literacy. Public knowledge and beliefs about mental disorders. The British journal of psychiatry : the journal of mental science, 177, pp.396-401.

KELLY, S. 2010. Qualitative Interviewing Techniques and Styles. In: I. L. BOURGEAULT, R. DINGWALL and R. G. DE VRIES, eds. The SAGE handbook of qualitative methods in health research. Los Angeles: SAGE, pp.307-326.

KHAN, K. S. 2003. Systematic reviews to support evidence-based medicine : how to review and apply findings of healthcare research. London; Lake Forest, IL: Royal Society of Medicine Press.

KICKBUSCH I AND MAAG D. 2008. Health Literacy. In: K. H. A. STELLA and QUAH, eds. International Encyclopedia of Public Health. San Diego: Academic Press, pp. 204-211.

KICKBUSCH, I. S. 2001. Health literacy: addressing the health and education divide. Health promotion international, 16(3), pp.289-97.

LEE, M. S., M. H. PITTLER and E. ERNST. 2008. Effects of reiki in clinical practice: a systematic review of randomised clinical trials. International Journal of Clinical Practice, 62(6), pp.947-954.

LIAMPUTTONG, P. and D. EZZY. 2005. Qualitative research methods. Australia: Oxford University Press.

LIEBENBERG, L. 2009. The visual image as discussion point: increasing validity in boundary crossing research. Qualitative Research, 9(4), pp.441-467.

LINCOLN, Y. S. and E. G. GUBA. 1985. Naturalistic inquiry. Beverly Hills, Calif.: Sage Publications.

LONG, A. F. 2002. Critically appraising research studies. In: A. A. P. MCSHERRY R AND SIMMONS M, ed. Evidence-Informed Nursing. A Guide for Clinical Nurses. London: Routledge, pp.41-64.

LONG, A. F. 2009. The potential of complementary and alternative medicine in promoting well-being and critical health literacy: a prospective, observational study of shiatsu. BMC complementary and alternative medicine, 9.

LONG AF AND GAMBLING T. 2012. Enhanced confidence and knowledge following tele-care intervention. Health Expectations 15(3)(3), pp.267-282. 
LONG, A. F. and T. BENNETT. 2009. Coping with Ménière's disease: experience and benefits from the use of complementary and alternative medicine. Chronic Illness, 5(3), pp.219-232.

LORENC, A., B. PEACE, C. VAGHELA and N. ROBINSON. 2010. The integration of healing into conventional cancer care in the UK. Complementary Therapies in Clinical Practice, 16(4), pp.222-228.

LOW, J. 2007. Unstructured Interviews and Health Research. Researching Health: Quantitative, Qualitative and Mixed Methods. Los Angeles: SAGE Publications.

LÜBECK, W., F. A. PETTER and W. L. RAND. 2001. The spirit of reiki : the complete handbook of the reiki system : from tradition to the present : fundamental, lines of transmission, original writings, mastery, symbols, treatments, reiki as a spiritual path in life, and much more. Twin Lakes, WI: Lotus Press.

MACKAY, N., S. HANSEN and O. MCFARLANE. 2004. Autonomic nervous system changes during Reiki treatment: A preliminary study. Journal of Alternative and Complementary Medicine, 10(6), pp.1077-1081.

MASON, J. 2002. Qualitative researching. London: SAGE.

MAY, T. 2001. Social research : issues, methods and process. Buckingham [UK] u.a: Open University Press.

MELAND, B. 2009. Effects of Reiki on pain and anxiety in the elderly diagnosed with dementia: a series of case reports. . alternative therapies in health and medicine, 15(4), p56.

MELLOWSHIP, D. and A. CHRYSOSTOMOU. 2008. The essence of Reiki : the definitive guide to Usui Reiki. Ropley: O Books.

MENTAL HEALTH FOUNDATION. 2012. Mental Health Statistics: The Most Common Mental Health Problems [online]. [Accessed 23/9/2012]. Available from: $\quad$ http://www.mentalhealth.org.uk/help-information/mental-healthstatistics/common-mental-health-problems/.

MILES, P. 2003. Preliminary report on the use of Reiki for HIV-related pain and anxiety. Alternative Therapies in Health and Medicine, 9(2), pp.36-36.

MILES, P. and G. TRUE. 2003. Reiki - Review of a biofield therapy history, theory, practice, and research. Alternative Therapies in Health and Medicine, 9(2), pp.62-72.

MORSE, J. M. 2000. Determining Sample Size. Qualitative Health Research, 10(1), pp.3-5.

NIELSEN-BOHLMAN, L. and L. INSTITUTE OF MEDICINE . COMMITTEE ON HEALTH. 2004. Health literacy a prescription to end confusion [online]. [Accessed]. Available from: http://search.ebscohost.com/login.aspx?direct=true\&scope=site \&db=nlebk\&d $\underline{b}=$ nlabk\&AN=117106.

NIELSEN-BOHLMAN, L., A. M. PANZER, D. A. KINDIG and L. INSTITUTE OF MEDICINE . COMMITTEE ON HEALTH. 2004. Health literacy a prescription to end confusion [online]. [Accessed]. Available from: http://catalog.hathitrust.org/api/volumes/oclc/54537926.html.

NUTBEAM, D. 2000. Health literacy as a public health goal: a challenge for contemporary health education and communication strategies into the $21 \mathrm{st}$ century. Health promotion international, 15(3), p259. 
NUTBEAM, D. 2008. The evolving concept of health literacy. Social science \& medicine (1982), 67(12), pp.2072-8.

NUTBEAM, D. 2010. The Evolving Concept of Health Literacy. In: Health Literacy Annual Research Conference, October 18 -19th, 2010, Bethesda, Maryland.

NUTBEAM, D. and O. WORLD HEALTH. 1998. Health promotion glossary. Geneva, Switzerland: World Health Organization.

OAKLEY, A. 1981. Interviewing Women: A contradiction in Terms. In: H. ROBERTS, ed. Doing Feminist Research. London London ; Boston : Routledge \& Kegan Paul, 1981.

OLSON, K. and J. HANSON. 1997. Using Reiki to manage pain: a preliminary report. Cancer Prev Control, 1(2), pp.108-13.

OLSON, K., J. HANSON and M. MICHAUD. 2003. A phase II trial of Reiki for the management of pain in advanced cancer patients. Journal of Pain and Symptom Management, 26(5), pp.990-997.

PAASCHE-ORLOW, M. K. and M. S. WOLF. 2007. The causal pathways linking health literacy to health outcomes. American journal of health behavior, 31.

PEERSON, A. and M. SAUNDERS. 2009. Health literacy revisited: what do we mean and why does it matter? Health promotion international, 24(3), pp.285296.

PETTER, F. A. 1997. Reiki fire : new information about the origins of the reiki : a complete manual. Twin Lakes, WI: Lotus Light Publications.

PETTER, F. A. 1998. Reiki : the legacy of Dr. Usui : rediscovered documents on the origins and developments of the Reiki system, as well as new aspects of the Reiki energy. Twin Lakes, WI: Lotus Light Publications.

PETTER, F. A. 2001. The Japanese Reiki Techniques. In: W. LUBECK, PETTER FA, RAND, WL, ed. The Spirit of Reiki. USA: Lotus Press, pp.136-189.

PETTICREW, M. and H. ROBERTS. 2005. Systematic reviews in the social sciences : a practical guide. Malden, MA: Blackwell Pub.

PLEASANT, A. and S. KURUVILLA. 2008. A tale of two health literacies: public health and clinical approaches to health literacy. Health promotion international, 23(2), pp.152-9.

POPAY, J., H. ROBERTS, A. SOWDEN, M. PETTICREW, L. ARAI, M. RODGERS, N. BRITTEN, WITH and K. R. A. S. DUFFY. 2006. Guidance on the Conduct of Narrative Synthesis in Systematic Reviews: A Product from the ESRC Methods Programme.

POPE, C. and N. MAYS. 2006. Qualitative research in health care. 3rd ed. Malden, Mass.: Blackwell Pub./BMJ Books.

POPE, C., N. MAYS and J. POPAY. 2007. Synthesizing qualitative and quantitative health evidence : a guide to methods. Maidenhead, England; New York, NY: Open University Press, McGraw Hill Education.

POTTER, P. J. 2007. Breast biopsy and distress: feasibility of testing a Reiki intervention. Journal of holistic nursing : official journal of the American Holistic Nurses' Association [online]. (4), pp.238-48; discussion 249-51. Available

from: http://www.mrw.interscience.wiley.com/cochrane/clcentral/articles/173/CN00621173/frame.html.

PROTHEROE, J., D. NUTBEAM and G. ROWLANDS. 2009. Health literacy: a necessity for increasing participation in health care. The British journal of 
general practice : the journal of the Royal College of General Practitioners., 59(567), pp.721-723.

QUEST, P. 2002. Reiki for life : a complete guide to Reiki practice. London: Piatkus.

QUEST, P. 2003. Self-healing with Reiki : how to create wholeness, harmony \& balance for body, mind \& spirit. London: Piatkus.

RAND, W. L. 2005. Reiki : the healing touch : first and second degree manual. Southfield, MI: Vision Publications.

RAND, W. L. 2009. Reiki in an Indian Prison [online]. [Accessed 22/08/2009]. Available from: http://www.reiki.org/reikinews/reikiinprison.html.

RATZAN, S. C. and R. M. PARKER. 2000. National Library of Medicine Current Bibliographies in Medicine: Health Literacy. In: Z. M. SELDEN CR, RATZAN SC, PARKER RM, ed. National Library of Medicine Current Bibliographies in Medicine. Bethesda, MD: National Institutes of Health, U.S. Department of Health and Human Services.

RICHARDSON, J. 2004. RESEARCH AND PRACTICE - What Patients Expect From Complementary Therapy: A Qualitative Study. American journal of public health, 94(6), p1049.

RICHARDSON JANET AND SAKS MIKE. 2007. Researching Orthodox and Complementary and Alternative Medicine. In: M. SAKS and J. ALLSOP, eds. Researching Health. Qualitative, Quantitative and Mixed Methods London: SAGE.

RICHESON, N. E., J. A. SPROSS, K. LUTZ and C. PENG. 2010. Effects of Reiki on anxiety, depression, pain, and physiological factors in community-dwelling older adults. Research in gerontological nursing, 3(3), pp.187-99.

RING, M. E. 2009. Reiki and Changes in Pattern Manifestations. Nursing Science Quarterly, 22(3), pp.250-258.

ROOTMAN and GORDON-EL-BIHBETY. 2008. A Vision for a Health Literate Canada. Report of the Expert Panel on Health Literacy Ottawa, ON.

ROOTMAN, I. and B. RONSON. 2005. Literacy and health research in Canada: where have we been and where should we go? Canadian journal of public health. Revue canadienne de santé publique, 96.

ROWLAND, A. Z. 2008. Reiki for the heart and soul : the Reiki principles as spiritual pathwork. Rochester, Vt.: Healing Arts Press.

ROYAL GEOGRAPHICAL SOCIETY. 2012. Who wants to live forever? - Why are people living longer? [online]. [Accessed 22 / 9/ 1012]. Available from: http://www.rgs.org/OurWork/Schools/Teaching+resources/Key+Stage+3+reso urces/Who+wants+to+live+forever/Why+are+people+living+longer.htm.

RUBIN, H. J. and I. RUBIN. 2005. Qualitative interviewing : the art of hearing data. Thousand Oaks, Calif. ; London: SAGE.

SAKS, M. and J. ALLSOP. 2007. Researching health : qualitative, quantitative and mixed methods. Los Angeles: SAGE Publications.

SHARMA, V. G., C. SANGHVI, Y. MEHTA and N. TREHAN. 2000. Efficacy of reiki on patients undergoing coronary artery bypass graft surgery. Ann Card Anaesth, 3(2), pp.12-8.

SHIFLETT, S. C., S. NAYAK, C. BID, P. MILES and S. AGOSTINELLI. 2002. Effect of Reiki treatments on functional recovery in patients in poststroke rehabilitation: A pilot study. Journal of Alternative and Complementary Medicine, 8(6), pp.755-763. 
SHORE, A. G. 2004. Long-term effects of energetic healing on symptoms of psychological depression and self-perceived stress. Alternative Therapies in Health and Medicine, 10(3), pp.42-48.

SHREFFLER-GRANT. 2009a. CAM Health Literacy: Development of a Conceptual Model. In, 2011-10-17.

SHREFFLER-GRANT. 2009b. Measuring CAM Health Literacy. In.

SILENZIO, V. M. B. 2002. What is the role of complementary and alternative medicine in public health? American journal of public health., 92(10).

SILVERMAN, D. 2000. Doing qualitative research : a practical handbook. London; Thousand Oaks; New Delhi: Sage.

SOINTU, E. 2006. The search for wellbeing in alternative and complementary health practices. Sociology of Health and Illness, 28(3), pp.330-349.

SØRENSEN, K., S. VAN DEN BROUCKE, J. FULLAM, G. DOYLE, J. PELIKAN, Z. SLONSKA, H. BRAND and E. CONSORTIUM HEALTH LITERACY PROJECT. 2012. Health literacy and public health: a systematic review and integration of definitions and models. BMC public health, 12.

ST LEGER, L. 2001. Schools, health literacy and public health: possibilities and challenges. Health promotion international, 16(2), p197.

STIENE, B. and F. STIENE. 2005. The Japanese art of Reiki. Winchester, UK; New York: O Books.

STIENE, B. and F. STIENE. 2008. The reiki sourcebook. Ropley: O Books.

THOMAS, K. and P. COLEMAN. 2004. Use of complementary or alternative medicine in a general population in Great Britain. Results from the National Omnibus survey. J Public Health, 26(2), pp.152-157.

THOMAS, K. J., J. P. NICHOLL and P. COLEMAN. 2001. Use and expenditure on complementary medicine in England: a population based survey. Complementary Therapies in Medicine, 9(1), pp.2-11.

THOMAS, T. M. 2005. Reiki adds a new dimension to the term "quality of life" in the nursing home community. American Journal of Recreation Therapy, 4(4), pp.43-48.

TOMLINSON, D., C. L. VON BAEYER, J. N. STINSON and L. SUNG. 2010. A Systematic Review of Faces Scales for the Self-report of Pain Intensity in Children. Pediatrics, 126(5), pp.e1168-e1198.

TONES, K. 2002. Health literacy: new wine in old bottles? Health education research, 17(3), pp.287-90.

TSANG, K. L., L. E. CARLSON and K. OLSON. 2007. Pilot crossover trial of Reiki versus rest for treating cancer-related fatigue. Integrative Cancer Therapies, 6(1), pp.25-35.

USUI, M. and F. A. PETTER. 1998. The original Reiki handbook of Dr. Mikao Usui. Twin Lakes, WI: Lotus Press.

VANDERVAART, S., G. KOREN, V. M. G. J. GIJSEN and S. N. DE WILDT. 2009. A systematic review of the therapeutic effects of Reiki. J. Altern. Complement. Med. Journal of Alternative and Complementary Medicine, 15(11), pp.11571169.

VENNELLS, D. F. 2005. Reiki mastery : for second degree, advanced, and Reiki masters. Winchester: O Books.

VINCENT, C. and A. FURNHAM. 1996. Why do patients turn to complementary medicine? An empirical study. British Journal of Clinical Psychology, 35(1), pp.37-48. 
VITALE, A. 2007. An integrative review of Reiki touch therapy research. Holist Nurs Pract, 21(4), pp.167-79; quiz 180-1.

VITALE, A. 2009. Nurses' Lived Experience of Reiki for Self-care. Holist Nurs Pract, 23(3), pp.129-145.

VITALE, A. T. and P. C. O'CONNOR. 2006. The effect of Reiki on pain and anxiety in women with abdominal hysterectomies: a quasi-experimental pilot study. Holist Nurs Pract, 20(6), pp.263-72; quiz 273-4.

WARDELL, D. W. and J. ENGEBRETSON. 2001. Biological correlates of Reiki Touch(sm) healing. Journal of Advanced Nursing, 33(4), pp.439-445.

WENGRAF, T. 2001. Qualitative research interviewing : biographic narrative and semi-structured methods. London ; Thousand Oaks, Calif.: SAGE.

WHELAN, K. M. and G. S. WISHNIA. 2003. Reiki therapy: the benefits to a nurse/Reiki practitioner. Holist Nurs Pract, 17(4), pp.209-17.

WILLIAMS, M. V., R. M. PARKER, D. W. BAKER, N. S. PARIKH, K. PITKIN, W. C. COATES and J. R. NURSS. 1995. Inadequate functional health literacy among patients at two public hospitals. JAMA : the journal of the American Medical Association, 274(21), pp.1677-82.

WILLIG, C. 2008. Introducing qualitative research in psychology : adventures in theory and method. Maidenhead: Open university press.

YAMAGUCHI, T. 2007. Light on the origins of Reiki : a handbook for practicing the original Reiki of Usui and Hayashi. Twin Lakes, Wis.; Enfield: Lotus ; Publishers Group UK [distributor].

ZARCADOOLAS, C., A. PLEASANT and D. S. GREER. 2005. Understanding health literacy: an expanded model. Health promotion international, 20(2), pp.195-203. 


\section{Appendix 1: Example Appraisals}

\section{Systematic Review}

au: Lee, Pittler and Ernst

ti: Effects of Reiki in clinical practice: a systematic review of randomised clinical trials

source: International Journal of Clinical Practice

year: 2008

aims of study: to summarise and critically evaluate the evidence for the effectiveness of reiki.

aims of paper:

key findings: Nine RCT's identified that met the study inclusion criteria, however, authors identify flaws with each of these trials; limited in terms of blinding and small sample size. Methodological quality of Reiki RCT's 'moderate. 'Finds that the evidence is insufficient to suggest that Reiki is an effective treatment for any condition. Therefore the value of Reiki remains unproven.

summary evaluative comments: This is a rigorous systematic review. There is good level of detail regarding the search strategy, study inclusion and exclusion criteria and quality assessment. Quality was assessed using a modified version of the jadad scoring system. However, this is a narrow review of nine RCT's with copious exclusion criteria. The authors provide the following rationale for this;

we strongly feel that non-randomisation introduces selection bias which, in turn, would render any results uninterpretable. The exclusion of RCTs on healthy subjects or without clinical outcomes or qualitative studies might be criticised. We feel that such trials would not give objective clinical information of value. Moreover these studies cannot provide reliable data on the effectiveness of reiki. 
Given the apparent small number of RCT's in the area it would arguably be worth taking into consideration other types of study as exploratory studies are often a precursor to larger scale RCT's.

study type: Systematic review

intervention: Reiki alone or Reiki as an adjunctive to conventional treatment comparison intervention: Any type of control group. Varied amongst included studies e.gs; sham/placebo Reiki, Progressive muscle relaxation, usual care, rest

sufficient detail: Yes good introduction to Reiki and excellent detail of all elements of the review process

geog and care setting: Studies included from USA, Canada and UK. Various clinical settings.

beginning and duration of study: studies searched for up to Nov 2007

source pop: Published studies of use of Reiki in clinical practice

inclusion: RCT's only. If they assessed human subjects who received Reiki alone or adjunctive to conventional treatment. Trials comparing Reiki with any type of control group

exclusion: Any trials with Reiki as part of a complex intervention. Trials which aimed to develop the methodology of Reiki procedures without clinical outcomes. Studies in which no data or no statistical comparisons were reported. Trials assessing healthy subjects.

sample selection: All studies meeting the inclusion criteria.

number of groups:

group allocation:

study size: 9 studies included in review

adequate sample size:

loss to follow-up:

appropriate sample: Included studies are appropriate in light of inclusion and exclusion criteria. All sources searched and terms used are well described thus the 
review could be repeated. Authors note that own files and relevant journals plus reference lists were hand searched however no description of how this was done is included

sample characteristics: sample varied between studies, characteristics of sample not described by authors.

review studies' quality: The quality of individual studies is reviewed. No study is excluded on quality grounds.

comparable groups:

how confounders controlled:

adequate control:

any / what uncontrolled confounders:

authors take into account in interpretation:

outcome criteria:

outcome measures: Modified version of the jadad scoring system for this review. Within the review - variety of outcome measures used

appropriate outcome measures: jadad commonly used to assess clinical trials

other (e.g. process) measures:

well validated:

known responsive to change:

perspective of measures:

sufficient breadth: Sufficient breadth in terms of this systematic review however, did have a rather limiting inclusion and exclusion criteria. Solely RCT's

use outcome criteria in routine practice:

use outcome measures in routine practice:

length of follow-up: few studies have a follow up period. 1 study followed up after 1 year.

sufficient length of follow-up: More studies with longer follow-up times would be valuable. 
to what setting to generalise: Clinical usage only

to what population to generalise: on the basis of this systematic review it is not possible to generalise to a single population. Reiki has been used with a variety of patient groups.

justified conclusions: The review concludes that there is insufficient evidence to suggest that Reiki is an effective treatment for any condition. States also that the value of Reiki therefore remains unproved. Within the context of this review yes the authors have been sufficiently rigorous in reaching this conclusion. However I would argue that the wording may be slightly misleading. This review highlights the fact that Reiki is ineffective for the treatments of the conditions included in this review as explored using an RCT design. The lack of inclusion of research studies based on designs other than RCT's may have shed a different light on this.

implications for service practice:

implications for policy:

ethical committee approval: Not appropriate

informed consent:

other ethical issues:

total no of refs: 34

other noteworthy features: Authors note the following;

We are therefore confident that our search strategy has located all relevant data. However, a degree of uncertainty remains. A further weakness of systematic reviews pertains to the quality of the primary studies. Even though quality of the reviewed studies is moderate, methodological shortcomings such as small sample size and inadequate level of blinding render our review at best inconclusive.

other study references:

reviewer: Helen Gibson

review date: $31 / 1 / 12$ 


\section{Quantitative Study}

au: Assefi, $\mathrm{N}$ et al

ti: Reiki for the treatment of Fibromyalgia: A Randomized control trial

source: The Journal of Alternative and Complementary Medicine V14 (9)

year: 2008

aims of study: To determine whether Reiki is beneficial as an adjunctive fibromyalgia treatment

aims of paper if different to above:

key findings (Make sure that the key findings are what you think these are - i.e. it is your evaluation) Reiki treatment (both distance and hands on) did not improve the pain, fatigue, well-being or physical and mental functioning of patients with fibromyalgia.

Summary evaluative comments (strengths and weaknesses, which has the following implication for (your) use of the study): This is a well designed rigorously conducted study using the 'gold standard' of randomized, double blind, placebo controlled trial. It offers sound evidence for Reiki having no effect on this type of pain. The study is replicable due to excellent and transparent detail. My only criticism of this trial is that the participants mean pain score was $6.4 \mathrm{~cm}, 6.8 \mathrm{~cm}$ for fatigue, 4.1 for sleep quality and 4.5 for overall wellbeing. It appears that these participants were in 'average' pain and I would have liked to see some accounting for extreme case e.g. people with high and minimal pain. As is the case with such trials there is no accounting for how participants felt during or after receiving Reiki therefore whilst the authors conclude that Reiki did not improve the symptoms of fibromyalgia It would be interesting to know if receiving Reiki had any other effect in participants' lives.

study type: RCT

intervention (description of):30 minutes hands on Reiki twice per week for 8 weeks comparison intervention: 30 minutes placebo hands on Reiki twice per week for 8 weeks 
intervention (description of): 30 minutes distance Reiki twice per week for 8 weeks comparison intervention: 30 minutes distance placebo Reiki twice per week for 8 weeks

Nature/form of treatment: hands on and distance Reiki

sufficient detail (Is sufficient detail given for someone else to do something likewise? If not, what else is needed?) : Yes there is sufficient detail for replication - hand positions and length of each are noted.

Practitioners giving Reiki: 3 female Reiki masters with 5-18 years of experience Appropriateness: All practitioners at Master level with good range of experience Treatment environment: Participants laid down on a massage table in a white walled treatment room in a private medical office. No incense or music used

geog and care setting: Private medical offices in Seattle, USA

beginning and duration of study: 8 weeks study 3 month follow up

source pop: People from the Seattle, Washington metropolitan area

Inclusion: English speakers, 18 years old or over, medical diagnosis of fibromyalgia, have a global pain score of 4 or more on a visual analogue scale, willing to be randomized, keep pharmacological and non pharmacological therapies for fibromyalgia constant throughout the study and use only acetaminophen and ibuprofen for breakthrough pain

exclusion: Reported other pain related medical conditions, were pregnant or breastfeeding, used narcotics, were involved in ongoing litigation in relation to their fibromyalgia or receiving disability payments (which might reduce their incentive for improvement), lived more than an hour away from research centre, were unable to attend 8 weeks of biweekly therapy or had previously received an energy medicine modality (to maximize blinding).

sample selection: RCT so no sampling

number of groups: 4 groups (hands on Reiki, distant Reiki, placebo / sham hands on Reiki, placebo / sham distance Reiki)

group allocation: randomized using a computer-generated blocked random allocation sequence 
study size: 100 but using intention to treat , 81 completed study

adequate sample size: 81 is good sized sample although authors state it as being 'modest'.

loss to follow-up: No follow up stated for lost participants

appropriate sample: Thorough inclusion criteria ensured appropriate sample

sample characteristics: Most participants were white women with college degree. Mean age of 49 and $43 \%$ were married. Mean pain score was $6.4 \mathrm{~cm}, 6.8 \mathrm{~cm}$ for fatigue, 4.1 for sleep quality and 4.5 for overall wellbeing

comparable groups: Yes, demographic characteristics, clinical features, and treatment expectations did not differ across the treatment groups.

how confounders controlled: Using sham Reiki practitioners controlled for touch and healing intention. Blinding of participants, data collectors and data analysts

Adequate control: Yes adequate

any / what uncontrolled confounders (n.b. may not know what the uncontrolled confounders might be until have read all of the papers): Not applicable

Limitations: Study not powered to detect subtle changes; study used standardized hand positions and not geared towards individual needs. Because the trial was so tightly controlled it may not have reflected the optimum environment for healing to take place.

authors take into account in interpretation: Whilst the authors do not discuss confounders per se, they do reflect on the limitations of the study in their discussion

outcome criteria: Subjective pain during the previous month, fatigue intensity, sleep quality, general wellbeing. Secondary outcomes were physical and mental functioning

outcome measures: Visual analogue scale, Medical outcomes study 36 item short form health survey

appropriate measures: Yes, measures correlate with outcome criteria which in turn correlate with aims of study

other (e.g. process) measures: Non

well validated: VAS not commented on but Short form health survey has high reliability and validity including with those with chronic fatigue and pain 
known responsive to change: Not stated

perspective of measures: Patients perspective

sufficient breadth: Yes, breadth sufficient as subjective measures only in study aim use outcome criteria in routine practice (potential for use in my research):

use outcome measures in routine practice (potential for use in my research): Have used SF36 before so am familiar with it - reassuring to see it used in Reiki research so would definitely consider using it.

When measures administered: Baseline, midway through intervention (week 4) and end of treatment (week 8) - although specifically when (and where) not specified possible impact of measures on treatment: I would not have thought that the point in time would have made a difference but the point of completing the measures might have made a difference - as it is it is not stated when this was.

length of follow-up: Three months after completion of treatment sufficient length of follow-up: Three months is reasonable.

to what setting to generalise: Difficult to generalise to settings as authors state themselves this was a very artificial situation.

to what population to generalise: Adults experiencing fibromyalgia related pain justified conclusions: The authors are justified in their conclusions based on the trial that they ran. There is sufficient detail of the findings to justify the conclusions with limitations taken into account.

implications for service practice: Energy medicine modalities such as Reiki need to be rigorously studied before being recommended to patients with chronic pain symptoms.

implications for policy: Non stated

ethical committee approval: University of Washington

informed consent: Participants provided written informed consent 
other ethical issues: study used standardized hand positions and not geared towards individual needs. I understand why this was necessary and that it passed via an ethics committee but it does not really sit well with the ethics of Reiki. If someone has pain, you help! Reiki practitioners perspective??? Why would they do this?

other noteworthy features: Non

other study references: Non

reviewer: Helen Gibson

review date: $21^{\text {st }}$ May 2009 


\section{Qualitative Study}

au: Vitale, A

ti: Nurses' Lived Experience of Reiki for self - care

source: Holistic Nursing Practice V23 (3)

year: 2009

Aims of study: To explore the lived experience of nurses who practice Reiki for selfcare

Aims of paper:

key findings (to be inserted by reviewer even if not summarised in paper):

Self-care benefits, especially for stress management, underpin the nurses' lived experience of self-Reiki use. There is a relationship between the relaxation effects and clarity of thought with self-Reiki. The ability to quickly restore the self to a tranquil state and awareness to shifting back into a centred state are essential for nurses working in today's healthcare environments. The practice of self-Reiki is individualized and has personal meaning. Reiki healing energy facilitates a mindbody-spirit connection and healing consciousness that is integral for self-healing transformations, healing journeys, and a deepening of spirituality. Self-Reiki use helps the nurses have connections with the self, others, and the Universe as well as spiritual connections with dimensions of religiosity to the Divine, God, or a Higher Power. Nurses at more advanced Reiki levels travel a more spiritually based journey facilitated by caring for themselves with Reiki, more than just the use of Reiki as a CAM modality. The mystical phenomenon of Reiki and the understanding that it is a humanistic practice are accepted by those who practice this modality. Self-Reiki use by nurses enhances their ability to care for themselves and others from a reverent, loving space. Reiki promotes the importance of human caring in nursing.

summary evaluative comments(strengths and weaknesses, which has the following implication for my use of the study): This is a really thorough study that is one of only 2 that looks at the issue of using Reiki for self care. Structured description of analysis process and data presented using participants own words really allows the reader to get a good picture of what was said. Excellent reflexivity demonstrated and conclusions linked to wider issues. The only apparent weakness to 
this study is that it did not draw upon a representative sample and focuses on a female viewpoint. Where are all the male Reiki practitioners?

study type: Descriptive study with a phenomenological approach

intervention: Reiki self care

comparison intervention: not applicable

sufficient detail:

outcome criteria:

perspective of measures:

sufficient breadth:

geog and care setting: USA

setting rationale:

sufficient detail:

beginning and duration of study: Not stated

source pop: Mid-Atlantic Reiki / holistic network branches as identified through the American Holistic Nurses Association and in close geographic proximity to the researcher

inclusion: Registered Nurses who self identified as Reiki practitioners, reported that they used self Reiki practice, were English speaking and able to articulate the experience of Reiki in self care or self treatment.

exclusion: Nurses / Reiki practitioners not trained in the Usui Lineage

sample selection: Purposive and snowball sampling - all who met inclusion criteria invited to participate

study size: 11 Nurse / Reiki practitioners

appropriate sampling frame: Appropriate place to seek potential research participants but as noted by the author the majority of participants were members of AHNA (American Holistic Nurses Association) so all may have shared similar experiences and viewpoints 
appropriate sample (informants, setting, events): Yes - good inclusion criteria ensures participants are appropriate.

Sample Characteristics (age, gender, ethnicity) All female, white and living in mid - Atlantic region. Majority ( $\mathrm{n}=6$ ) were level III Reiki masters $91 \%$ aged between 45 60

practitioners giving Reiki: Focus on self care

appropriateness:

treatment environment:

conduciveness to treatment:

data collection methods: Open ended guided interview

researcher's role: Unclear but strongly suggests it is author

adequate description of fieldwork: Interviews conducted in participants home, which was their preference. Not so much a description but good to note that location was of the participant's choosing. Interviews lasted $28-61$ minutes

Process of analysis: Colaizzi method as adapted by Beck

adequate description of analysis process: Yes excellent description; 1) Extraction of essence as well as the whole of informants descriptive experiences 2) Validation of the transcripts with each participant 3) extraction of significant statements from the transcripts 4) restatement to formulated meanings 5) arrangement of formulated meanings to groups 6) development of thematic clusters 7) development of emergent theme categories 8) integration of themes into an exhaustive description of the phenomenon containing the participants own words 9) validation of the data and exhaustive description of self -Reiki with the participants.

adequate evidence to support analysis: Yes really good use of quotes to support key themes and author states she used the participants' own recognizable words. Appendix contains plenty of sample participants quotes

study findings set in broader context: Yes - section considering the implications for nursing practice and education. Primarily author suggests that the findings have implications for nursing leaders as they explore innovative ways to recruit and retain nursing staff and promote nurses well being.

Researcher's potential bias/position: None - author goes to good lengths to ensure any bias was minimised. A reflective personal statement was written by the 
researcher before the study and reread throughout. Reflexive journaling also used to document researchers personal reflections, thoughts, ideas and potential biases throughout the study.

to what setting to generalise: Non - setting not within remit of the research to what population to generalise: Recruitment of sample that was in close proximity to researcher makes it difficult to generalise about other nurses or Reiki practitioners justified conclusions: Yes, I think the author is justified in her conclusions. There is excellent use of the raw data to support her conclusions. It is well linked into wider issues of caring and nurse education and practice. The author also provides a good section on the limitations of her study and suggests that this work is preliminary until further work is carried out. Al this bore in mind, I would argue that conclusions are justified.

ethical committee approval: Villanova University’s Institutional Review Board informed consent: Yes - written consent obtained other ethical issues:

other noteworthy features: I am quite interested in the researcher having written a reflective statement and use of personal journaling as this is going to be a really important issue in my own work. HG to chase up references for this.

other study references:

reviewer: Helen Gibson

review date: $25^{\text {th }}$ June 2009 
Appendix 2: Participant Information Sheet

UNIVERSITY OF LEEDS

The University of Leeds, Faculty of Medicine and Health, School of Healthcare

\section{Participant Information Sheet for Reiki Masters / Teachers}

\section{Exploring the Effects of Reiki Self-Use on Health Literacy}

I would like to invite you to take part in this research study. Before you decide whether to do so it is important for you to understand why the research is being done and what it will involve. Please read the following information carefully and discuss it with others if you wish.

\section{What is the purpose of this study?}

This study aims to examine the views of Reiki Masters on the skills and knowledge that people who self use Reiki have in order to manage their health. The research will help further our understanding of self use of Reiki and deepen the existing understanding of the benefits of learning Reiki.

\section{Who is doing the study?}

The study is being carried out by Helen Gibson a student in the School of Healthcare at the University of Leeds. The study is for a PhD and the supervision team is led by Professor Andrew Long. 


\section{Why have I been asked to participate?}

You are being asked to participate in this research because you are a Reiki Master / Teacher. I am seeking the views of approximately 10 Reiki Masters / Teachers.

\section{Do I have to take part?}

The decision to take part in this study is entirely voluntary. You do not have to take part if you do not want to.

\section{What will be involved if I take part in this study?}

If you are happy to take part in the project, I will contact you to discuss the study and invite you to meet with me for an interview during which I would like to talk to you about your experiences of teaching Reiki and of using Reiki on yourself. The interview will be tape recorded and will last approximately one hour. The interview will be informal and can be arranged at a time and place that is convenient for you.

\section{What are the advantages and disadvantages of taking part?}

By taking part in the study you will be helping us to understanding more about the self use of Reiki and about the benefits of learning Reiki.

Participating in an interview will involve giving up approximately one hour of your time. It is unlikely that I will ask you any questions that may cause upset. I appreciate that, for some, self use of Reiki as related to health can be a sensitive subject. If at any point during the interview questions arise that you do not want to answer that is fine. You can take a break from the interview at any time or decide to withdraw from the study without having to give a reason.

\section{Can I withdraw from the study at any time?}


You are free to withdraw from the study during or at the end of the interview and you don't have to give a reason. If you chose to withdraw from the study, any information you have already provided me with during the interview and your contact details will be destroyed.

\section{Will the information I give be kept confidential?}

The information that you tell me in the interview will be treated in the strictest confidence. Only I will have access to your personal data (for example, your name and contact details). The interview will be stored securely and separately from your personal details. With your permission the interview will be tape recorded so that it can be transcribed. I and my supervisors will have access to the interview transcripts. These will be made anonymous and any identifying features will be removed. The tapes will be destroyed once they have been transcribed and the transcripts will be stored securely for 3 years.

All data will be stored in a secure and locked location in accordance with data protection requirements and all information collected about you during the study will be stored securely in a locked office and on a password protected computer.

\section{What will happen to the results of the study?}

The study is for my $\mathrm{PhD}$ and the results will form a part of this. The results may also be reported in scientific and academic journals and during conference proceedings. No individual will be able to be identified from details in any reports, papers or presentations that come out of the study.

\section{Who has reviewed this study?}

This study has been reviewed and approved by the School of Healthcare Research Ethics Committee (SHREC) September 2009. 
If you agree to take part, would like more information or have any questions or concerns about the study please contact me;

Helen Gibson

PhD Student

Room 3.35

School of Healthcare

Baines Wing

University of Leeds

LEEDS

LS2 9UT

Tel: 01133432298

Email: spl1heg@leeds.ac.uk

Thank you for taking the time to read this information sheet. 


\section{Appendix 3: Advert Posted in Reiki Association Magazine}

Calling all Reiki Level 1 and 2 People!

My name is Helen Gibson and I am attuned to Reiki Level two. I am also in the second year of my $\mathrm{PhD}$ studies at the University of Leeds. My $\mathrm{PhD}$ research is looking broadly at the benefits of self use of Reiki and as part of my fieldwork I am looking for people like you to take part in an interview with me.

Do you.......

- Regularly use Reiki on yourself (i.e. give yourself a self treatment on a regular basis)

Do you live in one of the following regions?

- Yorkshire OR

- Lincolnshire OR

- Derbyshire

If this is you or someone you know I would like to talk to you about your experiences of using Reiki on yourself.

All interviews will be confidential and will take place from July onwards.

For further information please email me at spl1heg@leeds.ac.uk or you can telephone me on 01133432298

I look forward to hearing from you, Helen 


\section{Appendix 4: Interview Schedule Phase One (Reiki Masters)}

\section{Introductions}

HG to introduce research, explaining and obtaining consent, permission to tape record etc...

\section{Opening / Beginning Questions}

- I'd like to begin if I can by asking you how long you've been practising Reiki?

- And what level of Reiki practice are you at?

- Could you tell me about how you got into Reiki?

PROMPT: When was that?

- Why did you decide to become a Reiki Master / Teacher?

- Is your main occupation as a Reiki teacher? If not would you mind telling me what it is?

\section{Main questions (with planned prompts)}

\section{About being a Reiki Master/ Teacher}

- Can you tell me what being a Reiki teacher involves?

- Can you talk me through what you teach at each level of Reiki?

PROMPT: What sort of practical skills do you teach?

PROMPT: What sort of knowledge (for example theory) do you teach?

PROMPT: You mentioned 'energy'. Would a person's knowledge and understanding of energy change over the course of learning each level of Reiki? How? 
PROMPT: How might sending Reiki backwards be helpful? Can you tell me about the last time you did this?

PROMPT: How might sending Reiki forwards be helpful? Can you tell me about the last time you did this?

\section{Self Use of Reiki}

Hopefully at this point the participant will have mentioned the fact that Reiki can be used on self if not PROMPT: Can you use Reiki on yourself?

- Can you tell me some more about using Reiki on yourself?

PROMPT: Once a person has learned Reiki, how important is it for them to use it on themselves? Why is this?

PROMPT: How does a person know when to give themselves a treatment? Is it routine or instinctive or are there a set number of times?

PROMPT: How would you describe the level of skill involved in giving either yourself or someone else a Reiki treatment? For example is it a basic skill, an easy thing to do? Why is this?

PROMPT: How often would you advise your students to give themselves Reiki? Why is that?

- Is using Reiki on yourself beneficial in any way? How?

What would a person get out of using Reiki on themselves?

What do you get out of it?

- How does it feel to give yourself a Reiki treatment?

PROMPT: Does this (how it feels) have any effect on your wellbeing? How?

PROMPT: Do you think this is the same for others? 


\section{Health}

- Can using Reiki on yourself help with a person's health and wellbeing?

PROMPT: How could using Reiki on yourself help if say a person has physical problems?

PROMPT: Can you give examples of the types of physical health problems that Reiki might help with?

PROMPT: How could Reiki help you more holistically for example mentally / emotionally?

PROMPT: Are there any benefits relating to relaxation?

- Except for giving themselves a treatment are there any other ways that a person might use Reiki in your daily life? How?

- Would a person give themselves self-treatments if they were in good health? What would be the benefits of doing so?

- Are there any disadvantages of self treatment?

- When people learn Reiki and begin to use it on themselves do you think they begin to view their own health differently? And the whole concept of 'health' in general differently? How?

- So Reiki can help with your health - do people still use 'traditional', 'nonReiki' health advice and information? How does your Reiki knowledge 'fit' with 'regular knowledge'?

\section{Learning Reiki}

- What do you consider to be the main advantages of learning Reiki?

- Are there any disadvantages to learning Reiki?

- Can anyone learn?

PROMPT: Would you need to have any particular skills or knowledge in order to learn? 


\section{Closing Questions}

- Is there anything else about Reiki that we haven't talked about that you think might be useful for me to know?

- Would it be okay for me to telephone you at a later date if I need to clarify anything that we've talked about today?

\section{DEMOGRAPHICS SHEET}

\section{Demographics}

Interviewee no:

Date of Interview:

Sex: Male Female

Age:

Under 20

$20-30$

31-40

41- 50

51- 59

60-69

Ethnic background:

White

British

Irish

Any Other White background

\section{Mixed}

White and Black Caribbean 
White and Black African

White and Asian

Any Other Mixed background

\section{Asian or Asian British}

Indian

Pakistani

Bangladeshi

Any other Asian background

Black or Black British

Caribbean

African

Other Black groups

\section{Chinese or Other ethnic group}

Chinese

Other ethnic group

Other (please state):

Interviewee's comments: 
Appendix 5: Interview Schedule Phase 2 (Reiki level one and two self users)

\section{Opening / Beginning Questions}

- I'd like to begin if I can by asking you how long you've been practising Reiki?

- And what level of Reiki practice are you at?

- How long have you been at level one / two

- Why did you decide to learn Reiki?

Main questions (with planned prompts)

- Just thinking about before you had your Reiki attunement: Did you discuss having your Reiki attunement with anyone beforehand?

PROMPT: Did you know what to expect from having a Reiki attunement when you did your first course?

Just wanting you to think about when you did your actual Reiki course...........

- Can you tell me what sort of things you learned on your Reiki Level one / Reiki Level two course?

PROMPT: Did your Reiki Master talk to you about

- What Reiki is and the history of Reiki

PROMPT: What did he / she tell you about the history of Reiki?

- How to self treat with Reiki

PROMPT: What did he/she tell you about self treatment?

- Energy

PROMPT: What did he/she tell you about Energy?

- How to ground yourself

PROMPT: What did he/she tell you about grounding?

- Knowledge of Symbols

PROMPT: What did he/she tell you about symbols? 
- How to give a Reiki treatment to family or friends

PROMPT: What did he/she tell you about giving a Reiki treatment?

- Chakras

PROMPT: What did he/she tell you about chakras?

- How to protect self

PROMPT: PROMPT: What did he/she tell you about protection?

I'd like to talk to you now a little bit about giving Reiki to yourself............

- How often do you give yourself Reiki?

PROMPT: Is that a full treatment or is it as and when you feel you need it?

- Thinking about the times when you give yourself Reiki / a Reiki treatment. Why do you do it at those times?

- Obviously you use Reiki on yourself - why do you choose to do so?

PROMPT: What do you get out of it?

PROMPT: How do you benefit?

- Would you give yourself a Reiki treatment even if you were in good health? PROMPT: Why / Why not?

- Would you say there are any disadvantages to being able to give yourself Reiki?

PROMPT: Can you tell me what these are?

\section{And I'd like to talk to you about your health........}

- Since learning Reiki have you made any changes to your life or lifestyle?

PROMPT: Has this helped? If so how?

- Do you think your health benefits from your Reiki treatments / giving yourself Reiki?

PROMPT: if so how?

- Can you think of any times when you have used Reiki on yourself for health reasons or to help with a health problem?

PROMPT: Did it help and if so how?

- Since learning Reiki and then using it on yourself have you at all noticed a sense of feeling more in control of your health? 
PROMPT: If so can you explain more?

- Since learning Reiki and then using it on yourself do you think that your view of your own health has changed?

PROMPT: How?

PROMPT: What about your understanding of your own body, your whole self? Has this changed or improved? If so how?

- Since learning Reiki has your opinion of 'traditional' / 'bio-medicine' / 'nonReiki' medicine changed?

PROMPT: If so how?

- Do you think your Reiki knowledge 'fits' with mainstream medical views?

PROMPT: How?

\section{Reiki with others and Reiki Support...........}

- How do you explain Reiki to family and friends

- Do you give Reiki to anyone else - friends / family?

- If member of a group: What do you do at the group when you meet?

\section{Scenario's 1 and 2}

Show participant cards with scenarios on

- Have you ever been in a situation similar to this?

- If so what did you do?

\section{Picture Card}

- What do you see when you look at the picture?

- What would you do?

\section{Closing......}

- If you had to sum up, what would you say for you, has been the main advantage to learning Reiki?

- Is there anything else about Reiki that we haven't talked about that you think might be useful for me to know? 
- I'll be doing a focus group as part of this work later on in the year - this would involve a group of people who like yourself are attuned to Reiki discussing their self use of Reiki. Could I contact you at a later date to see if you would be interested in taking part in this group? Remind participant that they have the option to decline to participate.

\section{DEMOGRAPHICS SHEET}

\section{Demographics}

\section{Interviewee no:}

\section{Date of Interview:}

Sex: Male Female

Age:

Under 20

$20-30$

31-40

41- 50

51- 59

60-69

Ethnic background:

\section{White}

British

Irish

Any Other White background

\section{Mixed}

White and Black Caribbean 
White and Black African

White and Asian

Any Other Mixed background

\section{Asian or Asian British}

Indian

Pakistani

Bangladeshi

Any other Asian background

Black or Black British

Caribbean

African

Other Black groups

\section{Chinese or Other ethnic group}

Chinese

Other ethnic group

Other (please state):

Interviewee's comments:

Place of Interview

Rapport

Initial impressions of data 
Appendix 6: Grid used in initial stages of analysis (Phase Two)

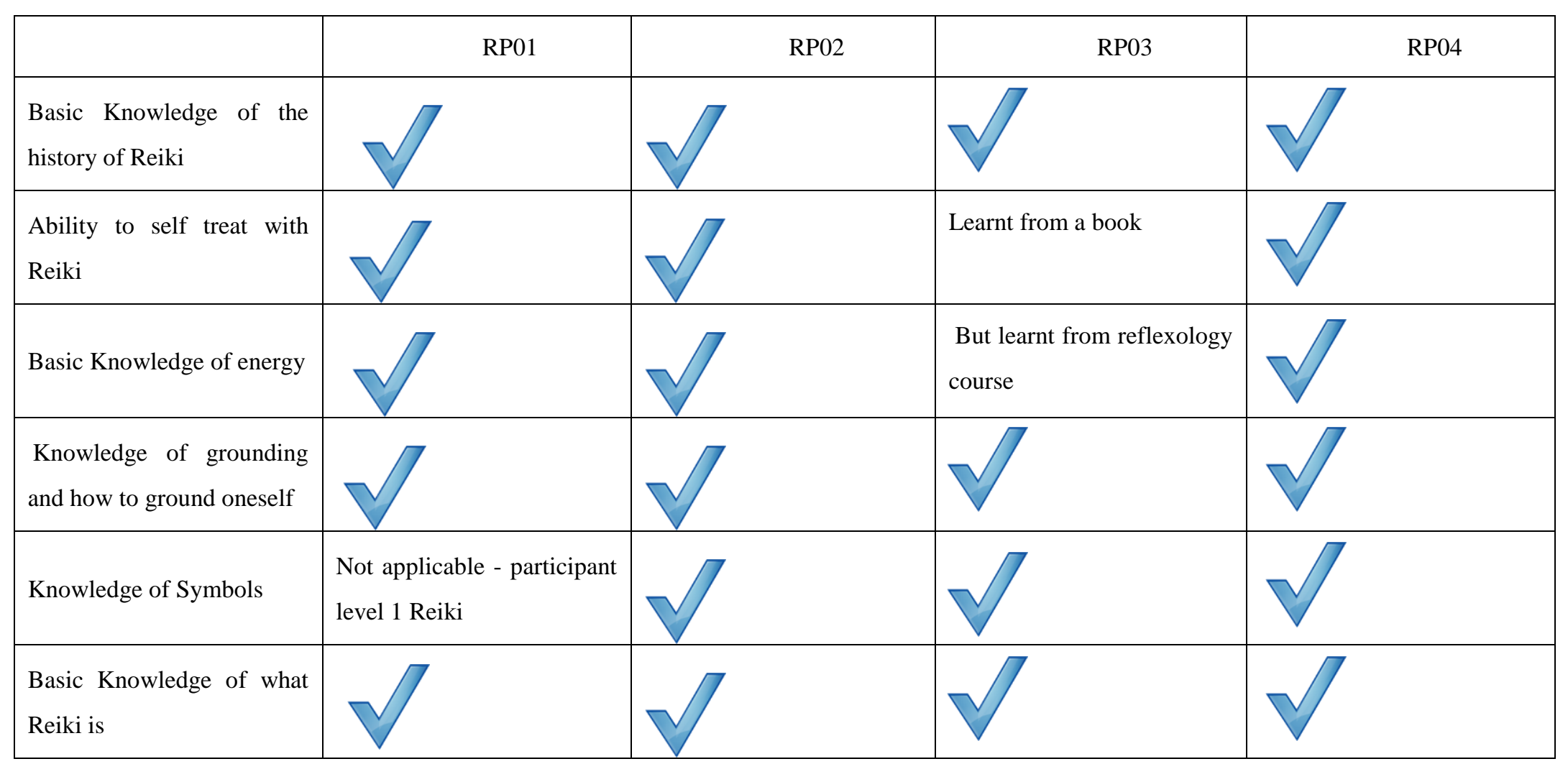




\begin{tabular}{|c|c|c|c|c|}
\hline $\begin{array}{l}\text { Knowing what to expect } \\
\text { from having a Reiki } \\
\text { attunement }\end{array}$ & & & $\begin{array}{l}\text { Yes but not what was } \\
\text { involved in actual } \\
\text { attunement process }\end{array}$ & Little bit \\
\hline $\begin{array}{l}\text { Ability to give a Reiki } \\
\text { treatment to family or } \\
\text { friends }\end{array}$ & & & & \\
\hline $\begin{array}{l}\text { Basic Knowledge of } \\
\text { Chakras }\end{array}$ & & & & \\
\hline $\begin{array}{l}\text { Knowledge of protection } \\
\text { and how to protect self }\end{array}$ & & & & \\
\hline $\begin{array}{l}\text { About skills and } \\
\text { knowledge: } \text { Interactive }\end{array}$ & & & & \\
\hline $\begin{array}{l}\text { Knowing when to use Reiki } \\
\text { and knowing why you are } \\
\text { using it }\end{array}$ & $\begin{array}{l}\text { "when I feel the need" "Its } \\
\text { normally If I can't sleep" "If } \\
\text { there's something not right" } \\
\text { "It quietens me down, it } \\
\text { quietens my head, it relaxes } \\
\text { me" } \\
\text { "Even if it relaxes me its }\end{array}$ & $\begin{array}{l}\text { "It seems to work! You } \\
\text { know when I've done it, it } \\
\text { seems to work" }\end{array}$ & $\begin{array}{l}\text { "if I feel I need it for } \\
\text { whatever reason" } \\
\text { If I just feel sort of a bit out } \\
\text { of balance or not } \\
\text { calm...then I tend to find it } \\
\text { calms me down I suppose" } \\
\text { "You've got the ability to } \\
\text { de-stress yourself I suppose }\end{array}$ & $\begin{array}{l}\text { "as often as I need } \\
\text { it...because often I'll be } \\
\text { having a peaceful moment } \\
\text { and I" want to enjoy it } \\
\text { even more" } \\
\text { "Other times, a lot of it is } \\
\text { based on my stress levels at } \\
\text { work" }\end{array}$ \\
\hline
\end{tabular}




\begin{tabular}{|c|c|c|c|c|}
\hline & going to help me" & & $\begin{array}{l}\text { because obviously stress } \\
\text { isn't good for anybody is } \\
\text { it?" }\end{array}$ & $\begin{array}{l}\text { "if I'm quite stressed and I } \\
\text { need to calm myself down I } \\
\text { will think right, I'll go do } \\
10 \text { minute Reiki" } \\
\text { "A calming effect" } \\
\text { [knowing why using it] }\end{array}$ \\
\hline $\begin{array}{l}\text { Applying Reiki knowledge } \\
\text { to own health (applying } \\
\text { Reiki knowledge to me). }\end{array}$ & & $\begin{array}{l}\text { "I was quite stressed out } \\
\text { through work...but then I } \\
\text { were physically ill because } \\
\text { I'd got celiac and I didn't } \\
\text { know [...] and I was } \\
\text { having a lot of migraines } \\
\text { and on beta blockers but I } \\
\text { totally came off them, now } \\
\text { whether that's a } \\
\text { coincidence....it just } \\
\text { seemed to work instantly } \\
\text { more or less, I'd practically } \\
\text { fall asleep when I did it" }\end{array}$ & $\begin{array}{l}\text { "Well I tend to use it if I'm } \\
\text { not sleeping well" }\end{array}$ & $\begin{array}{l}\text { "I used it when I had my } \\
\text { wisdom teeth out }[\ldots] \text { it } \\
\text { helped ease the pain" }\end{array}$ \\
\hline
\end{tabular}




\begin{tabular}{|c|c|c|c|c|}
\hline $\begin{array}{l}\text { Making meaning from } \\
\text { Reiki knowledge in } \\
\text { different formats (written, } \\
\text { verbal non-verbal) }\end{array}$ & $\begin{array}{l}\text { Not detailed responses to } \\
\text { vignettes } \\
\text { Picture:" It wouldn't be } \\
\text { initial instinct to think...I } \\
\text { think [unbalanced] I would } \\
\text { think I'm tired or I'm a bit } \\
\text { moody today" } \\
\text { Demonstrating interactive } \\
\text { by recognizing that out of } \\
\text { balance chakras can result } \\
\text { in such feelings }\end{array}$ & $\begin{array}{l}\text { [Knowing own body]!” it } \\
\text { helped me to pick up when } \\
\text { I weren't feeling right" } \\
\text { Vignette responses: } \\
\left.1^{\text {st }}\right) \text { Would try both Reiki } \\
\text { and RICE } \\
2^{\text {nd }} \text { I would definitely do } \\
\text { some Reiki } \\
3^{\text {rd }} \text { Oh yeah, I've had } \\
\text { loads of days like that }\end{array}$ & $\begin{array}{l}\text { [regarding feeling 'groggy' } \\
\text { after a Reiki treatment] } \\
\text { "you've had some Reiki and } \\
\text { your body is just re- } \\
\text { balancing itself } \\
\text { Vignettes: } \\
\text { 1)Would try a bit of Reiki } \\
\text { 2)I would use Reiki } \\
\text { 3) Wouldn't know how to } \\
\text { do chakra balancing }\end{array}$ & $\begin{array}{l}\text { "Because the chakras } \\
\text { relate to bits of the body as } \\
\text { well so if my legs are } \\
\text { aching I'm going to go to } \\
\text { my base" } \\
\text { Vignettes: } \\
\text { 1) Spot treatment } \\
\text { 2) Has sat in a meeting and } \\
\text { sent emotional symbol } \\
\text { across room to another } \\
\text { person } \\
\text { Would use meditation to } \\
\text { switch off, wouldn't feel } \\
\text { the need to use Reiki on } \\
\text { self } \\
\text { 3) "I see lots of chakras out } \\
\text { of balance" Would do Reiki } \\
\text { to draw them back into line }\end{array}$ \\
\hline
\end{tabular}




\begin{tabular}{|c|c|c|c|c|}
\hline $\begin{array}{l}\text { Better understanding of the } \\
\text { self }\end{array}$ & "I'm not very self aware" & $\begin{array}{l}\text { "I think you listen more to } \\
\text { your own body, I think } \\
\text { you're more tuned in" }\end{array}$ & $\begin{array}{l}\text { "Just being more aware of } \\
\text { your body...more in tune } \\
\text { with it" }\end{array}$ & $\begin{array}{l}\text { "I think I'm certainly more } \\
\text { conscious of my... } \\
\text { especially when you relate } \\
\text { it to the chakras, I think I } \\
\text { am more conscious of } \\
\text { myself. I know if I'm not } \\
\text { feeling quite right, I can } \\
\text { pretty much go to the point, } \\
\text { the chakra. So yeah I think } \\
\text { I am more aware of my } \\
\text { own self and my body and } \\
\text { what's going on and how to } \\
\text { treat it, what chakra it } \\
\text { might be related to" }\end{array}$ \\
\hline $\begin{array}{l}\text { Ability to talk about Reiki } \\
\text { and communicate about } \\
\text { Reiki. May involve } \\
\text { participating in a Reiki } \\
\text { group or being a Reiki } \\
\text { teacher or passing on }\end{array}$ & $\begin{array}{l}\text { See interview question that } \\
\text { is intended to address this. } \\
\text { From RP01 I am not sure } \\
\text { that the question is enabling } \\
\text { participants to talk about } \\
\text { this. }\end{array}$ & $\begin{array}{l}\text { Unclear - not member of a } \\
\text { group. Has a friend who is } \\
\text { attuned to Reiki but don't } \\
\text { talk about it a lot" }\end{array}$ & $\begin{array}{l}\text { Has a friend at same level } \\
\text { but doesn't really talk about } \\
\text { it }\end{array}$ & $\begin{array}{l}\text { "because somebody who's } \\
\text { got quite a scientific } \\
\text { mind... when you're talking } \\
\text { to them about energy, it's } \\
\text { easy, its comparative to } \\
\text { electricity, its comparative } \\
\text { to switching a light bulb on }\end{array}$ \\
\hline
\end{tabular}




\begin{tabular}{|c|c|c|c|c|}
\hline information about Reiki & & & & $\begin{array}{l}\text { and off and wavelengths } \\
\text { and things" [regarding } \\
\text { using the concept of energy } \\
\text { to explain Reiki] }\end{array}$ \\
\hline $\begin{array}{l}\text { Taking steps to prevent ill } \\
\text { health from occurring } \\
\text { (overlap with critical Reiki } \\
\text { health literacy) }\end{array}$ & $\begin{array}{l}\text { Not sure that the interview } \\
\text { question works. How do } \\
\text { you know if you have } \\
\text { prevented ill health? }\end{array}$ & $\begin{array}{l}\text { "Yeah definitely" } \\
\text { [Regarding maintaining } \\
\text { own health] }\end{array}$ & & \\
\hline $\begin{array}{l}\text { Making changes to life } \\
\text { (style) as a result of } \\
\text { learning Reiki that are } \\
\text { beneficial to health. }\end{array}$ & $\begin{array}{l}\text { "I'm a lot more relaxed } \\
\text { about things, I'm a lot more } \\
\text { laid back" } \\
\text { "I'm more open to } \\
\text { alternatives" }\end{array}$ & $\begin{array}{l}\text { "I just think there's this } \\
\text { whole ....more relaxed" } \\
\text { "It's that awareness and } \\
\text { even through you are aware } \\
\text { you get your } 5 \text { a day...I } \\
\text { just think it, to me it } \\
\text { emphasizes it even more" }\end{array}$ & $\begin{array}{l}\text { "I think I probably am more } \\
\text { aware of my own health" } \\
\text { "too much coffee and tea, } \\
\text { I've definitely cut down on } \\
\text { those. I don't think I drink } \\
\text { as much alcohol" }\end{array}$ & $\begin{array}{l}\text { Since I've been doing } \\
\text { Reiki I'm quite conscious } \\
\text { of detoxifying really and } \\
\text { I'm doing Reiki, it's like } \\
\text { well I want to drink plenty } \\
\text { of water to keep myself and } \\
\text { my system all clean and } \\
\text { flushed out." } \\
\text { "I think I do appreciate } \\
\text { what's round me more do } \\
\text { tend to take care more of } \\
\text { what I'm eating" }\end{array}$ \\
\hline
\end{tabular}




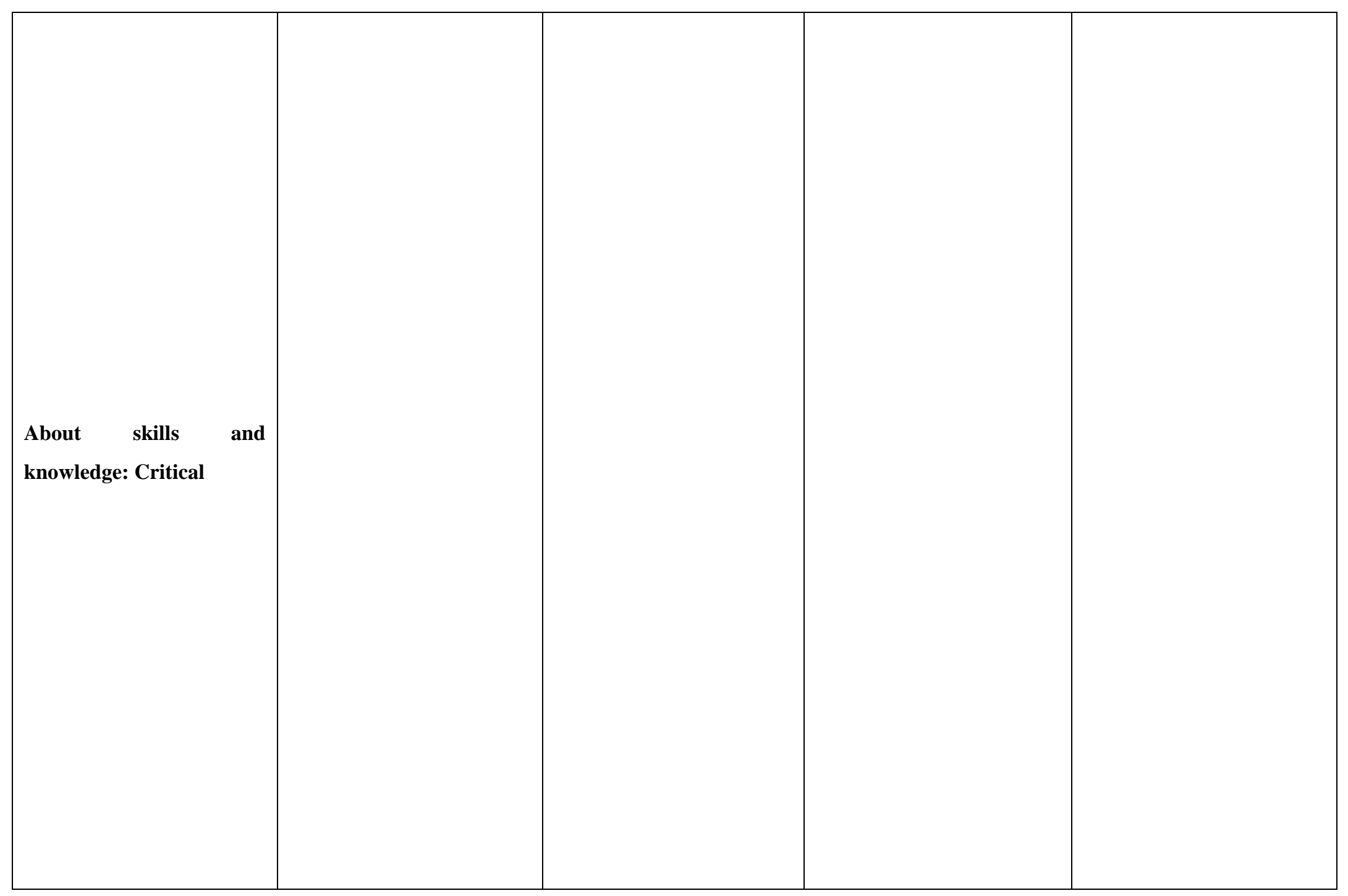




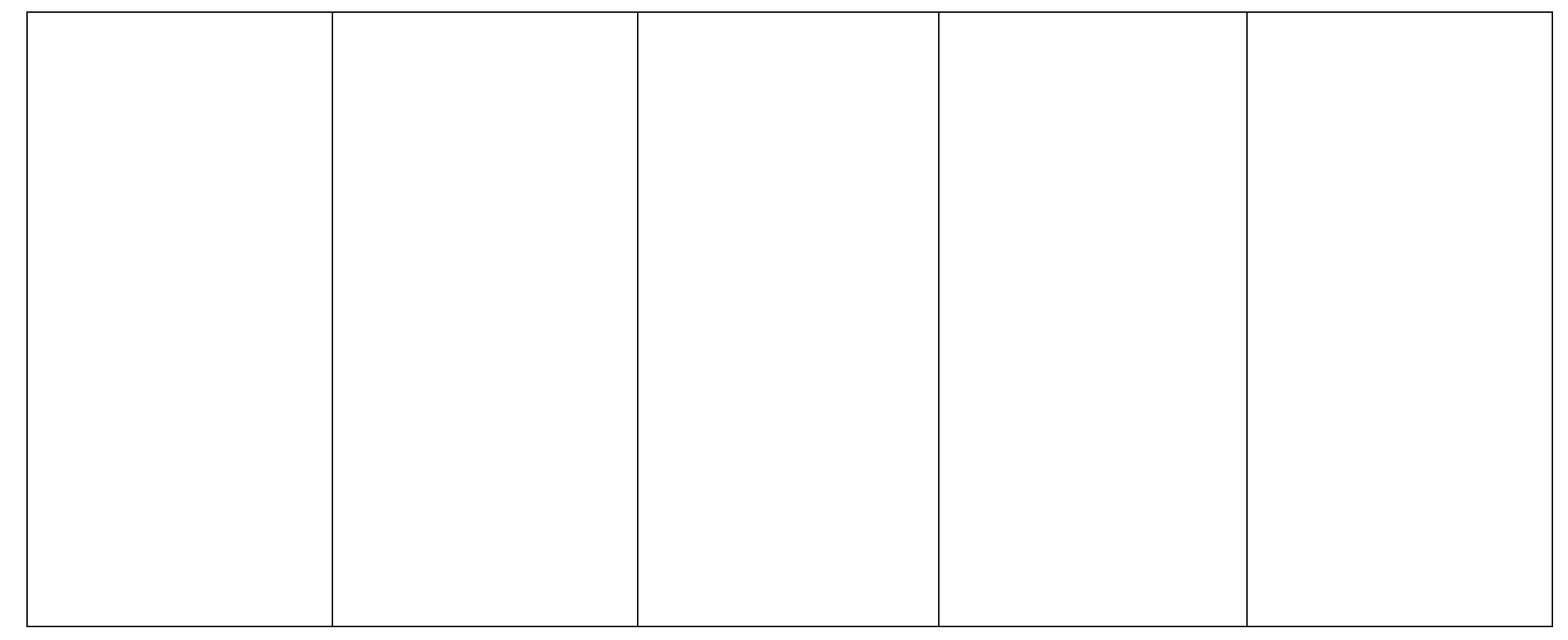




\begin{tabular}{|c|c|c|c|c|}
\hline $\begin{array}{l}\text { Critically analyzing } \\
\text { information about Reiki } \\
\text { and health, about medicine } \\
\text { and health, health in } \\
\text { general }\end{array}$ & $\begin{array}{l}\text { "I'm more open to } \\
\text { alternatives" } \\
\text { "You can treat so much } \\
\text { [with CAM] but sometimes } \\
\text { you need to recognize you } \\
\text { need a bit more help" } \\
\text { "I don't rely on traditional } \\
\text { medicine for minor things" }\end{array}$ & $\begin{array}{l}\text { "I think there's room for } \\
\text { both" [Biomedicine and } \\
\text { CAM] } \\
\text { "but I think we prescribe } \\
\text { too many drugs sometimes } \\
\text { [...] and I think it's more, } \\
\text { we should be letting people } \\
\text { know who aren't aware of } \\
\text { Reiki to try it on } \\
\text { themselves and a lot more } \\
\text { talking to people and } \\
\text { getting to the root of the } \\
\text { problem...well teaching } \\
\text { them to get to the root of } \\
\text { the problem and making } \\
\text { them more aware rather } \\
\text { than just pills" }\end{array}$ & $\begin{array}{l}\text { "I think they're [doctors] } \\
\text { treating the symptoms of } \\
\text { illness rather than the cause } \\
\text { of illness" }\end{array}$ & $\begin{array}{l}\text { "I think at the onset of an } \\
\text { illness, I'm all for let's try } \\
\text { Reiki, it might just be that } \\
\text { I'm run down and need to } \\
\text { pick myself up, however, } \\
\text { there is a time when you } \\
\text { need to seek medical advice } \\
\text { because no amount of } \\
\text { holistic therapy is going to } \\
\text { cure certain illness"” }\end{array}$ \\
\hline
\end{tabular}




\begin{tabular}{|c|c|c|c|c|}
\hline $\begin{array}{l}\text { Exerting control over all } \\
\text { aspects of health }\end{array}$ & $\begin{array}{l}\text { "It gives me a sense of } \\
\text { I'm doing something about } \\
\text { it as well" } \\
\text { "I'm more at peace and } \\
\text { more sort of accepting of } \\
\text { things and it's just another } \\
\text { option you have }\end{array}$ & $\begin{array}{l}\text { "I think you listen more to } \\
\text { your own body" } \\
\text { "Because I am a worrier, I } \\
\text { am one of these people that } \\
\text { just ... worrier for nothing } \\
\text { and I think it really helps } \\
\text { like that, it just makes you } \\
\text { focus, calms you down, } \\
\text { helps you sleep" }\end{array}$ & $\begin{array}{l}\text { "You've got the ability to } \\
\text { de-stress yourself I suppose } \\
\text { because obviously stress } \\
\text { isn't good for anybody is } \\
\text { it?" } \\
\text { "I'm aware that I think I am } \\
\text { in control of my own health } \\
\text { if you know what I mean } \\
\text { and it's my responsibility. } \\
\text { You know you can't just } \\
\text { expect that good health is a } \\
\text { right that it's just going to } \\
\text { happen" }\end{array}$ & $\begin{array}{l}\text { "I think that ties in with } \\
\text { the looking after myself in } \\
\text { general, the drinking of the } \\
\text { water and that sense of } \\
\text { calmness" } \\
\text { "the thing is, the beauty of } \\
\text { Reiki is that you've always } \\
\text { got that feeling of I'm in } \\
\text { control, I can control } \\
\text { myself, my feelings, my } \\
\text { health because I can offer } \\
\text { myself this" }\end{array}$ \\
\hline $\begin{array}{l}\text { Identify the wider social } \\
\text { and political benefits of } \\
\text { Reiki }\end{array}$ & & $\begin{array}{l}\text { "and I think it's more, we } \\
\text { should be letting people } \\
\text { know who aren't aware of } \\
\text { Reiki to try it on }\end{array}$ & & \\
\hline
\end{tabular}




\begin{tabular}{|c|c|}
\hline & $\begin{array}{l}\text { themselves and a lot more } \\
\text { talking to people and } \\
\text { getting to the root of the } \\
\text { problem... well teaching } \\
\text { them to get to the root of } \\
\text { the problem and making } \\
\text { them more aware rather } \\
\text { than just pills" }\end{array}$ \\
\hline $\begin{array}{l}\text { Advocacy / helping or } \\
\text { supporting others in a Reiki } \\
\text { context }\end{array}$ & $\begin{array}{l}\text { Example of sending } \\
\text { distance Reiki to friend } \\
\text { with Parkinson's disease }\end{array}$ \\
\hline
\end{tabular}




\section{Appendix 7: Coding Scheme Phase Two}

\section{Codes based on Model of Reiki Health Literacy}

Functional

- Knowing what to expect from first course / Knowing what to expect from attunement

- Knowledge of Chakras

- Background to Reiki / what Reiki is / History of Reiki

- Knowledge of energy

- Knowledge of grounding

- Knowledge of Symbols

- Knowledge of how to self treat and how to treat others / Hand positions

- Knowledge of protection

Interactive

- Applying knowledge of Reiki to own health.

- Giving Reiki to family and friends

- $\quad$ active use of the symbols

- making meaning from different forms of communication / chakra vignette

- Interactive RHL use on family and friends

- Developed understanding of energy.

- IRHL: active use of skills (protection)

- Interactive ability to explain about Reiki

- IRHL Self Treatment

- IRHL Making changes to lifestyle

- Making decisions informed by multiple perspectives

- Use in Daily life

- Benefits of making changes to lifestyle

- More advanced cognitive skills e.g. thinking, reflecting 
- Adapting to own needs and circumstances

\section{Critical}

- Exerting control

- realistic about the outcomes and effects of reiki

- Critical - identifies wider benefits of Reiki in working environment

- CRHL: Joining a Reiki group

- critically (and actively) analyzing her experiences

- Critically analyzing mainstream medical views

\section{New Codes / codes not based on model of Reiki HL}

\begin{tabular}{|c|c|c|}
\hline Code Name & Description & Example \\
\hline Background & $\begin{array}{l}\text { Any information relating to the } \\
\text { participants background for } \\
\text { example how they got into Reiki, } \\
\text { their education, their work, } \\
\text { whether they had treatments }\end{array}$ & $\begin{array}{l}\text {...I've always been very rational, } \\
\text { I've had a strongly scientific } \\
\text { background you know, everything } \\
\text { I've ever done has been, } \\
\text { psychology, I've done chemistry, } \\
\text { haematology - I've always worked } \\
\text { in laboratories. } \\
\text { I've got a science background, so } \\
\text { anything like that really does } \\
\text { intrigue me, you know, I'm just } \\
\text { fascinated with the meta physics as } \\
\text { well. }\end{array}$ \\
\hline $\mathrm{HL}$ & $\begin{array}{l}\text { Clues as to participants existing } \\
\text { levels of Health literacy }\end{array}$ & $\begin{array}{l}\text { yeah I'm a really healthy person I } \\
\text { just happen to have crohn's } \\
\text { Erm, because it's like with most } \\
\text { things when there's something new, } \\
\text { especially if you go on a training } \\
\text { course, if you go and do all your } \\
\text { research first and you can read }\end{array}$ \\
\hline
\end{tabular}




\begin{tabular}{|c|c|c|}
\hline & & $\begin{array}{l}\text { yourself to death, there's too much } \\
\text { information and I didn't want to } \\
\text { get a lot of information that may } \\
\text { have been wrong, because I trust } \\
\text { Grace, so I was quite happy to go } \\
\text { with the flow and for her to teach } \\
\text { me. }\end{array}$ \\
\hline Stress & $\begin{array}{l}\text { Any words or phrases relating to } \\
\text { stress relief benefits of Reiki for } \\
\text { example 'calming', 'peace', 'less } \\
\text { worry' }\end{array}$ & $\begin{array}{l}\text { And my motto at work is I want to } \\
\text { eliminate stress not cause stress } \\
\text { [...] And that's what Reiki does. } \\
\text { I tend to feel much calmer, more } \\
\text { centred, things don't worry me. } \\
\text { and if you've got anything } \\
\text { important for the day it just clams } \\
\text { you down }\end{array}$ \\
\hline Context & $\begin{array}{l}\text { Where and when participant has } \\
\text { used Reiki over and above for own } \\
\text { individual health } \\
\text { Example might include for } \\
\text { journeys, for work, recovering } \\
\text { from surgery }\end{array}$ & $\begin{array}{l}\text { It was a health related I was going } \\
\text { to an occupational health doctor. } \\
\text { because I have had this really } \\
\text { serious illness so its kind of, I } \\
\text { know if I think about it in recovery } \\
\text { from that I know I have really used } \\
\text { Reiki to help myself to recover } \\
\text { from that } \\
\text { Yer, I do, if I know I'm driving as } \\
\text { well, I erm, I'm an activities } \\
\text { coordinator and I also used to be a } \\
\text { senior care worker, so they call on } \\
\text { me when they need me, but if like, } \\
\text { you know, I've got a long journey } \\
\text { or anything like that I send it } \\
\text { ahead, you know, or I'll ask, you } \\
\text { know, for protection or things like } \\
\text { that, but I really do think its made } \\
\text { a different to me because before I }\end{array}$ \\
\hline
\end{tabular}




\begin{tabular}{|c|c|c|}
\hline & & $\begin{array}{l}\text { had it I used to find it quite } \\
\text { stressful and I was thinking of } \\
\text { leaving you know. }\end{array}$ \\
\hline Combining & $\begin{array}{l}\text { When participant mentions } \\
\text { combining their reiki with other } \\
\text { techniques or CAM's. }\end{array}$ & $\begin{array}{l}\text { so yeah it's a combination of using } \\
\text { standard medical intervention plus } \\
\text { stress management - I think I could } \\
\text { stick Reiki under that }\end{array}$ \\
\hline Meditation & Self explanatory & $\begin{array}{l}\text { but you've got to be calm and } \\
\text { you've got to meditate sometimes } \\
\text { to settle down so if your minds too } \\
\text { active and agitated you can use } \\
\text { meditation to calm you down } \\
\text { meditation, she sort of took } \\
\text { us through that }\end{array}$ \\
\hline Spirituality & $\begin{array}{l}\text { Any mention of things linked to } \\
\text { spiritual matters }\end{array}$ & $\begin{array}{l}\text { Although they know more than we } \\
\text { do and they're more, how can I put } \\
\text { it, erm, highly developed, but } \\
\text { they're there to assist us, we can } \\
\text { ask them for guidance. } \\
\text { But the shamanism does intrigue } \\
\text { me and I have this thing about the, } \\
\text { erm, the three levels, the lower, } \\
\text { middle and little erm. }\end{array}$ \\
\hline Lineage & & $\begin{array}{l}\text { I remember, erm talking about the } \\
\text { lineage of where it came from }\end{array}$ \\
\hline Reiki Principles & & $\begin{array}{l}\text { talking about you know the Reiki } \\
\text { principles. }\end{array}$ \\
\hline Effects & $\begin{array}{l}\text { Any effects or benefits of } \\
\text { having/learning/self using Reiki } \\
\text { mentioned y participant }\end{array}$ & $\begin{array}{l}\text { It helps you put things into } \\
\text { perspective and I just think to } \\
\text { myself 'oh well, life's too short'. } \\
\text { Ever so many, I've started eating a } \\
\text { lot healthier. }\end{array}$ \\
\hline Visualisation & & $\begin{array}{l}\text { how to sort of visualisation to clear } \\
\text { any negative energy, so you didn't } \\
\text { pick it up. }\end{array}$ \\
\hline
\end{tabular}




\begin{tabular}{|c|c|c|}
\hline $\begin{array}{l}\text { Examples of participant asking } \\
\text { questions of interviewer }\end{array}$ & & $\begin{array}{l}\text { INT: Are you hoping to do it here } \\
\text { from home? } \\
\text { RP: I'm hoping to do it here, yes, } \\
\text { so do you think it will be } \\
\text { alright? }\end{array}$ \\
\hline Awareness & $\begin{array}{l}\text { Participant speaks of awareness of } \\
\text { own body, self, health }\end{array}$ & $\begin{array}{l}\text { I think I am more conscious of } \\
\text { myself. I know if I'm not feeling } \\
\text { quite right, I can pretty much go } \\
\text { and point to a chakra, erm, so 'yes' } \\
\text { I think I am more aware of my own } \\
\text { self and my own body and what's } \\
\text { going wrong and what chakra it } \\
\text { might relate to. } \\
\text { My health ...................... to me } \\
\text { erm, and its kind emphasised that } \\
\text { as well.[It's emphasised erm how } \\
\text { important your health is?] Exactly } \\
\text { yeh. }\end{array}$ \\
\hline Intuition / sensing & & $\begin{array}{l}\text { because I've got more intuition } \\
\text { now. I seem to be able to spot } \\
\text { things, you know, I seem to be able } \\
\text { to go to a zone and pick up on } \\
\text { things } \\
\text { It's like a sixth sense sort of } \\
\text { feeling, it's like, I'm not getting a, } \\
\text { sometimes I do get that ....... that } \\
\text { flies to your solar plexus like, you } \\
\text { know, a gut reaction, but it kind of } \\
\text { when I, I suppose it is just like a } \\
\text { knowing }\end{array}$ \\
\hline
\end{tabular}

